

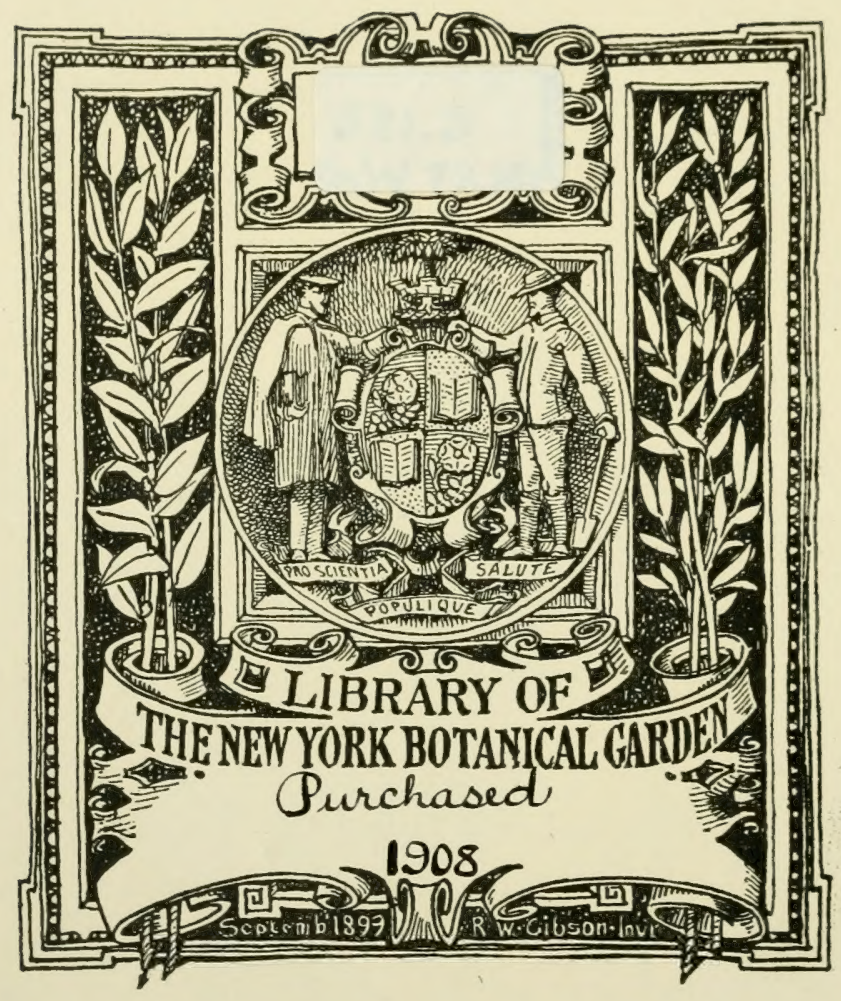








\title{
Parthenogenesis und
}

\section{Apogamie im Pflanzenreiche.}

\author{
Von
}

\section{Dr. Hans Winkler,}

a. o. Professor an der Universität Tübingen.

Mit 14 Abbildungen im Text.

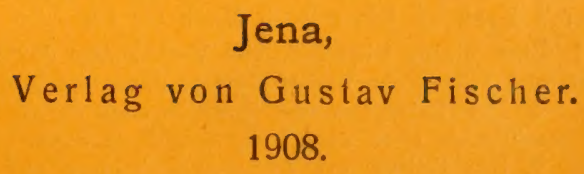




\section{Wissenschaftliche Ergebnisse der Dentschen Tiefsee-}

Expedition auf dem Dampfer "Valdivia" 1898-1899. Im Auftrage des Lxichsamts des Innern herausgegeben von Carl Chun, Prof. der Zoologie in Leipzig, Leiter der Expedition.

Der Bericht über die reichen wissenschaftlichen Ergebnisse der deutschen Tiefsee-Expedition ist für die naturwissenschaftichen Forscher nicht nur Deutschlands, sondern anch des Auslandes eine der wertvollsten Mitteilungen über zum Teil ganz neues Material für die naturwissenschaftliche Forschung. Das größte Interesse für die Erlebnisse wurde bereits in weiteren Kreisen erweckt, als der Leiter der Expedition, Herr Geheimrat Chun in Leipzig durch sein Werk ,Aus den Tiefen des Weltmeeres, Schilderungen von der deutsehen Tiefsee-Expedition" (Zweite Auflage erschienen) darauf hingewiesen hat, welche umfassenden und wichtigen Bereicherungen unserer Kenntnisse anf biologischem Gebiete zu erwarten sind.

Die auBerordentliche Reichhaltigkeit des gewonnenen Materials überstieg alle Erwartungen. Um dasselbe so gründlich wie nur möglich bearbeiten zu können, haben sich 61 namhafte Forscher in die Bewältigung des Stoffes geteilt, deren Abhandlungen nach und nach erscheinen.

Es erschienen $и$. a.:

Aus Band II, Teil 1:

Lfg. 1. H.S eh en ek, I. Vergleichende Jarstellung der Pflanzengeographie der subantarktischen Inseln, insbesondere iiber Flora und Vegetation von Kerguelen. Mit Einfügung hinterlassener Schriften A. F. W. Schimpers. Mit 11 Tafeln und 33 Abbildungen im Text. II. Über Flora und Vegeta. tion von St. Paul und New-Amsterdam. Mit Einfiigung hinterlassener Berichte A.F.W. Schimpers. Mit 5 Tafeln 14 Abbildungen im Text. Einzelpreis: 50 Mark, Vorzugspreis : 40 Mark. III. Beiträge zur Kenntnis der Vegetation der Canarischen Inseln. Mit Einfügung hinterlassener Schriften A. F. W. Schimpers. Mit 13 Tafeln, 2 Kärtchen und 60 Abbildungen im Text. Preis für Text und Atlas: für Abnehmer des ganzen Werkes 36 Mark, für den Einzelverkauf 45 Mark.

Aus Band II, Teil 2:

Lfg. 1. G. Karsten, Das Phytoplankton des Antarktischen Meeres nach dem Material der deutschen Tiefsee-Expedition 1898-1899. Mit 19 Tafeln. Einzelpreis: 50 Mark, Vorzugspreis: 39 Mark 50 Pf.

Lfg. 2. G. Karsten, Das Phytoplankton des Atlantischen 0zeans nach dem Material der deutschen Tiefsee-Expedition 1898-1899. Mit 15 Tafeln. Einzelpreis: 35 Mark, Vorzugspreis: 28 Mark.

Lfg. 3. G. Karsten, Das indische Phytoplankton. Dritte Lieferung der Gesamtbearbeitung. Mit 5 Abbildungen und 20 Tafeln. Einzelpreis: 70 Mark, Vorzugspreis: 60 Mark.

Biochemie der Pflanzen. Von Dr. phil. et med. Friedrich Czapek, Czernowitz). Zwei Bände. Preis: brosch. 39 Mark, geb. 4 L Mark 50 Pf.

Inhalt: Geschichtliche Einleitung. Allgemeiner Teil. Spezieller Teil. Der Kohlenhydratstoffwechsel der Pilze. - Der Kohlenhydratstoffwechsel von Samen und anderen Pflanzenorganen. - Der Eiweißstoffwechsel der Pilze und Bakterien. - Der Eiweißstoffwechsel der Samen und anderer Pflanzenorgane. - Die stickstoffhaltigen Endprodukte des pflanzlichen Stoffwechsels. - Die Sauerstoffaufnahme. — Stickstofffreie Endprodukte des Stoffwechsels. - Die Mineralstoffe im pflanzlichen Stoffiwechsel.

\section{Botanische und landwirtschaftliche Studien auf Java.}

Von Ur. W. Detmer, Professor an der Universität Jena. Mit einer Tafel. 1907. Preis: 2 Mark 50 Pf., geb. 3 Mark 50 Pf.

Inhalt: 1. Über einige wirtschaftliche Verhälnisse Javas. 2. Das Produktionsvermögen der Pflanzen und klimatische Verhältnisse in Java und Mitteleuropa. 3. Einiges über den Boden Javas. 4. Der Reisanbau der Eingeborenen Javas. 5. Die Kultur des Teestrauches nebst Bemerkungen über die "Indigofrage" in Java. 6. Die Kultur des Kakaobaumes auf Java. 7. Die Kultur des Fieberrindenbaumes auf Java. 8. Der botanische Garten zu Buitenzorg. 9. Vergleichende physiognomische Studien über brasilianische und javanische Urwälder. 10. Vergleichende Beobachtungen über Stärke- und Zuckerblätter tropischer sowie einheimischer Pflanzen. 11. Beobachtungen über Transpiration der Pflanzen. in Java und in Jena. 12. Kautschukgewinnung in Singapore. 


\title{
Parthenogenesis und
}

\section{Apogamie im Pflanzenreiche.}

Von

Dr. Hans Winkler,

a. o. Professor an der Universität Tübingen.

Mit 14 Abbildungen im Text.

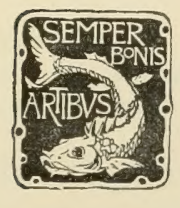

\author{
LIBRARY \\ NEW YORK \\ BOTANILAL \\ GARUEN.
}

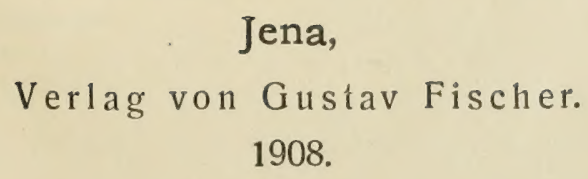




\section{W53 \\ 1908}

Sonderabdruck

aus "Progressus rei botanicae" herausgegeben von Dr. J. P. Lotsy. Zweiter Band. Drittes Heft. 


\section{LIBRARY}

NEW YORK

IOTANMCAL

LARUEN.

\section{Inhalt.}

Seite

Einleitung

Erstes Kapitel: Nomenklatur und Definitionen. . . . . . . . . . 6

Zweites Kapitel: Lnsichere und noch nicht genügend untersuchte

Fälle.

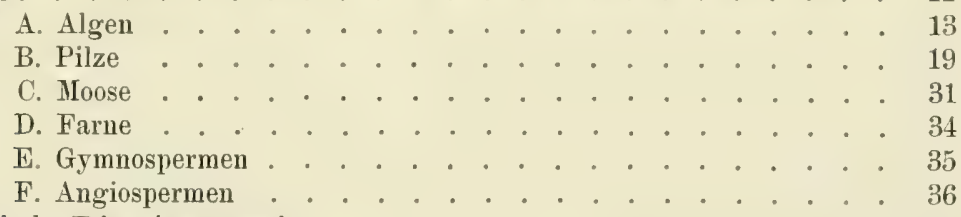

Drittes Kapitel: Die Apogamie. . . . . . . . . . . . . . . . 58

A. Somatische Apogamie . . . . . . . . . . 60

B. Generative Apogamie. . . . . . . . . . . 67

Viertes Kapitel: Die Parthenogenesis . . . . . . . . . . . . 70

A. Somatische Parthenogenesis . . . . . . . . 71

B. Generative Parthenogenesis . . . . . . . . 94

C. Die Merogonie . . . . . . . . . . . 100

Fünftes Kapitel: Die Parthenokarpie . . . . . . . . . . . 101

rechstes Kapitel: Das Wesen der Apogamie und Parthenogenesis . 104

1. Ist die diploide Eizelle einer somatischen Sporophytenzelle gleichwertig? . . . . . . . . . . 106

2. Kommt der diploiden Eizelle Keimzellcharakter zu? . . . 111

Hiebentes Kapitel: Die Beziehungen avischen Apomixis und Generationswechsel . . . . . . . . . . . . 116

Achtes Kapitel: Ursache und Auslösung von Parthenogenesis und Apogamie . . . . . . . . . . . . . . . 126

Teuntes Kapitel: Biologische Bedeutung von Parthenogenesis und Apogamie . . . . . . . . . . . . . . . . 144

Zehntes Kapitel: Die Beziehungen zwischen Purthenogenesis und Polymorphismus . . . . . . . . . . . . . . . 147

Literaturverzeichnis . . . . . . . . . . . . . . . 152

Simen- and Sachrerzeichnis . . . . . . . . . . . 163 


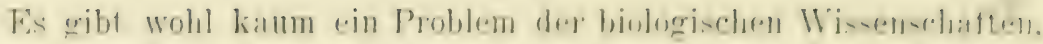
dessen Geschichte zu verfolgen mehr Reiz gewährt als das der

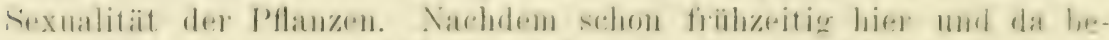
haupter worden war. dab die Pflanzen eine efeschlechtliehe font-

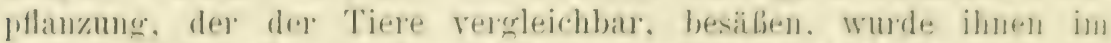
weiteren Verlaufe der Futwicklung der Wissens-laft diese immer und immer wirder ans theoretischen Grinden aberkannt und ele-tion oft ans theoretischen Grïnden wiedor zugesprochen. Auf exakte Grundlage equstelt komnte naturgemalib die Lehre erst dam werlen. als man gelernt hatte, exakt und mit Beriicksichtignmor und mïglichster Üherwindung aller Fehlerquellen zu experimentieren. Find das war erstaunlich spät.

Fiü den Einsichtigen stand es freilich schon seit den beriihnten Versuchen von Camerarius, also seit dem Ende des 17. Jahrhumderts fest, daf die Pflanzen. um keimfähige Samen herworbringen zu können. der Mitwirkung des Pollens bedürfen. Gemäh der alten Erfahrung indessen, daß eine Wahrheit, die dem Einsichtigen längst als unwiderleglich festgestellt gilt, noch lange Zeit braucht, l,is sie zum Allgemeingut geworden ist. dauerte es doch noch fist andertlaalb Jahrhunderte, ehe die immer wiederholten Einwendungen gegen die Ergebnisse von ('amerarius und von denen, die seine Tersuches be. stätigt hatten, endgiiltig verstummten und so endlich auch die immer von neuem erforderlichen Nachuntersuchungen überflüsig machten.

So datiert die Zeit, von der an die Lehre von der Sexualität der Pflanzen als definitiv bewiesen gilt, eigentlich erst rom . Tahre 1844 an, in dem Gaertner's .. Tersuche und Beobachtungen ïber die Befruchtungsorgane der vollkommenen Gewächse und über die natiirliche und kïnstliche Befruchtung durch den eigenen Pollen" erschienen. Seitdem war das Ziel der Forschung nicht mehr zu untersuchen, ob überhaupt die Pflanzen sexuell difierenziert und befirchtungsbediurftig sind. soudern vielmehr genau festzustellen. wie der Vorgang der Bestäubung und Befruchtung in seinen Einzelheiten verläuft.

In Anbetracht des langen, hartnäckigen und oft mit grober Leidenschaftlichkeit geführten Kampfes, den es gekostet hatte. bis die Zweifel an der Sexualitait der Pflanzen definitir niedergeschlagen wurden, kann es nicht überraschen. dab man zunächst die Angaben über das Vorkommen einer Parthenogenesis bei Pflanzen geradezu mit Unbehagen aufnahm. Zwar komnten diese Angaben. da sie sich ja immerhin nur auf rereinzelte Fälle bezogen. die Lehre ron der Sexualität der Pflanzen nicht mehr erschiittern. die durch so zahlleiche Tersuche und, nach Tervollkommnung der Lntersuchungsmethoden, auch auf entwicklungsgeschichtlichem Tege bewiesen war. Aber zu den Torstellungen, die man sich. nach glïcklicher Über- 
windung der Schleiden'schen Irrlehre. iiber die Notwendigkeit und die Wirkungsweise des Pollens bei der Keimerzengung gebildet hatte, paßte eben das Vorkommen der Parthenogenesis, d. h. der Erzeugung von Keimen bei zweifellos geschlechtlich differenzierten Gewächsen ohne Mitrirkung des männlichen Elementes, gar nicht, und so gab der eine sicher erwiesene Fall von der Entbehrlichkeit des Pollens zur Samenbildung allen den Behauptungen erneuten Nachdruck, nach denen doch die Zahl der höheren Pflanzen gar nicht so klein sein sollte, bei denen zur Keimbildung der Pollen nicht nötig wäre.

Dieser eine sichere Fall war der der Caelebogyne iticifolia J. Sm ith. Es ist das eine diöcische Euphorbiacee, die, im östlichen Australien einheimisch, seit 18:9 in Kew in drei weiblichen Stöcken kultiviert wurde, und daselbst alljährlich keimfähige Samen erbrachte, aus denen der Mutter völlig gleichende Tochterpflanzen hervorgingen. Da nun männliche Bliiten an den drei Pflanzen durchaus fehlten und auch keine verwandten männlichen Euphorbiaceen in den betreffenden Gewächshäusern standen, sich auch keine Pollenschläuche in den auffallend lange frisch bleibenden Narben und Griffeln trotz sorgfältiger Untersuchung nachweisen ließen, so kam Smith (1841) zu dem Schlusse, daß für diese Pflanze ,pollen is not essential to the perfecting its seeds". Da damals die Schleiden'sche Theorie noch zahlreiche Anhänger hatte, benutzte $\mathrm{S} m$ it h dieses Ergebnis, um gegen sie Front zu machen, indem er (1841, p. 511) bemerkt: "that the absence of pollen is irreconcileable with the theory that every grain of pollen furnishes a germ. and that the ovulum is merely a matrix to receive and nourish it till it becomes a perfect seed".1)

Wir können nun an dieser Stelle, so verlockend es wäre, nicht im einzelnen verfolgen, wie man sich innerhalb der nächsten Jahrzehnte mit den Angaben von $\mathrm{Smith}$ abfand, sie bestritt, ignorierte, bestätigte und sich theoretisch zurechtlegte. Es genüge, daran zu erinnern, daß man zunächst die unbequeme Tatsache ableugnete und die Smith'schen Beobachtungen damit zu erklären suchte, daß man - was gelegentliche Befunde als nicht ausgeschlossen erscheinen lassen mußten — annahm, es seien eben doch innerhalb der sonst

') Es ist eigentlich zu bedauern, daß nicht schon länger ein einwandfrei bewiesener Fall von Embryobildung ohue Mitwirkung des Pollens bekannt war: die ganze Schleiden sche Theorie wäre dam ron Anfang an unmöglich gewesen und viel mühsame Arbeit hätte fruchtbringender gestaltet werden künnen. Der Erfolg, den die Schleiden'sche Befruchtungstheorie hatte, ist wohl zum größten Teil damit zu erklären, daß viele Forscher unter dem Eindruck der wichtigen Entdeckung des Pollenschlanches standen, und diese Entdeckung. wie das so hänfig geschieht, in ihrer Tragweite zu überschätzen geneigt waren. Die s'chleiden'sche Theorie stellt in dieser Hinsicht ein vïlliges Analogon zu der viel früheren Lehre der Spermatisten dar, die nach der Entdeckung der Spermatozoen in diesen anch rorgebildete Embryonen erblickten, die in den Eiern nur ausgebrïtet wïrden. 
rein weiblichen Bliite gelegentlich Antheren aufogtreten, deren Pollen zur Bestiubung verwanlt worden wäre. Am nächsten der Wahrheit kam, freilich auf tirund ungenügender I'ntersuchungen. Klotzseh (1857), der in einem anonym erschienenen Aufsat\% die Keime der Cucloogyne gar nicht als Embryonen, sondern als vecretative Knospen ansprach.

Glauben und Bestätigung fand die Behauptung, daf bei Cacleboryme wirklich Parthenogenesis rorliege, erst dam, als die Pflanz: in blühreifen Exemplaren den emropäischen botanischen Gärten allgemein zugänglich wurde, so daß Nachuntersuchungen leicht angestellt werden konnten, und vor allem dadurch, dah der Fall aus seiner Vereinzelung im Jahre 1856 heraustrat, als vo n siebold (1856) sein Beobachtungen über die Parthenogenesis bei der Honigbiene und anderen Tieren veröffentlichte. Es war A. Brat un, der im Anschlub daran auf der Naturforscherversammlung zu Wien 1856 nachdrücklich die Wichtigkeit der Smith'schen Beobachtungen an Cueleboryme betonte. Im Jahre 1857 erschien dann seine ausführliche Abliandlung uiber Parthenogenesis bei Pflanzen, in der er nicht nur die Angaben von Smith durch sorgfültige und kritische Nachprüfung bestätigen, sondern, was wichtiger war, einen nenen unbezweifelbaren Fall echter Parthenogenesis beschreiben konnte, nämlich bei Chara crimita Wrallr.. die innerhalb ihres recht ausgedehnten Verbreitungsbezirkes so gut wie ausschließlich in rein weiblichen Exemplaren vorkommt, dessenungeachtet aber allenthalben reichlich keimfähige Sporenfrüchte zur Reife bringt.

Freilich wollten anch nach den Arbeiten Bran n's (185̃ und 1860) die Zweifel noch nicht verstummen. Zwar die tatsächliche Richtigkeit des von Braun an Chara crinita Beobachteten ist mohl nie bestritten, im Gegenteil oft bestätigt worden; doch wurde die prinzipielle Bedeutung des Falles noch nicht recht gewürdigt. Und was Caelebogyne anbetrifft, so wurde die Frage, ob bei ihr in der Tat der Pollen zur Keimerzeugung umnötig ist, ob, wenn es der Fall wäre, das damn als Parthenogenesis aufzufassen, und wie das Verhältnis dieser Fortpflanzungsart zur sexuellen zu verstehen sei, nach wie vor hin und her diskutiert, ohne dab es zu einer definitiven Entscheidung kam und kommen konnte.

Das letztere war deshalb nicht gut möglich, weil noch eine klare Einsicht in das eigentliche Wesen des Befruchtungsvorganges fehlte; aus dem gleichen Grunde blieben auch im allgemeinen die umfangreichen theoretischen Erörterungen über das Wesen der Parthenogenesis ziemlich unfruchtbar. So konnte die endgiiltige Entscheidung über die vieluntersuchte Caclebogyne erst fallen, nachdem die Einzelheiten des Befruchtungsvorganges genauer bekannt geworden waren und die moderne Untersuchungstechnik ihre Ausbildung erfahren hatte, 
und das Jahr 1877 kam heran, bis durch Strasburger (1877, p. 67; 1878, p. 659) die alte Streitfrage dahin entschieden wurde, daß die Embryonen bei Caelebogyne ilicifolia zwar allerdings ohne Befruchtung gebildet werden, daß aber trotzdem keine Parthenogenesis vorliegt, da die Keime nicht aus unbefruchteten Eiern hervorgehen, sondern adventive Sprossungen des Nucellargewebes darstellen.

Damit war denn nun zwar erwiesen, daß bei höheren Pflanzen aus den Ovulis keimlinghaltige Samen entstehen können, ohme daß eine Befruchtung vorausgegangen ist, aber es war damit auch zugleich der einzige Fall von Parthenogenesis beseitigt, der bei höheren Pflanzen einigermaßen sichergestellt schien. ${ }^{1}$ ) Denn alle anderen Angaben übel vermeintliche Parthenogenesis bei Bliitenpflanzen konnten und mußten von nun an erst dann als sichergestellt gelten, wenn die cytologische Untersuchung ergeben hatte, daß die Keimlinge auch tatsächlich aus der unbefruchteten Eizelle entstehen. Solange diese Konstatierung ausstand, waren die betreffenden Angaben bestenfalls nur Nachweise der Tatsache, daß bei dieser oder jener Pflanze Samenbildung ohne Bestäubung erfolgen kann; ob aber Parthenogenesis oder Adventivembryobildung vorliegt, konnte und kann noch heute schlechterdings nur durch die cytologische Untersuchung entschieden werden.

Es dauerte nun aber sehr lange, ehe eine solche Untersuchung vorgenommen wurde, und so galt bis fast vor einem Jahrzehnt Chara crinita als die einzige Pflanze, bei der eine der tierischen vergleichbare Parthenogenesis festgestellt war. Die Algen waren es auch, die dann durch die wichtigen experimentellen Untersuchungen von K lebs (1896) über die Fortpflanzungsverhältnisse besonder's der Conjugaten und ihre Abhängigkeit von äußeren Faktoren die ersten neuen Beispiele von Parthenogenesis im Pflanzenreiche lieferten. Erst die im Jahre 1900 erschienene Arbeit ron J u el über Antemaria erbrachte damn den Nachweis, daß doch auch bei höheren Pflanzen echte Parthenogenesis vorkommt, und so ergab sich die merkwürdige Sachlage, daß die älteren Forscher, die, sich auf das Verhalten der Caelebogyne ilicifolia stützend, die Möglichkeit der Parthenogenesis bei Bliitenpflanzen so energisch verteidigt hatten, zwar im Hinblick auf den speziellen Fall der Caelebogyne im Unrecht waren, im Hinblick auf das gesamte Phanerogamenreich aber doch Recht behielten.

Mit dem Jahre 1900 nun und der in ihm erschienenen Arbeit von Juel haben wir den Ausgangspunkt für die im folgenden zu gebenden Darlegungen erreicht. Es ist deren Ziel, in übersichtlicher

$\left.{ }^{1}\right)$ Als Kuriosität sei erwähnt, daß Kerner von Marilaun noch in der zweiten Auflage seines Pflanzenlebens $(1896$, p. 421) in der Keimbildung der Caelebogyne ilicifolia Parthenogenesis erblickt. 
Anordmumg mod mit funlichele Vollstindiekeit alles das kitisch znsammenzustellen, was seit 1900 ïber das Problem ler Parthenogene- iboi Jflanzen veröffentlicht worden ist. Vatiolich worde and die altere Literatu, soweit das nötigr wal, gebülnend beriblisirhtigrt. Auberdem erwies es sich aus Grinden. die sofort dentlich werden werden. als erforderlich, das von delo Parthenogenesis nicht zu tremnende Problem der Apoganie mit zu berïcksirhtigen.

Whe wir nun aber mit der I)arlecrung der 'Tatsachen selbst begimmen kömnen. mïssen wir einige nomenklatorische Vorbemerkungen vorausschicken, die zugleich die Disposition fïr msere Einteilung des Stoffes enthalten.

Erstes Kapitel.

\section{Nomenklatur und Definitionen.}

Sowohl die Bezeichnung Parthenogenesis wie die Bezeichnung Apogamie sind vol den Forschern, die sich mit unserem Problem beschäftigt haben, durchaus nicht immer in ïbereinstimmendem Sinne gebraucht worden. Wir mïssen daher von vornherein genau angeben. in welchem Sinne nir sie im folgenden anwenden wollen. Dabei soll aber die Rechtfertigung im einzelnen für die von uns einzuhaltende Begriffsumgrenzung einem späteren Kapitel überlassen werden.

Parthenogenesis und Apogamie sind zwei charakteristische Arten (ler Fortpflanzung, und es fragt sich daher zuerst, wie sie sich zu den anderen bei Pflanzen rorkommenden Fortpflanzungsweisen verhalten. Um darin einen klaren Einblick zu bekommen, teilen wir die bei Pflanzen überhaupt möglichen Termehrungsarten in drei Lnterabteilungen ein: die Amphimixis, die Psendomixis und die Apomixis.

Die Amphimixis ist die normale Art der geschlechtlichen Fortpflanzung, bei der also der Keim entsteht aus dem Terschmelzungsprodukt zweier Keimzellen, seien diese nun als Isogameten ausgebildet oder in Ei und Spermatozoon differenziert.

Als Pseudomixis bezeichnen wir den Ersatz der echten geschlechtlichen Keimzellverschmelzung durch einen pseudosexuellen Kopulationsprozeß zweier nicht als spezifische Befruchtungszellen differenzierter Zellen. Was die Psendomixis ron der Amphimixis unterscheidet, ist also im wesentlichen nur der Lmstand, daß die beiden miteinander verschmelzenden Zellen nicht als Gameten differenziert 
sind. Naturlich ist die Pseudomixis stets mit Autogamie rerbunden; doch ist es wenigstens theoretisch auch nicht ausgeschlossen, daß sie mit Allogamie verbunden auftreten kann, wenn anders es sich bewahrheiten sollte, daf es Pfropflhybride gibt, die aus einer Zelle des Terwachsungsgewebes hervorgegangen sind, in die der Kern (und vielleicht auch Protoplasma) aus einer benachbarten artfremden Zelle hiniibergewandert war.

Bekannt ist pseudomiktische Fortpflanzungsweise bis jetzt vor allem bei einigen Farnen, so z. B. bei Lastrea pseudomas var. polydactyla Wills (Farmer, Moore und Digby 1903), wo der Sporophyt aus einer Prothalliumzelle hervorgeht, deren Kern mit einem aus einer Nachbarzelle heriibergewanderten zweiten Kern verschmilzt, elıe die Entwicklung beginnt. Farmer und Digby (1907, p. 191) nemmen diesen Vorgang Pseudapogamie.

Tielleicht gehören anch die Tredineen hierher, bei denen der binukleäre Zustand durch Übertritt eines Kerns in eine Nachbarzelle des uninukleären Mycels erreicht wird (B lackman 1904).

Da es aber in dieser Arbeit nicht unsere Absicht ist, uns eingehender mit der Erscheinung der Pseudomixis zu befassen, sollen diese Fälle, auf die wir iberdies später noch werden zurïckkommen müssen, nicht näher diskutiert, sondern nur kurz auf sie hingewiesen werden. Es sei nur noch bemerkt, daß sich die Abgrenzung der Pseudomixis gegen die Amphimixis in zweifelhaften Fällen vor allem daraus ergibt, daß der Aushilfscharakter erkennbar sein muß, den die Psendomixis als Ersatz der verlorenen typischen Amphimixis besitzt.

Andererseits ist auch zu bedenken, daß nicht jede nichtsexuelle Kern- oder Zellverschmelzung nun ein pseudosexueller Torgang sein mub. Es kann selbstverständlich außer der sexuellen und der pseudosexuellen Zellverschmelzung auch noch eine asexuelle geben. Hierher gehören z. B. die von Nĕm ec (1902; 1903) beschriebenen Kernverschmelzungen in chloralisierten Wurzeln von Ticia, und auch die vielbesprochene Kernverschmelzung im jugendlichen Ascus der Ascomyceten ist unseres Erachtens nicht als eigentlich sexueller Vorgang aufzufassen, auch nicht als Pseudomixis, sondern als ungeschlechtiche Kopulation. ${ }^{1}$ )

1) Wir können hier natürlich keine eingehende Begründung dieser Auffassung geben und verweisen auf die Besprechung der Frage besouders bei Harper (1905, p. 61 ff.), Lotsy (1907, p. 451 u. a. a. 0.) und Vuillemin (1907, p. 80 ff.). Was uns ror allem gegen die Deutung der "Dangeard'schen Fusion" (wie Juel (1902, p. 54 , die Endokaryogamie in der jungen Spore der Ustilagineen, der jungen Teleutospore der Uredineen und dem jungen Ascus der Ascomyceten nennt im Gegensatz zu (ter "Harper'schen Fusion" im Ascogon der Ascomyceten), als sexuellen Vorgang zu sprechen scheint, ist die Tatsache, daß die Harper'sche Fusion zweifellos als solcher anzusehen ist und doch nur eine von beiden als wahre Befruchtung gedeutet werden kann. Man künnte nun allerdings in der Dangeard'schen Fusion einen 


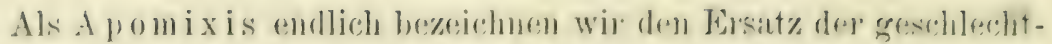
lichen Jortpflanzung durch cinen anderen, ungeschlechtlichen, nicht

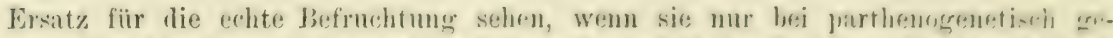
worlenen Ascomyceten anftrite. was aber eben nicht der foall ist. Lind der an irh

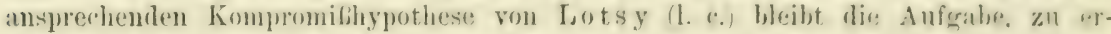
klïren, warum nach dor liefruchtung die chen arst verschmolgenen wterlichen k.rue sich nachtrïglich wieder trennen.

Wenn also die Kernfusion im Ascus der Ascomyceten kein sexueller Prozel' ist, so fragt es sich, ans welchem anderen frumde sie erfolgt; berlentungsios ist der lin-

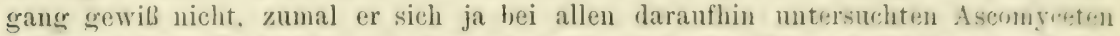
gefunden liat. II a rper (l. c.), der, was auch mir als das Wahrscheinlichste erchlyeint. annimmt, dal durch die Fusion ein Kern mit quadrivalenten ('hromosomen mutstht, bringt ihn in Zusammenhang mit der Kernplasmarelation: "the ascus is to be developed as a relatively large cell to serve as a storehouse, with an abundant supply of material for the formation of ascospores; and in order that the murlen-cytoplasmic: equilibrium may be maintained, it must be provided with an excess of muclear material as compared with the other cells of the ascogrenous hyphae and the ascogonium" (1. c., p. 66). Aber auch diese Hypothese erkliirt nicht die Fusion self,st. Nach dem, was wir sonst über die Beziehungen zwisehen Kern und Plasma wissen. müssen wir sogar annehmen, daß mehrere kleine grleichmäßig in rem P'rotoplasmakürper verteilte Kerne besser imstande sind, die Aufrechterhaltung der Kernjlasmarelation zu besorgen, als ein einziger großer Kern.

Ohne sie num hier ausfïhrlicher darzulegen und zu begründen. möchte ich die Ansicht äußern, daß die Kernfusion im Ascomycetenascus als ein karyokinetisch-technischer Vorgang anzusehen ist. An anderer Stelle (Winkler 1906, p. 266 ff.) wurde auseinandergesetzt, daB, wenn ans einem Kem mit n Chromosomen solche mit n/2 Chromosomen entstehen sollen, das nur so müglich ist, daß ein Kern mit bivalenten Chromosomen sich nach dem Schema der Rerhlitionsteilung zweimal hintereinander teilt, so $d a b$ vier Kerne mit $n / 2$ univalenten ('hromosomen entstehen. Sollen nun anstatt vieren acht solcher Keme gebildet werden. wie im Ascus, dann mul der Ausgangskern quadrivalente Chromosonen besitzen und sich Ireimal unmittelbar hintereinander teilen, mit anderen Worten sich so verhalteu. wie sich der fusionierte Ascuskern verhält. Da der junge Ascus zweikernig ist, wäre das allerdings auch erreichbar, wenn die beiden Kerne je eine Reduktionsteilnurs nach dem Schema der höheren Pflanzen durchmachten; wem trotzdem eine Fusion stattfindet und somit ein einziger Kern als Ausgangspunkt der Sporenbildung dient, so mag das daran liegen, daß der Prozel so gleichmäßiger erfolgen, mit grüferer Sicherheit gleichzeitig einsetzen und gleichmäBigere Produkte liefern kanu, als wenu zwei voneinander unabhängige Kerne ihn selbständig auszuführen hätten. (Daß die Ascomyceten mit mehr als acht Sporen im Ascus dieser Dentung keine prinzipiellen Schwierigkeiten entgegenstellen, geht aus den Untersuchungen ron Orerton 1!106 iiber Thecotheus Pelletieri hervor.)

Nachtrïgliche Hinzufïgung. In einer eben erschienenen vorläufigen Mitteilung berichtet Claussen (1907) über eine Neumtersuchung der Kernserhältnisse rou Pyronema confuens, die, falls sie sich bestätigt und rerallgemeinern läbt, die Dangeard'sche Fusion in ganz anderer, einfacherer Weise erklïrt. Danach findet nämlich auch bei den Ascomyceten nur eine einmalige Kernverschmelzung statt. da die Kerne im Ascogon sich nur fest aneinanderlegen, ohne zu rerschmelzen, und dann als honjugierte Kerne in die ascogenen Hyphen einwandern. Hier erst findet die definitive Fusion zum primären Ascuskern statt, der also biernach natürlich uur bivalente Chromosomen hat. 
mit Kern- und Zellverschmelzung verbundenen Vermehrungsproze.. Hierfïr liegt an sich schon ein anderer Terminus vor, nämlich der der A pogamie. Dieser Ausdruck wurde von de Bary (1878, p. 479) für die Tatsache eingeführt, „daß einer Species (oder Varietät) die sexuelle Zeugung verloren geht und durch einen anderen Reproduktionsprozeß ersetzt wird". Die Apogamie im Sinne von de Bary deckt sich also genau mit dem, was wir Apomixis nennen, und wenn wir diesen neuen 'Terminus an Stelle des alten setzen, so geschieht es notgedrungen deshalb, weil, wie bereits anderwärts nachgewiesen wurde (IV ink l e r 1906, p. 251ff.), alle neueren Autoren den Ausdruck Apogamie nicht mehr im de Bary'schen Sinne verwenden, sondern ihm eine andere engere Bedeutung zulegen, in der er allgemein gebräuchlich geworden ist. Als Beleg sei zunächst auf Juel (1900, p. 40) hingewiesen, der unter Apogamie nur die Erzeugung eines Sporophyten durch den Gametophyten ohne geschlechtliche Fortpflanzung versteht. Genau so sehen auch (oulter und Chamberlain (1904, p. 210) Apogamie als ,the production of a sporophyte by a gametophyte without the act of fertilization" an. Prinzipiell ebenso, aber noch enger umgrenzend, weil nur die Verhältnisse der Angiospermen berücksichtigend, definiert Guérin (1904, p. 80): „L'Apogamie ne comprend que les embryons naissant dans le sac embryonnaire, aux dépens de toute cellule autre que l'oosphère." Und ebenso versteht Treub (1905, p. 149) unter Apogamie diejenigen Fälle, „où l'amphimixie fait défaut, et dans lesquels l'embryon tire son origine d'un élément quelconque né dans le sac embryonnaire, à l'exception de l'oosplière*.

Alle die genannten Autoren sehen also in der Apogamie nicht mehr wie de Bar'y allgemein den Ersatz der verlorenen geschlechtlichen Fortpflanzung durch einen anderen Vermehrungsvorgang; sondern nur noch die Erzeugung eines Sporophyten durch den Gametophyten ohne geschlechtliche Vorgänge. Ausdrïcklich nehmen dabei Guérin und Treub von denjenigen Zellen des Gametophyten, die den Sporophyten liefern können, die Eizelle aus. Anders Strasburger, der auch in der Embryobildung aus dem unbefruchteten Ei einen echten Apogamiefall sieht, vorausgesetzt, daß das Ei einen Kern mit der unreducierten, diploiden Chromosomenzahl besitzt (Strasburger 1904, p. 113, 118; 1907, p. 170). Auch Farmer und Digby (1907, p. 192) bezeichnen die ungeschlechtliche Entstehung eines Sporophyten aus einem diploidchromosomigen Gameto-

Wenn sich das bestätigt, damn bleibt sehr auffällig die Achtzahl der Sporen im Ascus, die, wenn eine doppelte Kernverschmelzung da wäre, als deren notwendige Folge verständlich ist. Hat der primäre Ascuskern aber nur bivalente Chromosomen, dann verlangt die Tatsache Erklïrung, daß bei den Asconyceten im Gegensatz zu allen anderen Organismen derjenige Kern, der die Reduktionsteilung durchführt, drei und nicht nur zwei Teilungsschritte eingeht. 
phrten als Apoganie und unterscheiden zwischen Panthenaporamie. d. h. der Entstehung des suorophyten ans der mbefruchteten diplojiden Fizelle. und Euapogamie. d. h. der Entstehung des sporophyten ans Gametophytengewebe.

Inwefern es zulässig ist, anch die Entwicklung der unbefruchteten diploidchromosomigen Eizelle als aporamen Torgang anfoufitsen. werden wir später zu untersuchen haben. Hier soll vorerst nur darauf hingewiesen werden, dab. während F armer und Digl,y sich an die auch sonst ïbliche Definition der Apoganie halten, Strasbureg insofern von ihr abweicht, als er $(1905$, p. 58 , das Fi der ..apoganeme" Alchimillen und anderer sich wie diese verhaltender Pflanzen als ..eine regetative, nur wie ein Ei geformte Zelle des Sporoply ts" 1, bezeichnet. Es ist, worauf auch de c'andolle 1905, 1. 9) schon hingewiesen hat, klar, dab man von Apogamie im sinne der herrschenden Definition in diesem Falle nur dann sprechen kann. wenn man auch in der diploiden Eizelle eine Zelle des Gametophyten sieht: hält man sie für eine Sporophytenzelle, dann ist die Entstehung eines sporophyten aus ihr nicht als apogamer, sondern als rein regetativer Propagationsprozeb anzusehen, durchaus gleichwertig der Adrentivkeimbildung aus Nucelluszellen oder der Termelırung durch Auslïufer. Strasburger kehrt also damit zur älteren weiteren Fassung des Apogamiebegriffes zurück.

Nachdem sich aber der de Bary'sche Terminus spontan in seiner Bedeutung so gewandelt hat. erscheint es uns als rorteilhafter. ihm, anstatt ihn in seine alten Rechte wieder einzusetzen, die neue Bedeutung zu lassen und als Ersatz für ihm eine nene Bezeichnung einzuführen. Als solche wurde früher ( $\mathrm{I}$ in $\mathrm{kler} 1906,1 \% 253$, Apomixis vorgeschlagen, und diesen Ausdruck werden wir anch im folgenden benutzen in der Bedeutung: Ersatz der geschlechtlichen Fortpflanzung durch einen anderen, ungeschlechtlichen Termehrungsprozeb. Es ist selbstverständlich. daß Organismen wie die Bakterien oder die Cyanophyceen. die sich nur ungeschlechtlich vermehren. nicht als apomiktische Tesen aufzufassen sind, da sie ja, soviel wir wissen. eine geschlechtliche Fortpflanzung niemals besessen haben, und es zum Begriff der Apomixis gehört, daß ein Verlust der Sexualität eingetreten ist.

Der ungeschlechtliche Termehrungsvorgang nun, der den sexuellen bei der Apomixis ersetzt, kann nach sehr verschiedenartigen Modalitäten erfolgen, und wir unterscheiden darnach als Lnterarten der Apomixis:

1. regetatire Propagation, d. h. Ersatz der Befruchtung durch Auslüuferbildung, Entstehung blattbürtiger Sprosse.

1) Ton mir gesperrt. W. 
Viviparie und ähnliche Torgänge vegetativer Termehrung: für die sich z. B. bei Kerner (1896, p. 5 ff.) und anderswo zahlreiche Beispiele angeführt finden. Auch die Adventivembryobildung aus Nucellarzellen, wie sie sich bei Caclebogyne ilicifolia und anderen Pflanzen findet, gehört hierher. Es handelt sich dabei (außer bei der Aposporie, vgl. Kapitel 3 । immer um die apomiktische Entstehung von Sporophyten aus Sporophyten, oder von Gametophyten aus Gametophyten, und alle diese Fälle fallen also außerhalb unseres Themas, auch die Nucellarembryonie von Caclebogyne, die sich ja von der Entstehung adventiver Knospen etwa am Hypocotyl von Euphorbia cyparissias oder Linum usitatissimum nur dadurch unterscheidet, daß sie sich innerhalb der Nakrospore abspielt, und daß die Adventivsprosse morphologisch (wenigstens meistens) echten Embryonen völlig gleichen. Mit Parthenogenesis oder Apogamie direkt haben sie nichts zu tun.

2. Apogamie, d. h. die apomiktische Entstehung eines Sporophyten aus vegetativen Zellen des Gametophyten, und zwar

a) somatische Apogamie, wenn die Zelle oder der Zellkomplex, die den Sporophyten liefern, in ihren Kernen die diploide Chromosomenzahl besitzen (Euapogamie von Farmer und Digby),

b) generative Apogamie, wenn die Kerne der Mutterzellen des Sporophyten nur die haploide Chromosomenzahl führen (meiotische Euapogamie von Farmer und Digby).

3. Parthenogenesis, d. h. die apomiktische Entstehung eines Sporophyten aus einem Ei, und zwar

a) somatische Parthenogenesis, wenn das Ei einen Kern mit der diploiden, unreducierten Chromosomenzahl besitzt (Parthenapogamie von Farmer und Digby),

b) generative Parthenogenesis, wenn der Kern des Eies mit der haploiden Chromosomenzahl ausgestattet ist.

Wir finden also in dem Umstande, daß der Sporophyt das eine Mal aus einer Eizelle, das andere Mal aus einer oder mehreren vegetativen Körperzellen hervorgeht, einen wesentlichen Unterschied, und legen erst in zweiter Linie Gewicht auf die Zahl der Chromosomen, die sich in den Kernen der Ausgangszellen finden. Damit befinden wir uns vor allem in scharfem Gegensatz zu Strasburger. der den Hauptnachdruck auf die Chromosomenzahl legt und von echter Parthenogenesis nur dann reden will, wenn ein ,haploides, somit auf Befruchtung eingerichtetes Ei mit seiner einfachen Chromosomenzah! in die Keimbildung" eintritt (1907, p. 170). 


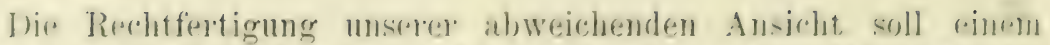
spaiteren liapitel vorbehalten bleiben. Wir werden jedenfalls in folgenden die im vorstehenden angefiilnte Bugriffimgrenzung einhalten und die Darlegung der Tatsachen anch nach ihr dispmieren.

Bemerkt mub noch werden. dal. das Vorkommen des einen Wodus der Fortpflanzung das gleichzeitige Vorhandensein noch eines anderen bei dersellen Species und sogar beim gleichen Individum nicht minzipiell ansschlielit; es kann im Gegenteil \%. B. Amphimixis konbiniert mit allen Cnterarten der Apomixis auftreten. Inshesomlere aber ist die vegetative I'ropagation häufig als aushelfende Termehrungsweise neben irgendeiner der anderen Methoden der Fortpflanzung vorhanden. Joch scheinen Apogamie und Parthenogenesis niemals oder nur ausnahmsweise nebeneinander vorzukommen (si) bei Alchimilla sericata und vielleicht bei Emplorthic dulcis?). Während Amphimixis und Parthenogenesis \%. B. bei Thalictmon purpurusmos nebeneinander vorhanden sind.

\section{Zweites Kapitel.}

\section{Unsichere oder noch nicht genügend untersuchte Fälle.}

Bevor wir nun daran gehen kömnen, die einzelnen Fälle ron Parthenogenesis oder Apogamie in der Reilıenfolge zu besprechen. die ihnen nach den im ersten Kapitel getroftenen Unterscheidungen zukommt, empfiehlt es sich, die zweifelhaften oder noch nicht genügend untersuchten einschlägigen Fälle rorweg zı erörtern. Denn es lassen sich selbstrerständlich die einzelnen in der Literatur bekannt gegebenen Torkommnisse ron Parthenogenesis oder Apogamie erst damn sicher rubricieren, wenn sie auch cytologisch und mit besonder'er Berücksichtigung der Kernverhältnisse untersucht worden sind. Das ist nun aber keineswegs bei allen den Pflanzen, bei denen das Torhandensein einer der beiden uns interessierenden Apomixis-Arten festgestellt ist. der Fall, ja oft ist es überhaupt noch fraglich, ob Apogamie oder (b) Parthenogenesis vorliegt, und. wenn das eine oder das andere zntrifft, ob es sich $u m$ die generative oder um die somatische Modalität handelt. In manchen Fällen ist sogar nur das sichergestellt, daß Samenbildung ohne Bestäubung erfolgen kamn, so dab es also noch unentschieden bleibt, ob das Pseudomixis oder eine der drei Arten der Apomixis ist. Alle diese Fälle sollen num, soweit sie mir bekannt geworden sind, schon an dieser Stelle zusammengestellt rerden. 
damit im folgenden, falls erforderlich, auf sie Bezug genommen werden kann, und in der Hoffnung, daß die Zusammenstellung der unsicheren und noch nicht genügend untersuchten Angaben dazu anrege, sie eingehender nachzuprüfen.

Die Zahl der Pflanzen, bei denen das Bestehen von Parthenogenesis oder Apogamie vermutet, aber bisher noch nicht sicher nachgewiesen worden ist, oder bei denen, wenn auch das tatsächliche Torhandensein einer der beiden Apomixis-Arten sichergestellt wurde, doch die Untersuchung nicht so weit gediehen ist, daß sie mit völliger Sicherheit in eine der von uns aufgestellten Kategorien untergebracht werden könnten, ist ziemlich groß. Auf absolute Vollständigkeit macht unsere Zusammenstellung natürlich keinen Anspruch; doch blieben, soweit das möglich war, in der Hauptsache nur solche Angaben unberïcksichtigt, die von vornherein durch allzu ungenügende Begründung außer Betracht fallen. Das gilt begreiflicherweise vor allem von älteren Angaben, hinsichtlich derer hier auf die Zusammenstellungen bei Gaertner (184t und 1849), A. Braun (185̃7 und 1860) und besonders bei Regel (1859) verwiesen sei.

Wir führen der Übersichtlichkeit wegen die in diesem Kapitel zu behandelnden Fälle nicht in historischer, sondern in systematischer Anordnung an.

\section{A. Algen.}

Unter den Algen sind aus den verschiedensten Familien mehrere Fälle von Parthenogenesis sichergestellt; doch liegen auch eine Reihe von Angaben vor, die noch näher zu untersuchen sind. So z. B. das Verhalten mancher Diatomeen.

Diatomeen. Yanche Antoren, wie z. B. Lotsy (1907, p. 284) reden hier direkt von Parthenogenesis. So sollen bei Synedra affinis und Corethron parthenogenetische Auxosporen vorkommen; auch Rhabdonema arcuatum soll sich ähnlich verhalten. Doch fassen sowohl Oltmanns (1904, p. 126 ft.) wie Karsten (1900), welch letzterer wohl der beste Kenner der Fortpflanzungsverhältnisse der Bacillariaceen ist, die Sache ander's auf. Sicher scheint mu, daß in der Tat bei einigen der erwähnten Formen und ihren Verwandten Apomixis vorliegt. Im übrigen aber ist die Sachlage noch so wenig geklärt. daß wir an dieser Stelle keine Veranlassung haben, näher darauf einzugehen und auf die Diskussion der einschlägigen Tatsachen bei den drei citierten Autoren verweisen können.

Chlorophyceen. Innerhalb der großen Gruppe der Chlorophyceen ist bei verschiedenen Unterfamilien Parthenogenesis konstatiert. So kommt z. B. unter den Chlamydomonadaceen vielleicht bei Polytoma spontane Parthenogenesis vor, da Francé $(1894$, p. 323) 


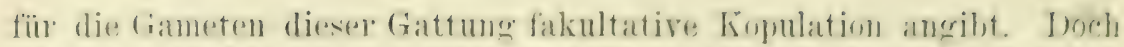

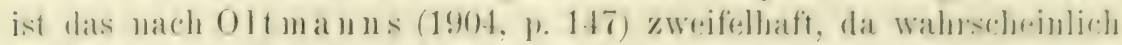

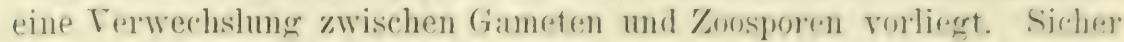

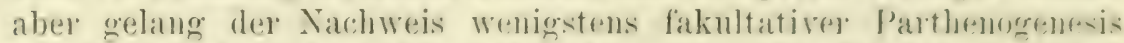

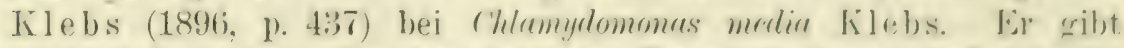
daribber l. c. an: „In den fouchten Kammekultuen lief ich die Zellen sich bis zam Aufteten der Gameten vermehren, die zum "Teil an ihrem kontrahierten Plasmakörper erkennbar waren. Damn fïgte ich einen 'Tropfen einer Sährlissmg vou 1 l'roz. zu und strllte die Kultur wieder hell. Alle \%ellen kamen zur Ruhe. die Kopulation war unmöglich geworden. Jetzt sah ich, wie der kontrahierte Plasmakïrper einer Gamete imerhalb der alten Zellhaut sich mit piner neuen umgab und nach einiger Zeit sich zu teilen begann. Die nicht kojulierenden Gameten werden also wieder rein ungeschlerhtich. Allerdings ist der Unterschied in der Keimung gegenïber den Zygroten gering. Denn auch diese rerhalten sich bei ihrer Keimung nicht anders, als daß sie sich teilen und ungeschlechtliche Zellen bilden.:

Bei den Tolvor-Arten soll nach Angaben Klein's (rgl. Oltman $n$ s 1904. p. 16:) echte Parthenogenesis nicht ausgeschlossen sein. Sie ist selbstrerständlich für den bei Jolrox sichergestellt, der mit Bütschli in den Parthenogonidien dieser Pflanzen parthenogenetische Eier erblickt.

Selr interessante Terhältnisse finden wir bei der Protosiphonacee Protosiphon botryoides ( $\mathrm{K}$ ï tzing) Klebs. Diese einzellige aber vielkernige Alge bildet in Masser zahlreiche Gameten, die normalerweise zu je zwei kopulieren und eine sternförmige abgeflachte Zygote lief'ern. Diese mu eine längere Ruheperiode duchmachen, ehe sie keimt. Bei der Keimung geht aus ihr sofort rieder ein nenes Pflänzchen hervor, indem sie sich einfach streckt und vergröbert. Es gelang nun aber Klebs $(1896,1) .216 \mathrm{ff}$.) dadurch, daß el die Alge in nährsalzreicher Flïssigkeit oder bei einer Temperatur von 25-27" ( hielt, sie zur Bildung von Schwälmern zu veranlassen. die olme zu kopulieren zu je einer Parthenospore wurden. Dab es sich dabei um echte Gameten und nicht un ungeschlechtliche Schwärmsporen handelte, ging daraus hervor, dab die in der nährsalzreichen Lösung entstandenen Schwärmer, in reines Wasser übertragen. schon nach 10-15 Minuten kopulierten. - Wir haben hier also einen wohlkonstatierten Fall von fakultativer, experimentell erzeugbarer Parthenogenesis, auf den wir später noch werden zurickkommen mïssen. Die Kern- und Chromosomenverhältnisse sind dabei aber leider unbekannt. Ian wird aber wohl rermuten dürfen. dab bei der Keimung der Zygoten eine Reduktion eintritt, bei der der Parthenosporen aber nicht. Daß jedenfalls die beiden nicht völlig gleichnertig sind, geht auch daraus herror, daß die Parthenosporen 
kugelrund, nicht sternförmig gestaltet sind, und daß sie im Gegensatz zu den längere Zeit ruhenden Zygoten sofort auskeimen. Andererseits ist freilich zu beachten, daß die Keimung der beiden Sporen gleichartig verläuft, sie erfolgt also auch bei den Zygoten ohne vorhergehende Schwärmerbildung, so daß man wohl annehmen muß, die Reduktion erfolgt bei der Schwärmerbildung. Da nun aber eine solche auch in den aus Parthenosporen hervorgegangenen Individuen erfolgt, so miißte sie hier nach ganz anderem ILodus, ohne Reduktion vor sich gehen. Das läßt sich aber natïrlich nur durch die Beobachtung entscheiden.

Ähnlich verhält sich nach Klebs $(1896$, p. 321; vgl. auch die älteren Angaben von Dodel 1876, p. 506) Ulothrix zonata Ktz., die wie alle Ulotrichaceen unverzweigte Fäden bildet. Sie hat neben ungeschlechtlicher Fortpflanzung durch Makro- und Mikrozoosporen geschlechtliche Vermehrung durch Gameten, die zu je zwei miteinander zu einer Zygote verschmelzen. Durch Übertragen der Gameten - die durch den Besitz von nur zwei Cilien mit. Sicherheit von den vierciligen Mikrozoosporen zu unterscheiden sind - in eine 0,5 proz. Nährlösung konnte aber Ḱlebs die Kopulation verhindern und die Gameten dazı veranlassen, ohne vorhergehende Verschmelzung je eine keimungsfähige Parthenospore zn liefern. Bei der Keimung teilt sich die Zygote in vier Zellen, von denen jede für sich zu einem nenen Faden auswächst, während die Parthenosporen nur je zwei solcher Zellen ergeben. Wenn sich das bestätigen sollte, dann könnte man wohl annehmen, daß bei der Keimung der Zygoten eine Reduktion erfolgte, bei der der Parthenosporen aber nicht. Doch wäre dann nicht recht verständlich, warum sich die Parthenospore iiberhaupt bei der Keimung teilt, anstatt sofort zum Faden auszuwachsen, was die Zygote natürlich nicht kann, da sie die diploide, der Faden aber die haploide Chromosomenzahl besitzt, oder aber, warum die Parthenospore nicht auch durch zwei Äquationsteilungen in vier Fadenmutterzellen sich teilt. Doch ist die ganze Sache noch der Nachuntersuchung und Aufklärung bedürftig, da Klebs selbst das geschilderte verschiedene Verhalten der beiden Sporenarten bei der Keimung nicht als direkt beobachtet, sondern nur als wahrscheinlich vorhanden angibt, während andererseits Dodel $(1876$, p. 433$)$ behauptet, daß die Zygote bei der Keimung 2-1t Zoosporen bildet.

Vermutlich kommt auch bei der monotypischen Gattung Cylindrocapsa Parthenogenesis vor, doch liegt daruiber nur eine kurze Notiz von Cienkowski vor $(1876$, p. 529), auf die hier verwiesen sei.

Ebenfalls noch nicht genügend geklärt sind die Verhältnisse bei der Chatophoracee Draparnaldia, deren Mikrozoosporen nach Klebs (1896, p. 420) sowohl mit wie ohne Kopulation Ruhezellen erzengen können, sich also bald als Gameten, bald als Zoosporen verhalten. 


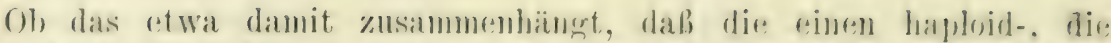
amberen diploidchromosomior sind, und wie sich die beiderles Ruhezellen bei der Keimung verhalten, ist nicht bekannt.

Auf Grund einer Beobachtmog von $\mathrm{H}$ ub ere dab den weiblichen Gameten gleichende Schwärmer von Aphomorduce reprus A. Br. keinten und Pflänchen mit sexualorganen ergaben, vermutet oltmanns (1904, p. 241), dafis man es auch hier mit jarthenogenetisch keimenden Eiern zu tun hat. Auch hier ist die nïhere Cntersuchung erwiinscht.

Dasselbe gilt von manchen Chroolepidaceen, bei denen die Schwärmer der Gametangien unter Umständen auch olne Kopulation keimen können (Oltmanns 1904, p. 253).

Unter den Siphonales sind es Codtum tomentrosum und Bryopsis. bei denen das Vorkommen von Parthenogenesis vermutet wurde. und zwar von Went $(1890$, p. 3í2) für Codium, und von Oltmanns (1904, p. 306) für Bryopsis. Beide Fälle sind näher zu untersuchen.

Pha e o h y ceen. Unter den Phaeophyceen bietet besonderes Interesse die Gattung Ectocarpus. Deren Arten bilden neben ungeschlechtlichen Zoosporen auch Gameten, die zwar äußerlich alle gleichgestaltet sind, aber insofern eine erste Andeutung von sexueller Differenzierung als Eier und Spermatozoen erkemnen lassen, als die einen - die weiblichen Gameten - sich eher als die anderen mit ihrer Geißel festsetzen, so daß sie also in diesem ruhenden Stadium ron den anderen noch lebhaft herumschwimmenden - männlichen Gameten befruchtet werden. Es ist nun sehr bemerkenswert, daß beide Arten von Gameten zu parthenogenetischer Keimung befähigt sind, wie von Berthold (1881, p. 404) und Oltmanns $(1899,1) .93$ । beobachtet wurde. Wir werden auf dieses seltene Beispiel „männlicher Parthenogenesis" noch zurückzukommen haben.

Auch bei den Cutlerien und ihren Verwandten kommt Parthenogenesis vor, über die aber im einzelnen noch manche wichtige Frage aufzuhellen ist. Oltmanns (1905, p. 256) berichtet darïbei zusammenfassend: "Reinke wie Falkenberg konnten bei Neapel die Kiopulation der Cutlerien glatt beobachten, unbefruchtete Eier gingen stets zugrunde, deshalb glaubte man, Thuret's und Crouan's ältere Angaben, wonach die weiblichen Gameten der fraglichen Form an den bretonischen Küsten unbefruchtet keimen, möchten wohl auf einem Irrtum beruhen. Allein sie sind zweifellos richtig, denn nenerdings zeigte Church (1898), daB auch an den Fïusten ron England Cutleria multifida meistens parthenogenetisch keimt. Während bei Teapel nach Reinke das Terhältnis von Männchen und Teibchen 3:2 zu sein pflegt, treten an Englands Küisten im August männliche Pflanzen nur ganz spärlich auf, und in den übrigen Monaten werden sie iiberhaupt nicht mehr gefunden. Die weiblichen Exem- 
plare sind dagegen sehr reichlich vertreten, und die entleerten Eier keimen fast alle ohne Befruchtung.

Die Neigung zu parthenogenetischer Entwicklung ist unter den Braunalgen aber keineswegs auf die ('ntlerien beschränkt. S'a u rage a u schildert auch für Griffordia secunda ein reichliches Auftreten der Antheridien im Juli, ein völliges Schwinden derselben im August. Oogonien werden zu dieser Zeit noch reichlich entwickelt. Die Eier keimen parthenogenetisch aber sehr langam - fast wie \%oosporen. Lompliziert wird der Vorgang. der im einzelnen wohl noch einmal studiert werden miißte. dadurch. daß viele unbefruchtete Eier unter Aufplatzen zugrunde gehen.

sehen wir aber bei den genamnten Gattungen ein periodisches Schwinden der Antheridien, so liegt die Ammahme nahe, dab ähnliche Formen in dieser Pichtung noch weiter vorgeschritten sind und ihre Antheridien vollends einbüßten; sie behielten nur noch Oogonien mit parthenogenetischen Eiern. Das dürfte besonders für einige Erto(tripus-Arten zu rermuten sein. welche aus plurilokinlären Sporangien große. olme Befruchtung keimende Schwärmer entleeren, denen eine außerordentlich große Ähnlichkeit mit den Fiern ron Giffordir secunda zukommt."

Man wird rermuten dïrfen, dab anch hier wie bei Protosinhlon äußere noch nicht näher präzisierte Faktoren für den Eintritt oder das Fehlen der Befruchtungsbedürftigkeit der Gameten maßgebend sind. Zu erwähnen ist dabei noch. daß sich bei Cutleria die Parthenosporen weder im Aussehen noch in ihrer Weiterentwicklung nennenswert von den Zygoten unterscheiden.

Characeae. Auch den allbekannten Fall der Chara $c$ rinita Trallr. müssen wir unter die noch nicht genïgend untersuchten Vorkommnisse ron Parthenogenesis rechnen. Zwar kann es hier keinem Zweifel unterliegen. dab echte Parthenogenesis vorliegt; aber die Tiernrerhältnisse sind noch röllig unbekannt, und es läbt sich schlechterdings nicht entscheiden, ob es sich $u m$ somatische oder generative Parthenogenesis handelt.

Bekanntlich wurde die Tatsache, daß bei Char crinte die unbefruchteten Oogonien zu keimfähigen Oosporenfrüchten heramreifen. ron Braun (1857) entdeckt. Die reitverbreitete Pflanze ist diöcisch. einjährig und nicht imstande. sich durch Bulbillen oder überwinternde Stengelknoten zu erhalten. Sie ist also auf die Vermehrung durch Oosporen angewiesen und benutzt diese auch allenthalben, obwohl männliche Exemplare an den allermeisten Standorten der Pflanze durchaus fehlen. Schon daraus geht so gut wie sicher hervor, dals die Oosporen parthenogenetisch reifen müssen. Durch besondere Kulturversuche mit isolierten rein meiblichen Stöcken wurde es überdies auch noch experimentell von II gula (1897. p. 357) bewiesen. 


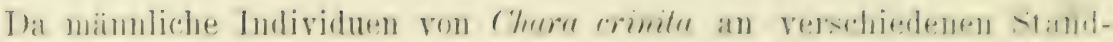

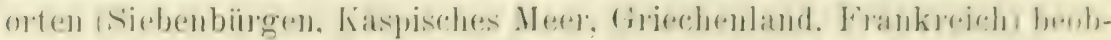
arhtet worden sind. ist es nicht ansegeschlossen, dalf anch Amphimixi-

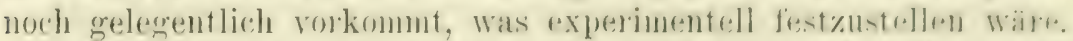

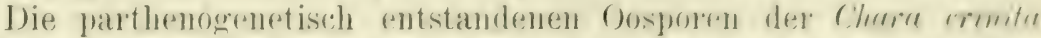

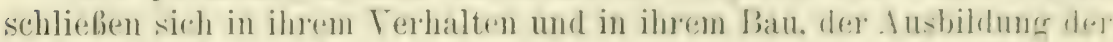
schwarzen Hartschale usw. durehans an die entspechenden lephälnisse der geschlechtlich erzengten (hara-Frichte an. ()b die liecolach-

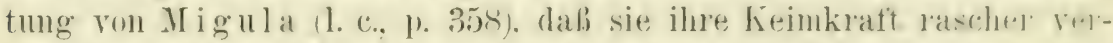
lieren als diese, allgemein gilt und mit der Parthenogenesis in \%/nsammenhang steht, ist noch zu untersuchen.

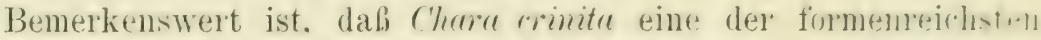
Chara-Arten überhaupt ist; bei $1 \mathrm{igula}$ 's Kulturversuchen mit $7 w+$ verschiedenen Formen erwiesen sich diese als konstant.

Über die Kernverhältnisse der Chara crinita wissen wir noch nichts. Debski (1897 und 1898) und Goet\% 1 1s!99) haben (hor, fragitis und foetida näher cytologisch untersucht und gefunden. dali weder bei der Entwicklung der śpermatozoen noch bei der ite. Oogonien eine Reduktion der Chromosomenzahl stattfindet. Man muli also annehmen, dab eine solche mit den ersten Teilungen der kimenden Oospore verknüpft ist. Das ist cytologisch noch nicht näheuntersucht worden, aber sehr wahrscheinlich.

Tehmen wir also an, daß bei den amphimiktisch geblieben'n Charen die ersten beiden. Teilungsschritte in der keimemlen Frucht durch eine Reduktionsteilung erfolgen, so ist es klar. daß bei 'thro" crinita anch die ersten beiden Teilungen typische Karyokinesen wie alle anderen sein müssen. Die Chromosomenzahl wird also imm-1' konstant die gleiche bleiben. Ob das aber die haploide oder die diploide ist, läßt sich nicht entscheiden, ehe nicht weitere Intersuchungen vorliegen. Es könnte die diploide Chromosomenzahl sein. und also somatische Parthenogenesis vorliegen; dann mïßte man allnehmen, daf bei der Keimung normal befruchteter Oosporen rom Chara crimita einmal die Reduktionsteilung unterblieb, so dali eine diploidchromosomige Pflanze resultierte, deren Oosporen die Fähigkeit zur Parthenogenesis besaßen. Es kam aber auch die haploide Chromosomenzahl sein, und also generative Parthenogenesis vorliegen: dann müßten unbefruchtete Oosporen direkt die Fähigkeit zu slontaner Weiterentwicklung erhalten haben. Die letztere Ammalme ist wohl die wahrscheinlichere, da nach ihr ron allen Zellen nur die Oospore nicht die ihr gebührende Chromosomenzahl besitzt. Während nach der anderen Annahme die Oospore als einzige von allen Zellen die normale Chromosomenzahl im Kern hat. Entscheidung bringen kann hier wohl nur der Befruchtungsversuch und der Vergleich mit den Chrumosomenzahlen der anderen amphimiktisch gebliebenen Chara-Arten. 


\section{B. Pilze.}

Phycomycetes. In den beiden Gruppen der Phycomyceten, den Zygomyceten und den Oomyceten, finden wir Formen mit Apomixis, wenn diese auch in der überwiegenden Mehrzahl der Fälle noch nicht genügend bekannt ist.

Von den Zygomyceten sind hier alle diejenigen Arten zu nennen, die zur Bildung von Azygosporen befähigt sind. Die normale geschlechtliche Fortpflanzung dieser Pilze besteht bekanntlich darin, daß an benachbarten Mycelästen keulenförmige Seitenäste entstehen, die ihre Spitzen, mit denen sie sich paarweise berïhrer, durch je eine Querwand von dem Reste des Mycels abgrenzen. Die so isolierten Zellen werden zu Gameten, die miteinander zu einer meistens dickwandigen Zygote verschmelzen (Fig. 1A), wobei die zahlreichen Kerne, wie Dangeard (1906, p. 645) bei Mucor fragilis und Sporodinia grandis feststellte, paarweise miteinander kopulieren, offenbar wohl je einer aus der einen Gamete mit je einem aus der anderen.

Es gibt nun eine ganze Anzahl von Zygomyceten, bei denen Azygosporen entstehen können, d. h. Danersporen, die denselben Bau wie die typischen Zygosporen besitzen, nur in manchen Fällen weniger voluminös sind, die aber nicht durch Kopulation ziveier Gameten entstehen, sondern dadurch, daß entweder sich überhaupt nur ein Kopulationsast bildet, dessen apikale Kopulationszelle unmittelbar zur Azygospore wird (Fig. 1C), oder aber dadurch, daß die beiden $\mathrm{Ko}$ pulationsschläuche zwar ausgebildet werden, ihre Gametenzellen aber nicht ver-

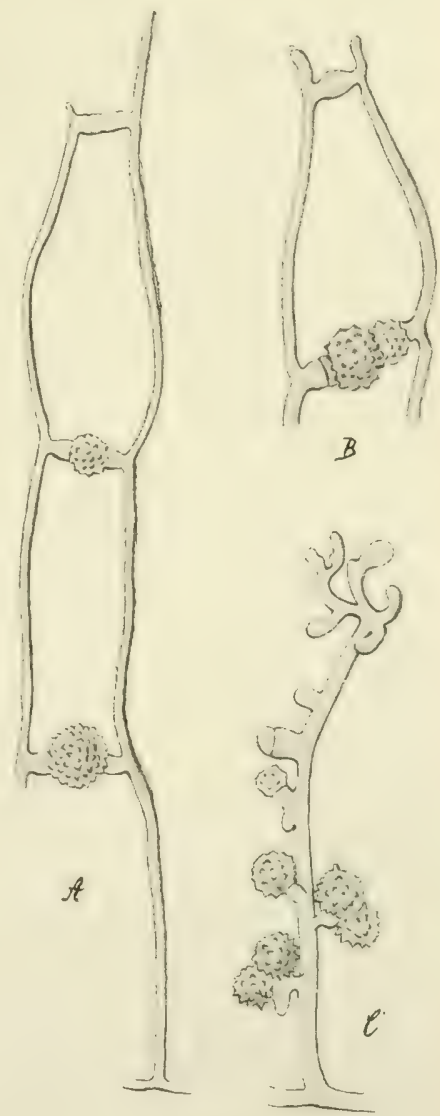

Fig. 1. A. Mucor racemosus. Normale Zygosporenbildung (nach Bainier 1883, Taf. 17, Fig. 6). - B. Mncor racemosus. Azygosporenbildung (nach Bainier 1. c., Taf. 18, Fig.9). C. Mucor temis. Azygosporentragender Ast (nach Bainier 1. c., Taf. 19, Fig. 11). schmelzen. sondern je für sich zu einer Azygospore reifen (Fig. 1B). - Die Zahl der zu solcher Azygosporenbildung befähigter Zygomyceten ist wahrscheinlich ziemlich grob. Fischer $(1892$, p. 170) fuilhrt als 


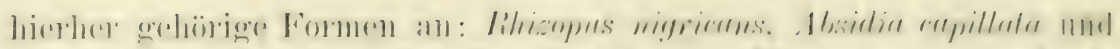

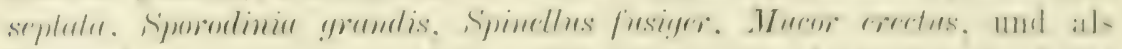

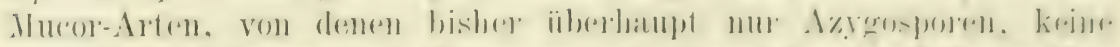

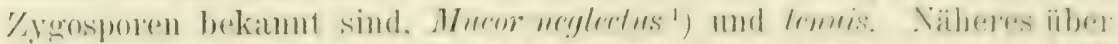

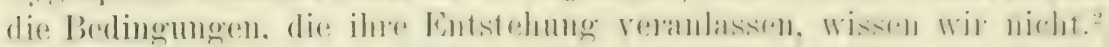

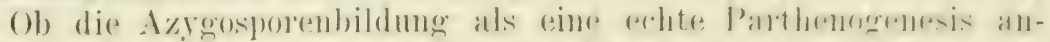
gesehen werden darf', ist nicht leicht zoll entscheiden. zunnal cotologische Intersuchungen daribler norlh alustehen. Da bei der nomalen

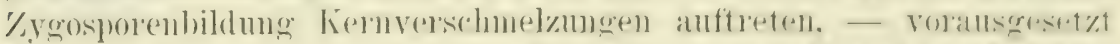
(lat) man den eben angeführten brgobnissen von I) angeard .llgemeingültigkeit für alle sexuellen \%ygomyceten znsprechen darf - so wäre es selor wohl denkbar, dab auch in der reifenden Azyeropore die Kerne patrweise miteinander kopulierten. In der Tat gribt aur.ls Vuillemin (1900) an, solehe Kernverschmelzungen in den Azyogsporen von Entomophthore glocosport beobachtet zu haben. was fireilich Olive (1906. p. 205) bei der Nachuntersuchumg nicht bestitigen komte.") Sollte der negative Befund von () live den Tatsach ent entsprechen, dann miißte man allerdings in der Azygosporenbildung einen der Parthenogenesis sehr nahe stehenden Prozeß erthlicken. Finden aber tatsächlich auch in der Azygospore Kernfusionen statt. damu wäre das wohl weder als Pseudomixis norh als eine Art Autogamie aufzufassen, sondern als Parthenomixis in dem 1. 2x definierten Sinne. Ehe aber die Tatsachen nicht genau festgestellt sind. hat es wenig Zweck, diese Frage eingehend zu diskutieren.

Unter den 0 omyceten ist die Parthenogenesis verhältnismäbig weit verbreitet, wir können sie geradezu mit Lotsy (1907. p. 151) in zwei Gruppen einteilen, von denen bei der einen echte Befruchtung herrscht, während diese bei der anderen fast vollkommen durch Parthenogenesis abgelöst ist. Die erste Gruppe ist die der Peronosporeae, die zweite die der Saprolegnieae. Wir haben es also hier allein mit den Saprolegnieen zu tun. Von ihnen nahm man sogar, nachdem zuerst Prings heim (1874, p. 192) festgestellt hatte. daß Saprolegnia-Arten imstande sind, Oosporen ohme Befruchtung ans-

1) Mucor neglectus ist nach Vuillemin (1907, p. 29) nur eine apomiktisch gewordene Form von Zyyorhynchus heterogamus. Anch Zygorhynchus Moelleri bildet nach demselben Autor Azygosporen.

2) Man vergleiche dazu die Ausführungen von Vuillemin (1907, p. $27 \mathrm{ff}$.). Besonderes Interesse und genanere Nachpriifung verdient dessen Angabe (1. c., p. 31). daf er auf Spinellus chalybeus, der auf einer Iycena schmarotzte, und der an sich agam ist, Zygosporen fand, die unter dem Einflub des gleichzeitig auf derselben Myccna wachsenden Spinellus macrocarpus entstanden sein sollen. Tuillemin sieht num aber in diesen Zygosporen keine hybride Bildung, sondern betrachtet sie als Azygosporen rou Spinellus chalybeus, die sich infolge der "excitation sexuelle" des Spinellus macrocarpus gebildet bätten.

${ }^{3}$ ) Die Arbeiten von Riddle (1906 a und b) waren mir unzugänglich. 
zubilden, bis vor wenigen . Tahren allgemein an, daß bei ihnen überhaupt keine Befruchtung vorkäme, obwohl es längst bekannt war, dab bei vielen Arten neben den Oogonien auch typisch ausgebildete Antheridien vorhanden sind.

Diese treiben, wie es in Fig. 2 für Achlya racemosa Hildebr. dargestellt ist, zarte schlauchförmige Ausstïlpungen, die, genau wie die echten Befruchtungsschläuche etwa bei Pythium, in das Oogonium hineindringen und sich je einem Ei fest anpressen. Es liegt aber, wie de Bary (1884, p. 154) sagt, „kein Grund vor, sie für wirklich befruchtende Organe zu halten. Dies um so weniger, als ihre Bildung zwar bei manchen Arten, z. B. Achlya polyandra, Saprolegnia monoica, immer in der beschriebenen Form verläuft; als es aber andere Arten gibt, bei welchen neben den beschriebenen Erscheinungen, an denselben Stöcken, Antheridien ohne Befruchtungsschlauch, oder gänzlich antheridienfreie Oogonien (z. B. Aphanomyces scaber, Saprol. hypogyna) häufig sind, und endlich manche, den erstgenannten sonst äuberst ähnliche Arten oder Rassen Antheridien iiberhaupt nie, oder höchstens als überaus seltene Ausnahme entwickeln. Die Ei- und Oosporenbildung aber verläuft in allen diesen Fällen bis in die kleinsten Einzelheiten gleich."

Diese Auffassung, wonach also den Saprolegnieen überhaupt keine echte Befruchtung mehr zukäme, hat sich nun allerdings nicht in dieser allgemeinen Fassung aufrecht erhalten lassen.

Zwar ist es sicher, daß es Formen gibt, bei denen iiberhaupt keine Antheridien auffindbar sind, so Saprolegnia monilifera oder die von D a vis (1903) genau untersuchte Saprolegnia mixta forma agama, bei denen das Oogonium

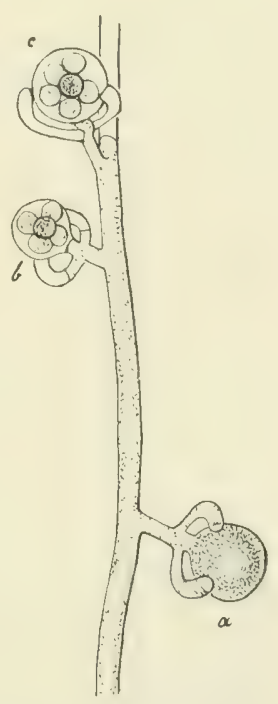

Fig. 2. Achlya racemosa. Fruchtzweig mit drei Oogonien nebst Antheridienästchen:

a noch vor, b und o nach Abgrenzung von Oogon und Antheridium, b mit sechs, c mit sieben Eiern.

(Nach de Bary 1884,

Fig. 69 A, p. 153.) also sicher auf apomiktischem Wege reifen muß.

Auch das läbt sich nicht bezweifeln, dab bei manchen Arten zwar Antheridien, aber aus diesen keine Befruchtmusschläuche entstehen, und es ist anch wahrscheinlich, daß, so wie es de Bary furr Achlya racemosa schildert, die Befruchtungsschläuche sich zwar eng an die Eier anjressen, aber keinen geformten Inlıalt in dieses über'treten lassen. Aber unbedingt verallgemeinern läßt sich das nicht mehr, seit Trow (1904, p. 552) bei Achlya debaryana nachwies, daß (vgl. Fig. 3) der Befruchtungsschlauch sich an der Berührungsstelle mit dem Li öffnet, $u m$ einen Spermakern in dieses eindringen zli 
lassen, der mit dem Eikern verschmilzt. Is kommt darnach doch

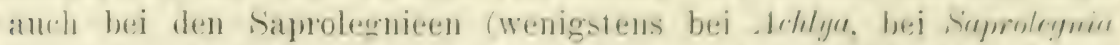
ist Entsprechendes bisher now hicht nather wesen echte Befruchtume

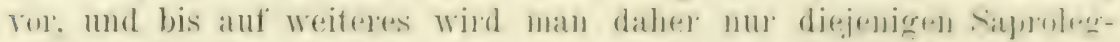
nieen sicher als parthenogenetisch ansehen diirfou. bee denen keine Antheridien oder wenigstens keine Pefruchtumgsirhlainche gebildet werden.

Zum mindesten gilt das vorerst unbedingt. soweit labbituelle. Parthenogenesis in Betracht kommt. Fakultativ parthenogenetisch künnen natiurlich aber anch diejenionen Arten sein, bei denen normalerweise eine regelrechte Befruchtung erfolgt. I'nd das ist denn auch nach den Lntersuchumgen von Kilebs (1s99. 1).562 der Fall.

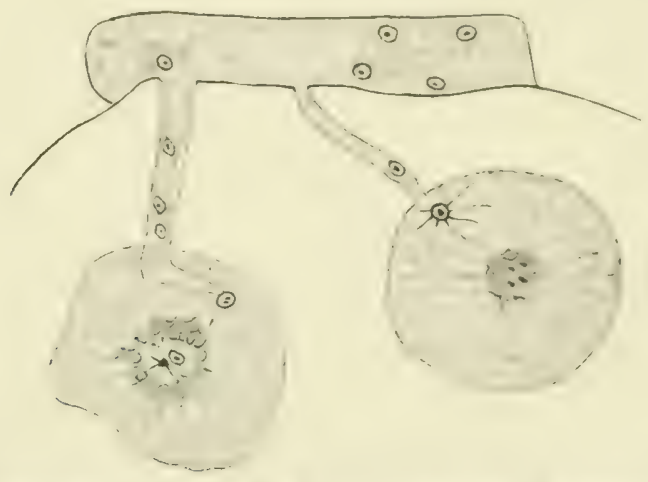

Fig. 3. Achlya debaryana. Schnitt durch ein Oogon mit Antheridium, den Moment der Befruchtung der Eier zeigend. (Nach Trow 1904, Taf. 36, Fig. 26.)

Klebs fand nämlich bei Samolegmia mixta. dah diese species unter gewissen Kulturbedingungen, z. B. bei Kultur in remen Lösungen von Hämoglobin, saurem äpfelsaurem Ammon und Lencin. gar keine Antheridien melı ausbilden kann, während normalerweise bis zur Hälfte der Oogonien mit Antheridien besetzt sein künnen. Trotz dieses völligen Mangels der männlichen Organe entstehen in den Oogonen zahlreiche Oosporen, die sich in keiner Hinsicht ron den befruchteten Oosporen zu unterscheiden scheinen. Man kann. wie das Klebs auch tut, hieraus schlieben, dab bei Saprolegniu mixtu fakultative Parthenogenesis möglich ist.

Freilich sind diese Tersuche nicht eindentig. da eben Saprolegnia mixt $\iota$ eine Species ist, bei der auch unter den normalen Bedingungen am natïrlichen Standorte sich ein Teil der Oogonien parthenogenetisch entwickelt; Klebs (1899. p. 563) fand, daß auf dem natürlichen Substrat, z. B. auf toten Fliegen. nur etwa 10 bis 20 Proz. aller Oogonien mit Antheridien besetzt waren. Nun wird, wie Klebs mit 
de Bary annimmt, die Bildung der Antheridien höchstwahrscheinlich durch einen von den Oogonien ausgehenden chemischen Reiz veranlasst. und wenn daher unter gewissen Kulturbedingungen keine Antheridien entstehen. so braucht das nicht daran zu liegen, daß, wie Klebs (l. c., 1. 564) ausführt, durch diese Kulturbedingungen die Oogonien in einen Zustand versetzt werden. in dem sie nicht fähig sind, den für die Antheridienbildung nötigen Stoff anszuscheiden, sondern es kann auch darauf bertuhen, daß bei Sumolegmia mixta von rornherein zweierlei Arten ron Oogonien entstehen können: parthenogenetische und der Befruchtung bedürftige. Nimmt man nun an, dal' nur die letzteren die für die Antheridienentstehumg maßgebenden Substanzen ausscheiden können, so würde das völlige Ansbleiben der Antheridienbildung bei der Hämoglobinkultur bedeuten, daß eben nul parthenogenetische Oogonien unter diesen Kulturbedingungen zur Ansbildung kommen, gar keine befruchtungsbedürftigen mehr. Damn aber wïrden die Tersuche von Klebs nicht mehr die Befähigung der Saprolegnia mixta zu fakultativer Parthenogenesis beweisen, sondern eben nur ein Hintreis darauf sein, daß bei dieser Art - ähnlich wie bei Thatictum mupurascens - habituelle Parthenogenesis neben normaler Amphimixis vorhanden ist, und daß man es durch Variieren der Kulturbedingungen in der Hand hat, die eine der beiden Fortpflanzungsarten bei völliger Tnterdriickung der anderen zu alleinigen Herrschaft zu bringen. - Bei dieser Sachlage Träre es erwïnscht, daß die Versuche von Kilebs auf eine Saprolegniee ausgedehnt würden, die, wie das bei Achlya debaryana der Fall zu sein scheint. obligatorisch amphimiktisch - unter ".normalen“" Kulturbedingungen - ist.

Wie die Oosporenbildung ohne Befruchtung bei den Saprolegnieen aufzufassen ist. ob als echte Parthenogenesis oder als pseudomiktischer Torgang, kann nicht sicher entschieden werden, ehe nicht genaue crtologische Untersuchungen über die Kernverhältnisse der apomiktischen Oosporen im Vergleich zu denen der amphimiktischen vorliegen. Bisher ist, soviel mir bekannt, nur Saprolegnia mixta forma agame durch Davis (1903) untersucht worden, und zwar in einer sicher antheridienfreien Peinkultur, so daßalle sich darin entwickelnden Oosporen apomiktisch entstanden sein mußten. Davis fand, daß in dem von Anfang an vielkernigen Oogonium eine Anzahl Ovocentren auftreten, in denen je ein Kern erhalten bleibt, während die anderen Kerne degenerieren. So entstehen einkernige Eier, in denen sich der Ker'n nachträglich noch erheblich vergrößert. Doch kam es auch vor, daß zwei Ovocentren zur Bildung eines Eies herangezogen wurden, welches Fi dann zweikernig war. Irgendwelche Kernverschmelzungen, die man etwa als pseudomiktischen, die sexuelle Karyogamie ersetzenden Torgang deuten könnte, scheinen also wenigstens bei dieser 


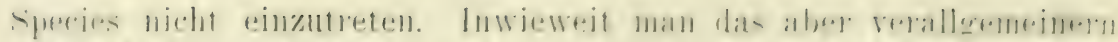

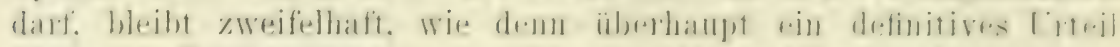

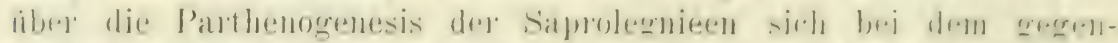

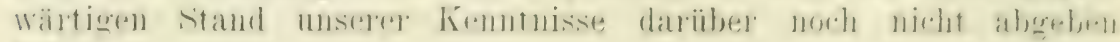
läit. -

Bei Basidiobolus ranarum Eidam, einem Pilze, dessen Stellung in system noch nicht völlig gekliat ershlueint. der aber berschiedene Bergehungen zu den Phycomyceten anfweist mod daher al Anhang zo diesen erwälnt sei, beobachtete Raciborski 16smj. 1) 125) monter gewissen. aber nicht näher gräzisierten Pedingungen
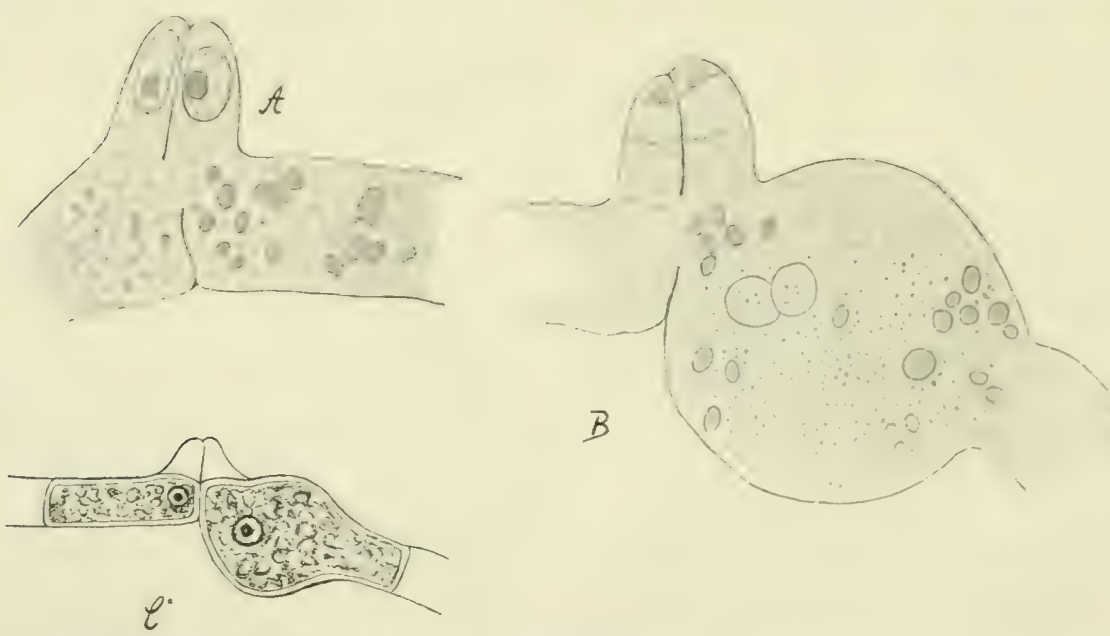

Fig. 4. Basidiobolus vanamum. A und B. Zwei Stadien der normalen Zygosporenbildumg (nach Fairchild 1897, Taf. 13, Fig. 1 und Taf. 14, Fig. 12). - C. Izygosporenbildung (nach Raciborski 1896, Fig. 11, p. 125).

die Entstehung ron Azygosporen. In welcher Weise sie ror sirh geht, erhellt unmittelbar aus Fig. 4, in der die Azygosporenbildung (') neben der normalen Zygotenbildung it und B dargestellt ist. und die keiner weiteren Erläuterung bedarf.

Sehr interessante, aber auch noch nicht gänzlich geklärte Ter'hältnisse finden wir bei den Ascomyceten (inkl. den Ascolichenen).

Die berühmte alte Streitfrage, ob die Ascomrceten Sexualität besitzen oder nicht, eine Frage, die bekanntlich zuerst ron de Bary bejaht, und ror allem von Brefeld verneint wurde, ist hente dank der Anwendung der modernen cytologischen Untersuchungsmethoden anf sie (zuerst ron Harper 1895) wohl definitiv zugunsten der de Bary schen Auffassumg entschieden worden. Es kam nicht mehr 
bezweifelt werden. dab unter den Ascomyceten, dit ja eine sehr artenund formenreiche Gruppe darstellen, eine sehr grobe Anzahl trpische Sexualität besitzen. Zwar sind naturgemäG vorerst noch nicht sehr viele Genera untersucht worden, doch rechtfertigen die rorliegenden Untersuchungen die eben ausgesprochene Behauptung zur Genüge.

Wir können nun selbstrerständlich an diesel Stelle nicht eine ins einzelne gehende Übersicht über die verschiedenen 'Typen der' Sexualität der Ascomyceten geben, sondern müssen in dieser Hinsicht auf die zusammenfassenden Darstellungen von Claulien (1906). Overton (1906). Lotsy (1907) und anderen verweisen. Hier mulís nur als eins der wichtigsten und mus in erster Linie interessierenden Ergebnisse der modernen Ascomycetenforschung angefülnt werden. dab nicht nur das Bestehen echter Amphimixis in dieser Pilzorupue. sondern auch das vou Apomixis als sichergestellt gelten mub. Die Zahl der aponiktischen Ascomyceten und Ascolichenen ist sogar wahrscheinlich ziemlich grob. Die wichtigsten der genaner untersuchten Fälle sollen in folgenden kury zusammengestellt werden. ohme dab übrigens unsere Zusammenstellung auf absolute Tollständigkeit Anspruch machte.

Man Kann annehmen. dal. das Vorhandensein typischer Sexualität das Ursprüngliche bei den Asconyceten war, sodab also diejenigen Formen, bei denen sie hente nicht mehr oder nur in redurierter Form nachweisbar ist, als abgeleitete zu gelten haben. als Arten also. die nicht von vornherein und jederzeit asexuell waren, die vielmehr die geschlechtliche Fortytlanzung zu gunsten einer aponiktischen Termehrungsweise eingebüßt haben. Der Grad, bis zu dem dabei bei den ver'schiedenen Arten die Sexualorgane rudimentäl geworden oder ganz verschwunden sind, ist ein sehr verschiedener; man hann eine Stufenleiter aufstellen. in der ron Formen, bei denen die Sexualorgane noch anscheinend typisch ausgebildet, aber nicht melur funktionsfähig sind, bis zu anderen, bei denen sie völlig verschwunden sind, alle Zwischenstufen rorhanden sind. Und es ist zu erwarten. daß die etwa noch vorhandenen Lücken durch die fortschreitende Forschung bald ausgefuillt werden.

Die normale geschlechtliche Fortpflanzung besteht bei den Ascomyceten bekanntlich darin, dab Antheridien und Oogonien (Ascogone, Carpogone) zur Ausbildung kommen, in denen männliche und weibliche Kopulationszellen entstehen; durch deren Tereinigung bildet sich dann das Ascus erzengende Organ. (Die Kernverschmelzung im jugendlichen Ascus können wir nicht für einen sexuellen Vorgang' ansehen; eine ausführliche Begründung dieser Ansicht wïrde hier zu weit führen. Man rergleiche übrigens Anm. 1, p. $7 \mathrm{ff.}$.) Es ist dabei fïr uns von nebensächlicher Bedentung, ob die Antheridien spermatien enthalten, die ('arpogone dementsprechend eine 'Trichogyne 


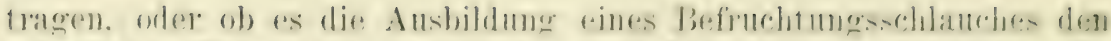

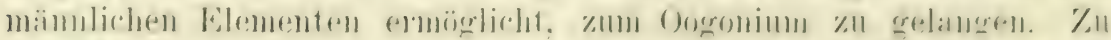

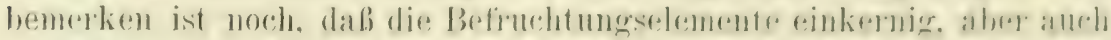

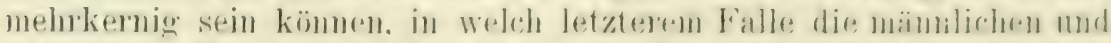

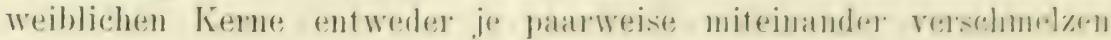
oder aber bis auf je einen Kopulationskern degenerieren.

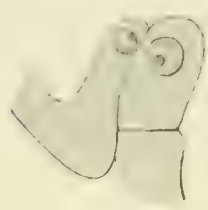

A1

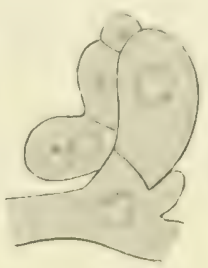

$A_{2}$
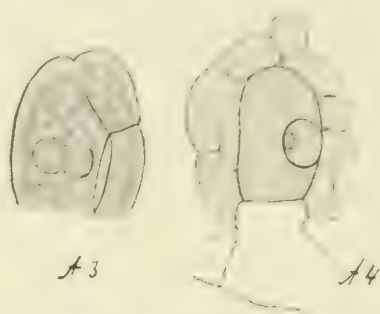

Fig. 5. A. Sphaerotheca castagnei. 1. Oogonium und Antheridiumzweig mit je einem Kern. Antheridiumzweig noch nicht vom Mycelfaden abgetrennt. - 2. Antheridiumzelle von der Stielzelle abgetrennt. - 3. Zellwand zwischen Antheridiun und Oogonimm aufgelöst. Eikern und Antheridiunkern neheneinander im Dogrnium. - 4. Befruchtetes Oogonium mit der ersten Schicht Hïllfarden, die aus der sticlzelle entstanden sind. (Nach Harper 1895, Taf. 39, Fig. 1, 4, 7 und 10.)
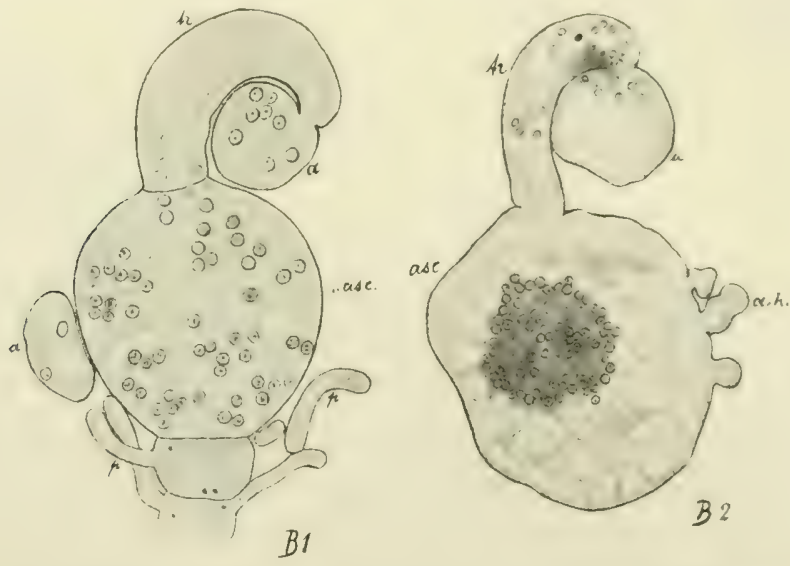

Fig. 5B. Pyronema confuens. 1. Antheridium (a) und Ascogon (asc) im Längsschnitt. Die Wand zwischen Antheridium und Trichogrne (tr) ist aufgrelöst: die Trichogynkerne als desorganisierte Reste noch erkembar. p hïllbildente Hrphen. 2. Die Wandung zwischen der 'Trichogyue (tr) und dem Ascogon (asc) ist aufgelüst; die männlichen Kerne auf der Wanderung zum Ascogon. ah ascogene Hrphen.

(Nach Harper 1900, Taf. 19, Fig. 10 und 15.)

Ton den apomiktischen Ascomyceten stehen nun den sexuell gebliebenen zweifellos am nächsten solche Arten, bei denen die Sexualorgane noch in typischer Ausbildung vorhanden sind, bei denen es aber nicht mehr zur eigentlichen Kopulation kommt. Hierher gehürt 
Polystigma rubrum (Pers.) DC, eine auf Prunus-Blättern schmarotzende Hypocreacee. Sie besitzt Carpogone mit Trichogynen und Spermogonien mit Spermatien. „An der Spitze dieser Trichogyne hat man öters Spermatien kleben sehen, Kopulation wurde aber nie beobachtet. Nach verhältnismäbig langer Zeit sterben die Trichogynen ab und das Ascogon vergrößert seine Zellen, während die Peritheciumanlage ïberhaupt an Größe zunimmt. Damn tritt ein Ruhestadium ein, welches den ganzen Winter anhült. Auf den abgefallenen Blättern bildet im Frühjahr jede Ascogonzelle ascogene Hyphen, welche in ïblicher Weise Asci bilden. Hier liegt also Parthenogenese vor" (Lots y 1907, p. 424). Wir werden dies Verhalten in der Tat als Parthenogenesis bezeichnen müssen, denn es entsteht ein Sporophyt (ascogene Hyphen und Asci) ohne Befiuchtung aus dem Ei: ob aber somatische oder generative Parthenogenesis vorliegt. das läßt sich natiirlich erst entscheiden, wenn die Kernverhältnisse durch cytologische Untersuchung genau bekannt geworden sind. Es ist übrigens auch die Mröglichkeit im Auge zu behalten, daß eine Art pseudomiktischer Kernverschmelzung eingreift, wie bei der sich hier anschließenden von Fraser (1907) näher studierten Lachnea (Peziza) stercorea Pers. Auch bei diesem Pilz trägt das vielkernige Ascogonium eine Trichogyne, die vier- bis sechszellig ist, und mit deren Endzelle gelegentlich ein ebenfalls mehrkerniges Antheridium verschmilzt. Da aber seine Kerne doch nicht in das Ascogonium gelangen, und iiberdies die Antheridien häufig nicht gut ausgebildet erscheinen, kann man in diesem Verhalten keinen normalen Sexualvorgang erblicken. Als Ersatz für die ansbleibende Befruchtung verschmelzen num hier die Ascogonkerne paarweise unter sich, ein Vorgang, der an die von Vuillemin beschriebenen Tiernfusionen in dell Azygosporen von Entomophthora erimnert (vgl. p. 20), und den wir auch noch bei anderen nicht mehr typisch sexuellen Ascomyceten wiederfinden werden.

Er ist nicht leicht zu deuten. Daß er als Ersatz für die ausbleibende Befruchtung aufzufassen ist, erscheint zwar sicher, und auf den ersten Blick mag es als das Nächstliegende erscheinen, ihn als Parallelvorgang zur Pseudomixis mancher Farne (vgl. p. 59) anzusehen, wie dies auch Fraser $(1908$, p. 42) tut. Aber die beiden Vorgänge lassen sich doch unseres Erachtens nicht ohne weiteres miteinander vergleichen. Tor allem deshalb nicht, weil sich hier die entscheidenden Vorgänge innerhalb des weiblichen typisch gestalteten Organs abspielen, so daß wie bei der echten Parthenogenesis der Sporophyt aus der umbefruchteten (oder wenigstens nicht durch eine andere Keimzelle befruchteten) Eizelle hervorgeht, während bei der Psendomixis nur rein vegetative, nicht als Keimzellen differenzierte Elemente beteiligt sind. Reine Parthenogenesis kann indessen auch 


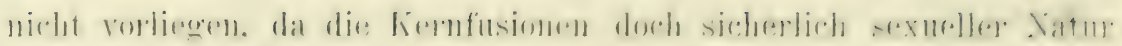
sind. So sagen demn anch Blackman und Fraser (1905), p. 3652) vous

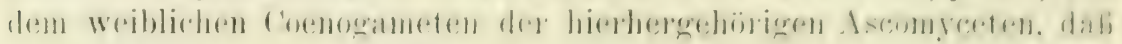
es ,possesses a very striking property - the capacity of fertilize

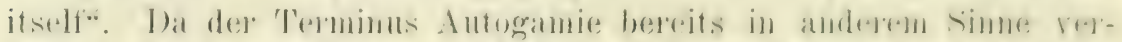
wendet wird. möchte ich vorschlagen. dies Vorhalten als Partheno-

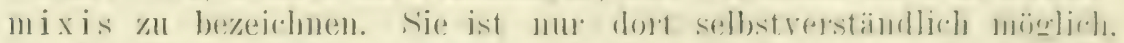
wo die Eizelle vielkernig ist. und theoretisch rbenen wie fiir die weibliche auch für die mämliche kémzelle denkbatr. so wie ja atuch eine Parthenogenesis der spermatelle möglich und wohl aurh hie nut da vorhanden ist. Die Parthenomixis ist keine eche Amplinixis, da fiir diese das Verschmelzen zweier Keimzellen orfordenlich ist. und auch keine echte Parthenogenesis, da diese ohne kernfusionon vor sich geht. Aber sie hat, wie anch im Terminus zum Ausdrurk kommt, mit beiden Fortphanzungsarten Gemeinsames: mit der Amphimixis die Kernverschmelzungen, mit der Parthenogenesis den Tustand, dab sich die morphologisch typisch gestaltete Eizelle spontan. whns Einwirkung eines männlichen Elementes zum sporophyten entwickelt. Nach analogen Vorgängen etwa bei höheren Pflanzen suchen zn wollen, wäre natirrlich zwecklos, da die Parthenomixis ein Prozeli sui generis ist, der nur bei Organismen mit mehrkernigen heimzellen verwirklicht sein kamm. und der bei diesen wohl aufgetreten ist, weil eben die paarweise parthenomiktische Kernverschmelzumg einen nalleliegenden und verhältnismäBig einfachen Weg darstellt, die sonst nul' durch amphimiktische oder psendomiktische Kernverschmelzung erreichbare Verdoppelung der Chromosomenzahl auf den für den Sprorophyten normalen Status zu erzielen.

In gewisser Hinsicht läßt sich die Parthenomixis auch als tin C̈bergangsstadium zur reinen Pseudomixis auffassen. Demn Psenlumixis würde vorliegen, wem die Zelle des Gametophyten. die als Ausgangspunkt für den Sporophyten dient, und in der die Kernfusionen stattfinden, sich äußerlich in nichts von benachbarten vegetativen Zellen unterscheidet. Phylogenetisch wäre anch sie aber vielleicht als Ascogonzelle aufzufassen. Ein solcher Fall scheint bei Humaria rutilans Fries vorzuliegen, die von Fraser (1908) näher untersucht wurde. Hier werden gar keine Sexualorgane mehr ausgebildet, die ascogenen Hyphen gehen vielmehr ans Mrcelzellen hervor, in denen sich beim Entwicklungsbeginn zahheiche Kernverschmelzungen auffinden lassen. Die miteinander fusionierenden Kerne entstammen aber nicht ausschlieBlich derselben ron Anbeginn an multinukleären Mycelzelle, sondern gelegentlich anch einer Nachbarzelle, ans der sie übergewandert sind. Das ist also echte Psendomixis in simne unserer Definition, und für die Auffassung, daß Parthenomixis dann, wenn das Ascogon auch äußerlich den Charakter 
einer weiblichen Sexualzelle völlig verliert, in Pseudomixis übergehen kann, spricht es gewib, daß sich in der gleichen Gattung Humaria eine andere Art findet, Inmaria gramulata. die noch typisch parthenomiktisch ist (Blackman und Fraser 1905, vgl. p. 30).

Es ist wahrscheinlich, dab, sich von den Ascomyceten, bei denen sich die Bildung der ascogenen Hyphen nicht auf Sexualorgane zurïckfülnren läßt. eine große Anzahl ebenso wie Humaria mutans verhält, also pseudomiktisch ist. Möglich ist aber natïrlich auch, dab Apogamie rorliegt. dab also die Entstehung des Sporophyten - als solcher ist die Summe der ascogenen Hyphen ja stets aufaufassen. ganz gleichgïltig; welche Chromosomenzahl ihre Kerne fülıren - einfach dadurch vor sich geht, dab eine vegetative Mycelzelle des Gametophyten ohne Kernverschmelzungen irgendwelcher Art zur ascogenen Hyphe wird. Propagation kam das naturlich nicht sein, da diese ja stets die gleichnamige Generation liefert. Ob nun Psendomixis oder Apogamie bei diesen Ascomyceten olme Sexualorgane vorliegt. kann natürlich in jedem einzelnen Falle nur die cytologische Untersuchung entscheiden. Clariceps, Cordiceps, Nectria, Pleospore, Teichospone, Teichosporella, L'snea, Xylavia und viele andere Arten wären hier als der näheren Untersuchung bedïrftig zu nennen.

Die nächste stufe der Reduktion ist die, daß zwar noch Antheridien und Carpogone entstehen, daß den letzteren aber die Trichogyne fehlt. Dieser Fall scheint besonders unter den flechtenbildenden Ascomyceten verbreitet zu sein, wie zuerst von F ï n fst ï ck (1884) gefunden wurde. Seine Ergebuisse sind von Baur (1904) bestätigt worden. Darnach finden sich bei den Flechtengattungen Peltigera, Peltider, und Tephome Spermatien und auch Carpogone, aber die letzteren tragen keine Trichogyne, und die ascogenen Hyphen entstehen also ohne Nitwirkung der männlichen Elemente. Übrigens stellt Nephroma schon einen Übergang dar zu der nächsten Gruppe, indem bei ihr die Spermatienentwicklung schon umnormal verläuft. Das ist zwar bei Peltigera nicht der Fall, doch kömnen hier die an sich nicht sehr zahlreichen Spermatien auch abgesehen vom Fehlen der Trichogyne nichts mit der Befruchtung zu tun haben, da bei dieser Gattung die Rinde bis zur Bildung der Asci über dem Apothecium geschlossen bleibt. Einzelheiten hinsichtlich der Kernverhältnisse sind anch hier noch völlig unbekannt.

Als letzte Gruppe von Ascomyceten mit reduzierten Sexualorganen sind schlieblich diejenigen Formen zusammenzufassen, bei denen die männlichen Organe völlig geschwunden und nur noch Ascogone volhanden sind. Hier ist zunächst Thelebolus stevcoreus 'T'ode zu nennen, bei dem Ramlow (1906) konstatierte, daß Antheridien völlig fehlen. so daß also von einer normalen Befruchtung keine Rede sein kann. Das junge Ascogon ist wie die vegetativen Zellen des Mycels ein- 


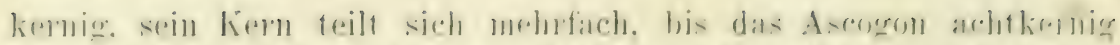

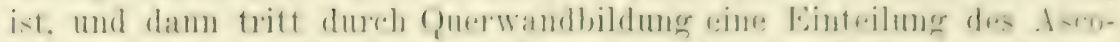

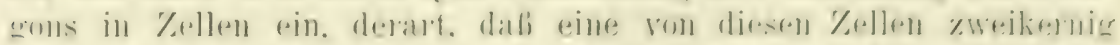

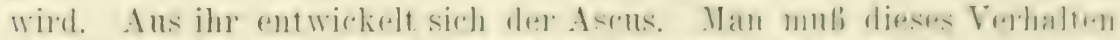

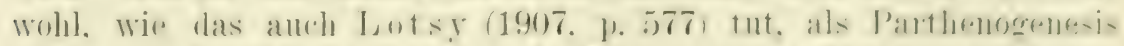

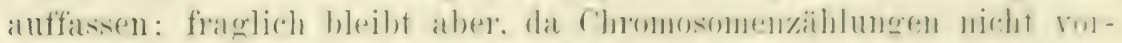
genommen wurden und bei der Kleinheit der keme and swh schwer

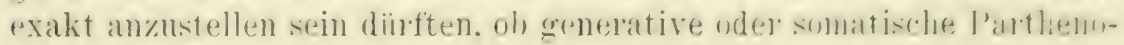
genesis vorliegt.

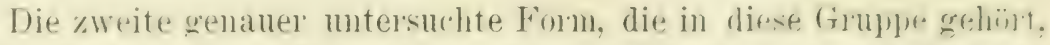
ist Humariagranulata Quél, die von Blackman und Fraser 11905, untersucht worden ist. Sie ist ebenfalls durchans antheridienlos, und trotzdem bildet ihr Ascogon regelmäBig ascogente Ifyhhen. Alle Zellen dieses Discomyceten. also auch das Ascogonium. sind rielkernig, und da in dem jugendlichen Ascogonium Kernverschmelgungen beobachtet wurden. so haben wir es hier mit Parthenomixis in dem früher gekennzeichneten Simue (vgl. p. 28) zu tum.

Selr wahrscheinlich wird sich bei fortschreitender [ntersuchung die Zahl der sich an die besprochenen Arten anreihenden Formen nor h sehr vermehren; bisher sind. soviel ich selıe. die einigermafien genan untersuchten Species mit den ron uns behandelten erschöpft. Grob ist. wie man sieht, und wie begreiflich ist, ihre Zahl noch nicht. Wir laben sie aus rein äuferen ZweckmäBigkeitsgründen eingeteilt in Gruppen je nach dem Grade der Reduktion. in dem sich die nicht meln normal funktionierenden Sexualorgane befinden. und hätten num als letzte Gruppe mit der weitestgehenden Reduktion diejenigen Arten zu besprechen. bei denen überhaupt keine Sexualorgane mehr zur Ausbildung kommen. Wir haben diese indessen schon im Anschlub an Humaria mutilans angeführt (vgl. p. 29), und da ausfïhrlichere Untersuchungen über sie. die eine genane Rubrizierung ermöglichten. noch ausstehen, so sei nur kurz darauf hingewiesen, dab in diesel Gruppe selbstrerständlich Parthenogenesis und Parthenomixis ausgeschlossen sind und nur entweder Psendomixis oder Apogamie möglich sind.

Ehe wir die Ascomyceten verlassen, miissen wir noch kurz auf die spermatienkeimung eingehen, da sie rielleicht als ..männliche Parthenogenesis" anzusehen ist. Es gelang bekanntlich II oeller (1887 und 1888), die Spermatien einiger Flechten (Arten ron Buellia. (opergrapha, Caticium und Collema) in Nährlösung zum Keimen zu bringen. Er schloß daraus. daß sie nicht als männliche Keimzellen. sondern als Pyknosporen zu bezeichnen wären. Aber dieser Schlul ist durchaus nicht zwingend.

Denn erstens ist, worauf B a ur (1901, p. 329) mit Recht hinweist. das kümmerliche Answachsen der Collema-Spermatien zu einem kurzen 
verzweigten Schlauche kaum als Keimen zu bezeichnen, zweitens und vor allem aber beweist, wie schon mehrfach bemerkt wurde, das Keimen eines Spermatiums zu einem anscheinend normalen Thallus nichts gegen die Keimzellnatur des betreffenden Spermatiums, sondern tut höchstens seine Befühigung zu parthenogenetischer Entwicklung. dar. Diejenigen Ascomyceten-Spermatien, die unter gewissen Kinlturbedingungen für sich zu einem Thallus auswachsen können, würden also Beispiele für die Möglichkeit einer Parthenogenesis auch der männlichen Keimzelle liefern, wie sie z. B. bei Ec ocronus unter den Algen vorhanden ist. Die Untersuchungen darüber verdienten wohl. bei der Seltenheit und der theoretischen Wichtigkeit der Erscheinung; nelt aufgenommen zu werden. -

Was nun endlich die Basidiomyceten anbelangt, so sind die Verhältnisse bei ihnen doch noch zu wenig geklärt, um eine einigermaßen sichere Deutung der bei ihnen rorkommenden Kernverschmelzungen zu erlauben. Am wahrscheinlichsten erscheint es bei dem gegenwärtigen Stand unserer Kenntnisse wohl, daß sie als Pseudomixis anzusehen ist. Doch soll, ehe nicht mehr Formen genau untersucht sind, hier auf eine nähere Diskussion verzichtet und auf die Erörterungen von Lotsy $(1907$, 1). $628 \mathrm{ft}$.) verwiesen werden.

\section{Moose.}

Unter den Bryophyten sind bisher noch keine Fälle von Parthenogenesis und Apogamie sichergestellt worden. Die einzige mir bekannt gewordene Angabe, die sich auf die Parthenogenesis der

\section{Lebermoose}

bezieht, rührt von D a chn 0 wski (1907, p. 283) her, der zunächst für Marchantic polymorpha erwies, daß natiurliche, spontane Parthenogenesis bei ihr nicht vorkommt. Über seine Versuche, bei dieser Species experimentell kïnstliche Parthenogenesis hervorzurufen, berichtet er: „In vereinzelten Fällen wurde diese Form der ungeschlechtlichen Vermehrung bis zu einem gewissen Stadium künstlich erzeugt. Doch die bisherigen Beobachtungen sind so zweifelhaft, die Einwirkung der benutzten Nährlösungen war so verschieden, daß die Termehrung durch natiirliche Parthenogenese noch nicht konstatiert ist."

Bei Anthoceros lacis hat Lang (1901) Anfänge einer aposporen Entstehung von Gametophytengewebe aus Sporogonzellen beobachtet. Da Aposporie und Apogamie oder Parthenogenesis häufig miteinander verknïpft sind, wäre es nicht undenkbar, daß die Fortsetzung solcher Versuche zur Entdeckung einer der beiden Apomixis-Arten auch bei Lebermoosen führen könnte. 


\section{Laubmoose.}

Fïr Lambmoose liegt die folgende Angabe von Kerner (1891. p. 460) vor:

,Bei den Moosen ist Parthenogenese eine nichts weniger als seltene Erscheimung... Es gibt melrere Arten, von welchen in

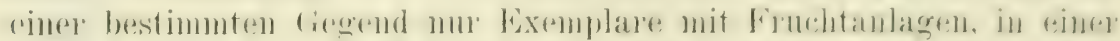

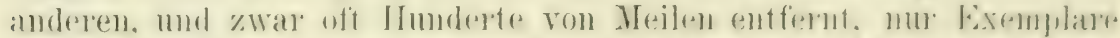

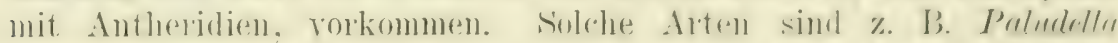

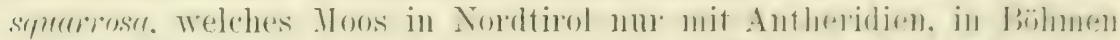

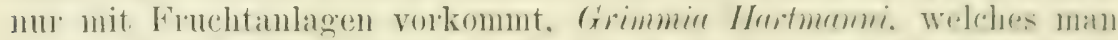
in den Alpen mit Antheridien, in den Farpathen mit Frublitanlagen

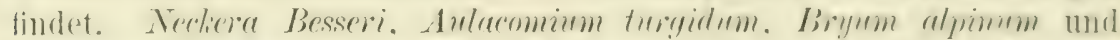

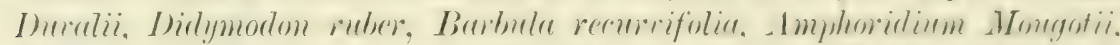

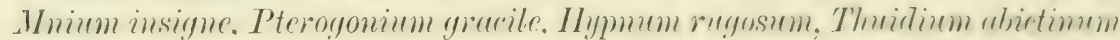
sind noch pinige weitere Beispiele, die hier eingehender zu behandeln der Raum nicht gestattet. Fs ist mü̈glich. daß lie Fruchtanlage eines in den Karpathen wachsenden Moosrasens durch die suermatuzoiden ans den Antheridien eines in den Alpen wachsenden Monsrasens befruchtet werde. md wemn daher demnoch Friichte aus den Fruchtanlagen herrorgehen, so kamn das nur anf dem ITege der Parthenogenese geschehen. Allerdings sind bei allen obengenamnten Troosen reife Früchte selten; aber genng an dem, sie kommen ror und zwar unter Terhältnissen, wo mit Bestimmtheit gesagt werden kann, daß eine Befruchtung nicht vorhergegangen ist."

Diese Angaben von Kerner, die er unverändert auch in die zweite, 1896 erschienene Auflage seines Werkes iibernommen hat. kïnnen abel nicht als genïgend begründet angesehen werden. Eist zunächst nicht ausgeschlossen, daß selbst bei trten mit lokal getremnten Geschlechtern regelrechte Befruchtung erfolgen kamm, da Insekten als Überträger von Spermatozoiden dienen kümnen $(\mathrm{R} u \mathrm{~h}$ land 1900, p. 219). Fermer ist bei Laubmoosen wie bei höheren Pflanzen ,das Auftreten einzelner Zwitterblïten bei ein- oder zweihïusigen Arten gar nicht selten" (Limpricht 1890. p. 37). und es müßte also, ehe von den citierten Arten mit Sicherheit behauptet werden könne. sie seien unter Lmständen parthenogenetisch, erst sicher nachgewiesen sein. daf bei ihnen Zwitterblüten niemals rorkommen. Ihr verhältnismäßig sehr seltenes Fruktifizieren spricht aber gerade dafür, daß dies doch der Fall ist. Beweisend wiirden unter allen Umständen erst sorgfältig ausgeführte Fulturversuche sein, und solange solche mit positivem Erfolg nicht rorliegen. muissen trotz I erner's Angaben die Laubmoose bis auf reiteres für Gerächse gelten, bei denen weder habituelle noch fakultative Parthenogenesis vorkommt. Auch Apogamie, also das Entstehen eines Sporogons aus 
irgendeiner vegetativen \%elle des beblätterten Moospflänzchens, ist nie beobachtet worden.

Näher zu untersuchen ist noch das Verhalten apospor entstandener Laubmoose.

Durch Pringsheim (1878) und stah I (1876) wurde gezeigt. dab isolierte Sporophytenfragmente verschiedener Laubmoose (Hypmm serpens und cupressiforme, sowie Bryum caespitosum nach Pringsheim. (ercitodon mipurens nach $\mathrm{Stahl}$ ) aus vegetativen Zellen des Sporophytengenebes Protonema bilden können, an dem in der üblichen Weise beblätterte Moospflänzchen, also Gametophyten entstehen. Da sie von diploidchromosomigen Mutterzellen abstammen, so erhebt sich die Frage, ob bei ihrer Anlage oder im Verlaufe ihrer Entwicklung vor der Bildung der Keimzellen eine Reduktionsteilung eingeschoben wird. oder ob sie durchgehends in allen Zellen, also auch in Ei und Spermatozoiden. die diploide Chromosomenzahl beibehalten. Nach den Befunden von Farmer und Digby (1907) bei aposporen Farnen ist die letztere Möglichkeit nicht von der Hand zu weisen.

Durch die neuen Intersuchungen von El. und Em. Marchal (1907) wird es sogar wahrscheinlich. daß die apospor entstandenen Moos-Gametophyten in ihren Zellen Kerne mit der unreduzierten Chromosomenzahl führen. Den beiden genannten Autoren gelang es zum ersten Male, apospor entstandene Moospflänzchen bis zur Geschlechtsreife aufzuziehen. Schon Correns (1899) hatte als erster nach Pringsheim und Stahl das versucht, bei Experimenten mit zahlreichen Moosen aber nur aus Seten von Amblystegium serpens Protonema und an diesem Pflänzchen erhalten, ïber deren weiteres Verlialten er aber keine Angaben macht. Ebensowenig gibt Brizi (189-2) Täheres an über die an sporophytenbiirtigem Protonema entstandenen Moospflänzchen, die er an einer atrophischen Kapsel von Fumaria hygrometrica am natiulichen Standorte beobachtete. El. und Em. II archal gelang es nun, unter gewissen Kulturbedingungen eine ganze Reihe voll Laubmoosen zur Aposporie zu veranlassen (Amblystegium serpens Sch. und A. subtile Sch.; Barbula convoluta Hedw. und B. muralis Tim m.; Bartramia pomiformis $\mathrm{Hed}$.; Brachythecium rutubulum Sch.; Bryum argenteum L., B. caespititium L. und B. camillare L.; Dicranoweisia cirrata S Sch.; Funaria hygrometrica H edw.; Mnium homum L.; Plagiothecium denticulatum Brid.: Pohlia nutans Lind b.).

Ausfïhrlich beschrieben werden die Versuche für Bryum caespititium. B. argenteum und Mnium hornum, und es geht daraus hervor, dab bei diesen an sich streng diöcischen Moosen die apospor aus Seten oder zerschnittenen Kapseln durch Vermittlung von Protonema hervorgegangenen Gametophyten hermaphrodit waren. Bei asexueller Vermehrung dieser Pflänzchen durch Stecklinge wird die bisexuelle 


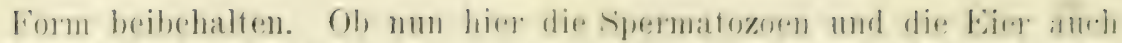

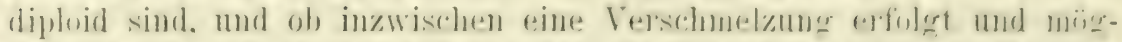

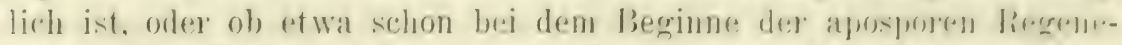
ration rine Reduktionstrilume stattlindet, in moch nälere zu mut...-

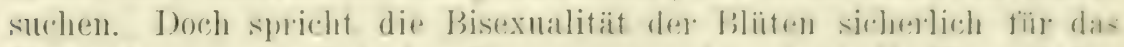
Torhandensein der diploiden (hromosomenzahl. Aurh die Eien wiirlent damm also diploid sein, und danit wären sie nach der Ansicht ron strasburger entwicklungsfühig, und man niibte erwarten. dab se sich parthemogenetisch zn sporophyten entwickelten. Xach den Berichten ron If a chal, soweit sie bisher vonliegen, scheint das abee nicht der Fall zu sein. Man wird jedenfalls rom dem Fortgange dieser I'ntersuchungen wichtige Aufschliisse ïber manche des nus hier speziell interessierenden Fragen erwarten dürfen.

\section{I). Farne.}

Seit Farlow (187t) zum ersten Nale nachwies, (laf bei einem Farn (Pteris cretica) die Keimptlanze an dem Prothallium nicht ans der befruchteten Eizelle. sondern durch regetative Sprossung entstelit, wurde dieser von de Bary (1879) Apogamie genamnte Torgang oft untersucht und sein Vorkommen bei zahlreichen Farnen festgestellt. (Man vergleiche die Zusammenstellungen bei sa debeck (1898. p. 34 ). Druery (1900. 1. 200) u. A.) Aber erst die neuesten Untersuchugen haben mit Hilfe der cytologischen Methoden festgestellt. dab die "Apogamie“ der Farne kein einheitlicher. bei allen Farnen in gleicher Weise vor sich gehender Prozeb ist, sondern dab sie mehrere nicht unwesentlich voneinander verschiedene und daher anch voneinander zu unterscheidende Vorgänge umfaßt.

Wenn die Kieimpflanze am Prothallium bei irgendeinem Farn nicht wie ïblich aus der befruchteten Eizelle herrorgeht, so sind theoretisch drei Möglichkeiten andersartiger Entstehung denkbar: erstens könnte sie ans der unbefruchteten Eizelle sich entwickeln. was Parthenogenesis wäre; zweitens aus einer oder mehreren normalen Prothalliumzellen durch unmittelbares Anssprossen, was Apogamie wäre: und drittens durch das Aussprossen von Prothalliumzellen. deren Kerne je mit einem aus der Nachbarzelle herübergewanderten Kern verschmolzen sind, was Psendomixis wäre. Alle drei Fälle kommen vor; welcher von ihnen jeweils rorliegt, kann im allgemeinen für jeden einzelnen Fall nur durch die cytologische Cntersuchung entschieden werden. Der so genau untersuchten Fälle sind es aber begreiflicherweise vorerst nur wenige, und diese werden im folgenden Kapitel an den ihmen gemäß unseren Definitionen zulkommenden Stellen Erwähnung finden. 
Hier sei nur von der groleu Schar von Farnen, deren ..Apogamie" bekannt, aber noch in den Einzelheiten näher zu erforschen ist, bemerkt, daß echte Parthenogenesis kaum oder nur selten vorkommen dürfte; meistens dürfte es sich um Psendomixis oder somatische resp. generative Apogamie handeln. Das ist insofern von theoretischer Bedeutung, als der Umstand. daß die Eizelle so selten zur apomiktischen Embryobildung herangezogen wird, darauf hinweist, dab zwischen ihr und den anderen Prothalliumzellen trotz der in ihnen allen gleichen Chromosomenzahl wesentliche Unterschiede bestehen, eine Schlubfolgerung, auf die wir später zurückkommen werden.

Über die Ursachen der apogamen oder pseudomiktischen Keimpflanzenbildung an Farnprothallien ist noch nichts sicheres bekannt. Es ist nicht unmöglich, daß äußere Faktoren in manchen Fällen eine Rolle dabei spielen; in vielen anderen Fällen aber ist die Apogamie oder Pseudomixis zweifellos habituell und tritt unter allen Umständen ein. Auch direkte korrelative Beziehungen zum Ausbleiben der Befruchtung. etwa derart, daß beim Nichtstattfinden der Befruchtung als Ersatz auch bei sonst sexuellen Arten Apogamie oder Psendomixis einträte, sind offenbar nicht vorhanden: werden die Eier in den Archegonien eines Farnes alle nicht befruchtet, so geht das ganze Prothallium zugrunde oder bildet höchstens propagative Wucherungen, wie z. B. bei Pilularia von Arcangeli (1876) experimentell festgestellt wurde.

Daß anch bei Eusporangiaten vielleicht Apogamie vorkommen kann, läßt sich auf Grund einer Beobachtung von Jeffrey (1896, p. 284) an Botrychium virginianum vermuten.

Die zuerst von Göbel (1879) beobachtete ..Apogamie" bei Isoetes ist ein reiner Propagationsvorgang: es handelt sich um blattbïrtige Adventivsprosse des Sporophyten, die an derselben Stelle entspringen, wo sonst die Sporangien entstehen. und die unmittelbar wieder Sporophytenpflänzchen liefern.

\section{E. Gymnospermen.}

Die frïheren Angaben über Parthenogenesis bei ('ycadeen haben sich alle als irtümlich erwiesen. Veranlaßt war der Irrtum durch ein bei manchen Cycadeen (z. B. Enceplealurtos, Cercatozumia u. a.) stark ausgebildetes Fruchtumgsvermögen. Nan vergleiche iiber die ganze Frage vor allem Regel (1859, p. $30 \mathrm{ff}$.).

Von den Coniferen kam man wohl auf Giund der sehr zahlreichen über sie vorhandenen Untersuchumgen und Beobachtungen hehaupten, daß sie ausnahmslos befruchtungsbedürftio und wahrscheinlich auch nicht zu fakultativer Parthenogenesis oder Apogamie be- 


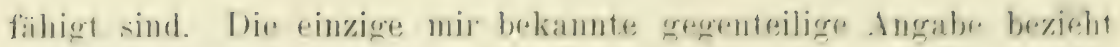
sich anf 'Taxus baccala, von dem Kirclinel (1904a, p. 78) angibt:

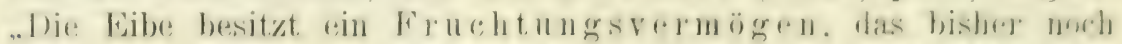
nicht bemerkt, zu sesin seleint. sich aber an einem in der Sabe fon Sigmaringen, zwischen Bingen und Billafingen. ganz isoliert stehenden weiblichen Bamme alljählich beobachten läbt. Ein kleiner Teil dor silmenanlagen dieses Bammes wäclsst ohme bestäubung zu tamben samen heran. welche keinen samenmantel besitzen, die Gestalt reinel verorölerten samenanlage zeigen, 4 5 mm dick, und mit riner ficktron bramen samenschale versehen sind. aber inwendig nur einige hantartig zusammengetrocknete Gewebereste aufweisen; andre entwickeln einen Samenmantel und enthalten ein Niilngewebe. bisweilen sogar einen verkiimmerten Embryo."1, Das wälen also Ansiatze zu echter Parthenogenesis. Jedenfalls aber sind nicht alle wriblichen Fiben dazu befïhigt, da mir selbst melnere ebenfalls völlig isoliert stehende weibliche stücke bekannt sind, die die rom $\mathrm{K}$ ir : I $n$ e r beobachtete Erscheinung niemals zeigen.

Für die Gnetaceen endlich liegt eine Angabe von Lotsy (1903) vor, wonach bei Gnetım ula Brongn. Parthenogenesis wahrscheinlich ist. Lotsy griundet seine Termutung darauf. dab die Zahl der Embryonen. die zunächst - später entwickelt sich vermutlich nur einer bis zur Reife - bei Gnetum ula entstehen, selu grof ist. Würden nun alle diese Embryonen infolge je eines Befruchtungsvorganges entstehen, so müßte die Zahl der eingedrungenen Pollenschläuche eine sehr hohe sein. Es gelang aber nie. auch nur einen einzigen Pollenschlauch zu sehen. Natïrlich bedarf diese Angabe. ehe sie als gesichert gelten kann, noch einer eingehenderen Nachpriifung. Bei Gnctum ynemon ist jedenfalls Befruchtung notwendig: woraus freilich keine Rückschlïsse auf Gnetum ula zu ziehen sind. da sich in dieser Hinsicht ja auch sonst nahe verwandte Arten durchaus verschieden verhalten (Thatictrum, Antennaria).

\section{F. Angiospermen. ${ }^{2}$ )}

\section{Monocotyledonen.}

\section{Pandanaceae.}

$P a n d a n u s$. Über eine vielleicht bei Pandanus vorhandene Parthenogenesis äußert sich der letzte Monograph der Gattung. WV arburg (1900, 1. 17) folgendermaßen: „Es sollen übrigens die

1) Von mir gesperrt. W.

2) In der Anordnung der Familien folge ich Engler (1904). 
Früchte von Pandams dubius nach Ki luz auch parthenogenetisch vollständig keimfähige Samen erzeugen, und Solms hält es auch bei andereu Arten für wahrscheinlich, daß adventive Embryonen erzengt werden; bei $P$. pygmacus glaubt er vielleicht daranf hindentende Erscheinungen beobachtet zu haben."

Da letztere Art nicht selten in Gerwächshäusern kultiviert wird, wird hoffentlich die wünschenswerte nähere Untersuchung nicht lange auf sich warten lassen. Auch in Buitenzorg wïrde sich unschwer an verschiedenen Species die Sache entscheiden lassen. Es ist dabei aber zu beachten, daß manche Pandanus-Arten, so z. B. P. furcatus nach Carrière (1881) weitgehend parthenokarp sind.

\section{Triuridaceae.}

Sciaphila. Wie Poulsen (1906) vermutet, bildet sich bei Sciaplita nana Bl. der Keim ohne Befruchtung, da Pollenschläuche in den Eiern, keimende Pollenkörner auf den Narben nud leitendes Zellgewebe im Griffel fehlen. (Da mir die Arbeit im Original unzugänglich ist, citiere ich nach einem kurzen Referat in Engler's Jahrb., Bd. 38, 1907, Literatur, p. 49.)

\section{Araceae.}

In seinen cytologischen Studien über die Fortpflanzmngsverhältnisse der Araceen macht Campbell (1905) darauf aufmerksam, daß die Struktur des Embryosackes bei den Araceen in vielen Fällen von dem typischen Verhalten der Angiospermen abweicht. Gesunde Pollenkörner sind selten, Befruchtungsstadien lassen sich nur sehr schwierig auffinden, und doch werden in sehr vielen Fällen gute Samen ausgebildet. Es mag also vielleicht hier und da Parthenogenesis oder Apogamie vorliegen.

\section{Bromeliaceae.}

Billbergia. Für Billbergia vittata Brongn. führt Focke (1881, p. 526) einen typischen Fall von Pseudogamie an. Diese Art, "die im Gewächshause spontan keine Samen bringt, wurde erfolgreich mit Pollen von B. pallescens C. Koch bestäubt. Aus den erhaltenen Samen ging aber kein Bastard, sondern einfach die $B$. vittata hervor. Belg. hort. 1875 , p. $120^{\prime \prime}$.

\section{Liliaceae.}

Dasylivion. Das mexikanische Dasylirion acrotrichum Zuec. bliihte in einem rein weiblichen Exemplar 1904 zum ersten Male im Utrechter botanischen Garten, wobei von WV ent und Blaa u w (1905) 


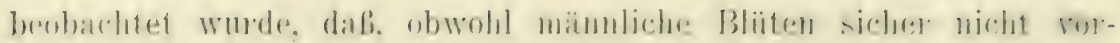

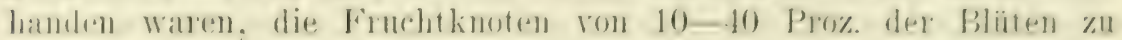

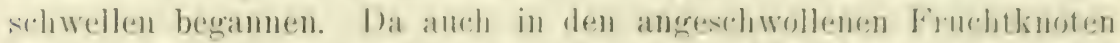

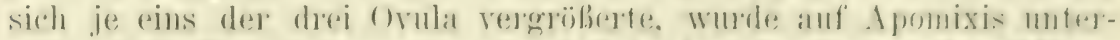

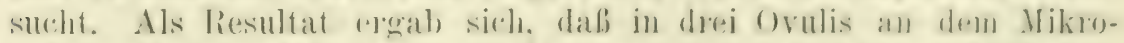

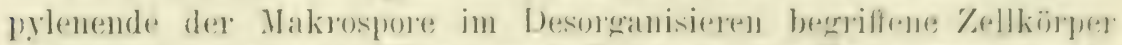

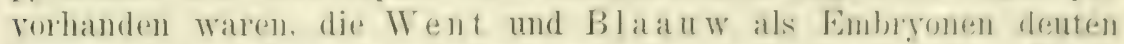
mörhten. Fudosperm fand sich in diesen mblyoührenden Makirospuren nicht. dagegen wurde es in zehn anderen oruis im lambryosack in verschiedenen Entwicklungsstarlien grefunden: in diesen endospermerfïllten Makrosporen fehlte nun aber der Kinbryo. Vialueres lief. sich bisher wegen Materiahmangel nicht feststellen. Lis kam ïbrigens nicht als ausgeschlossen bezeichnet werden, dal.j wir es hir. auch nu mit einem Ansatz zur Adrentivembryobildung zu tum habesu. wie sie innerhalb der Familie der Liliaceen bekamtlich bei Inosto coevulea und Tothoscordon frograns besteht (strasburger 1sis) und nach Furlani (1905) auch bei Colchicum antumale I. vortommesn soll.

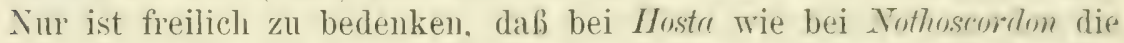
Bestänbung und Befruchtung des Fies zur Auslösung der Adrantivembryobildung erforderlich sind. ${ }^{1}$ )

Lilium. Focke (1881, p. 526) führt verschiedene Fälle von .Psendogamie" innerhalb der Gattung Lilium an. d. h. des Entstehens von Jachkommen mit rein mütterlichen Eigenschaften infolge einer Bastardierung. das nach Focke auf einer Auslösung ron Parthenogenesis durch die Fremdbestäubung beruht. Auf Grund nenerer Erfahrungen ist nun zwar auch eine andere Deutung des Terhaltens dieser ,einseitigen Bastarde* (d e Vries 1903, 1). 30 , möglich: doch sei der Tollständigkeit wegen die Angabe Fockes hier wiedergegeben:

.Lilium superbum Lam. wurde von Fr. Parkman mit Pollen von acht anderen Arten bestäubt, nachdem die Blumen in der Knospe castrirt waren. Es entstanden wohlgebildete Frïchte. in welchen bald keimfähige Samen in gröberer oder geringerer Zahl vorhanden waren. bald nicht. Aus den Samen wude reines $L$. suproum Lam. erhalten. Gard. ('hron. (new ser.) IX. 1). 19. - Das typische I. lomyiflorm 'Thbg. bringt in Amerika fixt niemals Früchte. wolnl aber' die var. taliesima. Durch Bestäubung dieser Tarietät mit Pollen von L. speciosum Th $\mathrm{b}$. und $L$. auratum Lindl. wurden von Fr. Parkma n Frïchte mit Samen erhalten, aus denen die mütterliche Stammptlanze helvorging, aber mit kleinen verbildeten, braunen (statt gelben) Antheren. Gard. Chron. (new ser.) IX. 1. 19. - L. speciosum Th b 2 ?

j) Die PHanze blühte im Winter 1907/8 im Tübinger botanischen Garten. Bei der Lntersnchumg zahlreicher Bliiten fand ich aber mur weitgehende Parthenoharpie: die samenknosien rertrockueten ansuihmslos nach rorühergehender schwellung. 
auratum Lind I. ¿ brachte wenig Samen, aus denen Fr. Parkman jedoch 50 Pflanzen erzog. Darunter war ein wirklicher Bastard; die anderen Exemplare unterschieden sich nur durch gefleckte Stengel und geringere Fruchtbarkeit von $L$. speciosum. Wieder mit Pollen ron L. andum befruchtet, lieferten sie acht bis zehn I'fanzen, darunter nur einen Bastard. Gard. Chron. l. c.; A s a Gray in Amer. Journ., 3. ser. XT, p. 151."

\section{Amaryllidaceae.}

Hippeastrum. Bei verschiedenen Arten der Gattung Hippeastrum soll nach einer Mitteilung von Bonavia (1890), der wohl wenig Gewicht beizulegen ist, Parthenogenesis vorkommen.

Hymenocallis. Focke (1881, p. 526) erwähnt einen Fall von T'sendogamie bei Hymenocullis amoena $\mathrm{Hrbt}$. var. princeps $\mathrm{Hr}$ bt.. der' aber auf' so ungenïgenden Angaben beruht, daß wir ihn übergehen wollen.

Zephyvanthes. Bei Zephyranthes sollen nach WVorsley (1906) .faux lıybrides" möglich sein, da er ,.in den Nachkommen einer Kreuzung von ₹ Hippeastrum mit \& Habranthus oder Zephyranthes bei 3n Krreuzungen in sieben Generationen nie einen Finfluß des Vaters sah" (Tischler 1908, p. 109, Anm. 1).

\section{Orchidaceae.}

Die Orchideen gehören zu den Familien, bei denen „fanx hybrides" im sime Millardet's vorkommen, Bastarde also, die in allen ihren Eigenschaften durchaus nu' dem einen Elter gleichen. Da nun für diese eine durch die Bestäubung ausgelöste Parthenogenesis als Erklärung der ausschlieblichen ̈̈hnlichkeit mit der Mutter angenommen worlen ist, müssen wir die falschen Hybriden an dieser Stelle erwähnen. Es war Hurst (1899, p. 55), der als erster $\left.{ }^{1}\right)$ die Hypothese aufstellte, der ausschließliche Besitz rein mütterlicher Eigenschaften bei diesen Pflanzen sei ,the result of a kind of parthenogenesis, the pollen probably not having the power to fertilise the egg-cells in the ordinary way, but exerting sufficient influence to cause them to start. growth". Die für die Orchideen vorliegenden Tatsachen werden von Hurst (1903, p. 227) folgendermaßen zusammengefaßt:

Es handelt sich dabei fast ausschlieblich um ,the various crosses that have been attempted by expert hybridists at different times and

1) Es muß übrigens darauf hingewiesen werden, daß bereits $1890 \mathrm{R}$. A. Rolfe (Gard. Chron., 3. Ser., Bd. 8, p. 361) angesichts der Tatsache, daß die Kreuzung von Zyygopetalum Mackayi o mit Orlontoglossum spec. or reine Zygopetalum-Nachkommenschaft ergab, die Hypothese anssprach, es möge wohl durch die Bestäubung parthenogenetische Entwicklung des Zygopetalum-Eies ausgelöst werden. 


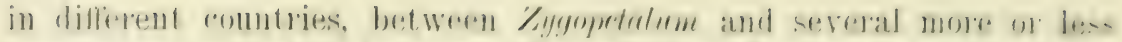

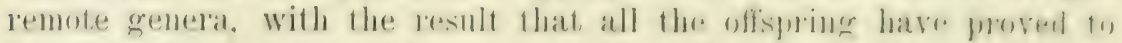

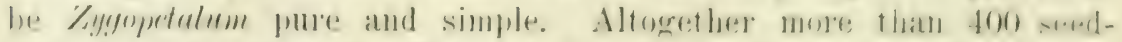

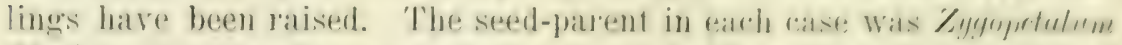

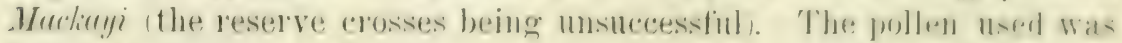
from Odontoglossum Pescutorei, O. crispum, O. monde, O. bictomense.

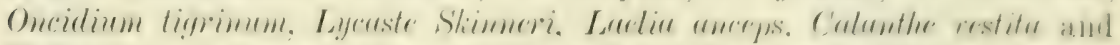

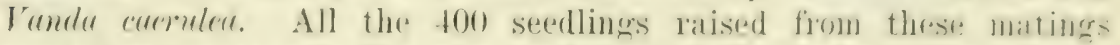
proved to be exactly like the seed-parent. \%. Marlang. It is interesting to note. however, that the individuals raised from the satme: capsule varied in size and colour of the flowers in the sams: Way that the seed-parent species does in its native habitat.

In other words, the ,false hybrids" behaved just ats if they latul been raised from self-fertilised seeds; but. as I shower in $18 ! 1$, . . Iffertilisation, direct or indirect. Was impossible in these cases. as the pollinia of the seed-parents were all calefully removed. before the crosses were made. Apart from this. too, the peculiar structure of these Orchids makes self-fertilisation impracticable. as I) ar win has well shown. Nor is it apparently a case of Mendelian dominance. for in the second generation ( $\mathrm{F}_{2}$ ) the characters of the seed-parent are again repeated pure and simple, even when the .false hylurid is re-mated with the supposed recessive. This experiment was curritel out by Mr. Me $\|^{2}$ illi a m, by re-mating one of the $\mathrm{F} 1$,. false liybrids." (Z. Mackayi o $\times L$. anceps) with pollen of $L$. anceps alba, and the result was still $Z$. Mackayi pure and simple.

It seems clear, therefore, that we have in these Zygopetalum seedlings, ..false hybrids", comparable to the original ones of Millardet (1894) in Frayaria. It may be noted that all the .. false hybrids". in Orchids so far are materual in all characters, as were the majority of Millardet's, and also Bateson and siander's. Mutthiola. Other experiments, however, show that ..false hybrids." may occur that are paterual in all characters. as in a few of Millardet is Fragaria and de Vries Oenothera.

Whether all these types of ..false hybrids" have a common explanation is difficult to say. but so far as the Zyyopetulum series is concerned, in 1900 I suggested that the stimulus of fertilisation might induce a kind of parthenogensis, without actual union of the sexual elements, causing the ..false hybrids* to resemble the seed-parent in all characters".

Diese Ansicht von Hurst, die ja in der Tat eine sehr nalieliegende und plausible Erklärung für das eigentümliche Terhalten der Zygopetalum-.,Bastarde" darstellt, und die auch von vielen anderen Forschern geteilt wird, bedarf natülich noch der Bestätigung durch die cytologische Untersuchung; die sehr erwüuscht wäre. Was sie 
ergeben wird. läbt sich nicht voraussehen, da hier verschiedene MIöglichkeiten denkbar sind.

Es wäre nämlich erstens denkbar, dab durch die Bestäubung. ähnlich etwa wie bei Citrus, nur Adventivembryobildung ausgelöst wïrde. Zweitens wäre möglich, daß in der Tat durch die Bestäubung das Ei, ohne daß irgendwie eine sexuelle Verschmelzung stattfände, zur Entwicklung angeregt würde; dann läge der Hypothese Hurst's entsprechend Parthenogenesis vor, und es wäre in diesem Falle besonders wichtig, die Zahlenverhältnisse der Chromosomen genan festzustellen. Drittens endlich wäre aber auch nicht ausgeschlossen, daß eine äußerlich durchaus normal erscheinende Verschmelzung der beiden Keimzellen vor sich ginge, so daß die Kerne des falschen Hybriden zur Hälfte mütterliche, zur Hälfte väterliche Chromosomen besäßen, ohne daß aber die väterlichen Chromosomen ihre Eigenschaften zur Geltung bringen könnten. Die letztere Möglichkeit ist auf Grund der Ergebnisse von Godlewski jun. (1906) bei seinen Bastardierungsversuchen zwischen Echiniden und Crinoiden in Betracht zu ziehen, durch die Bastardlarven mit rein mütterlichen Charakteren erhalten wurden, obwohl die Verschmelzung der beiden Keimzellen und ihrer Kerne in typischer. Weise erfolgt war und sich anch die Furchung:skerne durchaus normal verhielten.

Der wichtige Versuch von M c William zeigt jedenfalls, daß zum mindesten die falschen Zygopetalum-Hybriden nicht durch die einfache Annahme zu erklären sind, daß bei ihnen einfach sämtliche mütterlichen Anlagen dominierend, sämtliche väterlichen rezessir seien. So bleibt nur eine der drei eben erörterten Erklärungsmöglichkeiten übrig, von denen wohl die erste die unwahrscheinlichste ist, da Adventivembryobildung so gut wie ausnahmslos mit Polyembryonie verknüpft ist, diese aber bei Zygopetalum offenbar fehlt.

\section{Dicotyledonen.}

Moraceae.

Morus. Nach einer Angabe von Buysman (1892) trägt auf der Insel Walcheron ein sehr altes Exemplar von Morus nigra L. alljährlich reichlich Früchte, obwohl auf dem ganzen Baum keine männlichen Blüten vorhanden sind und auf der ganzen Insel kein männlicher Baum steht. Vielleicht handelt es sich hier nur um eine sonst freilich bei Morus wohl nicht beobachtete Parthenokarpie.

Cannabis. Der Hanf, Camnabis sativa L., gehörte früher seit den ersten Versuchen Spallanzani's (1785) bis zu den sorgfältigen Kontrollversuchen Regel's (1859) zu denjenigen Pflanzen, mit denen die meisten, angeblich die Parthenogenesis beweisenden Tersuche angestellt wurden. Aber erst Regel's Experimente halteu 


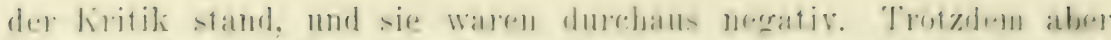

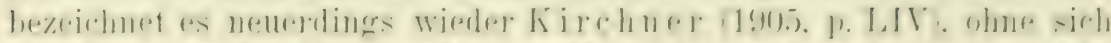

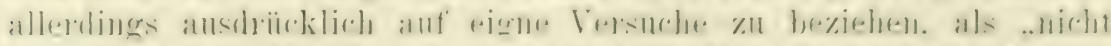

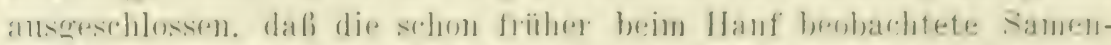

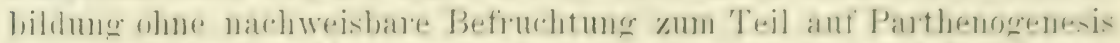

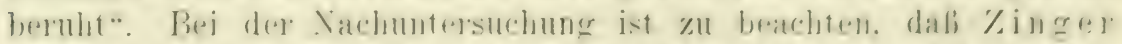

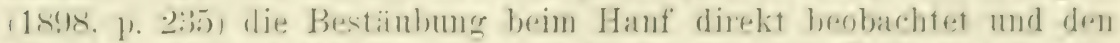
Teg des Pollenschlanchs von der Sarbe bis zum Embryosark verefolgt lat. Gimstigstenfalls hambelt es sich alse hief entweder num num

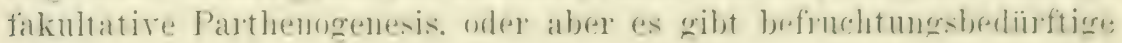
und apomiktisch gewordene Rassen.

$H u m u l u s$. Ganz das gleiche wie für den Hanf gilt auch für

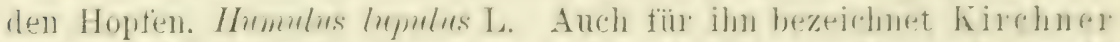
1905. 1). T.IV) die P’arthenogenesis als ..nicht ansegechlosifu”. obwohl die alteren Angaben daribler durchans nicht hewrojend simd und

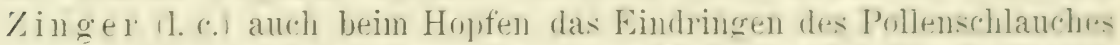

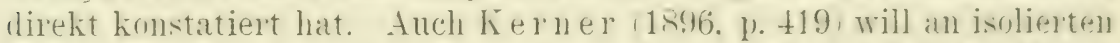
und nach seiner Ansicht sicher nubestäuhten weiblichen Hoffenstörken im tiroler Gschnitztale alljährlich reichlichen Samenansat\% herbachtet haben. und Tretstein (1907. 1). 225) benerkt, bei Humulus sei ..celerentliche Parthenogenese wahrscheinlich”. Fine genaue hritische und enrlgültige Lntersuchung der Fortpflanzungsverhältnisse rou Hopten und Hanf ist damach jedenfalls dringend erwïnscht. Wobej anch die zahlueichen verstrenten Angaben der Praktiker über den Finflub der Bestäubung auf die Ausbilumg des Houtimzäpfohoms zu beachten wären.

Fisus. Die mokwürdigen Bestäubungsterhältniss der fiattung Ficus haben diese von jeher zu einem bevorzugten I'ntersuchungsobjekt cemacht. Lns interessieren an dieser Stelle naturlich nur diejenigen Angaben. die sich mit der angeblichen ayomiktischen samenbildung bei einigen Ficus-Arten beschäftigen.

Ficus carica L. Unsere Kenntnisse über die seinerzeit besonders ron Gasparrini $18 \pm 6$, behauptete Partlenogenesis des kultivierten Feigenbammes wurde noch 1882 ron solms i 1582 . 1. 22. in den satz zusammengefaßt: .. Zweifelhatt bleibt es. ol der Feigenbaum etwa imstande, den Embryo seines Samens eventuell auf parthenogenetischem Wege zur Entwickelung zu bringen *. Doch neigt Solms selhst zur Ammahme. dab nur rite befruchtete Blüten samen ansetzen kïnnten. Die suätere Forschung hat ihm recht gegeben: es wurde rornehmlich durch Fisen (1896) und nenerdings durch Longo 1.1050, nachgewiesen. daß in der Tat bei ausbleibender Bestäubung keine einzige weibliche Blüte ron Ficrs carica eine samenhaltige Frucht liefert. Eisen (1. c. 1).933) zeigte auch durch Bastardierungsversuche. dab es sich auch nicht um eine Auslösung ron partheno- 
genetischer Entwicklung 'durch die Bestäubung oder den Blastophaga-Stich handeln kann. Damit ist wohl nun definitiv erwiesen, daß unter normalen Vegetationsbedingungen weder habituelle noch fakultative Parthenogenesis bei dem kultivierten Feigenbaum rorkommt.

Ficus hispida L. fil. King (1887) stellte fest, daßs bei Ficus hisplida die Receptakeln, die die weiblichen Blïten entlıalten, und in denen niemals männliche Blïten rorkommen, stets röllig geschlossen bleiben. Kein Insekt dringt in sie hinein. auf den Narben der Blïten sind niemals Pollenkörner zu finden, und doch ist die Mehrzahl der Blïten fertil. Dies Terhalten läbt natülich auf Apomixis schließen. doch muß noch crtologisch untersucht werden, ob Propagation, Apogamie oder Parthenogenesis vorliegt.

Ficus Roxburghii Wall. Von dieser Art wurde von Cunningh a m (1888) nachgewiesen, dab sie apomiktisch ist. Thre Keime entstehen indessen weder durch Apogamie noch durch Parthenogenesis. sondern propagativ aus Nucelluszellen, die den trühzeitig zugrunde gehenden Eiapparat rerdrïngend. in den Scheitel des Embryosackes hineinwuchern. Da eine Bestäubung dazu nicht notwendig zu sein scheint, so haben wir also in Ficus Rorburghii ein vollkommenes Gegenstück zu Cueldogynne ilicifolu, nur daß bei Ficus I. wahrscheinlich als auslösendes Moment der Stich der Eupristis erforderlich ist.

Fïus hirta Ta hl. Über Ficus Thirta liegen sehr solgfältige Untersuchungen von Treub (1902) vor, aus denen mit seln' grofer Wahrscheinlichkeit hervorgeht. dab diese species parthenogenetisch ist. Immerhin stehen der experimentelle Nachweis und die genanere cytologische Erforschmig noch aus. so dab wir den Fall rorerst noch in die Rubrik der ungenügend bekannten einzureihen haben.

Sicher ist bei Ficus hirta jedenfalls, daß der Embryo aus dem Ei selbst hervorgeht; die Angaben und Figuren Treub's lassen darüber keine Zweifel aufkommen. Was nun 'Treub ror allem veranlaßt. anzunehmen, daß das Ei sich ohne vorhergehende Befruchtung zum Embryo entwickle, ist (1. c.. p. 152) ...avant tout. le fait que l'on ne roit pas de tubes polliniques pénétrer dans l'orule à lépoque oi elles devraient sy trouver; en second lieu, la réduction dans la karyokinèse chez les noyaux d'albumen et, enfin, le caractère peu développé de lappareil sexuel en général et notamment des synergides". Dabei ist freilich andererseits zu beachten, dah die IIikrosporenentwicklung durchaus normal verläuft, und man keimende Pollenkörner auf den Narben findet. Treub bemerkt ansdrücklich (I. c., 1. 137), "que dans le Ficus hirta les grains de pollen introduits dans le réceptacle femelle seraient assez nombreux pour effectuer la fécondation. sinon de toutes, en tout cas de la grande majorité des fleurs." Zur Behebung der auf Grund dieser Tatsachen möglichen Zweifel wäre daher neben der Erledigung der Frage ob bei der Makro- 


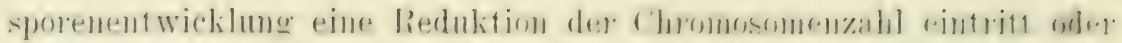

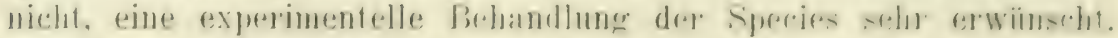
Dabei wäre anch noch gronan festzostellen, wh. wite Trenb amimm,

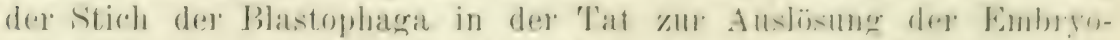
entwicklung unumgringrach notwendig, oder oh die fiemung ron

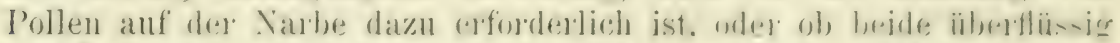
sind. Inureh die lsolierung weiblicher Receptakm. so dab sie rom dem

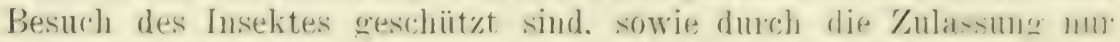
pollenfreier Blastophagen zo isolierten fieceptakeln dürfte sich das wohl rutscheiden lassen. In ersteren Falle fielen stich und Pollenwirkumg weg. im letzteren nur diese; als rritter Parallelver-ur-l, wäre damn die künstliche liestiubung isolierter lieceptakeln nïtigr. so dal, nur die Pollenwirkung ohne die des Insektenstiches zur Gettung käme.

\section{Urticaceae.}

Elatostema. Bei Elatostema ucuminatum Brong"n. beobachitete Treub (1905), daß männliche Blüten am natiirlichen standorte der. Pfianze, in Tjibodas. auferordentlich selten sind. daß aber trotzdem die sehr zahlreichen weiblichen Stöcke regelmälig fruktificieren. Die cytologische Lntersuchung ergal) demn auch. daß hier sehr wahlscheinlich die Embryobildung olne Befruchtung und Bestäubung elfolgt; die experimentelle Bestätigung durch Isolinungsversuche stelıt allerdings noch aus.

Die Makrosporenentwicklnng geht so vor sich, daf die Embryosackmutterzelle sich in zwei. drei oder vier Tochterzellen teilt. ron denen gewöhnlich die innerste zur keimenden Makrospore wird. Toch liefert diese nur in sehr seltenen Fällen einen normal ausgebildeten Gametophyten, da sich in den allermeisten Fällen der Embryosack nur bis zum Stadium von vier, gelegentlich auch sechs oder acht Kernen entwickelt. ohne einen typischen Eiapparat oder Antipoden zu differencieren. Wie num innerhalb des Embryosackes der Embrro entsteht, lieb sich nicht mit absoluter sicherheit entscheiden. 'Treub macht es wahrscheinlich. daß er aus einem ganz beliebigen dieser Embryosackkerne hervorgeh wie seine ïberaus wechselncle Lage innerhalb der Makrospore vermuten läßt. Die anderen Kerne liefern ein die ganze Embryosackhöhlung ausfüllendes Endosperm. trelegentlich kommt mehr als eine Irakrospore zur Entwicklung. und dann kann jede einen Embryo enthalten.

Fs läbt sich vorerst schwer entscheiden, wie dieser interessante Modus der Embryobildung zu verstehen ist. Parthenogenesis liegt natürlich auf keinen Fall vor, da ja ein morphologisch differenziertes Ei fehllt. das als Ausgangspunkt für die Embryogenese dienen künnte. Am ehesten vergleichbar ist das Verhalten der Elatostema mit der 
Apogamie der Balanophoraceen (vgl. p. 65 ff.), doch mïssen zur sicheren Fintscheidung weitere Untersuchungen abgewartet werden.

ob bei der Tetradenteilung eine Reduktion der ChromosomenZahl stattfindet, konnte Tre nb nicht entscheiden; doch rermutet er. dab es nicht der Fall ist.

\section{Polygonaceae.}

Rumex. Bei einer Untersuchung der Fortpflanzungsverhältnisse bei der Gattung Rumex will Roth (1907) gefunden haben, dab einige ihrer Arten apomiktisch seien. So Rumex acetosa L., Ii. Tispanicus

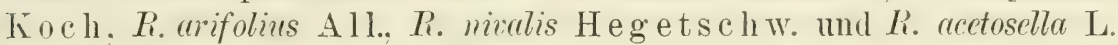

Der Embryo soll (p. 348) aus dem Ei hervorgehen, es würde sich also um Parthenogenesis handeln. Die Isolierungsversuche des Verfassers können indessen nicht als ganz einwandfrei gelten, und anch cytologisch sind seine Ergebnisse so wenig klar, daß die Angabe vorerst noch als zweifelhaft gelten mub.

\section{Chenopodiaceae.}

Obione. Die Gattung Obione ist an dieser Stelle zu erwähnen, weil ein so sorgfältiger Beobachter wie Wydler (1878, p. 325) von Gbione sibirica Fisch. bemerkt: .Ganz besonder's auffallend ist das verhältnissmäßig seltene Vorkommeu von männlichen Blüthen bei den äuberst zahlreichen weiblichen, die alle einen gut ausgebildeten Embryo besitzen, ein Fall. den ich anch bei Amblogyne persicarioides [Amarantaceae] beobachtete". Es verdiente, klargestellt zu werden, ob hier der naheliegende Verdacht auf Apomixis gerechtfertigt ist, wobei allerdings zu beachten ist, daß Kerner (1896, p. 423) im Wiener botanischen Garten bei einem weiblichen Stock von Obione hatimifolia nur weitgehende Parthenokarpie fand: die reichlich entstehenden und äußerlich normalen Früchte waren sämtlich taub.

\section{Nymphaeaceae.}

Nymphaea. Focke (1881, p. 525) zitiert einen Fall von Pseudogamie bei Nymphaea Capensis Thbg. Diese Art „vermag sich nicht selbst zu befruchten; mit Pollen von $N$. coerulea Savgn. erhielt Caspary nach vielen vergeblichen Versuchen einen keimfähigen Samen, aus dem eine sterile $N$. capensis hervorging. Staubblätter gering an Zahl, fädlich, olne Pollen; Fruchtknoten verkümmert. Abh. Naturf.-Ges. zu Halle XI."

\section{Menispermaceae.}

Disciphania. Über die Fortpflanzungsverhältnisse der südamerikanischen Menispermacee Disciphania Enstii Eichl. liegt eine 


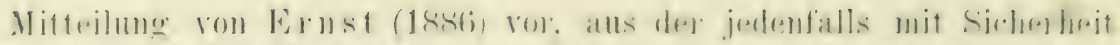

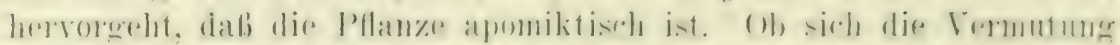

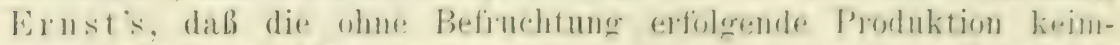

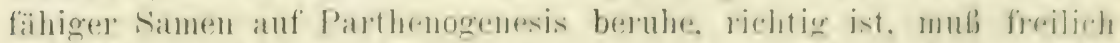
arst die rytologische Tntersuchung ergeben. die noch ansioleht.

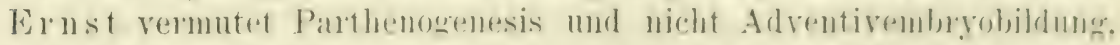
weil letztere mit Polrembryonie verbunden zu sein pefert. diese abes.

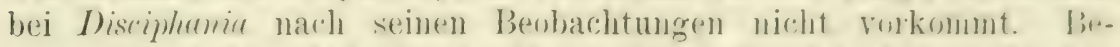
merkenswert ist. dab die 8 es am lange vinudel der weiblichern Öhren wïhrend der Anthese der Blïten anschwillt und zwar ron des. Basis nach der suitze zu in immer starkerem Mabe. und dab die (ohne Bestäubung) fortilen Blïten immer die am dickeren Ende der Infloreszenz-spindel stehenden waren. Aus dieser Lohalisation der. Friichte auf das keulentiormig angeschwollene Ende der spindel mördete Ernst den Schlub ziehen, dah die Anhäufung von Vähstoften denn auf einer solchen beruht die Anschwellung der Infloreszenz-Achse - das die Parthenogenesis auslösende Moment sei. I)a die P'flanze auch in ihrer Heimat (Tenezuela) selten ist und in botanischen Gärten nicht rorhanden zu sein scheint. wird leider wohl die genaut Nachuntersuchung des interessanten Falles nicht so bald erfolgrin können, als wünschenswert wäre.

\section{Rosaceae.}

Rosa. Mit Vorbehalt hatte Dingler (1906, p. 39) fuir Tiosa muigimosa die Befähigung zu fakultativer Parthenogenesis angegeben. Doch ist es ihm $(1907$, p. 31) .nach einem wiederholten, durch Trngunst der Terhältnisse leider wieder ungenügenden Versuch nenerdings zweifelhaft geworden". ob wirklich Parthenogenesis rorkommt. Sollte es sich im Terlanfe der fermeren Lntersuchung doch nuch bewahrheiten, so ist schon jetzt sicher, dab es sich nicht um habituelle sondern, wie ja auch Dinglel angibt, nur um fakultative Parthenogenesis handeln kamn. Denn es sind zweifellose Bastarde zwischen Rosa mbiginosa und anderen Arten bekannt, und überdies ist durch strasburger (1904. p. 149) ausdriicklich durch cytologische Untersuchung festgestellt worden. daß Rosa muiginosa normal sexuell ist. eine Feststellung, die freilich zunächst nur für die von Stras bur ger muersuchte Rasse bindend ist. Anch andere Rosen-Arten. wie Rosa cimamomer, camina, myracantha und andere sind sicher normal befruchtungsbedürftig; doch wäre, falls sich die Beobachtung Dingler's doch noch bewahrheiten sollte, anch hier auf das Torhandensein der Befähigung zu fakultativer Parthenogenesis zu prüfen.

Fragaria. Die Gattung Fragaria ist an dieser Stelle zu elerwähnen. weil bei ihr bekanntlich faux hybrides im Simne Millar- 
det's vorkommen, und die Möglichkeit vorliegt, dah es sich dabei um eine durch die Bestäubung ausgelöste Parthenogenesis handelt, wobei freilich hier die Nachkommenschaft nicht ausschließlich miitterliche, sondern im Gegenteil rein väterliche Eigenschaften zur Schan trägt. (Millardet 1894, p. 355). Es ist also hier nicht so wie bei Vitis (vgl. p. 52), sondern es scheint eine Art männliche Parthenogenesis vorzuliegen, wie auch Giard $(1900$, p. 12; 1903) ammimmt. So fand, um ein Beispiel zu geben, Solms (1907, p. 53), II illardet's Befund bestätigend, daß 1902 rein weibliche Fragariu virginiana mit Pollen von Fragaria clatior bestäubt reichen Fruchtansatz ergab. 1904 bliihten von den Produkten dieser Kreuzung 37 Stöcke „und glichen sammt und sonders so absolut dem Vater ( $F$. clatior), daß kaum ein Unterschied von demselben zu entdecken war.". Nur war diese der $F$. elatior so zum Verwechseln ähnliche Bastardform absolut steril, während die reine elatior reichlich fruktificiert. Dagregen ergab z. B. die Kremzung $F$. virginiana o collina eine viel decidiertere Zwischenform zwischen den beiden Eltern.

Wir haben auch anf tierischem Gebiete eine Parallele zu dieser merkwürdigen Erscheinung, nämlich in der Angabe von HéronRoyer (1883; vgl. Giard 1900. p. 13), daß ein voln Rana fusca befruchtetes Teibchen von Pelobates fuscus reine Rama fusca-Nachkommen brachte, und ebenso ein Weibchen von Bufo vulgaris nach der Begattung durch Bufo calamita reine calamita-Nachkommen.

Die Berechtigung, in diesen Vorkommnissen eine "Parthenogenesis des Mikrogameten" zu sehen, müßte freilich noch cytologisch begründet werden. Torerst scheint es mir einfacher anzunehmen, daß eine normale Befruchtung stattgefunden hat, daß aber in der Generation F' 1 die sämtlichen männlichen Merkmale über die weiblichen dominieren. Damit hätte diese Kategorie von faux hybrides, bei denen die Bastardgeneration durchaus dem Vater ähnelt. nichts mit Parthenogenesis zu tun und war hier nur der Vollständigkeit wegen nicht zu übergehen. (Vgl. auch das p. 41 Gesagte.)

Übrigens soll nach Millardet (1. c.) bei Fragaria auch der umgekehrte Fall häufig sein, Bastarde also, die in der ersten Generation durchaus der Mutter gleichen.

$R u b u s$. Auch die Gattung Rubus ist deswegen an dieser Stelle zu erwähnen, weil bei ihr fausse hybridation beobachtet worden ist (Millardet 1894, p. 362; Lid forss $1905 ; 1907$ ). Kistrierte Blüten von Rubus caesius L., R. villicantis Ko eh l., R. glandulosus B ell. und anderen Arten setzen niemals Samen an, wenn sie exakt vor Bestäubung geschiitzt werden. Bestäubt man sie aber mit dem Pollen von anderen Arten der Gattung Rubus, so erhält man neben typischen Bastarden Sämlinge, die durchaus der Mutter gleichen und bei Selbstbestäubung: vollkommen konstant sind. Leider ist bisher die von Lidfors in 


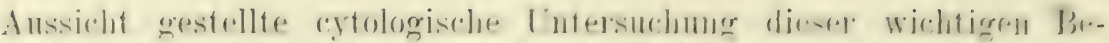

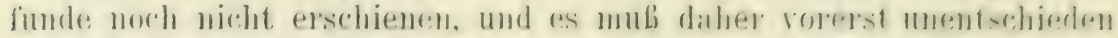

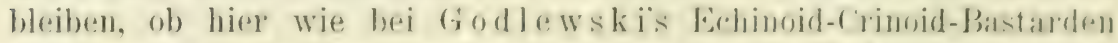

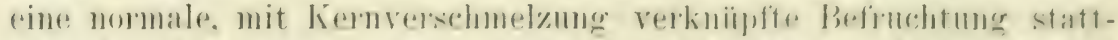

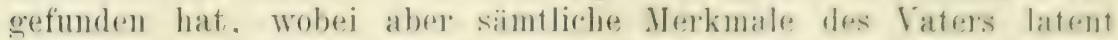

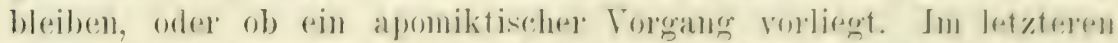
Falle mübte man ammehmen. dali die Apomixis dureh die Jestiabmuge

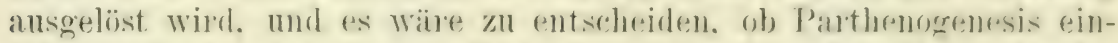

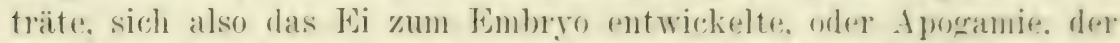
Embryo also ans einer Synergide Antipode oder Endospermzelle entstiunde, oder endlich Propagation, d. h. Adventivembryohildung ans Nucellus- oder Integumentzellen. Das ist natürliclo nur dur ols die hoffentlich bald kommende cytologische ['ntersurhung aufzukliucen: immerhin mag es schon jetzt als wahrscheinlich bezeichnet werden. dab. Adventivembryobildung nicht in Betracht kommt, da diese mit Polyembryonie zu rerbunden sein pflegt. von dem regelmäßigen Torkommen einer solchen aber bei liubs nichts angegeben wird. Fs. sei noch bemerkt, dab Strasburger (1904, 1). 145)), der innerhall, der Gattung Rubus als einer stark polymorphen Gattung nach Ajomixis suchte, bei liubus fruticosus L.. Ii. biflorus Buchan. und Ii. leucodermis Dougl. fand, dah sie ihre Keime auf geschlechtlichem Wege zur Ausbildung bringen. Auch F ischer $(1850$, p. 110) fand bei der Embryosackentwicklung von Rubus caesius ebensowenig ungewöhnliche Verhältnisse wie Péchoutre (1902. p. 12) bei der von R. fruticosus.

\section{Papilionaceae.}

Pisum sativum L. Bei der Erbse wird von Chr. Schröder (1901) die Möglichkeit parthenogenetischer Fortpflanzungsweise angenommen. Seine Versuche wurden indessen von Kirchner (1904b) mit negativem Erfolge wiederholt, so daß es sich wohl um eine Täuschung Schröder's durch Fruchtungsvermögen handeln wird. wie es nach den Beobachtungen Kirchner's bei manchen Papilionaceen nicht selten ist.

\section{Malpighiaceae.}

Unter den Malpighiaceen gibt es einige zentralamerikanische Gattungen mit kleistogamen Blüten, von denen Ritzerow (1907. p. 180) Aspicarpa longipes A. Gl., A. hirtella Rich. und A. lanata (an Herbarmaterial) untersucht hat. Sie vermutet parthenogenetische Embryobildung auf Grund folgender Beobachtungen (1. c., p. 180 und 181): „Nirgends wurden normal ausgebildete Pollenkörner beobachtet, keine Spur von Pollenschläuchen war zu sehen. Die Frucht ist gut entwickelt. und normal ausgebildete Embryonen wurden gefunden. 
Anf Mikrotomschnitten sah man, daß dieselben ziemlich weit von der Mikropyle entfernt sind. Auffallend ist eine auf bestimmtem Stadium vom Nucellus aus entstehende Wucherung auf der Seite der Mikropyle. Es geht aus allen diesen Beobachtungen hervor, daß diese Blüten nicht befruchtet werden, sondern sich wahrscheinlich auf parthenogenetischem Wege entwickeln... Wie die Entwicklung des Embryos vor sich geht, und welche Bedentung die an der Mikropyle entstehende Wrohermo hat, ob hier vielleicht Gallenwirkungen eine Rolle spielen. bedarf noch näherer Untersuchung an lebendem Naterial, das mir leider nicht zur Terfügung stand."

Die Beobachtung, daß die Embryonen auffallend weit von der Mikropyle entfernt inseriert sind, läßt wohl eher den schluß auf Adventivembryobildung zu. Die obturatorähnliche Wucherung iiber der Mikropyle braucht nicht auf Gallenwirkung zu beruhen, sondern ist wohl direkt veroleichbar der Wucherung. die z. B. bei der parthenogenetischen Witistrocmia indica die Mikropyle verschließt (rgl. Winkler 1906, p. 227).

\section{Euphorbiaceae.}

Ricinus communis. Meelıan (1899, p. 97) teilt Versuche über die Befähigung des Ricinus mit, ohne Bestäubung Samen zu liefern. Diese fielen in den ersten Jahren positiv aus, ergaben aber bei kritischerer Versuchsanstellung 1898 das Resultat, daß bei Ricinus communis nur eine sehr weitgehende Parthenokarpie. aber keine Parthenogenesis oder Apogamie vorkommt: es entstanden trotz der ausgebliebenen Bestäubung äußerlich normal ausgestaltete, aber taube Friichte. M e ehan meint (1. c., p. 99), das Vorkommen von Parthenogenesis bei Ricimus communis erscheine demnach zweifelhaft; man darf aber ans seinen Versuchen wohl den bündigen Schlub auf das Fehlen von Parthenogenesis und Apogamie ziehen.

Mercuralis anuи. Zu denjenigen Pflanzen, von denen seit langer Zeit immer wieder die Behauptung auftancht, sie seien parthenogenetisch, ohne daß bisher Entscheidendes bekannt geworden wäre, gehört Mercurialis amma. Bis auf Camerarius zurïck gehen die Stimmen, die sich für das Bestehen der Parthenogenesis bei dieser Pflanze aussprechen. Regel $(1849$, p. 7) hat die ältere Literatu zusammengestellt und auf Grund eigener Tersuche widerlegt (p. 35), nachdem bereits Gärtner (1844, p. 475 ff.) auf das durchaus L'nzulängliche der bis zu seiner Zeit vorliegenden Beobachtungen und Versuche ausführlich hingewiesen hatte. Später sind auch noch von Heyer (1883) entsprechende Experimente angestellt worden, mit dem Resultate, dab Parthenogenesis bei Mercurialis $\mathrm{ni} \mathrm{cht}$ vorkommt. 
Inffilligenweise lieren nun aber ans nenerer \%eit wioler aibe

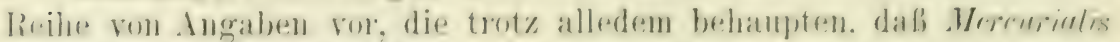

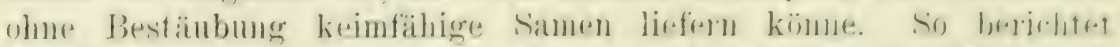

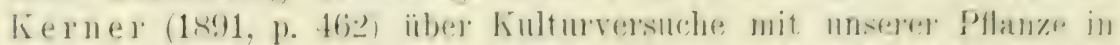
dem hochgelescenen tiroler lisohnitztale. Wo anf viele Veilen in die Runde kein Bingelkraut wild warhsend vorkommt. lis wurden dabei .,alle stäcke. an welehen sich Kinsplen von Pollenblïten zeigten. -n-

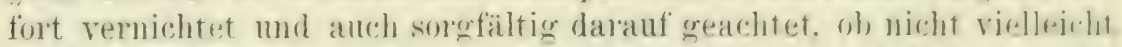
an dem einen oder anderen mit Fruchtbliiten ansegestattetren citrelie irgendwo rine vereinzelte Pollen- oder Zwitterbläte versterkt sei.

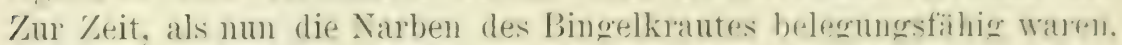
fanden sich anf viele Meilen in der hunde ganz bestinnt hrine Pollenzellen dieser Pflanze vor. und es komnte dales rime liefreme mit solchen Pollen auch nirht stattfinden. Lnd demuoch schwollen alsbald die Fruhtknoten an. aus den Samenanlagen entwickelten sich samen mit einem Keimlinge. und aus diesen ramen gringen narbh der Anssaat wieder nente. kuaftige Stricke des Bingelhrautes helvor..

Auch Kirchner (1905, p. LIII) bezeichnet es „als nicht ausgeschlossen. daf die bein einjährigen Bingelknant beobachtete samenbildung ohne nachweishare Befruchtung' zum 'Teil auf Parthenorenesis

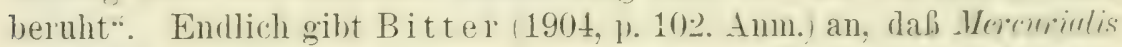
amma sich bei seinen 3 Jahre lang tortgesetzten Kulturen als ..tatsächlich in ziemlich hohem IIabe parthenogenetisch" erwiestrll habe. während Mercurialis peremis nur parthenokarp sei.

Entscheiden können hier offenbar nur ausgedehnte mol sehr sorwfältige Kulturversuche. die alle die besonders ron (; ä rtner 1 1 st4. 1. 120. 216. 481) angegebenen Fehlerquellen kritisch bericksichtignen und mit der cytologischen Cntersuchung Hand in Hand gehen. so wie die Dinge jetzt liegen. läßt sich eine Entscheidung nicht treften. Ian künnte höchstens vermuten, dab die auffällige Verschiedenheit der Resultate sich vielleicht dadurch erklärt, dal. es befruchtungsbediurftige und parthenogenetische Rassen quabe. ron denen entweder nux die eine oder nur die andere oder aber beide nebeneinander am gleichen Standort vorkommen. Unter allen L'mständen aber wirden die vorliegenden Tersuche. die volle Richtigkeit auch der positir'm rorausgesetzt. immer. erst ergeben, daß Apomixis vorläge: ob sie aber als Parthenogenesis. Apogamie oder Adrentivembryobildung aufträte. wäre natïrlich noch auf crtologischem Trege zu entscheiden.

Euphorbia dulcis Jacqu. Von Hegelmaier $(1901 ; 1903)$ wurde bei Euphorbia dulcis habituelle Polyembryonie konstatiert. Diese kann jedenfalls olne vorhergehende Bestäubung eintreten. ob aber nicht doch gelegentlich Bestäubung und damit Befruchtung des normal ausgebildeten Eiapparates stattfinden kann. ist nicht sicher. allerdings auch nicht gerade wahrscheinlich, da, wenigstens bei 
manchen Sippen der Pflanze, der Pollen in weitgehendem Maße abortiert. Schmidt (1907, p. 37) fand sogar bei den im Göttinger botanischen Garten kultivierten Exemplaren, daß meistens die männlichen Blïten zwar angelegt, aber nicht weiterentwickelt werden. so daß das fertige Cyathium ganz ohne männliche Bliten ist.

Die Adventivkeime gehen wie bei Caclebogyne aus Nucelluszellen hervor; da also ein Propagationsvorgang vorliegt, so würden wir an sich keinen Grund haben, die Pflanze an dieser Stelle zu besprechen, wenn nicht $\mathrm{Hegelmaier}$ beobachtet hätte, daß auch aus der Eizelle selbst ein Vorkeim hervorgehen kann, der sich von den Adventivembryonen durch den Besitz eines Suspensors unterscheidet. Leider hat sich nicht sicherstellen lassen, ob auch dieser Vorkeim zu einem keimfähigen Embryo heranwachsen kann. Da ferner auch die feineren Vorgänge bei der Entwicklung der Makrospore noch nicht untersucht sind, es insbesondere unbekannt ist, ob die Reduktion stattfindet oder unterdrückt wird, so läßt es sich nicht beurteilen, ob hier ein Fall von somatischer oder von generativer Parthenogenesis vorliegt. Die Pflanze verdient nähere experimentelle und cytologische Untersuchung:

\section{Anacardiaceae.}

Pistacia narbonensis L. Als erledigt dürfen wohl die Angaben von Tenore und Bocconi über Parthenogenesis bei Pistucia narbonensis gelten, worïber Regel $(1859$, p. 11) berichtet: "T e nore bemerkt im Samenkatalog des botanischen Gartens zu Neapel fürs Jahr 185̄3, daß die weibliche Pflanze von Pistacia narbonensis im dortigen Garten jährlich Samen trage, ohne daß männlicher Blïthenstaub einwirke, und daß diese Samen dennoch vollständig keimfähig seien. In einigen Gegenden Italiens habe Bocconi anch die gleiche Erscheinung an anderen Arten der Gattung Pistacia beobachtet. Genamere Nachweise sind nicht gegeben und so hat diese Beobachtung. gar keinen Wert."

Für Pistacia lentiscus L. habe ich mich durch eigene Kastrationsversuche davon überzengt, dab sie durchaus bestäubungsbedürftig ist.

\section{Vitaceae.}

Die Vitaceen sind an dieser Stelle zu erwähnen, weil Mill a r de t (1894, p. 362; 1901, p. 678) innerhalb der Gattung Vitis das Vorkommen von "fausse hybridation" festgestellt hat, für die ja, wie bereits mehrfach erwähnt, eine Erklärungsmöglichkeit in der Annahme liegt, daß es sich dabei um eine durch die Bestäubung ansgelöste Parthenogenesis handele. Da Millardet's sehr interessante Untersuchungen an einem schwer zugänglichen Orte (in der Revue 


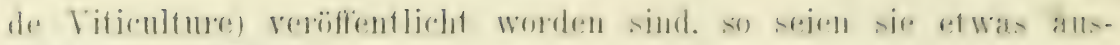
fiilhlicher referiert.

Es gibt innerhalb der Gattung Vitis bekanntlich eine aulier-

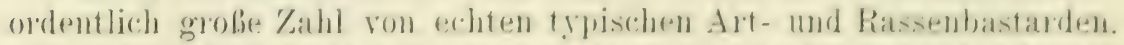

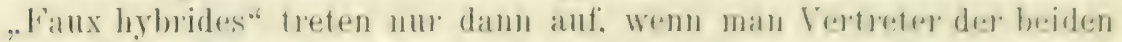
Sektionen, in die die Gattung zerfillt. der Sektim linvitis und der Soktion Muscadinia, miteinamder kreuzt. M illardet benutzre zu seinen Versuchem als Vartreter von Euvitis menrere sorten ronl Titis

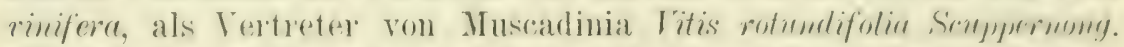
Wurden die Yinifera-Sonten Pedro-Ximenes, Clatselas ofler Pansejame mit Pollen von Scuppernomg bestäubt, so ergab sich eine Nachkommenschaft, die in allen Einzelheiten völlig der entsprechenden Tinifera-Hutter glichen, abgesehen davon. daß der Pollen schlechiter ausgebildet war als bei der reinen Sorte. Auch wenn ein solcher „Bastard" neuerdings mit dem I'ollen von Scuppernong belegt wude, wie das Millardet für die Kombination Pedro-Ximenes $\%$ Scuppernong durchfülnte, ergab sich wiederum eine Deszendenz, die kein einziges Rotundifolia-Merkmal besab. Genau das gleiche gilt auch für die Krewzung von Titis muestris mit V. rotumdifolia Scupperuong, voransgesetzt, daß auch hier letztere Art den Pollen liefert. Tie später Gard (1903, p. 106) zeigte, erstreckt sich die röllige Ähnlichkeit mit der Mutter nicht nur auf die morphologischen, sondern auch auf die anatomischen Charaktere.

Merkwürdigerweise liefert nun aber umgekehrt die Bestäubung des Scuppernong mit dem Pollen einer Euvitis-Art gewöhnlich normale Hybriden, die von beiden Eltern Merkmale besitzen.

Dagegen ergibt wieder, und das ist besonders beachtenswert, die Bestäubung einer Euvitis-Sorte (Millardet rerwandte die ViniferaSorten Aramon, Grumete und Decandolle) mit dem Pollen ron AmpeTopsis hederacea faux hybrides, die, wie Millardet in melurach wiederholten mit allen Kautelen angestellten Versuchen bewies, kein einziges Ampelopsis-Nerkmal besitzen. Die reziproke Krenzung gelingt in diesem Falle überhaupt nicht.

\section{Violaceae.}

Hier liegt nur eine kurze Angabe von Greene (1898) ror. die ich leider nicht im Original habe einsehen können. Nach dem Referat in der Botan. Gazette, Bd. 25, 1898, p. 376 behauptet Greene das Vorkommen von Parthenogenesis ,.in some of the so-called cleistogamous flowers of Viola“. Der Referent, J. M. C., fügt hinzu: „Of course he only means the setting of seed without pollination. It is hardly likely that it is a case of parthenogenesis, for this has been disproved for all such claims for the higher plants, but it is always 
interesting to know the origin of the vegetatively developed embryos." Da inzwischen eine ganze Reihe von höheren Pflanzen bekannt geworden sind, bei denen sicher Parthenogenesis vorkommt, so wäre es immerhin nicht ummöglich, daß auch die kleistogamen Violablitten unter Umständen parthenogenetisch sein könnten. Doch bedarf die Angelegenheit um so mehr der näheren Untersuchung, als gerade über die Bestäubungsverhältnisse der kleistogamen Veilchen zahlreiche Beobachtungen ans alter und neuer Zeit vorliegen (vgl. Göbel. 1904. p. 694, bei der Besprechung von dessen Arbeit auch der Referent E. in den Botanischen Jahrbüchern. Bd. 34, 1905, p. 77 des Literaturberichts, die Vermutung äuBert, bei T'iola könne trotz der Pollenkeimung in den Antheren Parthenogenesis oder Nucellarembryonie vorliegen). Ganz neverdings hat R itzerow (1907, p. 173) für mehrere kleistogame Viola-Arten ausdrücklich festgestellt, dab sie bestäubungsbediurftig und weder zu Parthenogenesis noch zu Nucellarembryonie befähigt sind. Leider gibt sie nicht an, welche Arten sie untersucht hat, und ihre Angaben sind überhaupt etwas sehr summarisch.

\section{Caricaceae.}

Usteri (1907, p. 491 ff.) spricht die Vermutumg als, dab sich die Samen bei Carica papayı L. auf parthenogenetischem Wege bildeten. Seine Versuche, das experimentell sicherzustellen, sind allerdings bisher negativ ausgefallen, und so gründet sich vorerst die Vermutung lediglich auf die Beobachtung, daß in Gärten häufig weibliche Pflanzen samenhaltige Früchte ansetzen, obwohl männliche auf Meilen im Umkreis nicht zu finden sind, sowie darauf, dab Usteri bei der cytologischen Untersuchung der Samenknospen auf keinem Entwicklungsstadium je eine Andeutung eines Pollenschlauches antraf (1. c., p. 494). - Man wird, da bei der Pflanze weitgehende Parthenokarpie sicher vorkommt, den Fortgang vor allem der experimentellen Untersuchung abwarten müssen, die Usteri in Aussicht stellt.

\section{Datiscaceae.}

Die von Fresenius (1837) herrührende Angabe, daß Datisca camabina L. Samen erbringe, ohne vorher bestäubt worden zu sein, eine Angabe, die eigentlich schon durch $\mathrm{Regel}(1859, \mathrm{p}$. 8) widerlegt worden war, ist von MI r i (1880) einer ausführlichen Nachuntersuchung unterzogen worden. Die von ihm im botanischen Garten zu Pisa isolierten Exemplare ergaben aber nur Früchte mit tauben Samen, so daß nur Parthenokarpie vorliegt und Datisca cannabina definitiv aus der Liste der parthenogenesisverdächtigen Pflanzen zu streichen ist. Auch die kurze positive Angabe von Odell (1904) iiber Parthenogenesis bei unserer Pflanze ist zweifellos durch Parthenokarpie zu erklären. 


\section{Oenotheraceae.}

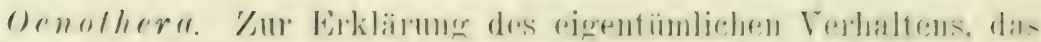

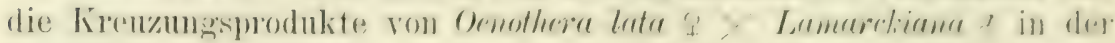
Generation F 1 zeigen, stellt Gates (1907, p. 7 und 1:3) u. a. die

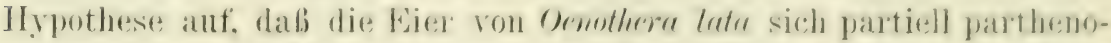
genetisch zu entwikeln remöghten. Bride Eltern bexitzen in ihren

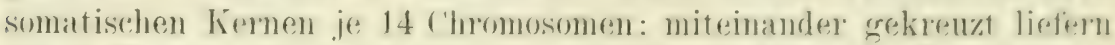
sie in F 1 15-25 P'roz. Oe. lata und 75-85 Proz. Oe. Lamarcliana.

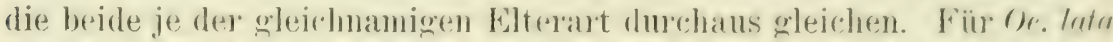
hylovidn triffit das auch himsichtlich der ('hromosomenzahl zu. wäluend

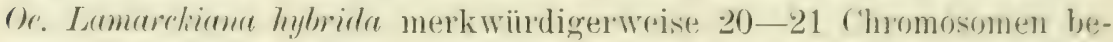
sitzt. Um dieses sehr auffälige Ferhalten zu erklären. erörtert (xates (1. c., p. 13) die Nöglichkeit, ..that all the egors of (). lutu have the umeduced number of chromosomes. and that part of them develop without fertilization (parthenogenetically). produring (). latu plants with fourteen chromosomes: while others are fertilized with (). Lamarchitum pollen, and produce Lamarckiana plants having twentyone chromosomes".

Da Ocnothera latı bei ausbleibender Bestiubung keine vamell ansetzt (de Vries 1901. 1). 168), so wäre hier die Hilfsammahme nütig. dab. die Parthenogenesis durch die Bestäubung mit dem LamarckianaPollen ausgelöst wïrde. Man könnte das ja auch gewib unbedenklich annehmen; mehr Schwierigkeiten abel scheint mir der Gates 'schen Hypothese die Notwendigkeit zu bieten, zu erklïren. warm sich regelmäbig gerade 15-25 Proz. der Eiel parthenogenetisch entwickeln. Jedenfalls bedarf die Angelegenheit noch der näheren Prïfung:

Fuchsia. Vielleicht kommen imnerhalb der Gattung Fuchsia faux hybrides vor. Lowe (Gard. ('hr., 3. Ser., Bd. 8, 1890. 1). ว3ऽ) "mentions Fuchsia fulgens crossed by .Semiramide and the reciprocal cross, the seedlings in both cases resembling the female.*. und auch I e e h an (ebenda, Bd. 10, 1891, p. 109) berichtet ron einer Fuchsia w.borescens, die, mit dem Pollen einer Gartenvarietuit von Fuchsiu sper. bestäubt, reine arborescens-Abkömmlinge lieferte.

\section{Halorrhagidaceae.}

Gunnera. Bei Gumera chilensis Lam., G. arenaria, G. dentata. G. densiflora Hook f. und $G$. microcarpa vermutet Schn eg $g$ (190.). 1. 203) Parthenogenesis auf Grund des folgenden Befundes: ..Die unter der Fpidermis liegenden drei bis vier Zellreihen zeigen schon in ziemlich jungen Stadien der samenanlage eine auffallende Ditterenzirung gegenibber den Zellen der ïbrigen Fruchtknotenwand. Sie erfahren schon sehr frühzeitig eine Formveränderung in der Weise, daß ihre Wände sich stark wellen und allmählich verdicken. so dab 
durch dieses Verhalten, das sich mehr und mehr steigert, bewirkt wird. daß die ganze Samenanlage zur Zeit der Ausbildung des Eiapparates schon von einer festen Masse starker sklerenchymzellen umgeben ist. Dieser Umstand scheint mir ein Hauptgrund für die Annahme einer Embryobildung olme vorausgegangene Befruchtung zu sein ... Ein Pollenschlauch wäre daher jetzt nicht mehr imstande, durch diesen vollständig geschlossenen Mantel von Sklerenchymzellen durchzukommen, man müßte denn annehmen, daß hier, wie in anderen Fällen, das Eindringen des Pollenschlauches zu einer Zeit erfolgte, in der die Samenanlage mit ihrem Eiapparat noch umvollständig entwickelt ist. Dagegen jedoch spricht wieder die Thatsache, dab einerseits zu dieser Zeit die Narben wenig entwickelt, jedenfalls noch nicht empfängnisfähig sind, andererseits das vollständige Fehlen von Pollenschläuchen auf gut ausgebildeten Narben, vor allem aber im Innern des Fruchtknotens, wo solche trotz der verschiedenartigsten zur Anwendung gelangten Färbungsmethoden nicht nachgewiesen werden konnten."

\section{Cornaceae.}

A ucuba. Im botanischen Garten zu München fand Eichler (1878. 1). 415. Amm. 3) Lucuba japonica ,immer mit wohlentwickelten Keimlingen, obgleich männliche Pflanzen nicht vorhanden waren". Er knïpft daran die Frage, ob wohl Parthenogenesis vorliegen möchte. Die Sache ist, obwohl die Angabe von einem so zuverlässigen Beobachter stammt, meines Wissens nicht geprïft worden. Doch gibt neuerdings L $0 \mathrm{mb}$ b rd-Dumas (1904) an, daß mämnliche Exemplare von Aucuba japonica gelegentlich auch einige weibliche Bliiten tragen. Wenn auch das Umgekehrte vorkäme. was bisher freilich noch nicht beobachtet worden zu sein scheint, aber natïrlich durchaus möglich ist. so wäre damit Eichler's Beobachtung vielleicht erklürt. Immerhin verdiente sie eine exakte Nachprüfung.

\section{Pirolaceae.}

Monotropa. Bei Monotropa hypopitys und M. uniflora ist es zwar nachgewiesen, daß sie bestäubungsbediurftig sind, und daß bei ihnen die Befruchtung regelmäßig und in duchaus typischer Form vor sich geht. Wir müssen sie indessen an dieser Stelle kurz erwähnen, weil bei Monotropa uniflora von Shibata (1902) Versuche ïber experimentelle Parthenogenesis angestellt worden sind. Die Versuche hatten in der Hauptsache negative Ergebnisse, es wurde nur (p. 712) „in einzelnen Fällen die Zweiteilung der vergrößerten [unbefruchteten] Eizelle beobachtet", ohne daß es aber gelang, die dabei wirksamen Faktoren näher zu präzisieren, oder gar die Weiterbildung der Eizelle zum Embryo zu veranlassen. 


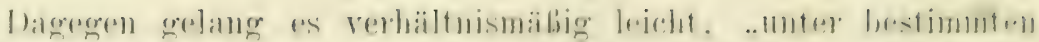

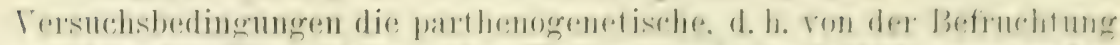

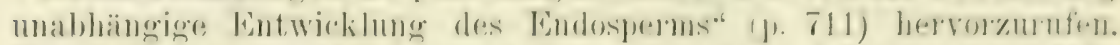
Damit ist experimentoll arecicht, was bei anderen loflanzen unter Lim-

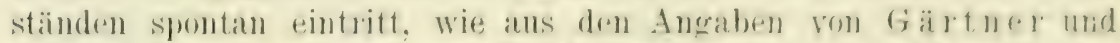

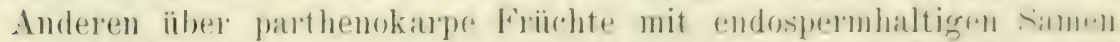
hervorgeht. Als parthenogenetischen Vorgang kamm man das ahere wrohl nicht betrachten. sondern muli darin einen sich an Gametophyten abspielenden mopagativen Prozel erblicken, der mit der Partlenegenesis nur das gemeinsam hat. dal. er mabhängig rom den sonst to forderlichen Finfliissen der Bestiubung und hernverschmelzung val sich geht.

\section{Myrsinaceae.}

Ardisiu. Verschiedene Arten der groben Gattung -1rolisin besitzen, wie schom Braun (1859, ]). 150) anfïhrt. Polyembryonie. J änsch (1905), der Ardisia crisya A. DC. cytologisch untersucht hat. gibt an, „daß der Fmbryo aus Zellen des inneren Integuments und der Chalaza hervorgeht", bemerkt aber (p. :30): „(ob) übrigens bei frotisin crispa die Eizelle, wo sie vorhanden ist, sich weiter zmm Embry entwickehn kam, erscheint nicht ganz ausgeschlossen. Eine bereits einmal geteilte Eizelle wurde in einem Falle bemerkt." Da eine liestäubung durch den übrigens ganz normal ausgebildeten, aber in Kulturversuchen nicht keimenden Pollen nicht stattzufinden sicheint. sich auch im Griffel oder der Mikropyle keine Reste vom Pollenschläuchen auffinden ließen. würde es sich also hier um einen, aller'dings der näheren Untersuchung noch dringend bedürftigen Fall von Parthenogenesis handeln.

\section{Asclepiadaceae.}

Vincetoxicum officinale L. Näher zu untersuchen bleibt auch noch das Verhalten von Vincetoxicum officinale, bei dem Polyembryonie sehr häufig ist. Sicher ist hier jedenfalls, daß Bestäubung der Fmbryubildung voraufgehen mub. C h a u v e a u d (1892) vermutet. dab die Polyembryonie bei Vincetoxicum officinale und mothum auf einer Befruchtung. der Synergiden und ev. der Antipoden durch die generativen Kerne des Pollenschlauches beruhe, deren ein jeder zwei bis fünf besitzt. Die nähere Untersuchung muß das aufhellen; in diesem Zusammenhange war der Fall nur mit anzuführen, weil unter Umständen eine durch die Bestäubung der Eizelle ausgelöste Apogamie der Sỵnergiden oder Antipoden vorliegen könnte. 


\section{Cucurbitaceae.}

Die Cucurbitaceen gehören zu den Familien, von denen seit alters her immer und immer wieder behauptet worden ist, es komme bei einigen ihrer Gattungen Parthenogenesis oder wenigstens Apomixis vor, ohne daß aber bis jetzt einwandfreie Beweise dafür vorlägen. Ich verweise hinsichtlich der älteren, teilweise außerordentlich unkritisch angestellten Versuche auf Gärtner (1844) und Regel (1859) und deren Kritik, und beschränke mich hier darauf, die neneren Angaben anzuführen.

Bryonia. Focke (1890) hatte bei einer isolierten weiblichen Pflanze von Bryonic dioice L. Ansatz von samenhaltigen Früichten beobachtet und daraus, wenn auch mit Torbehalt, auf Parthenogenesis geschlossen. Mit Recht galten aber seine Tersuche wegen des ungenügenden Schutzes gegen Bestäubung nicht als beweisend. Nun sind aber neuerdings die Versuche rou Bitter (1904) wieder antgenommen worden. und zwar mit positivem Erfolge. Er brachte (l. c., p. 101) eine weibliche Pflanze in ein Isoliergewächshaus und beobachtete, daß während der Hauptvegetationszeit alle ihre Blïten abwelkten, ohne Frucht anzusetzen. Erst gegen Ende der Vegetationsperiode kamen einzelne voll ausgebildete Beeren mit Samen zur Reife. von welch letzteren allerdings nur ein kleiner Teil keimfähig war und im nächsten Jahre neun Pflanzen lieferte, die alle männlich waren. wenigstens bis Ende Juli. Weitere Mitteilungen darïber hat Bitter bisher nicht gemacht, insbesondere steht auch noch die cytologische Untersuchung aus, so daß. falls die Tatsache an sich sich bewahrheitet. es immer noch zweifelhaft bleibt. ob Parthenogenesis, Apogamie oder' Propagation vorliegt. Unter keinen Umständen kann es sich jedenfalls um habituelle, sondern nur um fakultative Parthenogenesis handeln, die dann wohl auch zur Hauptvegetationszeit inducierbar sein müßte. Ich selbst erhielt übrigens bei einigen allerdings nicht sehr ausgedehnten Kastrationsversuchen mit Bryonic dioica im Jahre 1905 und 1907 auch gegen Ende der Vegetationsperiode keine Apomixis, sondern nur Ansätze zur Parthenokarpie, wie sie auch Bitter gelegentlich beobachtet hat. Da der Fall von Bryonic besonders wegen der eigentiumlichen Geschlechtsverhältnisse der apomiktisch entstandenen Keime spezielles Interesse bietet, ist zu wünschen, daß Bitter sich bald ansfühllich über seine weiteren Versuche und ihre Ergebnisse verlauten läßt. (Vgl. auch Correns 1907.)

Cucumis. Auch hier sei unter Übergehung der älteren, bei Gärtner und Regel behandelten Angaben gleich auf die nenesten Arbeiten hingewiesen. Die immer wieder auftauchende Behauptung. daß bei der Gurke anch ohñe vorhergehende Bestäubung normale Früchte mit keimfähigen Samen sich bilden könnten, schien durch die 


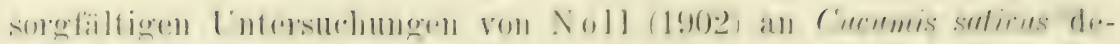

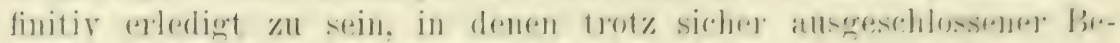

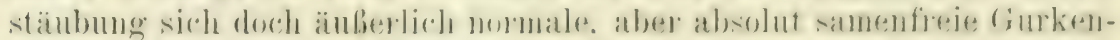

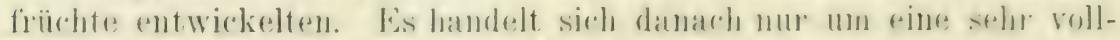
kommene Parthenokarpies, nicht aber auch Parthenogenesis. Com liocra

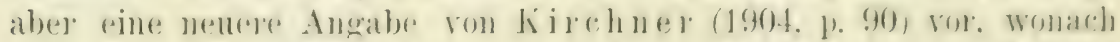

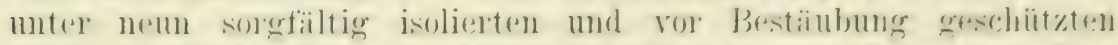

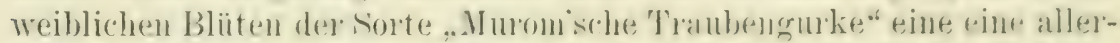

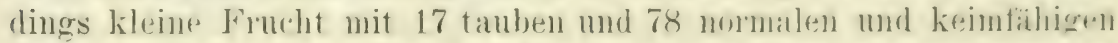
Samen geliefert hat. Da Noll mit anderen sionten experimentiert hat. mit .. Rytow's Gurke" und der .. (x)oben thollangengurke". so ist nicht unmö̈lich, dals dir rerschiedenen Befunde der beiden Forscher anf verschiedenes Verhalten der Sorten zurückzufïhren ist. Inch muls yor der Hand, ehe nicht Bestätigung mol die cytologische lintersuchung vorliegt, die Kirchner sche Angabe noch als unsichere gelten.

Drittes Kapitel.

\section{Die Apogamie.}

Apogamie hatten wir definiert als die apomiktische Entstehung eines Sporophyten aus vegetativen Zellen des Gametophyten. Es ist naturlich dabei prinzipiell bedentungslos. ob als Ausgangspunkt der sporophyten eine einzige Zelle oder ein Zellkomplex dient; beide Fälle kommen vor.

Apogamie in diesem Simne ist selbstverständlich nur möglich bei solchen Organismen, bei denen der Gametophyt mehrzellig ist; wo das nicht der Fall ist, wie bei manchen Fucaceen, den Tieren usw. da ist eben nur Parthenogenesis, nicht aber Apogamie möglich.

Da der Gametophyt normalerweise in seinen regetativen Zellen Tierne besitzt. denen die reducierte Chromosomenzahl zukommt. während für den sporophyten die diploide Chromosomenzahl das Normale ist. so sind, wenn die Entwicklmng von haploidelıromosomigen Gametophyten ansgeht, zwei Fälle denkbar: erstens kann die haploide Chromosomenzahl durchgehends beibehalten werden. so dab sie auch den Fernen des apogam entstandenen sporophyten zukommt. Das ist das. Was wir generative Apogamie genannt haben. Zweitens aber ist denkl)ar. daß durch irgendeinen Prozess ror, bei oder nach dem Beginn der Entwicklung des Sporophyten die Chromosomenzahl verdoppelt wird. Als solchen Torgang kemnen wir die Terschmelzung 
der Kerne derjenigen Gametophytenzellen, die den Sporophyten liefern, mit eingewanderten Kernen von Nachbarzellen. Da wir hierin zweifellos einen Vorgang erblicken müssen, der die normale Keimzellbefruchtung ersetzt, haben wir ihm als einen der Amphimixis wie der Apomixis gleichgeordneten VermehrungsprozeB von der Apogamie getrennt und Pseudomix is genannt.

Die eingehendere Behandlung der Psendomixis fällt auberhalb unseres 'Themas, so daß wir nur kurz an einem Beispiele erläutern wollen, wie die Psendomixis im einzelnen vor sich geht. Sie ist offenbar unter den Pteridophyten weiter verbreitet als wir bis jetzt wissen, und wurde auch bei einem Farn, Lastrea pseudo-mas var. polydactyla Wills zuerst entdeckt (von Farmer, Moore und Digby 1903). Die Kernwanderungen finden hier in Zellen der jüngeren
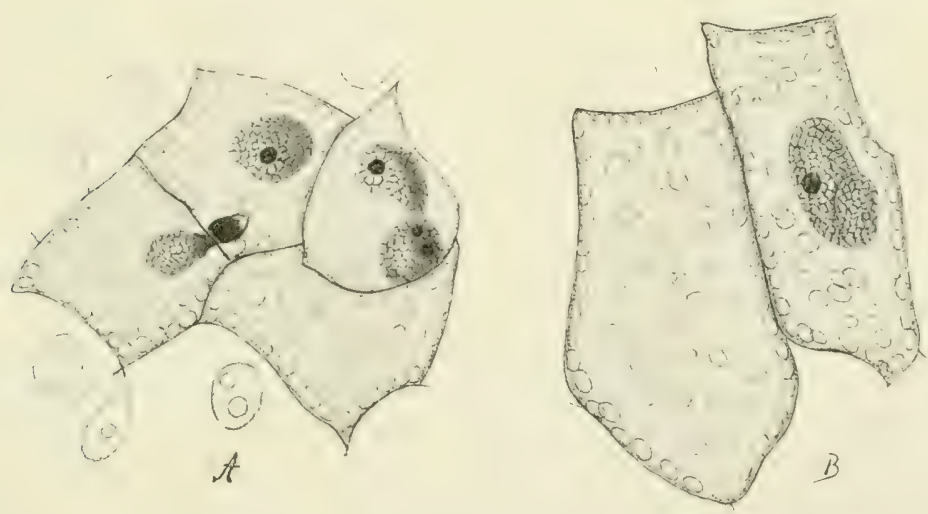

Fig. 6. Lastrea pseudomas var. polydactyla Wills. Pseudomixis. A. Kerniibertritte in verschiedenen Stadien. B. In der eimen Prothallinmzelle findet die pseudomiktische Kernverschmelzung statt; daneben die entleerte Nachbarzelle, die den iibergewanderten Kern geliefert hat.

(Nach Farmer und Digby 1907, Taf. 19, Fig. 46 und 50.)

Teile des Prothalliums statt, und zwar derart, daß der Kern der einen Zelle sich durch eine feine Pore in die Nachbarzelle hiniiberzwängt, um hier sofort oder nach einiger Zeit mit deren Kern zu verschmelzen. Da jeder Kern für sich haploidchromosomig ist, so ist damit wie nach der normalen Befruchtung ein Kiern hergestellt, der die für den Sporophyten normale Chromosomenzahl besitzt, eine notwendige Konsequenz des ganzen Vorganges, iiber deren tatsächliches Eintreten sich Farmer und Digby (1907, p. 177) anch durch Zählungen vergewisserten. Damit ist also sichergestellt, daß im Entwicklungsgang der pseudomiktischen Organismen derselbe periodische Wechsel zwischen einer haploiden und einer diploiden Generation beibehalten wird, wie er bei der normalen Amphimixis stattfindet. 
Fiir die Apogamie dagegen ist charakteristisch, dab bei den

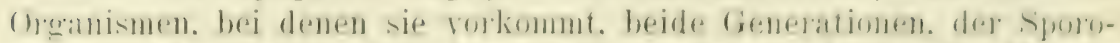

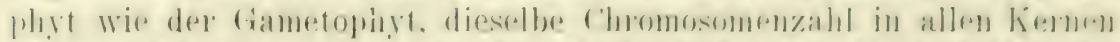
führen. Das kann mun entweder die haphoide onder die diphoide soin.

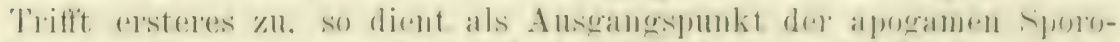
flytenhildung oin momal haploides Ponhallimn. ein Fall. den wif

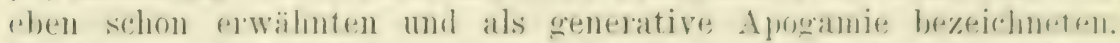
Ist dagegen die diphoide ('hromosomenzahl diejenige. die während dm ganzen Entwicklungsganges beibehalten wird. so muls ein fon vormherein diphoidehromosomiger Gametophyt rolhanden sein. und es liegt somatische Apogamie vor.

Bei der generativen Apogamie wäre es iibrigens nicht molenkhar, daß die haploide (hromosomenzahl nicht in gesamten Entwirklungszyklus beibehalten würde. sondern daß. nachdem die Entwicklung des sporophyten mit der haploiden (hromosomenzahl eingesetzt hat. nachträglich in seinen Zellen eine regenerat ive Verdoppelung der (hromosomenzahl einträte. Ein solcher Fall ist zwar niclit bekannt, sein Torkommen ist auch nicht sehr wahrscheinlich, aber theoretisch nicht ansgeschlossen. Tritt diese Chromosomenverdoppelung gleich bei der ersten Teilung der Ifutterzelle des Sporophyten ein. etwa derart, daß sich deren Kern teilt, daß aber der Kernteilung keine Zellteilumg folgt, sondern ein Wiederverschmelzen der Tochterkerne. so wäre das ein Torgang. der in gewisser Hinsicht einen Ühergang zur Psendomixis darstellte. und der vor allem an die Parthenomixis erinnern und sich zu dieser verhalten wïrde. wie die Apogamie zur Parthenogenesis, so dab man ihn etwa als somatugene Parthenomixis der vogenen gegeniiberstellen kömnte. bei welch letzterer die Zelle. innerhalb deren die Fernfusion eintritt. eine Fizelle ist. Während es bei der somatogenen eine regetative Kïrperzelle ist. Ehe indessen solche Fälle nicht bekamnt sind, hat es wenig Zweck. diese Beziehungen eingehender zu erörtern.

Ebenso kömnte auch umgekehrt bei somatischer Apogamie nachträglich, etwa bei der sporenbildung, eine Reduktionsteilung eingteschaltet werden. Anch dafïr aber fehlt es vorerst an Beispielen.

\section{A. Somatische Apogamie.}

Als somatische Apogamie bezeichnen wir also denjenigen Modus der Apogamie. bei dem die Intterzellen des Sporophyten regetative mit diploidchromosomigen Kernen ausgestattete Zellen des Gametophyten sind. Da num aber normalerweise die Zellen des Gametophyten stets die reducierte Chromosomenzahl besitzen, so ist ersichtlich, daf die somatische Apogamie immer mit einem anomalen Tor- 
gang verknïpft sein mub, der für den Gametophyten die Folge hat, daß die Kerne seiner Zellen die diploide Chromosomenzahl anstatt der haploiden erhalten. Es mus mit anderen Worten die Reduktionsteilung unterbleiben.

Ein solcher Vorgang ist denn auch in der längst von Farnen und Moosen, netrerdings auch von Phanerogamen bekannten und vielleicht auch bei Thallophyten vorhandenen A posporie gegeben. Diese besteht darin, daß der Gametophyt nicht wie gewöhnlich ans einer Spore entsteht, deren Kern die haploide Chromosomenzahl führt. sondern dadurch, daß eine oder mehrere vegetative Zellen des Sporophyten, deren Kerne mit der unreduzierten Chromosomenzahl ausgestattet sind. ummittelbar zu einem nun natürlich auch diploidchromosomigen Gametophyten auswachsen. Es mub indessen bemerkt werden, daß die Aposporie auch zur Entstehung normal haploidchromosomiger Gametophyten führen kann, dann nämlich, wenn abnor'merweise der Sporophyt durchgängig die reducierte Chromosomenzahl besitzt. wie das z. B. bei dem generativ apogamen Nephortum molle der Fall ist. Auch kann sich die Aposporie natürlich ebensogut wie mit Apogamie mit Parthenogenesis kombinieren, wie das bei Hieracium von Rosenber $g$ beobachtet wurde.

Es ist wahrscheinlich, dal.j die Beziehungen zwischen somatischer Apogamie und Aposporie sehr enge sind, da die erstere ja ohne die letztere nicht denkbar ist, denn für sie ist das Vorhandensein eines diploidchromosomigen Gametophyten Torbedingung. und ein solcher kann nur durch Aposporie entstehen, oder aus Sporen, die bei sonst typischer Sporangienentwicklung durch Ausschalten der Reduktionsteilung mit der diploiden (hromosomenzahl versehen worden sind. Und zwvar wird man annehmen müssen, daß die Aposporie der primäre Vorgang ist, dem sie ist ohne Apogamie. diese aber nicht ohne Aposporie denkbar. Die somatische Apogamie an sich muß ja durchaus nicht etwa notwendig Aposporie nach sich ziehen, da sie einen normalen Sporophyten mit typisch diploider Chromosomenzahl ergibt, der ohne weiteres die Reduktionsteilung bei der Sporenbildung durchführen kömnte. Nur würden dann eben keine diploiden Gametophyten wieder entstehen, und damit wäre die somatische Apogamie unmöglich geworden. Andererseits ist freilich auch zu bedenken, dab die Aposporie ihrerseits nicht notwendig Apogamie (oder Parthenogenesis) zur Folge haben muß, da ja bei der Entstehung der Eier und Spermatozoen eine Reduktion stattfinden und dann Amphimixis eingreifen könnte, und da wir auch den diploidchromosomigen Eiern und Spermatozoen der apospor erzeugten Gametophyten die Fähigkeit zur Amphimixis nicht ohne weiteres absprechen können: nach ihrer Verschmelzung könnte durch eine Reduktionsteilung die diploide Chromosomenzahl wiederhergestellt werden. Immerhin wird man es als sehr wahr- 


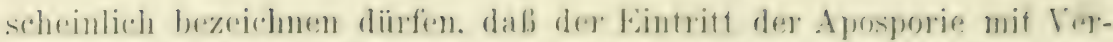

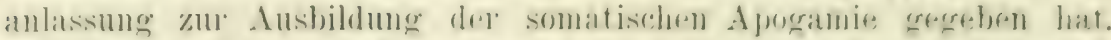
Vielleicht wird es möglich sein, experimentell die bezir.ungen atufzuhellen. die zwischen den beiden brscheinumen bestehen, nachdem foebel (1907) grezeigt hat. dab man bei manchen farnen dadurch Aposporie künstlich hervorufin kann, daf man junge keimblatter von sporophyten zo regenerativer Prothalliumbildung verandalit. All das gilt natiorlich anch für den Fall. dab nicht Aposprere sonderm das Unterbleiben der Reduktion bei sonst typisch verlaufender Sporenbildung als Mittel benutat wird. den kermen des Gametophytan die diploide Chromosomenzahl zu verleihen.

Thullophytew. Lnter den Thallophyten scheint Aposporis und damit anch somatische Ajogamie nicht vorzukommen. In den zulsammenfassenden Werken ron $01 \mathrm{t}$ man 11 s 11905$)$ und Lotsy (1907. sowie in der spezialliteratur. soweit sie mir bekannt ist. wird wenigstens nichts über Aposporie bei Algen oder Pilzen angegeben. Denkbar wäre sie aber wohl. etwa bei Organismen wie Dirtyota, wenn bei ihnen während der Tetrasporenbildung die Reduktionsteilung unterbliebe und aus der diploidchromosomigen spore ein diploidchromosomiger Gametophyt entstiunde, der dann seinerseits bei der Regeneration aus Thallusstiicken wieder eine Tetrasporenpflanze lieferte. Der letztere Vorgang wäre als somatische Apogamie anzusehen. Wir werden später in dem Kapitel äber die Beziehungen zwischen Apomixis und Generationswechsel noch auf die Müglichkeit eines solchen Vorganges kurz zurückzukommen haben.

Bryophyten. Bei dem Lebermoos Anthoceros laevis hat Lang (1901) einen Fall ron Aposporie beschrieben, der bisher der einzige unter den Hepaticis geblieben ist. Dagegen ist unter den Laubmoosen das regenerative Entstehen von Gametophyten aus sporophytengewebe häufiger beobachtet worden (vgl. die p. 3:) citierten Angaben). Da der Gametophyt hier sehr wahrscheinlich diploidchromosomig ist, so ist die Möglichkeit ins Ange zu fassen, dab isolierte Teile von ihm Sporophyten aus Blatt-oder Stengelzellen regenerieren kümnten. Dieser Vorgang wäre damn als somatische Apogamie anzusehen. Es wïre erwünscht. dab die apospor entstandenen Moospflänzchen daraufhin näher untersucht wïrden. -

Während so das Bestehen ron somatischer Apogamie bei Thallophyten und Bryoplyyten zwar keineswegs als unmöglich, aber auch nicht gerade als sehr wahrscheinlich bezeichnet werden kann, liefern uns die

Pteridophyten mehrere genau festgestellte Beispiele dafür. . Ta es darf wohl als wahrscheinlich angesehen werden, daß die Mehrzahl der ron Pteridophyten ïberhaupt bekamnten Fälle ron Apogamie hierhergehören. Sicher sagen läßt sich das aber natürlich nur ron 
solchen Formen. die genau cytologisch untersucht sind, und das sind vorerst nicht allzuviele.

Athyrium Filix-foemina var. clarissima Jones. Diesel von Farmer und Digby (1907, p. 163) genauter untersuchte Fam bildet an den Wedeln aus einer peripher gelegenen Zelle des sporangiums, also apospor; ein Prothallium. das typisch gebatut sein, aber auch Abweichungen ron der normalen Gestaltung aufweisen kann. auf deren nähere Schilderung wir indessen hier rel'zichten müssen. Bemerkenswert und durch zahlreiche C'hromosomenzälılungen der Autoren über allen $/$ Treifel sichergestellt, ist. dab bei der apogamen Entstehung des Prothalliums keine Reduktion der Chromosomenzahl stattfindet, so daß also der apogam entstandene Gametophyt hier die diploide ('hromosomenzahl, etwa 90, besitzt. Auch für die durchaus normal gestalteten Prothallien gilt das. An diesen werden num normale Antheridien und Archegonien gebildet, in welch letzteren allerdings gewöhnlich die Eizelle verhältnismäßig frihzeitig abortiert. Die Spermatozoen dagegen kommen zur fertigen Ausbildung. ohne dab auch dabei eine Reduktionsteilung stattfände. so dab wir diploidchromosomige Spermatozoen erhalten. Diese sind durchaus typisch geformt, nur — den Regeln der Kernplasmarelation entsprechend ïbernormal groh; sie sind lebhaft beweglich und werden durch reife Archegonien angelockt. sind also normal chemotaktisch empfindlich. Trotzdem kommt niemals eine Befruchtung zustande. schon deswegen nicht, weil eben das Ei meistens frühzeitig zugrunde geht. An dem Prothallium aber entsteht nichtsdestoweniger ein Embryo, und zwar durch Ausknospen einer Anzahl regetativer Prothalliumzellen. die gewöhnlich dem Scheitel des meistens knollenförmig gestalteten Gametophyten genähert liegen. Da die Zellen, die dem zum Sporophyten auswachsenden Embryo den Lrsprung geben. Kerne besitzen. die mit der diploiden Chromosomenzahl ausgestattet sind, so handelt es sich in diesem Falle also in der Tat um somatische Apogamie.

Bisher ist zwar Athyrium Filix-foemina var. clarissima Jones der eimzige Farn. von dem die cytologische Untersuchung somatische Apogamie ergeben hat; man wird indessen rermuten dürfen, daß solche in sehr vielen ron den Fällen eintritt, wo sich bei Pteridophyten Aposporie mit Apomixis kombiniert. Ebensogut könnte, rorauf schon hingewiesen wurde, in diesem Falle freilich auch generative Apogamie oder aber somatische oder generative Parthenogenesis in Betracht kommen. und es kann natiirlich nur durch die cytologische Untersuchung ron Fall zu Fall entschieden rerden, welche der erwähnten Apomixis-Arten eingeschlagen worden ist. Ist die Apomixis aber nicht mit Aposporie verbunden, das Prothallium also auf dem normalen Wege aus einer die reduzierte Chromosomenzahl führenden Spore hervorgegangen, so kanm es sich natürlich nur 


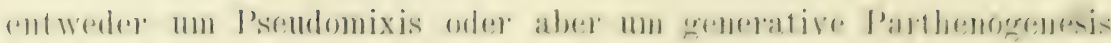
oder Apogamie handeln.

Phancrogamen. Auch von einigen wenigen Phanerogamen ist somatische Apogamie bekannt.

sie ist hier gunachst denkbat als Ausmahmefall bei Pflanzen mit somatischer Parthenogenesis derart, dab ein bimbryo anstalt ans der Eizelle ans einer synergide oder Antipode entsteht. Wobei wir

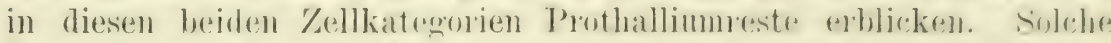
Synergiden- und Antipodenembryonen kommen ja bei manchen polyembryonaten Phanerogamen vor, unter den

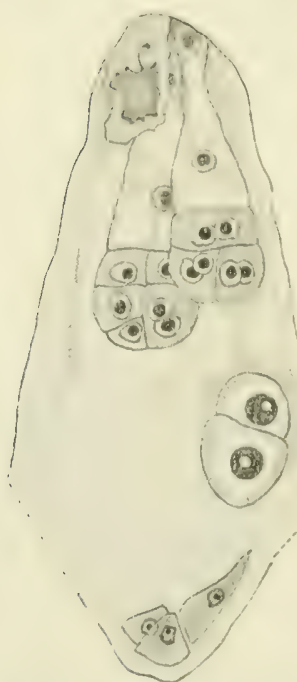

Fig. 7. Alchimilla sericata Rehb. Apogame und parthenogenetische Embryobildumg nebeneinander.

Erklärung im Text. (Nach Murbeck 1902, Fig. 4.) parthenogenetischen Pflanzen ist es aber wohl allein Ichimillu, bui der als gelegentliche Ausmahme somatische Apogamie berobachtet worden ist. Murbeck (1902, p. 4) beschreibt einen solchen Fall bei der somatisch parthenogenetischen Aldhimillu sericuta Richb. (vgl. Fig. 7).

Wie man sieht, sind hier im Embryosack zwei nebeneinander inserierte Embryonen vorhanden, und es kann nicht zweifelhaft sein, daß der eine aus dem Ei, der andere aus der einen Synergide hervorgegangen ist. Der Antipodenapparat ist normal entwickelt, die zweite Synergide schon halb verschleimt. Wir haben also hier neben dem somatisch-parthenogenetisch aus dem Ei entstandenen Keilis einen zweiten Embryo, der somatisch-apogam entstanden ist, da er aus einer vegetativen. diploidkernigen Zelle des Gametophyten ohne Befruchtung erwachsen ist.

Während aber, wie schon erwähnt, dieser Modus der somatischen Apogamie bisher ganz vereinzelt dasteht, ist ein anderer innerhalb der merkwürdigen Familie der Balanophoraceen offenbar weiter rerbreitet. Hier wurde die somatische Apogamie durch die Untersuchungen von Treub (1898) an Balanophore clongata Bl. sichergestellt, und seine Resultate sind von Lots y (1899) durch Forschungen iiber Balanophora globosa $\mathrm{J} u \mathrm{ng}$ h. durchaus bestätigt worden, während schon vor Treub van Tieghem (1896) für Balanophora indica Wall. an allerdings vielleicht ungenïgend fixiertem Material Befruchtungsbedürftigkeit konstatiert hatte.

Bei Balanophora elongata geht zunächst die Entwicklung des Gametophyten normal vor sich bis zum Stadium der Achtkernigkeit 
(rgl. Fig. 8 auf folgender Seite). Die acht Lerme sind wie üblich in zwei Tetraden an den Polen des scharf umgekrümmten Embryosacks angeordnet. von denen die den Eiapparat enthaltende die polare, die andere die antipolare Tetrade genannt sei. Die letztere geht stets friulnzeitig zugrunde, ohne dab es auch nur zur Ausbildung von Antipodenzellen gekommen wäre. Auch der ganze Eiapparat abortiert sehr bald schon. nachdem er sich individualisiert hat, und so bleibt einzig und allein der polare Polkern iibrig, der sich von vornherein durch seine beträchtliche Größe von den anderen Kernen der polaren Tetrade unterscheidet.

Aus ihm nun entwickelt sich, und zwar ohne daß vorher eine Terschmelzung mit dem um diese Zeit schon abortierten antipolaren Polkern stattgefunden hätte, ein ziemlich groß- und wenigzelliges Gewebe. das natiulich als Endosperm, als Prothallium aufzufassen ist. Tnd num wird eine central gelegene Zelle dieses Endosperms zur Embryomutterzelle. Der ganze Torgang spielt sich ab, olne daß Befr'uchtung oder auch nur Bestäubung vorhergangen ist. Balanophor globosa .T ungh. verhält sich nach Lotsy (1899) in allen Einzelheiten ebenso. Es kommt bei ihr dazu. daß männliche Exemplare auf großen Gebieten, wo die weibliche Pflanze sehr häufig und durchaus fertil ist, gar nicht mehr vorkommen. Während Balanophora elongata noch in vielen männlichen Individuen vorhanden ist.

Auch die ebenfalls zu den Balanophoraceen gehörige Helosis mnyanensis Rich. schliebt sich in ihrer Embryobildung nach Chodat und Bernard (1900) durchaus an Balanophore elongata an. Dagegen liegen die Dinge bei der Balanophoracee Rhopalocnemis phalloides J $u n g h$. nach den Untersuchungen von Lotsy (1901) anders, so daß die Treub'schen Befunde bei Balanophora elongata nicht etwa als trpisch für die Balanophoraceen überhaupt gelten können, nebenbei bemerkt ein Hinweis darauf, daß nicht etwa die eigenartige parasitische Lebensweise der Familie direkt mit der eigenartigen Fortpflanzungsweise verkniipft ist. Rhopalocnemis phatloides also bildet ïberhaupt nur äußerst selten Samen aus; wenn das aber geschieht, so spricht alles dafür, daß der Embryo ans der normal befruchteten Eizelle hervorgeht. Bleibt die Befruchtung aus, so stirbt die ganze weibliche Blüte ab, nachdem imnerhalb des Embryosackes die Entwicklung nicht weiter als bis zur Bildung des primären Endospermkernes gegangen war. Lotsy bemerkt zwar (1. c., p. 90), ,that no parthenogenesis occur's has not been proved", doch sprechen seine Befunde fast zwingend für die Notwendigkeit der Befruchtung zur Embryobildung.

Auch die ja wenigstens früher allgemein zu den Balanophoraceen gestellte Gattung Cynomorium ist nach Pirotta und Longo (1901) und Juel (1903) normalsexual. 

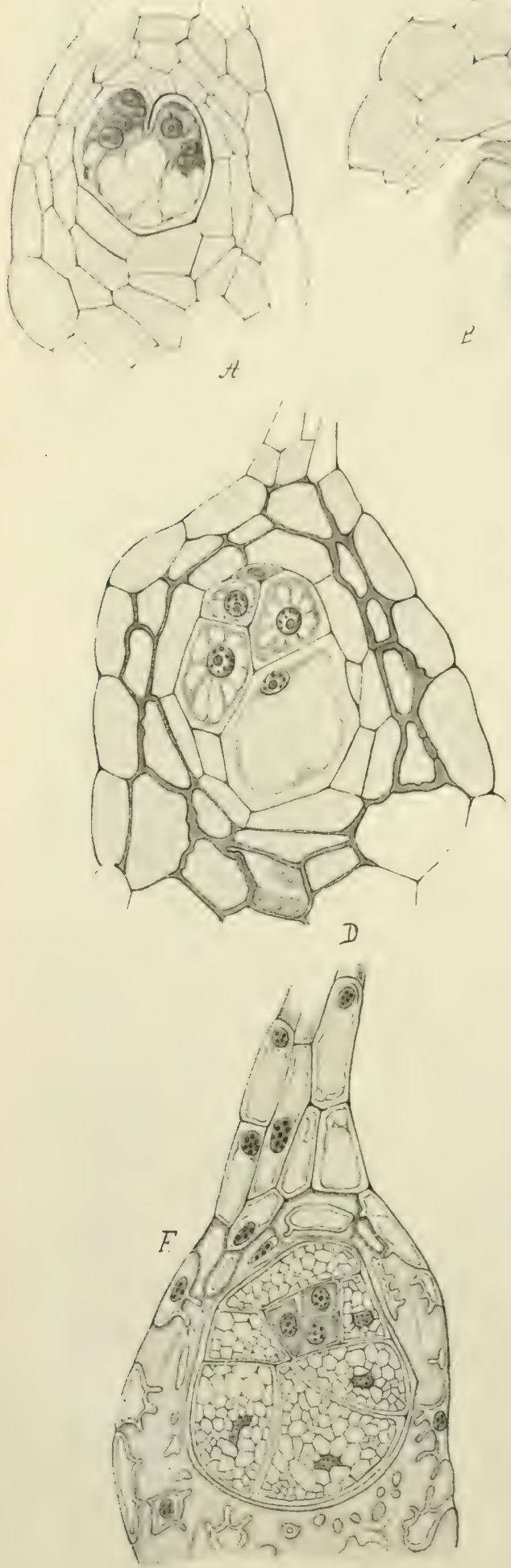
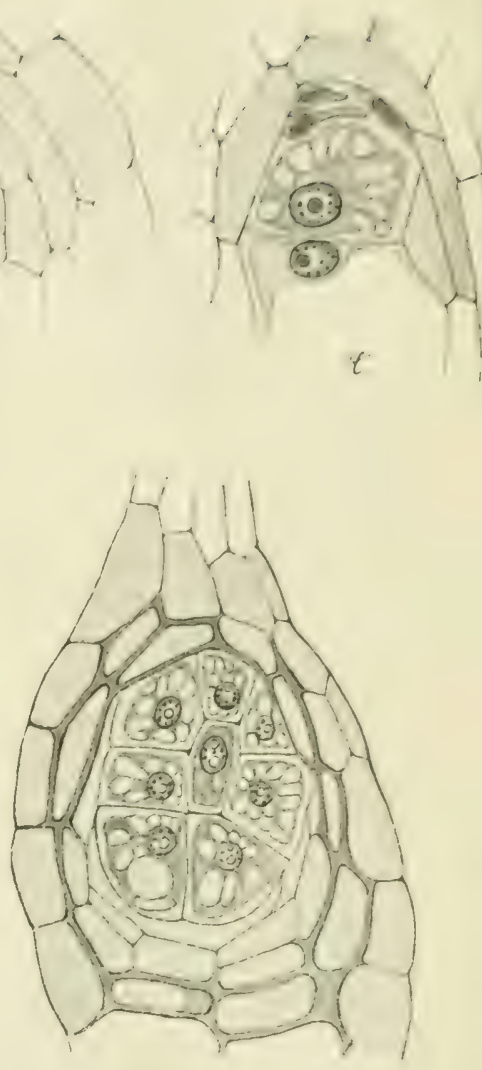

己

Fig. 8. Balanophora elongata Bl. A. Der gekriimmte Embryosack enthält acht Kerne. - B. Der Eiapparat im Begriff zu desorganisieren; links das Ei, rechts die beiden Synergiden übereinander. - C. Der Eiapparat völlig desorganisiert; die beiden ersten Endospermzellen gebildet. - D. Endosperm mehrzellig. Oben noch eine Zelle des Eiapparates erkenmbar. - E. Fast die ganze Embryosackhöhlung mit Endosperm erfüllt; im Centrum die Embryomutterzelle. - F. Reifer Same mit mehrzelligem. in das Eudosperm eingebettetem Embryo.

Nach Treub 1898. A: Taf. 5, Fig. 3.

B: Taf. 5, Fig. 11. C: Taf. 7, Fig. 1.

D: Taf. 7, Fig. 10. E: Taf. 8, Fig. o. F: Taf. 8, Fig. 12.) 
Für alle die erwähnten apogamen Balanophoraceen muß übrigens noch untersucht werden, ob bei ihnen im Verlanfe der Makrosporenentwicklung eine Reduktionsteilung durchgeführt wird oder nicht. Die bisherigen Untersucher äußern sich darïber nicht, doch muß es auf Grund der von ihnen gegebenen Abbildungen, wie schon $J$ uel $(1900$, p. 41) bemerkt, als sehr wahrscheinlich gelten, dab die Reduktionsteilung unterbleibt, so daß also alle Kerne des Embryosacks die diploide Chromosomenzahl führen. Sollte aber, was theoretisch natïrlich nicht ansgeschlossen ist, doch eine Reduktionsteilung vor sich gehen, die Elemente des Embryosacks also haploidchromosomig. sein, so wäre die Apogamie der Balanophoraceen nicht als somatische, sondern als generative aufzufassen. Eine solche könnte übrigens auch dann vorliegen, wenn die Reduktion deshalb unterbliebe, weil schon der Sporophyt nur haploidehromosomig ist. Es müßte also unter allen Umständen durch den Vergleich mit der Vikrosporenentwicklung festgestellt werden, ob der Sporophyt haploid- oder diploidchromosomig ist. Der Nachweis also, daß die Reduktion ausgeschaltet wird, berechtigt noch nicht zu der Schlußfolgerung; daß die danernd beibehaltene Chromosomenzahl die diploide sei; diese Schlıßfolgermug ist vielmehr erst dann berechtigt, wenn gleichzeitig nachgewiesen wird, daß bei der Mikrosporenentwicklung tatsächlich eine Reduktion der Chromosomenzahl erfolgt. Unterbleibt diese aber auch bei der Pollenentwicklung, so wäre daraus zu folgern, daß der ganze Entwicklungsgang der Pflanze mit der haploiden Chromosomenzahl durchgemacht wird, und dies Verhalten wäre im vorliegenden Falle als generative Apogamie aufzufassen. Ehe solche genaue Untersuchungen nicht vorliegen, läßt, sich natürlich auch keine definitive Entscheidung geben. Immerhin wird man es aus verschiedenen Gründen vorläıfig für wahrscheinlicher halten dürfen, daß somatische, als daß generative Apogamie vorhanden ist, weshalb wir eben auch die Balanophoraceen in diesem Kapitel mit behandelt haben.

\section{B. Generative Apogamie.}

Generative Apogamie liegt vor, wenn aus einer vegetativen Zelle des Gametophyten, der in allen seinen Kermen die für den Gametophyten normale haploide Chromosomenzahl führt, direkt, ohne vorhergehende pseudomiktische Kernverschmelzung ein Sporophyt entsteht. Dabei sind wie bei der generativen Parthenogenesis theoretisch zwei Fälle zu unterscheiden, je nachdem nämlich bei der Entwicklung des apogam entstandenen Sporophyten die Chromosomenzahl regenerativ verdoppelt wird oder nicht (vgl. p. 60). Im ersteren Falle würde sich also der Entwicklıngsgang mit periodischem Wechsel der Chromo- 
smmenzahl vollzichen. in letgteren Falle bliebe diene immer komstant dire haploide. Alle bisher hekannten Fille von generativer Apoganie haben die zweite der beiden Mïrlichkeiten rerwirklicht, regenerieren also die diploide Chromosomenzahl nicht.

Bei den Momsen. die ja einen sehr regenerationsfahlogen viedzelligen Gametophyten besitzen, ist kein Vorkommen von gesenatives Apogamie bekamnt. Fs wirde vorliegren, werm etwa alls einem iscolierten regenerierenden Moosblatt ummittelbar ein suorogon ento tinde. Wenn aber Teile des Monsanetophyten. der in dieser Hinsisht ja ziemlich genau untersucht ist. überhaut regenerieren. so bilden sie stets wieder (iametophytengewebe, nie aber nmittelbar einen Sporophyten.

Dagegen liefern uns die Pteridophrten Beispiele generativer Apogamie. Bisher sind allerdings mit Sicherheit nur ihrer zwei bekannt geworden, die kurz angeführt seien.

Lastrea pseudomas var. cristata apospora Druery. Abgeschnittene Wedel dieses Farnes bilden nach F a rmer und Dighy 1907, p. 180) reichlich Prothallien durch Aposporie: die Prothallien entstehen also nicht aus keimenden Sporen, sondern direkt aus Blattrellen, die gewöhnlich der Spitze eines Fiederchens angehören. An diesen mehr oder weniger trpisch herzförmig gestalteten Gametophyten entstehen Antheridien reichlich, niemals dagegen Archegonien. Trotzdem entsprossen ihnen Embryonen, die aus einer unmittelhar hinter dem Tegetationspunkt gelegenen Zellgruppe entstehen, also apogam. Eine Reduktion der Chromosomenzahl findet während des ganzen Entwicklungsgangs sicher nicht statt, weder bei der aposporen Prothalliumbildung noch auch bei der Spermatozoenentricklung in den Antheridien. Auch pseudomiktische Kernverschmelzung ist nicht zu beobachten. So bleibt im ganzen Lebenszyklus des Farnes die Chromosomenzahl in allen Kernen, sowohl des Gametophyten als des Sporophyten, konstant 60.

Was num hier die Vermutung; daß generative Apogamie rorliegt, daß also der ganze Entwicklungsgang hier mit der haploiden Chromosomenzahl durchgemacht wird, fast zur Gewißheit erhebt, ist die Tatsache, daß bei der typischen Lastrea pseudo-mas die reducierte Chromosomenzahl 72, die diploide also 144 beträgt. Cnd da auch bei den anderen, nicht generativ apogamen Tarietäten ron Lastrea pseudomas die Chromosomenzahl im Sporophyten immer wenigstens über 100 beträgt, so ist die Annahme gewiß gerechtfertigt, daß auch bei der var. cristate "pospora die diploide Chromosomenzahl etwa 120 sein diirfte, daß also der apogam entstandene Sporophyt in der Tat nur die haploide Chromosomenzahl in seinen Kernen führt.

Nephrodium molle Desv. Noch beweisender für das tatsächliche Torhandensein generativer Apogamie ist das ron Yama- 
nouchi (1907) bisher nur in einer kurzen vorläufigen Mitteilung geschilderte Verhalten von Nephrodium molle Desv.

Man findet bei diesem Farn nebeneinander sexuell und apogam entstandene Sporophyten, die sich äußerlich in keinerlei Weise unterscheiden. In den Prothallien von beiden betrug die Chromosomenzahl in allen Kernen 64 oder 66 , und diese Zahl wird bei den sexuell entstandenen Sporophyten natiurlich durch die Befruchtung auf 128 oder 132 erhöht. Bei den apogamen Prothallien dagegen, an denen zwar zahlreiche Antheridien mit normal beweglichen Spermatozoen, aber keine Archegonien entstehen, werden Prothalliumzellen direkt ohne psendomiktische Kernverschmelzung oder regenerative Verdoppelung der Chromosomenzahl zum Embryo, so daß also der apogam entstandene Sporophyt nur haploidchromosomig, dabei aber äußerlich völlig gleich dem diploidchromosomigen sexuell erzeugten Sporophyten ist. In diesem Falle kamn es also nicht dem geringsten Zweifel unterliegen, daß generative Apogamie vorliegt.

Die beiden eben geschilderten Fälle sind bisher die einzigen sichergestellten Beispiele für generative Apogamie im Pflanzenreiche. Doch läßt es sich wohl kaum bezweifeln, daß sich gerade unter den Pteridophyten noch andere finden werden. Sind doch von den sehr zahlreichen apogamen Farnen erst sehr wenig bisher genaner cytologisch untersucht. Aber selbst wenn sie vereinzelt bleiben sollten, genügten sie vollständig zur Feststellung der prinzipiell sehr wichtigen Tatsache, $d a b d u$ rehaus normal gestaltete Sporophyten mit durchweg haploidchromosomigen Kernen möglich sind. Man kann hiernach jedenfalls das Bestehen generativer Apogamie und Parthenogenesis auch bei höheren Pflanzen nicht mehr für unmöglich oder auch nur für unwahrscheinlich halten, wie das z. B. Strasburger (1907, p. 166) tut.

Ob tatsächlich bei höheren Pflanzen generative Apogamie vorkommt, ist noch unentschieden, wenn auch darüber noch nicht viel Untersuchungen vorliegen. Möglicherweise gehören die Fälle hierher, wo sich Embryonen ohne Befruchtung aus Synergiden oder Antipoden bilden. Diese sind ja vegetative Zellen des Gametophyten, und wenn aus ihnen ohne vorhergehende Amphi- oder Pseudomixis Sporophyten entstehen, so läge, da sie ja normalerweise haploidchromosomige Kerne besitzen, generative Apogamie vor.

Am besten bekannt ist hier durch die Untersuchungen von Tretjakow (1895) und Hegelmaier (1897) das Verhalten des polyembryonaten Allium odorum L., bei dem innerhalb des normal gestalteten Embryosackes nach erfolgter Befruchtung der Eizelle, und nur dann, sich eine, zwei oder alle drei Antipoden zu Embryonen entwickeln. Es ist dabei durch beide Forscher konstatiert, daß der Pollenschlauch sich nicht weiter hinab als bis zum Eiapparat bewegt 


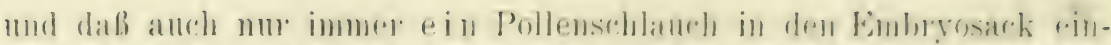
tritt. so dali es sich also nicht etwa un eine Befmehtume der Antipoden handeln katm. Wie sie somst wohl gelegentlich vorkommurn mag.

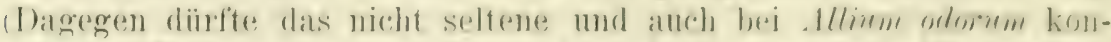

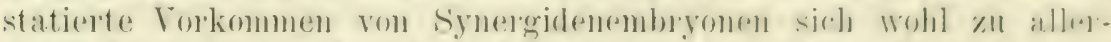

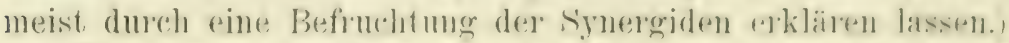

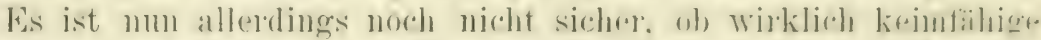
Pflänzchen ans diesen Antipodenembryonen lonsorgehen kïnum. Nach If egelmaier entwickehn sich die Antipodenkeine niemals sehr weit, währenl 'l'retjakow angibt. solche in schen seln weit fortgeschrittenem Stadium gesehen zu haben. Der Fall rerdiente pine ernente ['ntersuchmo mit spezieller Berieksichtigung der rotrolugischen Verhältnisse. Solange diese noch nicht vorliegt. ist man anf Vermutungen angewiesen, wird aber immerhin nit einiger Wahnscheinlichkeit ammehmen dürfen. dab die Entwicklung des trametuphyten normal vor sich gegangen ist, daf also eine Reduktionsteilung stattfand, und die Antipoden somit haploidchromosmig sind. E. lïgen damn hier also tatsächlich wenigstens die Anfänge zu einer generativ apogamen Entwicklung vor.

Viertes Kapitel.

\section{Die Parthenogenesis.}

Parthenogenesis ist die apomiktische Entstehnng eines sporuphyten aus einem Ei. Wie bei der Apogamie haben wir auch bei der Parthenogenesis eine somatische und eine generative Modifikation zu unterscheiden, je nachdem das unbefruchtete Ei, das sich zum Sporophyten entwickelt, einen Kern mit der diploiden oder mit der haploiden Chromosomenzahl besitzt. W'ir sehen auch dam. wemn der Keimzellkern mit der unreducierten Chromosomenzahl ausgerïstet ist. in dieser Keimzelle ein Ei oder ein Spermatozoon. eine Auffassung: die nicht ron allen Forschern geteilt wird. Doch müssen wir den Nachweis für die Richtigkeit unserer Auffassung einem späteren Kapitel vorbehalten.

Die Zahl der Fälle echter Parthenogenesis, die noch bis ror wenigen Jahren sehr beschränkt war, hat sich durch die Lntersuchungen der letzten Zeit auffällig erhöht. und man wird ohne weiteres vermuten dürfen, daß sich auch noch mehr Pflanzen als parthenogenetisch erweisen werden. Sind doch bisher begreitlicher- 
weise noch verhältnismäßig wenig Gewächse ganz genan auf ihıe Fortpflanzungsverhältnisse hin untersucht worden. Tmmerhin wird die Parthenogenesis stets als im allgemeinen nicht häufiger Ausnahmefall anzusehen sein, wenigstens was die habituelle Parthenogenesis anbelangt; inwieweit etwa die normal amphimiktischen Pflanzen unter gewissen Beding ungen experimentell zu kiunstliches: Parthenogenesis veranlabt werden kümnen, ist natiirlich eine andere Frage. Jedenfalls ist zur exakten Entscheidung der Frage, ob bei einer bestimmten Species Parthenogenesis vorliegt resp. möglich ist oder nicht, durchans ilıre experimentelle und cytologische Behandlung. nötig. Denn wie wenig hier die biologische Beobachtung allein sichere schlubfolgerungen zu ziehen gestattet, geht aus der überraschenden Feststellung 7. B. hervor, daß der Löwenzahn habituell parthenogenetisch ist, eine Pflanze, bei der man das auf Grund unzähliger Beobachtungen iiber den sehr zahlreichen Insektenbesuch und die regelmäBig dabei stattfindende Pollenübertragung gewiß nicht erwartet hatte. Und so mag unter den Pflanzen, von denen wir auf Grund biologischer Beobachtungen ammehmen. daß sie regelmäßig bestäubt werden, noch manche parthenogenetische (oder apogame) Art sein. Die Entscheidung darüber, ob eine Pflanze tatsächlich amphimiktisch ist, kann also immer erst exakt die direkte Konstatierung der erfolgten Befruchtung ergeben.

\section{A. Somatische Parthenogenesis.}

Trir bezeichnen als somatische Parthenogenesis die olne vorhergehende Befruchtung erfolgende Entwicklung einer Eizelle zum Embryo, deren Ker'n von vornherein die diploide Chromosomenzahl führt. Da nun die Eizelle als Zelle des Gametophyten normalerweise einen haploidchromosomigen Kern besitzt, so ist klar, daß auch die somatische Parthenogenesis wie die somatische Apogamie mit einem Torgang verbunden sein muß, der den Kernen der Gametophytenzellen anstatt der für sie typischen haploiden die diploide Chromosomenzahl verleiht.

Es sind zwei Modalitäten denkbar, durch die das erreicht werden kann, und fïr beide sind anch Beispiele bekannt. Erstens kann sich die somatische Parthenogenesis mit Aposporie kombinieren, d. h. also, es kann eine normale, also diploidchromosomige Sporophytenzelle unmittelbar zum Gametophyten auswachsen. Zweitens aber kann der' Gametophyt auf dem gewöhnlichen Wege, also aus einer Spore hervorgehen, wobei aber die sonst bei der Sporenbildung stattfindende Reduktionsteilung unterbleibt. Bei den höheren Pflanzen ist der letztere Fall der häufigere. Welcher von beiden jeweils realisiert 


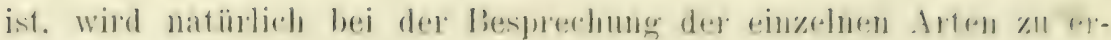
wähmen sein.

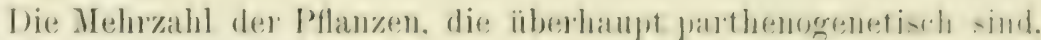

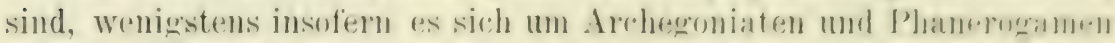
handelt, somatisch parthenggenetisch. Las hängt wohl \%wrifellow damit zusammen, dali bei Archegoniaten wie bei Phaneroganen dir. Sporophytengeneration, diejenige also. für die die diploide Chrmun-

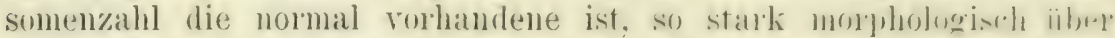
die oft nur wenigzellige (iametophytengeneration dominiert. [ind at bei der Parthenogenesis die eine Generation mit der abnormen ('hrumssomenzahl ansgestattet werden mub, so entfernt sich der ganze Entwicklungsgang weniger von der Norm. wemn die kleine haphide. als wenn die grobe so sehr viel stärker ausgebildete diploide Generation die abnorme Chromosomenzahl erhäit. Lmgekehrt ist es oft bei dell Thallophyten. Doch ist unseres Erachtens hierauf nicht allzuviel Gewicht zu legen und die principielle Bedentung. die der Besit\% der „normalen" "hromosomenzahl für die Generation hat. nicht zu iibelschätzen, da ebenso wie die morphologisch geringer ausgebildete Generation die stärker entwickelte bei durchans typischer (jestaltung mit der abnormen Chromosomenzahl regetieren kann. wie \%. P. der diploidchromosomige Gametophyt der apospor entstandenen Laulumose und der haploidchromosomige Sporophyt der generativ apogamen Farne beweisen.

Von den Thallophyten und den Bryophyten sind bisher noch keine Torkommnisse von Parthenogenesis bekannt geworden. die sich mit Sicherheit unter die Rubrik der somatischen Parthenogenesis bringen lieben. Doch sei unter Verweisung auf unser zweites Kapitel daran erimnert, daß vielleicht manche ron den Ascomycten. ferner (hara crimita hierher gehören. Auch die apospor entstandenen Moose wären hier zu nennen, falls sie, was freilich nach den bisher vorliegenden Mitteilungen nicht selır wahrscheinlich ist (rgl. 1.34; spontan parthenogenetisch sein sollten.

Pteridophyten. Unter den ,apogamen" Farnen sind mehrere Formen, bei denen die nähere Lntersuchung ergeben hat. dab sie somatisch parthenogenetisch sind. Es sind das Athyrium Filix-foeminu var. clarissima B olt on. Scolopendrum vulgare var. crispum Divimmondre und wahrscheinlich auch thyrium Filix-foemina rar. unco-glomerotum Stansfield nach Farmer und Digby (1907), nnd Mursilic Drmmmondii R. Br. nach Shaw (1897) und strasburger (1907).

Athyrium Filix-foemina var.clarissima Bolton erzengt, wie zuerst von Druery festgestellt wurde, apospor Prothallien aus den Spitzen der Fiedern oder in der Nähe der stets sterile Sporangien besitzenden Sori. An diesen Prothallien entstehen sehr reichlich Embryonen, die ausnahmslos aus Fizellen hervorgehen. Diese finden sich 
in durchans typisch gestalteten Archegonien, wie auch die Antheridien ganz normal ausgebildet sind und zahlreiche Spermatozoen enthalten, die sich in keinerlei Weise von denen des typischen amphimiktischen -1thyrium Filix-foemina unterscheiden, lebhaft beweglich sind und dank ihrer normalen chemotaktischen Empfindlichkeit in den Hals des Archegoniums eindringen. Zu einer normalen Befruchtung aber kommt es nicht, da nie ein Spermatozoon in das Ei selbst eindringt, so dab, wenn die männlichen Elemente hier überhaupt einen Einfluß auf die Entwicklung des Eies haben, dieser in einer stoftlichen Reizung bestehen müßte, die von dem bis in die Nähe des Eies vorgedrungenen Spermatozoon ausginge. Sehr wahrscheinlich ist eine solche Einwirkung nicht; da es aber Farmer und Digby bei der Reichlichkeit. mit der beiderlei Sexualorgane an den Prothallien erzengt werden. nicht gelang, rein weibliche Prothallien isoliert zu beobachten, so muß die Möglichkeit einer Mitwirkung des Spermatozoons often bleiben.

Als noch nicht ïber alle Zweifel experimentell sichergestellt muß freilich aus demselben Grunde die Parthenogenesis hier ïberhaupt gelten. Alle etwaigen Zweifel werden aber durch die Tatsache behoben. daß der Kern des Eies bei seiner ersten 'T'eilumg nicht mehr Chromosomen besitzt, als er vorher hatte, was natïrich beim Stattfinden einer Befruchtung ummöglich wäre. Und zwar beträgt die Chromosomenzahl etwa 84. Sie kehrt in allen Zellen des Prothalliums und in allen Zellen des Sporophyten wieder, bleibt also während des ganzen Entwicklungsganges konstant, so daß die beiden Generationen die gleiche Chromosomenzahl besitzen, und in keinem Entwicklungsstadium eine Reduktionsteilung eingeschaltet wird.

Daß es nun hier die diploide und nicht die haploide chromosomenzahl ist, die sowohl der Sporophyt wie der Gametophyt besitzen, geht mit sehr großer Wahrscheinlichkeit daraus hervor, daß die Prothalliumkerne des typischen Athyrium Fitix-foemina gegen 40, seine Sporophytenkerne gegen 80 Chromosomen fïhren. Das Unterbleiben der Reduktionsteilung bei der Sporenbildung gibt uns an sich natürlich noch keine Anhaltspunkte dafür, daß es sich um die unreducierte ('hromosomenzahl handelt, da die Reduktion ja auch dann ausbleiben mïßte, wenn die haploide Chromosomenzahl allein vorhanden wäre.

Wir haben also hier einen Sporophyten mit der fuir ihn normalen und einen Gametophyten mit der für ihn abnormen Chromosomenzahl, und es ist beachtenswert, daß der letztere auch bei der Ausbildung. der Keimzellen die zu hohe Chromosomenzahl nicht durch die Einschaltung einer Reduktionsteilung korrigiert. Besonderer Nachdruck ist auch darauf zu legen, daf der Sporophytenembryo immer und ansnahmslos aus dem Ei, niemals aus einer anderen Prothalliumzelle hervorgeht, immer also parthenogenetischer und nie apogamer Entstehung ist. Man muß daraus schließen, daß zwischen dem Ei und 


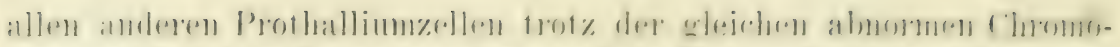

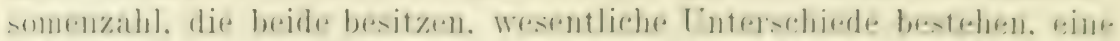

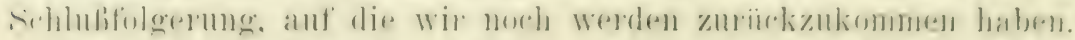

Ls sei noch bemerkt, daß, wie Farmer und Digrby ausdrïch-

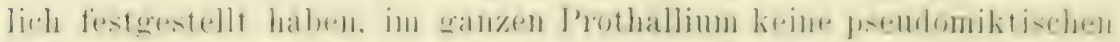
Kernwanderungen und Verschmelzungen vor sich gehen.

Ganz ähnlich scheint sich auch Athyrium Filix-foemina var.

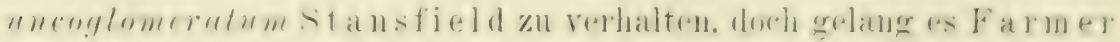

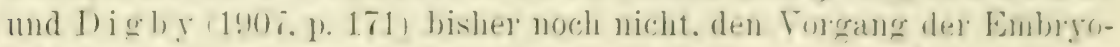
bildung in einzehen zu beobachten. Aposprie ist anch bri diesm. Varietat rorhandens. und der Embryo entsteht an den mit Archegonien mol Antheridien rersehenen P'rothallien stets endogen mul in Ferbindung mit einem Archegonium. Die (hnomosomenzahl betriget etwat 110 und bleibt konstant dieselbe in allen Entwirklungsstadien. Kernwanderungen im P'rothallium lieben sich nicht beobachtern. Bis auf weiteres wird man annehmen dürfen. wie ans diesen Angaben hervorgeht, daß sich die var. unco-glomeratum Stansfield wie die rroissima Bolton verhält. also somatisch parthenogenetisch ist.

Dagegen ist es wieder bei Scolopendrium vulgare var. crispum I) rum mondue sicher. dab der sporophytenkeimling ans der unhefruchteten Eizelle entsteht (F armer und Digl)y 1907. 1). 172 ff.). Bei dieser Form entspringen apospor dem Rande des Blattes zallireiche Prothallien. an denen sich Antheridien und Archegonien ansbilden. beicle in durchans typischer Weise. Doch hommt es nie zur Befruchtung. die oft geradezu ummöglich wäre. da sich das Ei. schon elie der Archegoniumbals sich öfnet, mit einer Membran umgeben kam. Fernïbertritte sind nicht zu beobachten. Der Embryo entwickelt sich aus der unbefruchteten Eizelle. Eine Reduktion der ('hromosomenzalıl findet weder beim Übergang rom Sporophyten zum Gametophyten noch auf sonst einem Entwicklungsstadium statt. su dab alle Fierne etra 80 bis 100 Chromosomen besitzen. Dab das die diploide Chromosomenzalıl ist, wird dadurch änliert wahrscheinlich gemacht, daß das typische Scolopendivm rulyare im Sporophyten Kerne mit 64, im Gametophyten solche mit 32 Chromosomen fülnt.

In allem Tesentlichen ebenso wie die eben besprochenen Pulruodiaceen rerhält sich unter den Marsiliaceen II arsilia Drummondii R. Br.

Bei dieser Art hatte zuerst Shaw (1897) festgestellt, dab ,over 50 1). c. of the isolated female prothallia produced embrros, while not more than $69 \mathrm{p}$.c. of those which were mixed with male prothallia produced embryos". Durch diese Angaben ron shaw bestimmt. wählte Na tha n so h n (1900) Mrarsilien zu seimen Tersuchen, experimentell durch Temperaturerhöhung Parthenogenesis bei an sich amphimiktischen Pflanzen zu inducieren. Auf seine positiven Angaben, wonach 
das bei Marsilia restita und einigen anderen Arten gelungen sein soll, brauchen wir nicht einzugehen, da Strasburger (1907. p. $141 \mathrm{ft}$.) bei einer sorgfältigen Nachuntersuchum Ta th a us o h n's Angaben nicht bestätigen komnte. Darnach ist also anzunehem, dab mit einziger Ausnahme der Mrorsilia Drummondii, die sich als somatisch parthenogenetisch erwies. alle Narsilia-Arten obligatorisch amphimiktisch sind (untersucht wurden bisher von Stras bu l'g e r l. c. ITarsitia elata, hirsuta, nardu. quadrifoliata und vestita: bei Marsitia salvatri, lat H a nstein 1865 die Befruchtung beobachtet. Nur bei IIarsitia macra fïhrt Strasburger 1. c., p. 157 Beobachtungen an. die darauf schließen lassen, daß sie sich vielleicht ähnlich wie $M$. Drummondii verhält). Auch die Angabe von Xathansoln (1. c., p. 109), er habe bei Pilularia, bei der Sadebeck (nach brieflicher Mitteilung an

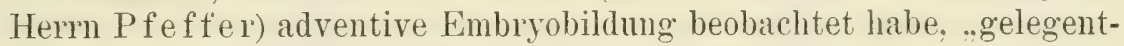
lich auch echte Parthenogenesis konstatieren" können. kamn als nicht genügend begrïndet angesehen werden; zu beachten ist jedenfalls. dab A reangeli (1876) ausdrücklich experimentell feststellte, dab am Prothallium von Pilularia, wenn die Eier nicht befruchtet werden. l)ropagative Tucherungen auftreten, während die Eier zugrunde gehen, olne auch nu den Anfang einer Entwicklung zu zeigen. Wir haben uns also vorerst lediglich mit Marsilia Drummondii zu beschäftigen, wobei wir uns durchgehends auf die Untersuchung ron Strasburger (1907) beziehen.

Strasburger konnte zunächst feststellen, daß bei den von ihm untersuchten amphimiktischen Marsilia-Arten die Kerne del Gametophyten je 16, die der Sporophyten je 32 Chromosomen besaßen. Dagegen fïhrten die Kerne sowohl der Prothallien wie der Keimanlagen bei Marsitia Drummondii die gleiche Chromosomenzahl, und zwar betrug diese 32. Daraus ist natürlich mit größter Wahrscheinlichkeit zu schließen, daß hier der ganze Entwicklungscyklus mit der diploiden Chromosomenzahl rollführt wird. Da nun der Embryo regelmäßig aus dem unbefruchteten Ei entsteht, so liegt also typische somatische Parthenogenesis vor. Eine Befruchtung ist hier schon deswegen sicher ausgeschlossen, weil der Archegoniumhals sich gar nicht öffnet, und auch die Bauchkanalzellen nicht verschleimen. Die Entwicklung der parthenogenetischen Keime verläuft durchaus ïbereinstimmend mit der geschlechtlich erzeugter.

Während nun aber bei den somatisch apogamen und parthenogenetischen Polypodiaceen, soweit sie bisher untersucht sind, sich die Parthenogenesis mit Aposporie kombinierte. wird bei MLrsitia Drummondii der andere zur Diploidchromosomigkeit der Gametophytenkerne führende Weg eingeschlagen, d. h. es unterbleibt bei der äußerlich normal verlaufenden sporenbildung die Reduktionsteilung. Das Prothallium geht also in typischer Weise aus einer Spore hervor, diese 

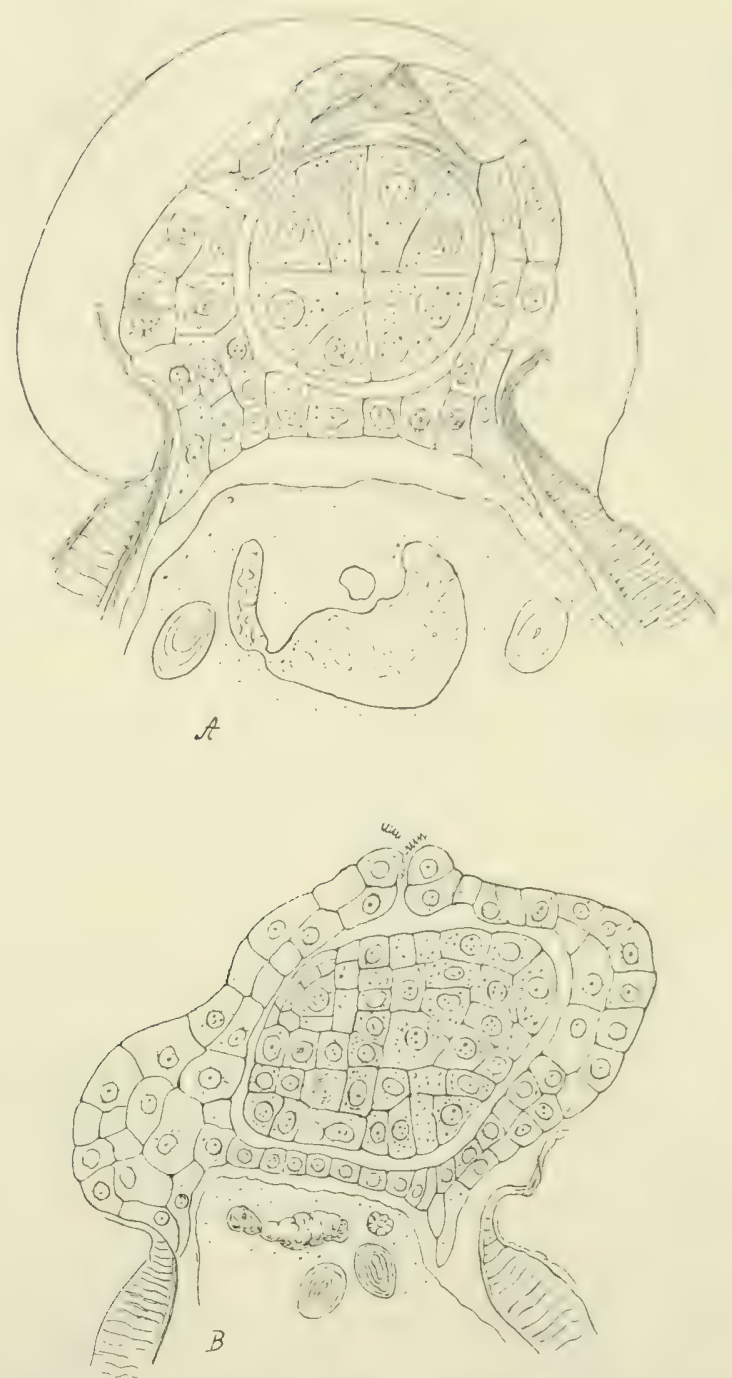

Fig. 9. A. Marsilia Dinmmondii. Partheuogenetisch entstandene Keimanlage nach Strasburger 1907. Taf. 4, Fig. 27). - B. Marsilia vestita. Geschlechtlich erzeugte Keimanlage. Im und am Archegoniumbals abgestorbene Spermatozoiden. In 1 ist die Kanalzelle erhalten, in B der Archegoniumhals offen.

(Nach Strasburger 1907, Taf. 6, Fig. 5́5.)

aber ist von Haus aus mit einem diploidchromosomigen Kerne versehen; und da der so erzeugte diploide Gametophyt die bei der sporenbildung ansgeschaltete Reduktionsteilung anch bei der Ei- und spermatozoenbildung nicht wieder einschiebt, resultieren naturgemäls auch diploidchromosomige Kerne in den Keimzellen. 
Wichtig und sich an mehrfach bei parthenogenetischen Angiospermen Festgestelltes anschließend ist die Beobachtung, daß die Kerne der Sporenmutterzellen doch noch gewissermaßen einen Ansatz zur Rednktionsteilung nehmen, denn es stellt sich regelmäßig bei ihnen eine Synapsis ein. Dann aber wird zur typischen Karyokinese zurïckgegangen, indem bei der Diakinese sich die Chromosomen nicht zu bivalenten Körpern vereinigen, sondern getrennt bleiben. Das gilt sowohl von der Lakrosporen- wie anch von der Mikrosporenentwicklung, bei welch letzterer ïbrigeus Entwicklungsstörungen recht häufig zu beobachten sind, was anch wieder an parthenogenetische Phanerogamen erinnert. Sehr bemerkenswert ist ferner noch, daß häufig bei der Mikrosporenbildung, gelegentlich aber anch bei der Makrosporenbildung normale oder mehr oder weniger unregelmäßige heterotypische Spindeln beobachtet wurden. „Es eröffnet damit sich die Möglichkeit, daß fertige Sporokarpien neben diploiden Makrosporen anch haploide führen können. Vorausgesetzt nun, es gelänge so ausgestalteten Pflanzen auch keimfühige Mikrosporen zu reifen, so wäre nicht ausgeschlossen, daß bei der Aussaat sowohl auf apogamem, als auch auf geschlechtlichem Wege Keimlinge entständen" (Strasburger 1907, p. 159). Das ist noch näher zu untersuchen.

Schließlich sei noch angeführt, daß in Übereinstimmung mit den neneren Ansichten über die Kernplasmarelation die Zellen und Kerne in den diploidchromosomigen Prothallien der parthenogenetischen Marsitia Drummondii erheblich größer sind, als die der haploidchromosomigen Gametophyten der amphimiktischen Marsilia vestita.

Phanerogamen. Alle bisher von Phanerogamen genauler bekannten Fälle von Parthenogenesis haben sich als somatische erwiesen. Die beiden bei apomiktischen Organismen möglichen Wege. Gametophyten mit diploidchromosomigen Kernen zı erzielen, nämlich das Unterbleiben der Reduktionsteilung bei der Sporenbildung und Aposporie, sind beide anch bei Phanerogamen realisiert. Doch scheint, soweit sich die Verhältnisse jetzt überblicken lassen, die Kombination der Parthenogenesis mit Aposporie sehr erheblich seltener benutzt zu werden als der andere Weg, wodurch die Phanerogamen in einen gewissen Gegensatz zu den Pteridophyten kommen.

Die hier anzuführenden Untersuchungen sollen in historischer Reihenfolge besprochen werden. Zuerst haben wir daher die Komposite Antennaria alpina (L.) R. Br. zu erwähnen, bei der J u el im Jahre 1900 den ersten unzweifelhaften Fall von Parthenogenesis bei Phanerogamen durch eingehende cytologische Untersuchung nachwies, nachdem allerdings die Vermutung, diese Art möchte parthenogenetisch sein, schon mehrfach geäußert worden war. Zuerst von Kerner (1876), der den experimentellen Nachweis erbrachte, daß die nebenbei bemerkt diöcische Antennaria alpina imstande ist, unter' 


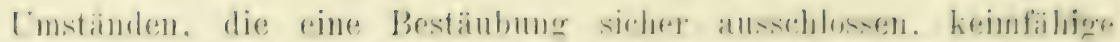

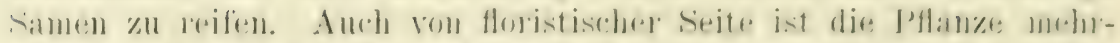

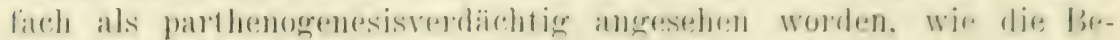
merkung von Loew (1894, p. 111) beweist: Antennaria alpina ist ..vermuthoh parthenogeretish. da die l'flanze an zahlorichen stellen

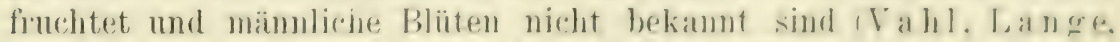

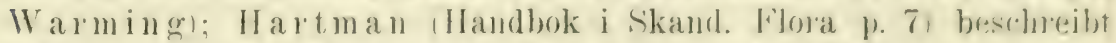
jedoch männliche Pllanzen narh Exemplanen, lie 1842 rom Laestatdius gefunden wurden." ()h einer der drei citiesten Autoren direkt die Vermutung, dab l'arthenogenesis vorliege. geanlbert lat. habe irdi nicht feststollen kömmen. Vatürlich waren alle diese Angaben nichot fiir Parthenogenesis beweisend, da anch Adventivemhryolildung nach

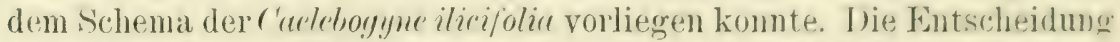
zugunsten echted Parthenogenesis erfolgte erst 1898 durch eine vorläufige Nitteilung von .Juel (1s:8). In gleichen Jahre berichtete freene (1898), Antemaria plantaginifolia sei parthenogenetisch. Was noch zu bestätigen und genauer zu untersuchen ist. und die von Nelson (1902, p. 115) gelegentlich ausgesprochene Vermutung, möchten wie Intomaria alpina anch einige nordamerikanische Arten der Gattung parthenogenetisch sein, wurde neuerdings von Leavitt und Spalding (1905) für Intemaria fallax und neortioicr als den 'Tatsachen entsprechend bestätigt. Nach denselben Autoren ist endlich auch bei intemaria canudensis nud Parlinii das Bestelıen von Parthenogenesis wahrscheinlich. Nach alledem ist jedenfalls sichn: daß die Parthenogenesis immerhalb der Gattung Antemaria nicht nur bei der Species alpina zur Ausbildung gekommen ist, wemn auch rorerst diese Art die einzige genauer untersuchte geblieben ist. Andererseits ist auch sicher, dab nicht alle Arten der Gattung parthenogenetisch geworden sind; so ist z. B. die vou Jue I zum Tergleich renau untersuchte Antemaria dioica normal amphimiktisch geblieben.

Daß bei Intemnaria alpina, deren Entwicklungsgang an der Hand der Angaben .J uel's knrz geschildert werden soll. mämuliche Stücke außerordentlich selten sind, wurde schon erwähnt. Juel honnte einige solche männliche Fxemplare untersuchen und fand, dab ihre staubbentel, wemn nicht völlig steril, doch nur in seln geringem Grade fertil sind. Wie bei Marsilia Drummondii und der Mehrzahl der noch zu besprechenden parthenogenetischen Phanerogamen rerläuft also die. Mikrosporenentwicklung nicht normal.

Was die Makrosporenbildung anbelangt, so rerläuft diese bei der amphimiktischen Antennaria divica durchaus nach dem normalen Phanerogamenschema, d. h. die Nutterzelle teilt sich durch eine Reduktionsteilung in vier 'T'ochterzellen, ron denen die basale, ron vornherein größte unter Terdräingung der anderen zum EmbrJosack wird. Vatïrlich haben dann diese Makrospore und der in ihr ent- 
stehende Gametophyt die haploide Chromosomenzahl, während der Sporophyt durch die bei der Befruchtung erfolgende Kernverschmelzung wieder die diploide erhält.

Wesentlich ander's verläuft die Makrosporenbildung bei Lntennaria alpina: hier unterbleibt nämlich die Vierteilung der Embryosackmutterzelle, so daß diese direkt zum Makrospore wird. Natuirlich fällt damit anch die sonst an dieser Stelle durchgefïhrte Reduktionsteilung: aus. und da anch bei der weiteren Ausgestaltung des Makrosporeninhaltes, also bei der Ausbildung des Gametophyten, eine solche nicht eingeschaltet wird, so resultiert ein Gametophyt, dessen Zellen die diploide Chromosomenzahl besitzen. Im iibrigen ist er durchan.
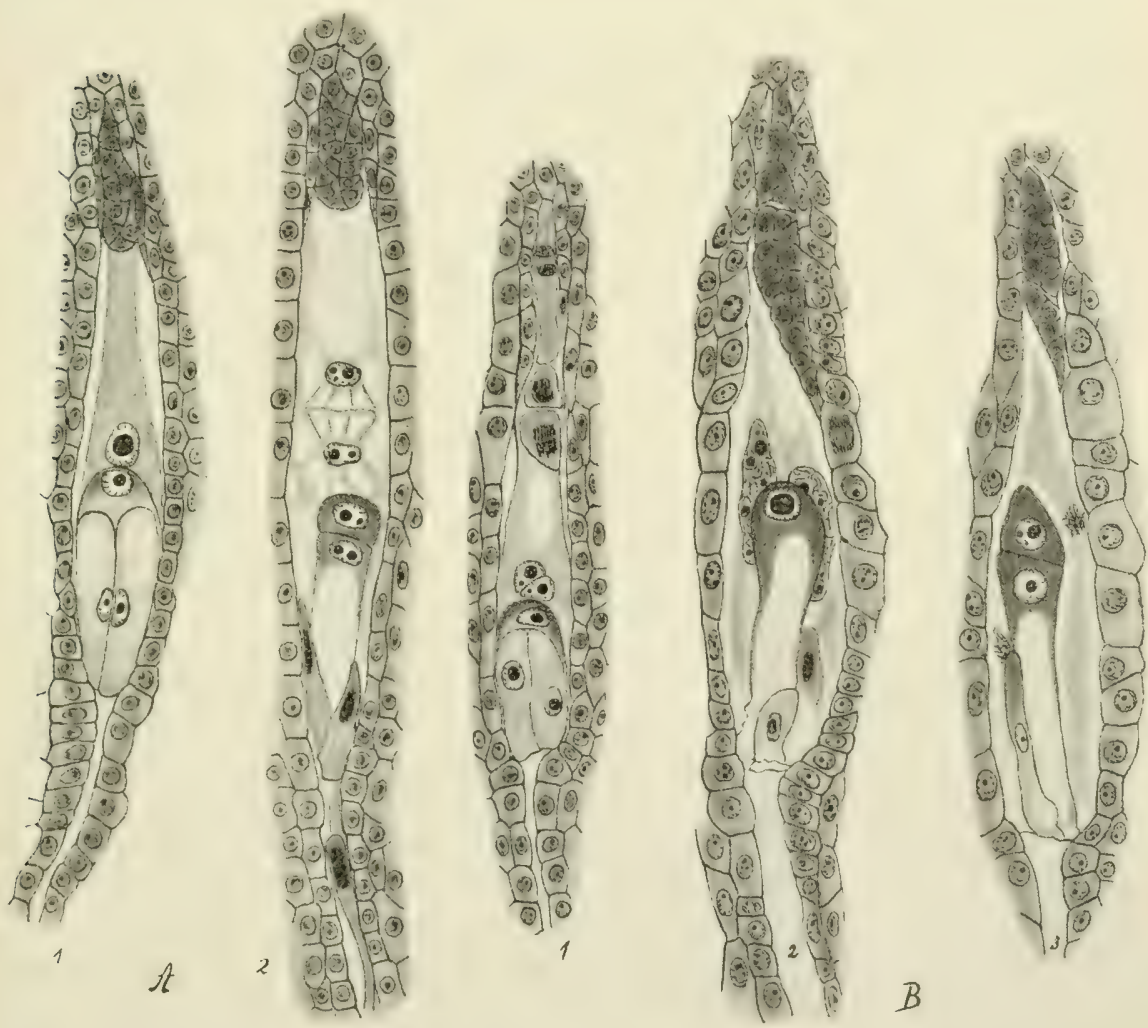

Fig. 10A. Antennaria dioica. Normale geschlechtliche Embryobildung. 1. Befruchtungsreifer Embryosack, unten der Eiapparat, oben die Antipodenwucherung. 2. Embryo zweizellig: In der Mikropyle noch Reste des Pollenschlauches; neben dem. Embryo die verfallenden Synergiden. (Nach Juel 1900, Fig. III, p. 18.)

Fig. 10B. Lutennaria alpina. Parthenogenetische Embryobildung. 1. Fertig ansrebildeter Embryosack. Die beilen Synergiden liegen vor dem Ei, die beiden Polkeme nebeneinander. - 2. Die Eizelle beginnt auszuwachsen, die Polkerue bereiten sich zur Teilung vor. In der Mikropyle keine Spur eines Pollenschlauches. -

3. Embryo zweizellig, Polkerne in Teilung. (Nach J uel 1900, Fig. V, p. 23.) 


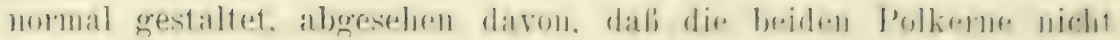
wie bei Anlemuriu dioicu miteinander zu einem Kentralkern ver-

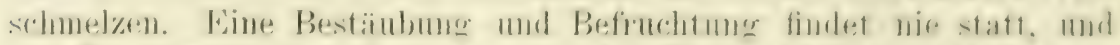

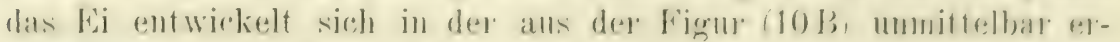
sichtlichen Weise zum Embryo.

Es liegt also typische Parthenogenesis vor. Ob es sich dabei

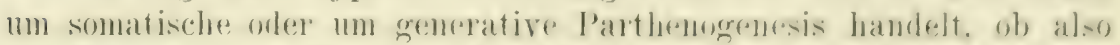

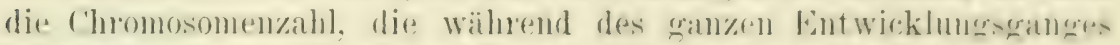
beibehalten wirle die diploide oder die haphoide ist. liaft sireh in

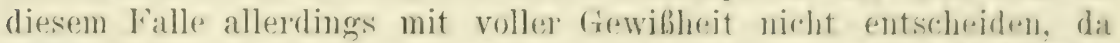
niclat feststeht, ob hei der Mikrosporrnentwicklung eines Reduktion mfolgt. Ist das der Fall. dann wäres es natiolich sicher somatische Jarthenogenesis: verläuft aber anch die Iollenbildung olne lieduktionsteilung. so kamn ebensogut generative Parthenogenesis vorlieren. I)er Tergleich mit Intemarin dioica ist hier anch nicht antschreidend. Bei dieser amphimiktischen Art beträgt die reducierte ('hromosomenzahl 12. 13 oder 14, die diploide 2t. 25 oder 26. während die bei Antenuria alpina beibehaltene (hromosomenzahl etwa t5 his jo buträgt. Würde sie 25 betragen, dam kïmte man wohl annehmen. dab beide Arten ursprïnglich gleiche Zahlen gelabt hätten, und daf. also die diploide bei der parthenogenetischen Species allein übrig geblieben sei. Da aber die Chromosomenzalnen beider Arten von Anfang an verschieden gewesen sein müssen. so läßt sich aus einen Tergleich beider kein sicherer Riichschluf daranf ziehen. ob t5 bis 50 bei Antemaria alpina die diploide oder aber die haploide ('hromosomenzahl ist. Denn ebensogut wie sie bei alprim doppelt so hoch als bei dioica sein konnte, konnte sie natürlich auch riermal so hoch sein. Immerhin darf es mohl aus Griunden der Analogie als wahrscheinlich angesehen werden, dab die bei Lntenuria alpina allein noch vorhandene Chromosomenzahl von 45 bis 50 die diploide ist, so daß also in der Tat somatische Parthenogenesis vorliegt. Mäglich. daß spätere Untersuchungen über die Nikrosporenentricklung das noch entscheiden können. Sollte übrigens der Ker'n der Embryosackmutterzelle auch bei Antennaria alpina gewisse Torstadien der Reduktionsteilung durchmachen, wie das einige Beobachtungen ron Juel (1901, p. 20) vermuten lassen, und wie es z. B. bei den parthenogenetischen Alchimillen der Fall ist. so wïrde auch das daranf hinweisen, daß die diploide Chromosomenzahl rorhanden ist. Demm jene Prophasen wird man natiulich selır viel eher bei einem diploid-als bei einem haploidchromosomigen Kern erwarten.

Die Entdeckung von Juel, daß Antemaria alpina parthenogenetisch ist, blieb nicht lange vereinzelt. Schon 1901 veröffentlichte II u r bek Untersuchungen. aus denen hervorging, dab innerhalb der großen Rosaceen-Gattung A7chimilla parthenogenetische Samenbildung 
weit verbreitet ist. Er hatte erst durch Kulturversuche (M urbeck 1897) festgestellt, daß in den Samen zahlreicher nord- und mittelemopäischer Alchimillen der Embryo zur vollen Ausbildung gelangt, ohne dab eine Befruchtung stattfindet. Das konnte anf Parthenogenesis, aber auch auf Adventivembryobildung beruhen. Die ansführliche entwicklungsgeschichtliche Untersuchung (M urbeck 1901) elgab, daß der Embryo aus der Fizelle entsteht. Später hat Strasburger (1904) an sehr umfangreichem Material die Angaben von M u rbeck nachuntersucht, sie in allem Wesentlichen bestätigt und nach verschiedenen Richtungen hin erweitert. Wir wollen im folgenden das Verhalten der parthenogenetischen Arten der Gattung kur\% nach den Arbeiten der beiden Forscher schildern. (Die kleine Arbeit ron Hegelma ier 1906 über die Alchimillen des schwäbischen Jura enthält nichts wesentlich Neues für unsere Frage.)

Die Parthenogenesis scheint innerhalb der sehr artenreichen Gattung Alchimilla auf die Sektion Eualchimilla beschränkt, in dieser aber so häufig zu sein, daß nur ganz wenige Arten von Eualchimillen sexuell geblieben sind; bemerkenswert ist, daß das ausschließlich hochalpine Arten sind (z. B. Alchimilla pentaphylla, A. getida, A. glacialis, A. yrossidens u. a.). Die anderen, parthenogenetischen Eualchimillen verhalten sich in allen wesentlichen Punkten gleich.

Das Archespor ist bei Alchimilla wie bei allen Rosaceen vielzellig, es wird aber normalerweise nu eine gewöhnlich central gelegene Archesporzelle zur Makrosporenmutterzelle. Als solche wird sie frühzeitig durch ihre Größe kenntlich, sowie, was besonders zu beachten ist und an das erinnert, was Strasburger bei der parthenogenetischen Marsilia Drummondii fand, dadurch, daß ihr Kern in die Synapsis eintritt und auffallend lange in diesem Zustande verharrt. Er unternimmt also gewissermaßen noch den Versuch, die heterotypische Teilung durchzuführen, durchläuft aber nur deren Prophasen und geht dann, anstatt die Reduktionsteilung fortzusetzen, in den typischen Teilungsvorgang über. Die beiden so entstandenen 'Jochterzellen können sich noch ein-oder mehrmal weiterteilen, und ron den resultierenden Makrosporen gelangt eine zur Keimung, wird also zum Embryosack und liefert einen durchaus normal gestalteten Gametophyten mit typischem Eiapparat. Aus dem Ei entwickelt sich der Embryo, ohne daß Bestäubung und Befiuchtung erfolgte. Wie bei Antemaria verschmelzen die beiden Polkerme gewöhnlich nicht miteinander.

Bei den sexuell gebliebenen Eualchimillen verläuft die Entwicklung genau so mit dem Unterschiede, daß bei der Makrosporenbildung die iibliche Chromosomenreduktion beibehalten ist, und daß der Embryo erst nach erfolgter Befruchtung aus dem Ei entsteht. Ebenso verhalten sich natïrlich auch die Alchimillen aus der Untergattung 


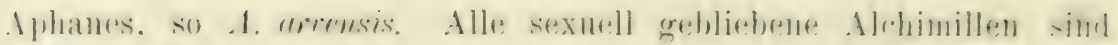
iibrigens chalazogam.

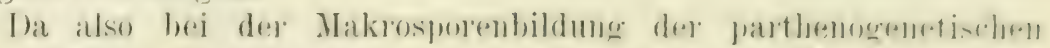
Fualchimillen die Reduktionsteilung unterbleibt. so haben Sporobugt

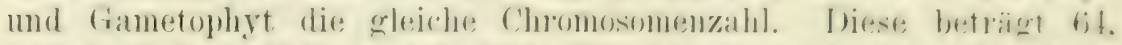
und das ist zweifellos die diploide ('hromosomenzahl. Deenn bei atlen Eualchimillen ist die chromosomenzahl die gleiche. mod da sirh muter. ihnen noch einige amphimiktische Vertreter finden. bei demen die Reduktion bei der sporenbildung noch stattindet. so lief sich feststellen. dalis die reducierte ('hromosomenzahl :32, die diploide tit loträgt. Also haben wir es hier sicher mit somatischer Parthenogente-is zil tun.

Auffallig ist. dab. wie Strasburger (1904. p. 10si konstatierte. ...bei den meisten Arten der Eualchimillen gegen ein Drittel der Präparate verbildete oder rerkümmerte samenanlagen fïhrt". Siehr vis stärker aber sind die Störungen bei der Mikrosporenbildung. Nur bei den sexuell gebliebenen Arten geht sie ganz ungestärt vor sich. bei den parthenogenetischen aber zeigen sich die verschierlensten firade der I'ollenverbildung: bei manchen Arten gehen schon die Pollenmutterzellen vor der ersten Teilung zugrunde. bei anderen gehen sie nur eine Teilung ein und es desorganisieren sich die Teilprodukte, bei manchen endlich wird zwar die 'Tetradenteilung durchgefïhrt. liefert aber verkümmernde und sich nicht normal ausgestaltemir Pollenkörner. Es sind da iibrigens anch bei stöcken derselben trt Verschiedenheiten zu beobachten. -

Die nächste Gattung; imnerhalb deren Arten mit parthenogenetischer Keimbildung gefunden wurden, ist die Ranunculaceen-Gattung Thalictrum. Schon 1896 hatte D a $(1896$ ) beobachtet. dab rein weibliche Exemplare von Thalictrum Fendleri anch bei Abwesenheit männlicher Stöcke derselben oder irgendeiner anderen Thalictrum-Art reichlich Samen ansetzten, die sich als keimfähig erwiesen mal eine aus männlichen und weiblichen Individuen gemischte Nachkommenschaft ergaben. Day hatte darans auf Parthenogenesis geschlossen, was freilich, da ja anch Nucellarembryonie vorliegen konnte. noch aut crtologischem ITege zu erweisen wäre. Eine solche cytologische Cntersuchung über Thalirtrum Fendleri steht noch aus; es mub aber doch als wahrscheinlich gelten. daß die Art tatsächlich parthenogenetisch ist (auch trotz der Bemerkung von $\mathrm{Loew}$ in $\mathrm{K} n \mathrm{n}$ th's Handbuch, Bd. 3. Abt. 1. p. 301, D a y's Tersuchsergebnisse seien. wemn Thatictrum Fendleri polygame Geschlechtsverteilung besitze. noch kein Beweis für Parthenogenesis, da Orerton (1902 und 1904), durch die Mitteilung von Day veranlaßt. die Fortpflanzungsverhältnisse ron Thalictrum purpurascens L. untersuchte, mit dem Ergebnis, dah diese Art sicher wenigstens partiell parthenogenetisch ist. Das ergab 
die cytologische Untersuchung von weiblichen Bliten der streng: diöcischen Pflanze, die im Gewächshans muter Lmständen, die eine Bestäubung mit Sicherheit ausschlossen, keimfähige Samen erbracht hatten, und bei denen der Embryo aus der Eizelle hervorging. Merkwiurdigerweise ging aber nun aus der gleichzeitigen ['ntersuchung ron weiblichen Blïten, die im Freien am natïrlichen Standorte gesammelt worden waren, hervor, dab hier neben parthenogenetischer Samenbildung auch echte Befiuchtung erfolgen kamm, so daf bei dieser Art die Bestäubung als möglich, aber nicht als unbedingt erforderlich, die Parthenogenesis also als scheinbar fakultativ gelten mußte. Die Untersuchung des Jahres $190+$ hellte das näher auf; der ausfïhrliche Bericht darïber steht noch aus, so daß wir uns an die vorläufige Mitteilung (Overton 1904) zu halten haben.

Die Nikrosporenentwicklung verläuft bei Thalictrum purpurascens zum Unterschiede von den parthenogenetischen Antennaria- und Alchimilla-Arten durchaus normal und liefert keimfähigen Pollen. Dabei findet in der iblichen Weise eine Rednktionsteilung statt, durch die die diploide Chromosomenzahl 24 anf die haploide 12 gebracht rird. Das gleiche kann auch bei der Makrosporenbildung eintreten. Das Archespor ist hier einzellig und liegt hypodermal. Die Archesporzelle teilt sich in eine Deck- und in eine Embryosackmutterzelle. welch letztere sich durch eine Tetradenteilung in vier ïbereinanderangeordnete Makrosporen teilt, von denen die innerste zur Keimung gelangt. Dabei findet wälırend der Tetradenteilung die Chromosomenreduktion von $2 \pm$ auf 12 statt, so daß die Makrosporen und der aus der einen ron ihnen entstehende Gametophyt wie ïblich die haploide Chromosomenzahl in ihren Kernen führen.

Daneben aber finden sich Orula, in denen die Entwicklung des Embryosackes sonst genau ebenso verläuft. wie es eben beschrieben wurde. nur' findet während der 'Tetradenteilung keine Chromosomenreduktion statt, so daß also bei der Keimung der Makrospore ein Gametophyt mit diploidchromosomigen Kernen entsteht. Die Bliiten, in denen das der Fall ist. schließen sich also in ihrem Terhalten durchaus den parthenogenetischen Eualchimillen an, Sporophyt wie Gametophyt haben beide die diploide Chromosomenzahl. in diesem Falle also 24.

Es liegt nun auf Grund dieser Feststellungen natiulich nahe, anzunehmen, daß diejenigen Eier, die zu einem haploidchromosomigen Gametophyten gehören, nur nach Befruchtung Embryonen liefern, während die Eier mit diploidchromosomigem Kern parthenogenetisch sind. Exakt beweisen läbt sich das anf direktem Trege nicht, da man ja, um die Chromosomenzahl feststellen zu können. die Blüte opfern mub. Da aber sämtliche von Overton untersuchten Embryonen 24 Chromosomen in ihren Kernen führen. die reducierten Eier aber. 


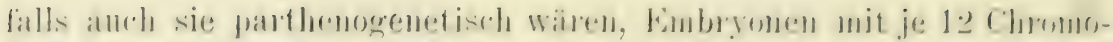

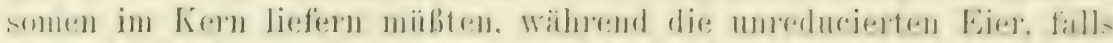

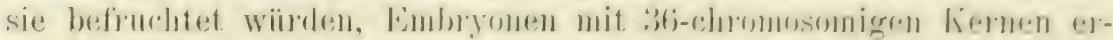

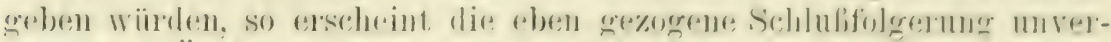

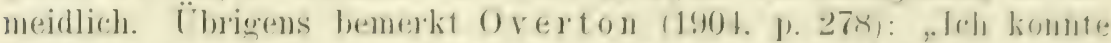
an bestaubten weiblirhen Pflanzen oft Pollensehlärhr in der Mikro-

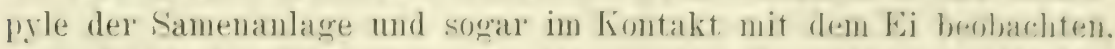
anch Fille der Verselmelzung des zweiten Syermakerus mit dom Endospermkern. Anderersuits fehlen mir l'räparate mit Ifol Terschmelzung von Spermakern mol Eikern. Aus diesem Grunde darl ich auch nicht positiv behaupten, dab zur normalen Keimentwicklung stets Tiefuchtung notwendig ist. wenn auch alle solnstigen 'Tatsarehen mol die Beobachtungen an Pflanzen im Freien keinen Zweifel daribus. lassen. dab Befruchtung stattfinden kann, wenn das Fi die reduzierte Zahl der Chromosomen fïhrt."

Wir haben also hier die sehr bemerkenswerte Tatsache. dal bei ein und derselben Species amphimiktische und somatisch parthenogenetische Blüten nebeneinander vorkommen. Und zwar mïssen wir amehmen, dab die Kahl beider gleich grob ist, dem O verton (190.). p. 373) sagt ausdricklich, daf ror Bestäubung geschïtzte Pflanzen „showed quite as many seeds per plant as those which had been fertilized and grew in the field". Es ware sehr wichtig. dab dieser Umstand genaner untersucht wïrde, denn wenn bestäubte und ros. Bestäubung geschïtzte Pflanzen gleichviel samen producieren. so kamn das entweder darauf beruhen, daß sich unter allen L'mständen nu' die parthenogenetischen Samen ausbilden, wonach also überhaupt keine Befruchtung mehr stattfände, oder aber darauf. daß die Zahl der amphimiktischen Bliiten genau gleich der der parthenogenetischen wäre: bei Isolierung wiuden letztere allein sich entwickeln, bei erfolgender Bestäubung dagegen brächten nur die ersteren Samen. und es wäre dam die Hilfsannahme nötig. daß nur damn Parthenogenesis benutzt wïrde, wenn keine durch Befruchtung entstandenen Keime sich entwickelten. Es mïßte mit anderen Worten von den amphimiktisch erzeugten Keimen eine hemmende Einwirkung anf die an sich zu spontaner Entwicklung befähigten Eier ausgeïbt werden. Das wäre eine prinzipiell wichtige Tatsache, die Thalictrum purpurascons zu einem geeigneten objekt fïr die experimentelle Behandlung mancher für das Terständnis der Parthenogenesis bedeutsamen Frage machen wïde; weitere Beobachtungen sind hier dringend erforderlich.

Von Einzelheiten sei noch angeführt, daß auch bei Thatictrum murpurascens der Kern der Embryosackmutterzelle selbst in den Fällen. wo el keine Reduktionsteilung durchmacht, wenigstens deren Prophasen aufzuweisen scheint, sowie daß hier die Polkerne immer rer- 
schmelzen. In den parthenogenetischen Bliiten setzt die Endospermbildung regelmäßig vor der ersten Teilung des Eies ein.

Es mögen noch mehr Thalictrum-Arten parthenogenetisch sein; daß es nicht alle sind, geht daraus hervor, daß Da $y$ und Overton bei Thalictrum dioicum die Notwendigkeit der Bestäubung ausdrücklich konstatiert haben. -

Die bisher allgemein für obligatorisch amphimiktisch gehaltene Kompositen-Gattung 'T araxacum ist die nächste, die sich in einer ganzen Reihe von Arten als parthenogenetisch erwies. Hier hatten zuerst Andersson und Hesselman (1900, p. 15), freilich aus durchaus unzureichenden Gründen, die Vermutung ansgesprochen, eine auf Spitzbergen einheimische Taraxacum-Species möge parthenogenetisch sein. Das Verdienst, nachgewiesen zu haben, daß nicht weniger als zwölf Arten von Taraxacum imstande sind, bei sicherem Ausschlub der Bestäubung keimfähige Samen zu reifen, gebührt R a unkiaer (1903), der Fruchtbildung an isolierten rein weiblichen Taraxacum-Pflanzen (T. Ostenfeldii, T. patudosum) sowie an hermaphroditischen beobachtete, bei denen die Bestäubung dadurch unmöglich gemacht worden war, dab bei ihnen an jungen Blïtenküpfchen zu einer Zeit, als die Blüten noch sämtlich geschlossen waren. alle Narben und Staubbeutelröhren durch einen kurz oberhalb der Fruchtknoten geführten Schnitt entfernt wurden. Die Blüten vertrugen diese radikale Operation und reiften ihre Fruchtknoten zu Achänen, die sich von normalen nur durch den Pappusstumpf unterschieden. Befruchtung scheint wenigstens bei den zwölf von Ra un ki a er untersuchten Arten gar nicht mehr vorzukommen, und Raunkiaer vermutet, daß alle Arten der Gattung habituell parthenogenetisch sind, was indessen noch der näheren Bestätigung bedarf, zumal HandelII azetti (1907) in seiner Monographie der Gattung Taraxacum Bastarde beschreibt.

Damit war freilich erst festgestellt, daß viele Taraxacum-Arten nicht der Bestäubung bedürfen, um zu fruchten; ob das auf Parthenogenesis oder auf Adventivembryonie beruhte, blieb zunächst noch unentschieden. Daß ersteres der Fall war, die Embryonen also aus der unbefruchteten Eizelle hervorgehen, wurde bei Taraxacum officinale von Kirchner (1904, p. 87) an kastrierten Bliiten festgestellt und von $\mathrm{II} \mathrm{u} \mathrm{rbeck}$ (1904, p. $287 \mathrm{ff}$.) etwas ausführlicher anch für Taraxacum vulgare (L a m.) $\mathrm{R}$ a $u \mathrm{n} \mathrm{k}$. und Taraxacum speciosum Raunk., zwei im botanischen Garten in Lund wildwachsende Arten konstatiert. Während aber Kirchner und II rbeck nur die fertig entwickelten Embryosäcke untersucht haben, verfolgte Juel (1904 und 1905) die Entwicklung der Samenanlage unter Berücksichtigung der Kernverhältnisse, so daß sich die Parthenogenesis von Taraxacum wenigstens einigermaßen auch in den Einzelheiten 


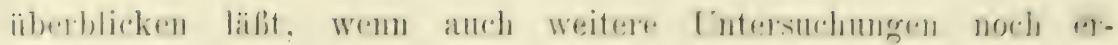
wiinscht sind.

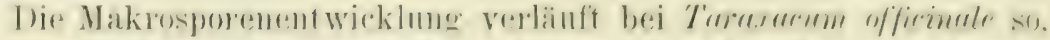

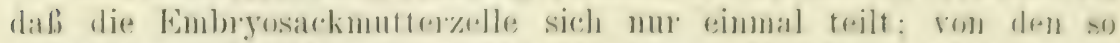
entstandenen 'Torhteryellen wird die basales direkt zorr Makrospore.

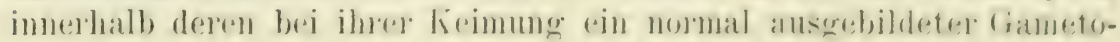

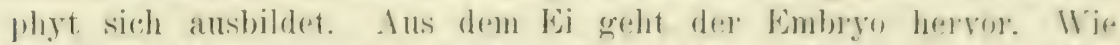
durch on lo lewesen ist. findet während dieser Vorgünge keine lieduktionsteilung statt. so dafi die Kerme der Makrospore und der Ganetoplytenzellen die unreducierte ('hromosomenzahl, nämlich 26 erhalten. Dalli das die diploide ('hromosomenzahl ist, die Parthenogenesis also als somatische zu bezeichnen ist, erhellt darans. daf die lierne der Mikjosporen. bei deren Entwicklung die Reduktionsteilung nicht ausgeschaltet ist. je 13 ('hromosomen haben. Fis ist aber auch hier wieder zu beobachten. dab der Kern der Embryosackmutteretle die Prophiasen der heterotypischen Teilung sogar bis zur Diakinese durchmacht. um erst dam in die homöotypische zurückzugehen.

Näher zu untersuchen sind bei T'araxacum auch noch die Reduktionserscheinungen bei der Mikrosporenbildung. Bei Traracum officimule scheint sie normal zu verlaufen, bei anderen Arten. so bei T. decipiens. Ostenfeldii, puludosum. speciosum und anderen, enthalten aber die fertigen staubbeutel überhaupt keinen Pollen mehr. -

Durch den Erfolg seiner Versuche bei Taraxamm angeregt. dehnte sie Raunkiaer in Terbindung mit Ostenfeld (Raunkiaer and Ostenfeld 1903) auf zahlreiche andere Kompositengattungen aus. mit positivem Erfolge aber nur bei der außerordentlich artenreichen Gattung Hieracium. Bei 20 verschiedenen. mehreren Grupuen der Untergattungen Pilosella und Archieracium angehörenden Arten dieser Gattung erfolgte reichliche Fruchtbildung auch in Blütenküpfchen. die nach der für Taraxum beschriebenen Iethode kastriert worden waren. Die embryologische Cntersuchung wurde wiederum ron Firchner (1904, 1) 87) bei Hieracium aurantiacum und ron MI urbeck (1904. p. 291 ff.) bei Hieracium grandidens, scrotifrons und colowhyllum vorgenommen, mit dem Ergebnis, daß in allen Fällen der Embryo aus den Eizellen hervorging. Ostenfeld (1904a) stellte noch ausdrücklich fest, dab die von kastrierten Bliiten gebildeten Samen keimfähig waren. Overton hat nach Strasburger 1904 . p. 117) die Angaben von Ostenfeld und Rannkiaer in Bonner botanischen Garten mit dem gleichen krgebnisse nachgeprüft.

Die Mitteilung, daß wahrscheinlich alle Pilosellen und Archieracien parthenogenetisch seien, mubte deswegen ganz besonderes Interesse erregen. weil Hieracien-Bastarde anch aus diesen beiden Cntergattungen bekannt waren (vgl. Z a hn 1904, Correns 1905. p. 348 ff. I. Da viele dieser Bastarde experimentell von einem so zuverlässigen 
Forscher wie Ml endel hergestellt worden waren, war an ihrem tatsächlichen Bestehen nicht zu zweifeln; uiberdies stellte Ostenfeld (1904b) selbst einen Bastard zwischen Hieracinm pilosella und aurantiucum her, denen er später (Ostenfeld 1906) noch mehrere andere amreilıte. deren Eltern ebenfalls Arten waren, von denen es feststand, dab sie nach Kastration keimfähige Samen ansetzen können. Übrigens stellte es sich heraus, dab nicht alle Arten der beiden Untergattungen parthenogenetisch sind. sondern nur die Mehrzahl; so sind z. B. im subgenus Pilosella Hieracium auricula, im Subgenus Archieracium Hieracium umbellatum amphimiktisch geblieben.

Die Tatsache, dab für ein und dieselbe Species die Befähigung zur Parthenogenesis und zur Amphimixis festgestellt worden war, bot nach dem, was $O$ vert 0 n bei Thatictrum mupurascens gefunden hatte. der Erklärung keine prinzipiellen Schwierigkeiten. Correns (1905, y. 250) dentete anch diese Erklärungsmöglichkeit an und führt zu ihren gunsten eine Beobachtung von ir endel an, ,nach der ein Hieracienköpfchen, das durch Parthenogenesis a keimfähige Frïchtchen hervorbringt. nach möglichst frühzeitiger Belegung aller Narben mit fremden Pollen $a+b$ keimfähige Früchtchen bringt, von denen a die Mutterpflanze, b den Bastard geben". Wie die Dinge tatsächlich liegen. darüber brachten zwei wichtige Arbeiten ron Rosenberg (1906 und 1907) Aufklärung. Nach ihnen 'wollen wir einen kurzen Überblick über die Fortpflanzungsserhältnisse der nicht mehr normal amphimiktischen Hieracien geben. wobei freilich bemerkt werden mub, dab unsere Kemntnisse dariber noch sehr lïckenhaft und weitere Arbeiten über die sehr interessante Gattung dringend erwünscht sind.

Der Übersichtlichkeit wegen bringen wir die Hieracien hinsichtlich ihrer Fortpflanzungsverhältnisse in drei Gruppen. von denen die erste alle Arten umfaßt, bei denen die normale Amphimixis in der typischen Form beibehalten worden ist. Hierher scheinen alle nicht zu den Sektionen Pilosella und Archieracium gehörigen Arten zu rechnen; ausdrücklich durch Kastrationsversuche festgestellt ist es allerdings bisher erst durch Ostenfeld (1906) für Hieracium renosum und II. Gronowii, die der [ntergattung Stenotheca angehören. Aber auch Hicracium umbellatum ans dem Subgenus Archieracium und H. auricula aus dem Subgenus Pilosella sind, wie schon erwähnt, obligatorisch amphimiktisch. Alle diese zur ersten Gruppe gehörenden Sivecies interessieren uns an dieser Stelle nicht, da sie sich in ihrem Terhalten in keinerlei Teise von anderen normal sexuellen Phanerogamen principiell unterscheiden.

Zur zweiten Gruppe zählen wir alle die Hieracien, die rein somatisch parthenogenetisch nach dem Schema der Fualchimillen sind, bei denen also die Diploidchromosomigkeit des Gametophyten einfach durch Ausschaltung der Reduktionsteilung erreicht wird, und 


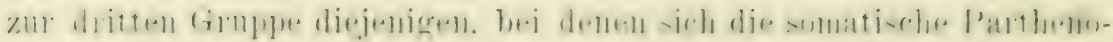

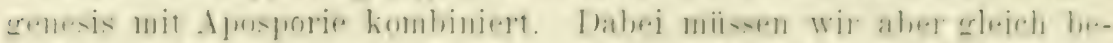

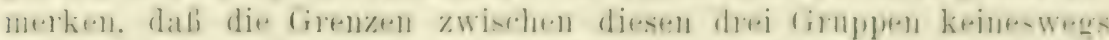

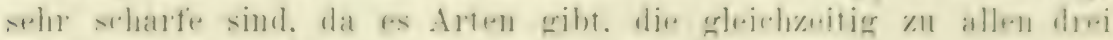
Gruppen oder zu zweien von ihnen gehören können.

Von den nicht apomiktischen Hieracien sei nur erwälnt. dab

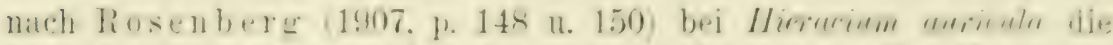

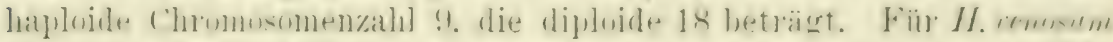

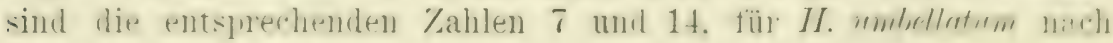
Juel (1905) 9 und 18.

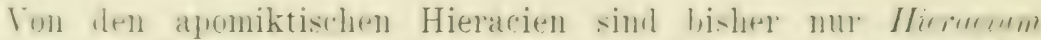

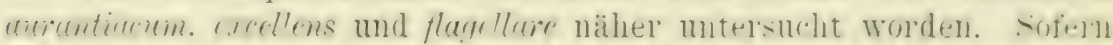
sich die an ditsen drei Arten gewomenen Ercebnisse verallgenminnm lassen. scheinen sie zu dem schlusie zu tühnen. dab bei der trattung? Hirarbm besonders häufig die Kombination der somatischen Palthenogenesis mit der Aposprorie auftritt. und dab Arten. die rein mus zweiten Gruppe angehören, verhältnismäßig selten sind.

Die Jikrosporenentwicklung verläuft bei Hierarim flumfllor normal und liefert Pollen. deren Ferne dis reducierte l'hrommonmenzahl 21 besitzen. Bei Hierminm ercollens findet sich in den fertigen Antheren kein Pollen mehr. da er, wie die entwicklungsceschichtlicht Entersuchung lehrt, schin vor oder während der Peduktionsteilung desorganisiert wird. Die haploide Chromosomenzahl scheint etwat 17 zu betragen.

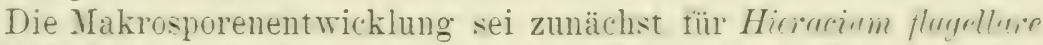
geschildert. Das Archespor ist wie bei allen anderen Hieracien einzellig. und der ganze Nucellus besteht nur aus dieser einen Archeslorzelle und einer sie umhiillenden Epidermis-Zellage. Die Archesforzelle stellt zugleich die Embryosackmutterzelle dar, die durch eine 'Tetradenteilung vier Makrosporen liefert. ron denen die immerste zur Keimung relangt, also zum Embryosack wird. Da mit del Tetradenteilung eine Reduktion der Chromosomenzahl ron 42 auf 21 relbunden ist. so entsteht ein normaler Gametophyt mit haploidchrmmosomigen Kernen. und die ganze Entwicklung verläuft also durchaus: typisch.

ther das ist nun bei Hieracium flagcllare seln selten zu beobachten. Es kommt zwar ror. dab die Makrosporenentwicklung in der then geschilderten Treise rerläuft, aber in den allermeisten Fällen hommt der normale Entwicklungsprozeb nach oder oft auch schon vor der Tetradenteilung zum Stillstand. und an Stelle der Makrospore liefert eine somatische Zelle des Sporophyten den Embryosack. Das kamn eine Epidermiszelle des Nucellus, aber auch eine Zelle aus der Chalazaregion oder rom Integumente sein. Fig. 11 erläutert diesen merkwïndigen Torgang. Bei A ist die Makrosporentetrade dentlich 
noch erkenmbar. neben ihr aber liegt eine gröbere Zelle, deren embryonale Natur unverkennbar ist. Sie hat sich bei B weiter vergrößert, während die Degeneration der Tetrade fortgeschritten ist, und bei C ist sie zum Embryosack im Stadium der Zweikernigkeit geworden und bereits sehr viel größer als der Nucellus mit den Makrosporenresten, der rechts oben in der Figur noch kenntlich ist. Von da geht die Entwicklung des Ersatzembryosackes durchaus normal weiter, die Antipoden, Synergiden und die Eizelle werden ausgebildet, und zwei Polkerne wandern zueinander hin und legen sich aneinander, um später zu verschmelzen. Die Eizelle des so entstandenen Embryosack teilt sich dann und bildet den Embryo, ohne befruchtet worden zil sein.

Zweifellos hat Rosenberg (1906, p. 159) Recht, wenn el diesen Vorgang als Aposporie auffaßt. Denn der Gametophyt entsteht ja nicht aus der Spore, sondern aus einer vegetativen Zelle des Sporophyten. Und da diese die unreducierte Chromosomenzahl, in diesem Falle 42, besitzt, und bei ihrer Entwicklung zum Gametophyten auch keine Reduktionsteilung eingeschaltet wird, so sind auch die Kerne des Gametophyten, also auch der Eizellkern mit der diploiden Chromosomenzahl ansgerüstet, während die Endo-
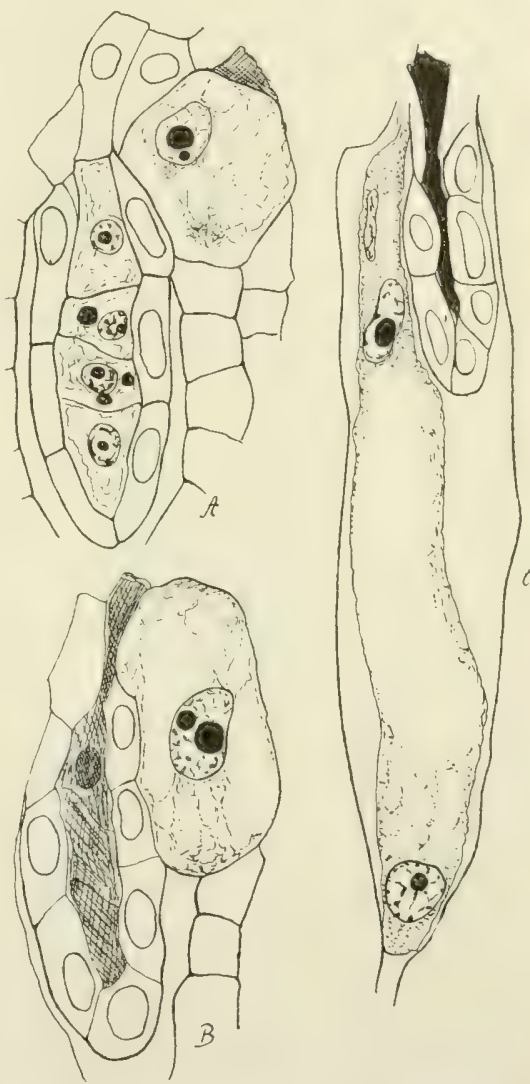

Fig. 11. Hieracium flagellare. Erklärumg im Text. (Nach Rosenberg 1907, Fig. VII, p. 158.) spermkerne je 82 Chromosomen führen müssen. Es liegt also somatische Parthenogenesis in Krombination mit Aposporie vor.

Wie wir sahen, kann bei Hicracium flagellare die Embryosackentwicklung auch ganz normal verlaufen und zul Entstehung von Gametophyten mit haploidchromosomigen Kernen führen. Es kommen hier also nebeneinander amphimiktische und apomiktische Blïten vor, und zwar nicht nur an demselben Individuum, sondern sogar in ein 


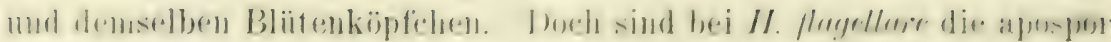
entstandenen Lmbryosäcke weit häufiger als die normalen.

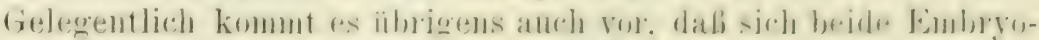

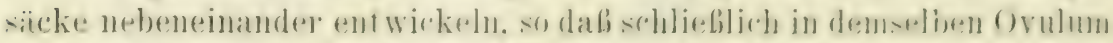
ein typisches und rin aposporer Embryosatek nebeneinander rorhanden sind. Wird das Ei des ersteren infolge der Bestäuhung mit r.ine. anderen Hierarimart befichtet - eigenen reifen Pollen entwickelt die Art ja nicht - so kïmnen anch zwei Embryonen auserebildet werden. Einige soldhe Fäle giht Fig. 12 wieder. Bei A sind zwei

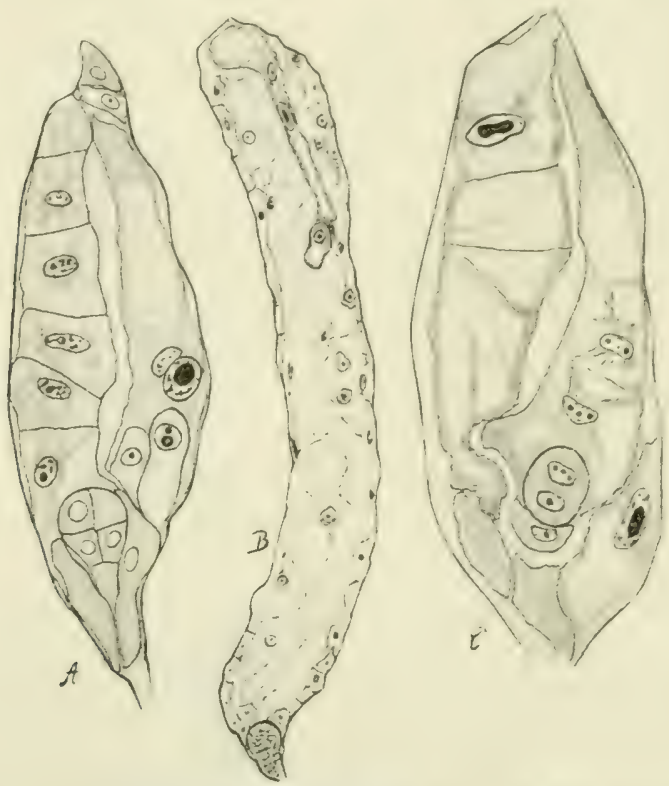

Fig. 12. Hieracium flagellare. Erklärung im Text. (Nach Rosenberg 1907, Fig. XI, p. 161.)

Embryosäcke vorhanden. von denen der linke bereits Endosperm und einen Embryo besitzt. während der rechte, wahrscheinlich der typische. sich nicht weiter entwickelt hat. rermutlich weil die Befruchtung. ausblieb. B stellt ein offensichtlich älteres stadium dar. in dem der typische noch das Ei und die Polkerne zeigende Embryosack röllig. rom Endosperm des aposporen umschlossen ist. Bei C' endlich sind zwei Embryosäcke zu sehen, beide mit Embryo und Endosperm. Hinsichtlich weiterer solcher Einzelheiten mub auf Rosenberg"s Originalarbeit verwiesen werden.

Hieracium excellens verhält sich insofern ganz ähnlich, als auch bei ihm normale und apospore Embryosackentwicklung in der fiur Hieracium flagellare geschilderten Weise eintreten kann. Aber die 
Zahl der normalen Embryosäcke ist hier verhältnismäßig erheblich gröber als bei der letzteren Art. und so erklärt es sich, dali Ostenfeld bei Bestäubung ron Hicracium excellens mit Pollen ron $H$. aurantiacum Hybride erhalten konnte. Offenbar sind es die Eier der typischen Gametophyten, die bei diesen Bastardierungsversuchen den Embryo liefern, wenn es freilich a priori auch nicht als ausgeschlossen gelten kamn, daß auch in den apospor entstandenen Gametophyten die diploiden Eizellen befruchtungstähig sind. Tielleicht läßt sich das gerade imnerhalb der Gattung Hieracium entscheiden.

Außer der normalen und der aposporen Entstehungsweise des Embryosackes findet sich nun bei Hieracium excellens wemn auch selten noch eine dritte: wie bei Taraxacum nämlich teilt sich die Embryosackmutterzelle nur einmal und mit der umreducierten Chromosomenzahl. Auch so entsteht also ein Gametophyt, dessen Kerne mit der diploiden Chromosomenzahl ausgerïstet sind; es kommt das aber nicht durch Aposporie. sondern durch Ausbleiben der Reduktionsteilung zustande.

Hieracium aurantiacum bildet nach Rosenberg (1907, p. 15̃8) fast ausschließlich apospore Embryosäcke, die gewöhnlich ans einer Epidermiszelle des Nucellus hervorgehen. Tielleicht indessen findet sich hier auch noch eine wesentlich andere Art der Embryosackbildung, die darin besteht, daß nach dem zweiten Teilungsschritte die Wandbildung zwischen den beiden hinteren Kernen der Tetrade ausbleibt. worauf diese beiden mit der haploiden Chromosomenzahl ausgestatteten Kerne miteinander verschmelzen. Aus dieser Zelle entrickelt sich dann der Embryosack. Die Beobachtungen, auf die sich Rosenberg hierbei stützt, sind allerdings noch sehr lückenhaft und bediirfen der Bestätigung. Sollten sie diese finden, so lïge ein Vorgang vor, der in mancher Hinsicht an psendo- und parthenomiktische Prozesse erinnerte.

Die letzte Phanerogame endlich, bei der mit Sicherheit Parthenogenesis konstatiert worden ist, ist die Thymelaeacee Wikstroemia indica (L) C. A. Mey. (Winkler 1904 und 1905). Das ist ein im indisch-malayischen Gebiete weit verbreiteter Strauch, der das ganze Jahr hindurch blüht und reichlich fruchtet, obwohl normaler Pollen sehr selten ist. Daß die Fruchtbildung hier ohne Mitwirkung des männlichen Elementes erfolgen kann, wurde durch zahlreiche Kastrationsversuche festgestellt; wahrscheinlich findet eine Befruchtung iiberhaupt nie mehr statt. Die cytologische Untersuchung ergab, daß der Embryo aus der Eizelle hervorgeht, es handelt sich also um echte Parthenogenesis.

Wie schon erwähnt wurde, verläuft die Mikrosporenentwicklung. nur sehr selten normal, wobei eine Reduktion der diploiden Chromosomenzahl 52 auf die haploide 26 stattfindet. Meistens treten schon 


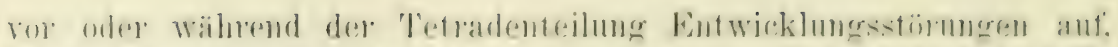

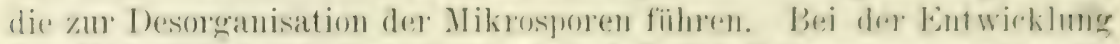

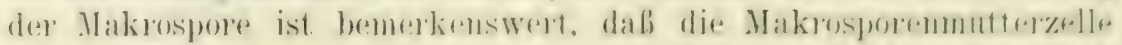

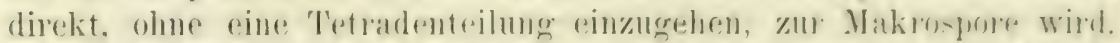

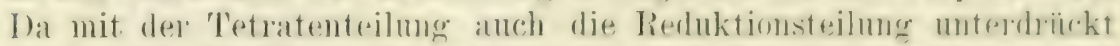

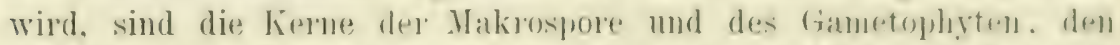
diese bei ihrer Keimmog in durchans typische Ausbildung liefert. mit

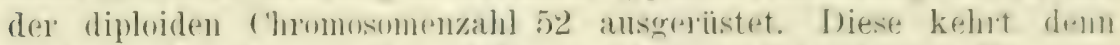
auch in den hernen des sich ans dem mbefiuchteten Fie entwickelnden Embryos wiederl. Dite Samen erwiesen sich als heimfähig. Fs liegt demmach also somatische Parthenogenesis vol, und zwar in eince Form, die sich durchans an die bei Traranam rorkommende anschließt.

Überblicken wir rückschanend die Torkommnisse ron somatischel. Parthenogenesis, so finden wir sie rerteilt anf folgende Familin:

Polypodiacene (Athyrium Fitix-focmina var. clorissima $\mathrm{B}$ olt 1 n n und var. unco-glomeratum Stansfield; Scolopendrium vulgare var. crispum Drummondae),

Marsiliaceae (Marsilia Drummondii R. Br.),

Ranunculaceae (Thatictrum purpurascens, Th. Fendleri),

Rosaceae (Alchimilla \& Eualchimilla),

Thymelaeaceae (Witistroemia indica),

Compositae (Antemaria alpina, A. fallax, A. neodioica: Tarararim: Hicracium \$ Archieracium und \$ Pilosella, je fast vollständig).

Bei allen den erwähnten Arten ist die Mikrosporenentwicklung: melır oder weniger gestört, so dab entwerler gar kein oder nur ganz wenig normaler Pollen mehr entsteht. Nur Thalictrum purpurascons und Hicracium aurantiacum machen hielvon eine Ausnalmme. indem sie vollkommen normalen und, wie wenigstens für Hicracium anrurtiacum durch Bastardirungsversuche ausdriicklich festoestellt worden ist, auch befruchtungsfähigen Pollen hervorbringen. Beide Arten sind aber auch im weiblichen Geschlecht noch nicht gänzlich apomiktisch geworden, da partiell bei ihnen die Nakrosporenbildung noch normal $\mathrm{TOP}^{\circ}$ sich geht. Doch kann zwischen diesem Tmstand und dem normalen Verlaufe der Pollenentwicklung kein direkter kausaler Zusammenhang bestehen, da bei dem ebenfalls noch partiell sexuellen Hieracium excellens kein guter Pollen mehr entsteht. und andrerseits manche habituell parthenogenetischen Taraxaca normale Mikrosporen auszubilden scheinen.

Daß der Kern der Eizelle die diploide C'hromosomenzahl erhält. wird auf zweierlei Teise erreicht: einmal durch Kombination mit Aposporie (so bei den parthenogenetischen Polypodiaceen und einigen 
Hieracien), und dam dadurch, dab der Gametophyt zwar aus einer Spore hervorgeht, daf aber bei deren Bildung die Reduktionsteilung unterbleibt (so bei den anderen erwähnten somatisch parthenogenetischen Gewächsen). Bei der zweiten Modalität bestehen zwischen den einzelnen Arten nicht unwesentliche Unterschiede hinsichtlich der Anzahl von Teilungen, durch die die Makrosporenmutter'zelle zur Makrospore wird. Normalerweise sind es zwei 'Teilungsschritte, die man unter dem Namen Tetradenteilung zusammenfaßt, und während deren die Reduktion der Chromosomenzahl erfolgt; es entstehen dabei natïlich vier 'Tochterzellen, die vier Makrosporen, von denen aber' bei den höheren Pflanzen gewöhnlich nur eine zur Keimung gelangt und den Gametophyten liefert, während die drei anderen resorbiert werden.

Da also nur noch die Entstehung einer einzigen Makrospore erforderlich ist, wäre die Tetradenteilung an sich überflüssig, und wenn sie trotzdem bei der ïberwiegenden Mehrzahl der amphimiktischen Phanerogamen beibehalten worden ist (und auch bei den Tieren in der Polkörperbildung), so hängt das wohl damit zusammen, dab eben mit der Tetradenteilung die Reduktion der Chromosomenzahl verknüpft zu sein pflegt.

Da num bei den somatisch parthenogenetisch gewordenen Pflanzen aber auch diese Reduktion unnötig geworden ist, fällt anch der letzte Grund für die Beibehaltung der 'T'etradenteilung, und so finden wir' dem auch, dab sie ganz oder' wenigstens partiell ausgeschaltet wird. Bei Marsilia, Thatictrum und den Eualchimillen finden wir den geringsten Grad der Rückbildung: hier ist die volle Tetradenteilung beibehalten, nur erfolgt sie durch zwei typische Karyokinesen. In anderen Fällen ist eine der beiden Teilungen unterdrückt, so bei Taraxucum, manchen Hieracien, und in wieder anderen schließlich fallen beide aus, so bei Antemaria und Wikstroemia.

Man kann darin eine Anpassung an die Parthenogenesis erblicken, was freilich im Grunde nur dann statthaft ist, wenn man die Korrelation zwischen Tetraden- und Reduktionsteilung für sehr enge hält; denn nur dann wïrde das Überflüssigwerden der letzteren das der ersteren begreiflich machen. Nun sind aber die Korrelationen zwischen den beiden Erscheinungen keineswegs unlösbare, denn wir kennen obligatorisch amphimiktische Pflanzen (Litium, Lemna, Narcissus, Costus, Sium u. a.), bei denen - offenbar in Anpassung daran, daß doch nur eine Makrospore zur Keimung gelangt - die Tetradenteilung nicht stattfindet und die Reduktionsteilung auf die ersten Keimungsteilungen der Makrospore verlegt worden ist. Ja sogar bei ein und derselben Species, Salix glaucopluylla, kann sich nach Chamberlain (1897) die Makrosporenmutterzelle einmal, zweimal oder gar nicht teilen. Es geht also daraus hervor, daß die Tetraden- 


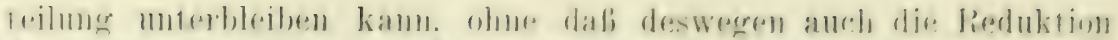

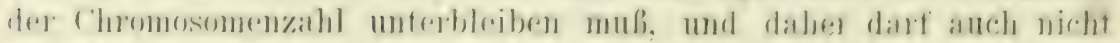

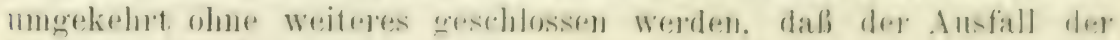
letzteren den der ersteren nach sich ziehen misse.

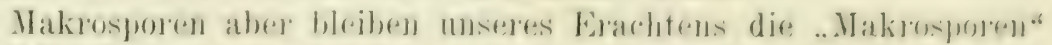

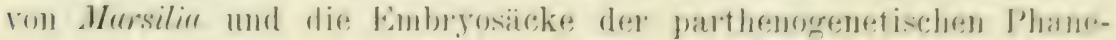

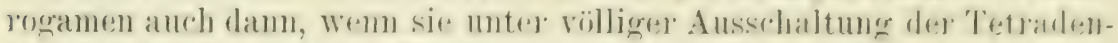

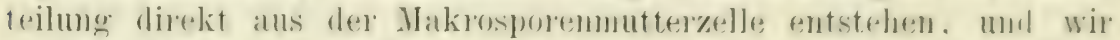
kionnen daher sitrasbureger (190)- 1\%. 160) nicht zustimmen. Wenu "re sie nicht mehr als Makrosporen gelten lassen. sombern in ihnen

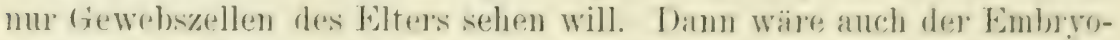
sack von Lithom usw. keine Makrospore. Whensowenig kijnnen wir

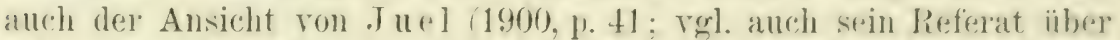
Rosenberg"s Hierarium-Arbeit im Botan. ('entrabl., Bal. 104. 1967,. 1. 646) beipflichten. wonach die Entstohng des Embrysarkes ans der Embryosackmutterzelle olme 'Tetradenteilung als ein mit der Aposporie homologer Vorgang aufgefalst wird; dem dann miifote auch bei Lilinm Aposporie vorliegen, was .T nel (1. c. 1900) ansdrürklich ablehnt, und ïberdies ist ja hier die sporenbildnng nicht ansqueschaltet wie bei der Aposporie. sondern sie erfolgt nur anf andere II eise. und der Gametophyt geht auch hier aus der Spore hervor.

\section{B. Generative Parthenogenesis.}

Das Tresen der generativen Parthenogenesis besteht darin. dabi sich ans einem unbefruchteten Ei, dessen Kern mit der haploiden ('hromosomenzahl ausgerüstet ist, ein Sporophyt bildet. Es sind dabei, wie bei der generativen Apogamie, theoretisch zwei Fälle denkbar: 1. kann der ganze Entwicklungscyklus olne Änderung der Chromosomenzalı, also mit damernder Beibehaltung der haploiden Phase durchgemacht werden. Der Gametophrt hat damn die fïr iln typische, der Sporophyt die fïr ihn abnorme haploide ('hromosomenzahl, und eine Reduktionsteilung bei der Sporenbildung wäre natürlich undenkbar: 2. kömnte bei der Entwicklung des haploidchromosomigen Eies zum Sporophyten eine regenerative Terdoppelung der ('homosomenzahl eintreten, so dab sich also der ganze Entwicklungsgang von dem normalen nur dadurch unterschiede, dab die an sich durch rlie Befruchtung erfolgende Verdoppelung der Chromosomenzahl hier auf eine apomiktische Weise erzielt wïrde.

Fiir die letztere Form der generativen Parthenogenesis sind aus dem Pflanzenreiche bisher noch keine Beispiele bekannt geworden, und es erïbrigt sich daher fuir uns eine eingehendere Diskussion rariber. Fs sei nur kurz darauf hingewiesen, daß jedenfalls keine 
theoretischen Gründe dafuir vorhanden sind, dab sie überhaupt nicht vorkommen könne; denn es sind aus dem Tierreiche Fälle von generativer Parthenogenesis mit stattfindender Chromosomenverdoppelung bekannt. So fand Kostanecki (1904), dab in den Eiern von Mactra, einem Mollusken, die er, obwohl sie nur die haploide Chromosomenzahl besaßen, durch gewisse Mittel künstlich zu parthenogenetischer Entwicklung veranlassen komnte, die bei der ersten Teilung auftretenden 'Tochterchromosomengruppen sich zu einem nunmelr mit der diploiden Chromosomenzahl ausgerïsteten Kern vereinigen. Es ist das ein Verhalten, das in mancher Hinsicht an die Parthenomixis erinnert (vgl. p. 28).

Die andere Form der generativen Parthenogenesis hat mit der generativen Apogamie das gemeinsam, daß bei ihr der ganze Entwicklungskreislauf mit der haploiden Chromosomenzahl verläuft, wie das ja auch z. B. bei dem generativ apogamen Nephrodium molle der Fall ist. Auch hierfür haben wir bemerkenswerte Beispiele aus dem Tierreiche. So ist die bekannte experimentelle Parthenogenesis der Seeigel an dieser Stelle zu nennen, vor allem aber die beriihmte Parthenogenesis der Honigbiene. Für deren sich parthenogenetisch entwickelnde Drohneneier hatte Petrunkewitsch (1901) angegeben. dab bei der ersten Furchungsteilung eine regenerative Verdoppelung. der Chromosomen einträte; nach den neuesten Untersuchungen von M eves (1907) aber liegen die Dinge hier anders: das Ei entwickelt sich einfach mit der haploiden Chromosomenzahl 16, so daß später bei der Spermatogenese im Drohnenhoden keine Reduktion stattfindet, und die eigentümliche Tatsache vorliegt, daß das Männchen einer Species durchgehends die haploide, das Weibchen in allen Zellen abgesehen von den reifen Eiern die diploide Chromosomenzahl führen.

Ton Archegoniaten und Phanerogamen kennen wir bisher noch kein sicheres Beispiel generativer Parthenogenesis. da sich, wie schon erwähnt, die Angabe von Nathansohn (1900), wonach bei manchen Marsilia-Arten solche durch Temperaturerhöhung künstlich inducierbar sein sollte, bei der Nachuntersuchung durch Strasburger nicht bestätigt hat. Für theoretisch unmöglich können wir es aber auch bei Archegoniaten und Phanerogamen nicht halten, daß ein Ei mit der reducierten Chromosomenzahl im Kern sich unbefruchtet zu einem Sporophyten mit haploidchromosomigen Kernen entwickelt, da es eben im Tierreich genug Fälle dafür gibt, und wir ïberdies wissen. daß bei der generativen Apogamie von Lastrea pseudomas cristata apospora und von Nepluodium molle aus den haploidchromosomigen Zellen des Prothalliums haploidchromosomige Sporophyten hervorgehen, deren Habitus durchaus normal ist.

So sind es nach dem gegenwärtigen Stande unserer Kenntnisse nur gewisse Algen (und vielleicht auch einige Pilze), die uns Beispiele 


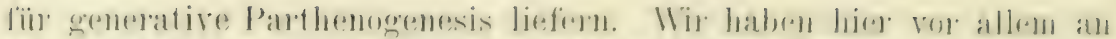

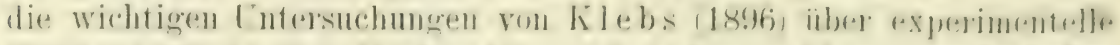

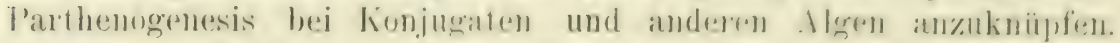
soweit es sich dabei mm lorkommmisse handelt. dise regologisch moreh nicht gekläl sind, wenn sie anch experimentell völligr surhorgostollt sind, haben wir sie bereits im zweiten Kapitel kur\%

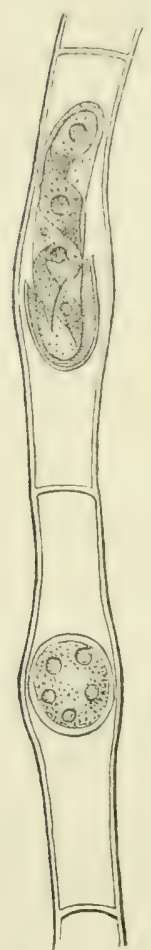

Fig: 13. Spirogyra mirabilis. Erklärung im Text.

(Nach Klebs 1896 ,

Fig. 7, p. 255.) besprochen, worauf hier nochmals verwiesen sei.

Conjugatae. Die Angaben über Parthenogenesis bei Mesotaeniaceen, über die man bei Oltmanns (1904, p. 55) einiges findet, sind noch unsicher. Dafür liegen um so genauere Untersuchungen uiber' die 'Zygnemaceen vor (K lebs 1896, p. 245), die zwar auch noch der ergänzenden Aufhellung der cytologischen Einzelheiten bedürfen, immerhin aber auch so schon eine verhältnismäßig genaue Beurteilung zulassen.

Es lagen, als $\mathrm{Klebs}$ seine Untersuchungen begann, schon eine Reihe von gelegentlichen friheren Beobachtungen dariber vor, daß die Protoplasten kopulierender Zellen mancher Spirogyra-Arten und anderer Zygnemaceen aus irgendwelchen zufälligen Grïnden nicht zur Verschmelzung gelangten, sondern fü sich zur Ruhe kamen und Azygosporen oder Parthenosporen bildeten. Wenn es sich dabei um an sich normal sexuelle Formen handelte, bei denen die Parthenosporenbildung offenbar nur unter ganz bestimmten Bedingungen eintrat, so waren andererseits auch Arten bekannt, die, vollkommen geschlechtlos geworden, nur noch zygotenähnliche ungeschlechtliche Sporen erzeugen. Beide Fälle sind natürlich scharf voneinander zu unterscheiden.

Was zunächst die völlig apomiktisch gewordenen Zyonemaceen anbelangt, so mag das Verhalten der bekamnten Spirogyra mirabilis (Hassall) Ktzg. als für sie typisch kurz geschildert sein (nach hlebs 1896, p. 25், wo auch ältere Literaturangaben).

Temn bei dieser Art die Sporenbildung einsetzt, so schwellen die Zellen der Fäden an, während sich gleichzeitig ihr Protoplast kontrahiert, um sich in eine braun gefärbte Spore umzuwandeln, die rollkommen den Zygoten der anderen Arten entspricht. Auch bei der Keimung verhalten sich die Parthenosporen genau wie die Zygoten. Bemerkenswert ist nun vor allem, daß, wie $\mathrm{K} l \mathrm{l}$ bs feststellte, die Sporenbildung bei Sprirogyra mirubitis von durchaus den gleichen Bedingungen abhängt, wie die Zygotenbildung durch Kopulation bei den 
normalgeschlechtlichen Arten. Freilich lälit sich darans allein nicht etwa der sichere Schlub ziehen, dab in der Tat eine apomiktisch gewordene Art vorliegt. Oltmanns $(1904$, p. 71) möchte das annelmmen, während Klebs dazu neigt, in Sprogyra mirabilis den einfachsten 'Typus einer noch nicht geschlechtlichen Art zu sehen. von der erst die konjugierenden Species abstammen. In diesem Falle würde es sich natïrlich nicht um Apomixis handeln. Wenn solche aber vorliegt, was sich freilich schwer wird entscheiden lassen, müßten wir in Spirogyra mirabilis eine habituell parthenogenetisch gewordene Art erblicken. Ebenso natürlich auch in anderen sich wie Spirogyra mirabilis verhaltenden Zygnemaceen, wie Zygnema spontaneum, Zygnema reticulatum $\mathrm{H}$ a $1 \mathrm{l}$ as und Gonatonema Wittrock.

Sicherer beurteilen läßt sich die fakultative Parthenogenesis der normal sexuellen Arten, wie sie nach Beobachtungen von Rosenvinge (1883) am natürlichen Standorte bei Spirogyra groenlandica vorkommt, bei der sich in den Fäden bald Zygoten, bald Parthenosporen fanden, und wie sie Klebs (1896, p. 246 ff.) durch künstliche Eingriffe bei Spirogyra inflata, longata und varians hervorrufen konnte.

Es gelang Klebs, bei den drei erwähnten Arten dadurch künstlich Parthenogenesis herbeizuführen, dab er die Protoplasten der Gameten im richtigen Moment durch schwach wasserentziehende, dabei nicht schädliche Substanzen an ihrer Tereinigung hinderte. Es entstanden so mit derber Irembran umgebene Parthenosporen, die im Bau

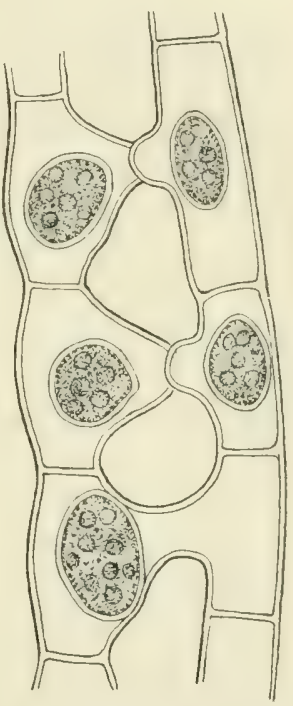

Fig.14. Spirogyra varians. Parthenosporenbildung. Die Alge war nach Begim der Kopulation in 1 proz Nährlösung ïbertragen worden. Unten eine Zygote in der Mitte und oben je zwei Parthenosporen.

(Nach K lebs 1896, Fig. 5, p. 249.) und in der Keimfähigkeit vollkommen den Zygoten entsprachen und sich von diesen nur durch geringere Größe unterschieden, anch wohl durch etwas geringere Widerstandsfähigkeit und späteren Eintritt der Keimung. Bei Spirogypo longata und rarians besteht zwischen den männlichen und den weiblichen Gameten nicht der geringste Unterschied hinsichtlich der Fähigkeit, Parthenosporen zu bilden, bei Spirogyra inflata dagegen scheinen die weiblichen Zellen besser dazu imstande zu sein als die männlichen.

Dabei ist nun sehr beachtenswert, daß nicht jede beliebige vegetative Zelle, sondern nur eine solche, die in der Vorbereitung fiur die Konjugation begriffen ist, zur Parthenogenesis genötigt werden 


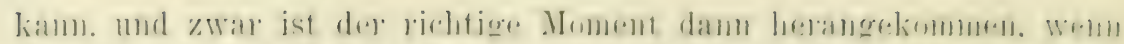

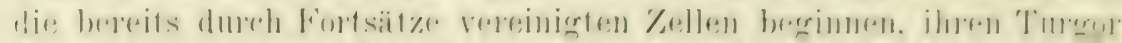

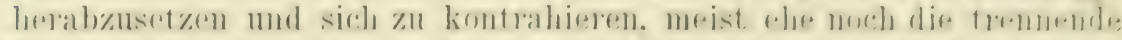

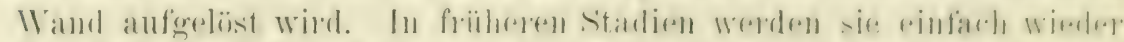

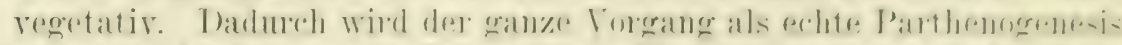

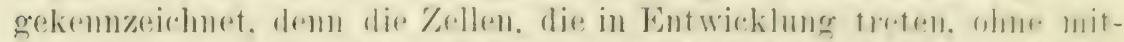

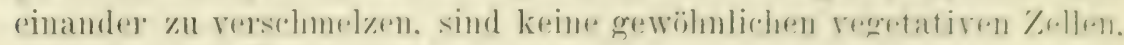
sondern echte Keimzellen.

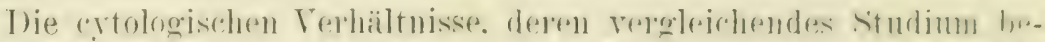

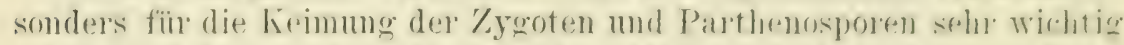

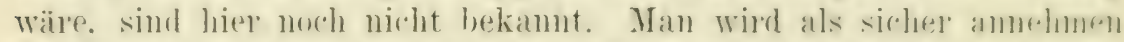

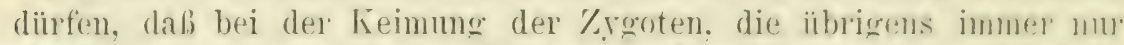
einen Keimling eroiht. eine lieduktion der ('hromosomenzall staltfindet. Anch die neneste Arbeit hierïber von Tröndle (1907: rol. dort die ailtere Literatur) gibt darïber noch keinen comoriltigen tufschluf. Da aber der spirogrra-Farden haploid ist. und in der zygute nachgewiesenermaßen eine regelrechte Kernvelschmelzung stattfindet. ist die Annahme mnermeidlich. dab die ersten Keimungstrilungen die Reduktion durchführen. Bei der Keimung der Parthenospuren wird man entsprechend annehmen können, dab einfach die Rednktion unterbleibt und die ersten Teilungen typisch rerlauf(en. wie das jat gar nicht anders sein kamn, da nur haploidchomosomice lierne vor'handen sind.

Wahrscheinlich ist die Befähigung zu solcher takultativer gentrativer Parthenogenesis imerhalb der Familie der Zygnemaceen w verbreitet. Untersuchungen dariber wären erwiunscht.

Auch bei verschiedenen Desmidiaceen konnte li lebs iscat. p. ¿ら́tif.) kïnstliche Parthenogenese herbeiführen. Fr berichtet dariiber (1. c., 1). 2(j0): .. Tch bemerkte sie [Parthenosporen] zuerst hui Cosmarizm Botrytis in 5jproz. Rohrzuckerlösung. Der Beginn der Kopulation verlief ganz normal, die beiden Zellen. durch Gallerte vereinigt, öfneten ihre Zellwand. die Protoplasten traten heraus. kamen aber. ohne Terschmelzung zu zeigen, jeder für sich zur Ruhe und bildeten sich zu Sporen um, an denen anch die clarakteristische Stachelbekleidung helrortrat. Sie glichen in allem den Zyoten. nur daß sie kleiner waren. Als ich kopulationsfïhiges Material von Closterim Lumla zur Terfïgung hatte. wandte ich ebenfalls eine 4 proz. Rohrzuckerlösung an. Es bildeten sich iiberhaupt ausschlieblich Parthenosporen ans. Diese blieben aber immerhalb der alten Zellmembran stecken, obwohl diese an der gewïhnlichen Stelle gesprengt und an der Öffnung mit Gallertesubstanz rerselien war. Ich bemerkte indessen auch Zellen. wo die Membran noch unzerrissen war und die Parthenospore noch ganz umschlob, die sich zu einer zygotenähnlichen, reifen spore ausgebildet hatte. Wir haben dem- 
gemäß bei den Desmidiaceen die gleiche Erscheinung wie bei Spirogyra. Zwei Zellen, die sich zur Kopulation anschicken, erzeugen bei Anwendung schwach wasserentziehender Mittel je eine Parthenospore."

Über die Keimung der Parthenosporen ist noch nichts bekannt, ebensowenig etwas über die Kernverhältnisse. Doch wird man, da bei der Keimung der Zygoten zweifellos eine Reduktionsteilung stattfindet und die vegetativen Desmidiaceenzellen haploid sind, die Parthenogenesis von Cosmarium und Closterinm als generative ansehen mïssen.

Dictyotaceae. Wenigstens Ansätze zu einer parthenogenetischen Entwicklung der Eier sind auch bei den Dictyotaceen beobachtet worden. Williams (1905, p. 553) fand, daß unbefruchtete Eier von Dictyota und von Haliseris "segmented a few times parthenogenetically and then died". Es war das iibrigens auch Th hret und Bornet schon bekannt.

Hier besteht also zwischen den befruchteten und den unbefruchteten Eiern der sehr wesentliche Unterschied, daß sich nur aus den ersteren lebensfähige Keimlinge entwickeln künnen. während das Trachstum der unbefinchteten Eier, soweit die Beobachtungen reichen, schon nach einigen wenigen Teilungen zum Stillstand kommt. Doch möchte ich es für wahrscheinlich halten, daß es gelingen dïrfte. sie unter gewissen Bedingungen doch zur Weiterentwicklung zu veranlassen. Da ihre Kerne die reducierte Chromosomenzahl besitzen, handelt es sich um Ansätze zu generativer Parthenogenesis.

In allen diesen Fïllen von generativer Parthenogenesis bei Algen könnte man freilich sagen, sie sei nicht unmittelbar mit einer eventuell bei Phanerogamen vorhandenen generativen Parthenogenesis vergleichbar, weil bei diesen der diploidchromosomige Sporophyt die dominierende Generation sei, die dann haploidchromosomig auftreten müsse, während bei Spirogyra. Cosmarim usw. der Thallus von vornherein haploid ist. In diesem Sinne haben sich auch \%. B. D a vis (1905, p. 562) und Strasburger (1906, p. 2) geäußert. Beide sind der Ansicht, die Leichtigkeit, mit der sich bei Chlorophyceen und bei Phaeophyceen Parthenogenesis einstelle. hänge damit zusammen, daß bei ihnen nur noch die haploide Generation vorhanden sei, und die Gameten die für diese nötige Chromosomenzahl besäßen. Sie brauchen demnach nur zum Thallus auszuwachsen.

Wir kömnen diese Auffassung nicht teilen und werden das in dem Kapitel, das die Beziehungen zwischen Parthenogenesis, Apogamie und Generationswechsel behandelt, ausführlich zu begründen versuchen. Hier sei nur kurz darauf hingewiesen, daß ja die Eizelle tatsächlich gar nicht direkt zum Thallus ausmächst, sondern zur Parthenospore wird, also zunächst in das Zygotenstadium uibergeht, und das stellt eben bei den erwähnten Algen die Sporophytengeneration vor. 


\section{Die Herogonic.}

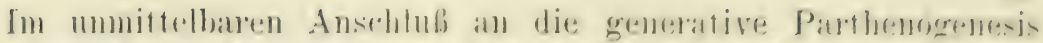

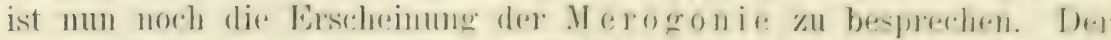

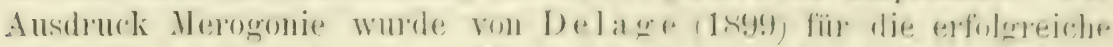

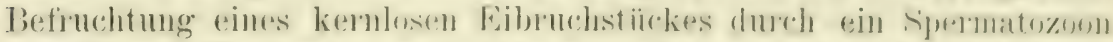

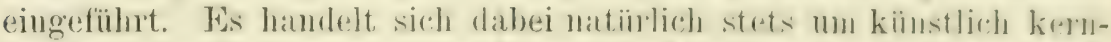
los gemachte Eifragmente, die durch das Eindringen riner mänlichen Keimzelle einen nenen haploiden Kern erhalten.

Sie wurde zuerst ron O. und R. Hertwig (1887) und Boveri (18s?) bei 'Tieren, und zwar bei Echinodermeneiern festgestellt, ist aher; wie spätere Lntersuchungen besonders von I)elage reigten. auch noch bei anderen T'ierarten, so Anneliden und Mollusken, möglich.

Für Pflanzen ist sie bisher nur bei der Fncacee Cystusinu burbutu gefunden worden (Winkler 1901, p. 753); es unterliegt aber wohl keinem Zweifel, daß sie sich anch noch bei anderen Pflanzen mit freischwimmenden Eiern wird feststellen lassen. Bei Cystosiro wurde nach einer im Original einzusehenden Methode das Ei im Moment des Ausschlüpfens aus dem Oogonium in einen kernlosen und einen kernhaltigen T'eil zerlegt und sofort nach Beendigung dieser Manipulation frisches spermatozoenhaltiges Trasser zinesetzt. In mehreren Tersuchen gelang es, aus den beiden Eiteilen. nachdem in jeden je ein Spermatozoon eingedrungen war, Keimlinge zu züchten. die sich so weit entwickelten. als sich unter den betreffenden Tersuchsbedingungen auch aus normal befuchteten Eiern hervorgegangene Keimlinge heranziehen ließen. Allerdings wuchs der aus dem kompletten befruchteten Ei entstandene Keimling etwas rascher als der aus dem besamten Eibruchstiick hervorgegangene. Trotzdem darf man wohl annehmen. daß es unter geeigneten Kulturbedingungen gelingen wird, auch aus solchen Keimlingen erwachsene Pflanzen zu erziehen.

Die Kernverhältnisse sind cytologisch noch zu untersuchen. Da das Eibruchstück kernlos war und der Kern des Spermatozoons die haploide Chromosomenzahl besitzt. wird man vermuten dürfen, daß - sofern nicht etwa eine regenerative Verdoppelung der Chromosomenzahl eintreten sollte - auch die Kerne des Sporophytenembryos haploidchromosomig sein werden. Es läge dann eine völlige Analogie zur generativen Parthenogenesis vor, mit dem Unterschiede, dab die Kerne hier nicht vom mütterlichen, sondern vom räterlichen Keimzellkern abstammen, und der entwicklungserregende Reiz hier derselbe wie bei der normalen Befruchtung ist, während er bei der Parthenogenesis in irgend einem anderen Faktor zu suchen ist. Es sei noch bemerkt. daß sich spontane Parthenogenesis bei der erwähnten Cystosiva nicht berbachten läßt, und daß es bisher auch noch nicht gelungen ist. sie experimentell zu künstlicher Parthenogenesis zu veranlassen. 
Giard (1901) hat darauf hingewiesen, daß bereits Rostafinski (1877) Versuche über die Frage angestellt hat, ob man das Ei von Fucus vesiculosus teilen und die Teile einzeln befruchten kann. Es gelang ihm das auch, und er konstatierte dabei, daf sich nach dem Zusatz von Spermatozoen um alle, auch die kleinsten Fragmente, Membranen ausbilden, daß sich aber nur diejenigen zu Keimlingen weiterbilden, „qui contiennent les substances constitutives des trois couches de l'oeuf" (nach der Übersetzung von Giard). Wenn Giard hieraus den Schluß glaubt ziehen zu müssen, daß Rostafinski als erster die Möglichkeit der Merogonie erwiesen habe, so scheint das angesichts des von Rostafinski selbst Berichteten nicht zulässig zu sein. Durch Rostafinski's Versuche ist nur der an sich sehr wichtige Nachweis erbracht, daß man von einem Ei Teile absprengen kann, ohne ihm die Möglichkeit zu nehmen, befruchtet zu werden und sich zu einem kompletten Keimling zu entwickeln. Ob aber auch kernlose Bruchstiicke dazu imstande sind, geht aus seinen Angaben nicht hervor; eher könnte man aus der Bemerkung, es würden nur die Fragmente befruchtet, die „die Bestandteile aller drei Schichten des Eies" enthielten, auf das Gegenteil schließen. Genaner rermag ich das nicht zu entscheiden, da die Arbeit von Rostafinski polnisch olme deutsches Résumé erschienen, in keiner botanischen Zeitschrift referiert und mir nur durch die kurze Inhaltsangabe bekannt geworden ist, die Giard 1901 vou ihr nach der Veröffentlichung meiner Merogonieversuche gegeben hat. Dieser Umstand entschuldigt zur Genïge, daß mir und übrigens allen anderen Merogonieforschern die Versuche Rostafinski's bis zu der erwähnten Veröffentlichung von Giard völlig unbekannt geblieben waren.

\section{Fünftes Kapitel.}

\section{Die Parthenokarpie.}

Mehr anhangsweise wollen wir auf eine Frscheinung etwas näher eingehen, die an sich manches Gemeinsame mit der Parthenogenesis und Apogamie hat, und deren nähere Erforschung insofern nicht ohne Wichtigkeit für die Parthenogenesisforschung ist, als damit eine sehr geführliche Fehlerquelle für Untersuchungen über das Vorhandensein oder Fehlen von Parthenogenesis oder Apogamie wegfällt. Es isf die Erscheinung der Parthenokarpie. 
Der 'lerminus Parthenokarpie wurde von Noll $(1902,1 \%$ 11) tür'

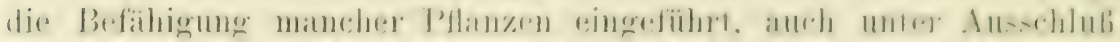

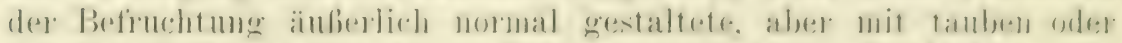

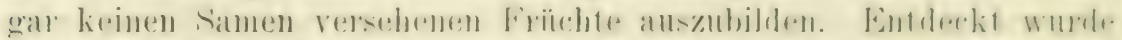

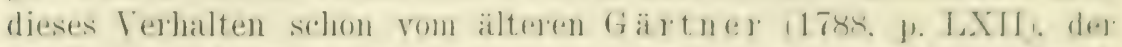

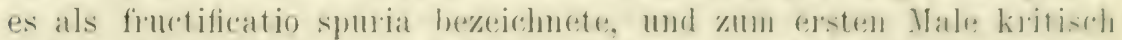

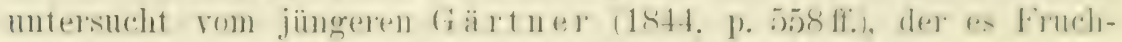

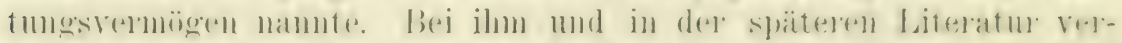
streut finden sich zahlowiche Angaben über die mehr oder weniger

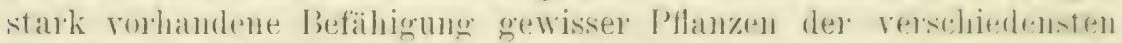
Familien zur P'arthenokarpie. und es wäre ein an sich und anth fïr the Parthenogenesis-Forsehung sehr dankenswertes Lntromehnen, all. diese Angaben zusammenzustellen und kritisch und experimentell ant ihre Zuverlässigkeit zu prüfen.

Mit Recht betont Noll (l. c.), es käme streng genommen als Parthenokarpie im eigentlichen sinne ..nu1 die Fruchtbildung unter. Ansschlub jeglicher Bestä ubung (und nicht etwa nur unter Ansschlul, der Befruclıtung') in Betracht; mit anderen Worten bleibt dabei die keuschheit des Gyäceums mabgebend und nicht die ans irgendwelchen Gründen ansbleibende Intterschaft trot\% erfolgter Bestäubung.". Doch diirfte es sich unseres Erachtens emptehlen. den Begriff weiter zu fassen und Parthenokarpie allgemein zu definieren als die Erzengung ron Früchten mit gar keinen oder nit tauben Samen. Es wäre dam etwa zu muterscheiden zrischen stimulativer Parthenokarpie, bei der die taube Frucht nur nach Bestüubung mit eigenem oder fremdem Pollen. infolge eines Insektenstiches vder sonst einer Reizwirkung entsteht, und vegetativer Parthenokarpie. bei der die taube Frucht ohne alle Bestäubung oder sonstige äubere Reizung gebildet wird.

Die bisher rorliegenden Tatsachen lassen es wahrscheinlich erscheinen, daß regetative Parthenokarpie verhältnismäbig seltener ist als stimulative. Toll beschreibt in seiner citierten Mitteilung einen Fall regetativer Parthenokarpie bei der Gurke und erwähnt als andere schon bekannte Fälle solcher rein vegetativen Fruchtentwicklung noch die Feige und die kernlose Mispel. Doch liegen über die Befähigung zu vegetativ parthenokarper Fruchtbildung auch noch anderer Pflanzen schon von Gärtner (18tt, p. כ60 u. a. a. O.) Angaben vor: an deren Zurerlässigkeit nicht zu zweifeln ist. Später sind dam auch noch von anderer Seite, so von Solacolu (1905), weitere Beispiele beigebracht worden, und neuerdings hat Ewert (1906 und 1907) es hewiesen, daß auch an Obstbäumen kernlose Früchte olme Einwirkung des Pollens entstehen können.

Die Beziehungen zwischen Parthenokarpie, und zwar regetativer Parthenukarpie, und Parthenogenesis der höheren Pflanzen sind in- 
sofer'n sehr enge. als ja die Parthenogenesis in allen bisher bekannten Fällen mit Parthenokarpie rerknüpft ist; denn es entwickeln sich ja dabei ohne alle Bestäubung nicht nur Embryonen und Samen, sondern anch Früchte. Schon Toll (l. c., p. 12) weist darauf hin und bemerkt, dab hier eine Parthenokarpie vorliege, .. die entweder ron der Embryobzw: der Samenentwicklung stimuliert wirl (embryogene P'arthenukarpies. oder aber anch selbständig neben dieser einhergehen künnte und dann einzureihen wïre in die Erscheinungen der antonomen. sterilen Parthenokarpie, wie sie bei der Gurke vorliegt".

Die Frage, ob bei parthenogenetischen Pflanzen sich die Parthenogenesis mit embryogener oder mit antonomer regetativer Parthenokiarpie kombiniert. ob also die Frucht sich infolge korrelativer Wechselbeziehungen zn den samen oder ron diesen mabhängig ausbildet, wird zugunsten der embryogenen Parthenokarpie dam bejahend beantwortet werden mïssen. wenn sich niemals neben den samenhaltigen Früchten auch normal gestaltete, aber samenfreie Frïchte finden. Kommen dagegen bei einer parthenogenetischen Pflanze tanbe Früchte nelen fertilen ror, so wird man annehmen müssen, dab anch die samenführenden Früichte sich autonom parthenokarp entwickelt haben, ohne daß notwendig ron den wachsenden Samen alls Reizwirkungen ausgehen mïßten.

Dab andererseits ïberhaupt solche korrelative Wechselwirkungen zwischen der Entwicklung von Samen und der Ausbildung der Frucht bestehen, zum Teil sehr inniger Art. ist nicht zu bezweifehn. Es geht schon laraus herror; dab eben zahlineiche Pflanzen bei ansbleibendel Samenentwicklung nicht zur Parthenokarpie befähigt sind, ist überdies z. B. durch II assart (1902) u. a. experimentell sichergestellt. Doch sind wenigstens in vielen Fällen diese korrelativen ITechselbeziehungen nicht so intimer Art. dab sie nicht gelöst werden könnten, derart. dab die eine der beiden korrelativ miteinander verketteten Erscheinungen olne die andere auftreten könnte. Das zeigt eben das Bestehen der vegetativen und besonders deutlich das der stimulativen Parthenokarpie, bei der es eines besonderen Reizes zur Auslösung der Fruchtentwicklung bedarf. bei der dam aber die Fruchtentwicklung selbst trotz der zwischen ihr und der Samenentwicklung. bestehenden korrelativen Wechselwirkungen nicht geniugt, nun auch die Samen- und Embryobildung, also Parthenogenesis auszulösen. Dariuber, ob auch umgekehrt normale Samenentwicklung ohne Fruchtbildung möglich ist, scheint nichts bekannt $\mathrm{zul}$ sein; theoretisch ist es natürich sehr wohl denkbar, und wenn ich nicht irre, kommt es z. B. beim Wein gelegentlich vor', daß die Beere nicht 'zur Ausbildung. kommt. obwohl sich gesunde Samen entwickeln. so dab diese dann anstatt von der Beere nur von einer dümen Fruchthaut umhüllt werden. 
Fuir die Frage nach der Ursache der Parthenogenesis ergibt

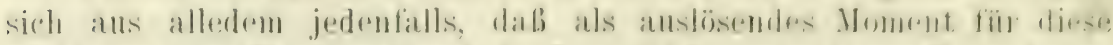
nicht etwa eine Parthenokarpie in Petratht kommen kann. die antonom

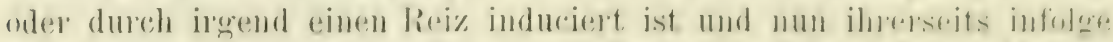

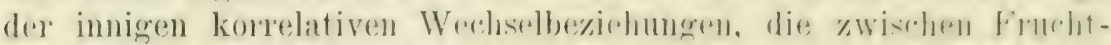
und Samenentwicklung bestehen. dis partlenogentisch. Emborebildung zur Folge hätte. Da solche Wexhelheziehungen narhgewiesenermaben existiren, bedarf das der ausdricklichen fr... stellung.

Noch in einer anderen Hinsicht ist, wie schon kurz angedelltet.

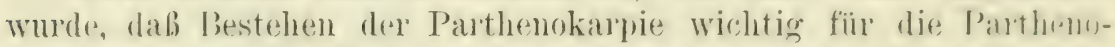
genesis-Forschung: es ist eine der wichtigsten Fehlerguellen bei unkritischer Untersuchung. Besonders zahlreiche ältere Angaben iber das angebliche Vorkommen von Parthenogenesis bei dieser oder jener Pflanze erklären sich als Verwechshung mit Parthenokarpie, die ja monter Umständen so weit gehen kann, daß sich nicht nur die Frucht, sondern auch die Samenhüllen völlig normal ausbilden; nur fehlt eben der Embryo, und dessen Vorhandensein mul, also immer ausdrürklich konstatiert sein, ehe eine Angabe iiber Parthenogenesis flauben rerdient.

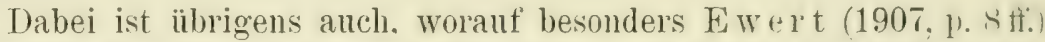
aufmerksam gemacht hat, zu beachten, dab Parthenokarpie untel' Umständen nur dann eintritt, wenn sämtliche Blüten des Individuums unbestäubt bleiben, da sonst die befruchteten Bliiten den ınbefruchtet gebliebenen gegeniiber so stark in der Entwicklung bevorzugt sind, daß die letzteren selbst bei vorhandener Befähigung zu vegetativer Parthenokarpie zurïckbleiben und schlieblich unreif ah)fallen. Auch bei Untersuchung iiber die Befähigung einer Ptlanze zu Parthenogenesis oder Apogamie ist dieser L'mstand zu berïcksichtigen (vgl. Winkler 1905, p. 215 und 256).

Natiirlich wäre bei cytologischer Untersuchung parthenokarper Frïchte besonders auf das Verhalten der im Embryosack befindlichen Elemente zil achten.

Sechstes Kapitel.

\section{Das Wesen der Apogamie und Parthenogenesis.}

Wir haben schon mehrfach darauf hingewiesen, daß die ron uns gegebenen Definitionen der Begrifte Apogamie und Parthenogenesis nicht von allen Forschern anerkannt werden. In diesem Kapitel 
sollen sie daher eingehender begründet und über die abweichenden Ansichten referiert werden.

Daß dariuber, daß Apogamie als die apomiktische Entstehung. eines Sporophyten aus vegetativen Zellen des Gametophyten anzusehen ist, im allgemeinen Übereinstimmung herrscht und nur Strasburger (1904, 1. 58) eine abweichende Ansicht ausgesprochen hat, wurde bereits erwälnnt (vgl. p. 9), und wir können hier auf das frïher Gesagte verweisen.

Auch hinsichtlich der Parthenogenesis herrscht insofern Einigkeit, als man allgemein in ihr die Entwicklung eines unbefruchteten Eies zum Sporophyten erblickt. Meinungsdifferenzen bestehen aber darüber, was als ein Ei, resp. als Keimzelle überhaupt anzusehen ist. Nach Juel (1900, p. 40, 45; 1904, p. 2), Murbeck (1901, p. 36), Guérin (1904, p. 81) und Stra s burger (1904, p. 58 f.; 1907, p. 164 ff.) ist ein $\mathrm{Ei}$, dessen Kern mit der diploiden anstatt mit der haploiden Chromosomenzahl ausgeriistet ist, gar kein echtes Ei, sondern nu eine eiähulich gestaltete Körperzelle des Sporophyten. Was wir also somatische Parthenogenesis genannt haben, das ist nach dieser Auffassung keine Parthenogenesis, da kein Ei, sondern eine vegetative Zelle als Ausgangspunkt der Sporophytenbildung dient, es ist aber auch nicht Apogamie, da der Embryo nicht aus einer Gametophyten-, sondern ans einer Sporophytenzelle hervorgeht, sondern es ist ein einfacher vegetativer Propagationsvorgang, der prinzipiell etwa der Entstehung eines nenen Vegetationspunktes aus einer Blattzelle von Begonia durchaus homolog ist und mit Parthenogenesis nichts zu tum hat. Parthenogenesis wäre dann nur das, was wir als generative Parthenogenesis bezeichnet haben.

Wie ersichtlich ist, ist in diesem Zusammenhange die Frage nach dem Wesen der Parthenogenesis identisch mit der Frage nach dem Wesen der Keimzelle und sie spitzt sich dahin zu: ist eine mit einem diploidchromosomigen Kern versehene, sonst aber völlig typisch gestaltete Keimzelle in der Tat als Keimzelle anzusehen oder nicht? Ist also z. B. das Spermatozoon des somatisch apogamen Afluyrium Filix-foemina clarissima, das vollkommen typisch geformt ist, lebhaft umherscbwimmt und auch chemotaktisch normal empfindlich ist, das aber einen Kern mit der unreducierten Chromosomenzahl besitzt, ein Spermatozoon oder nicht? (Demn es ist selbstverständlich, daß die Auffassung der erwähnten Forscher, wenn sie überhaupt gilt, für die männliche Keimzelle ebenso gelten muß wie für die weibliche). In einem solchen Spermatozoon nur eine spermatozoenähnlich gestaltete vegetative Zelle zu sehen, hat gewiß von vornherein wenig Überzeugendes; doch müssen wir uns natürlich zur Abweisung der Ansicht nach objektiven Grïnden umsehen. 
Wir werden also zn untersuchen haben, ob eine äuberlich als

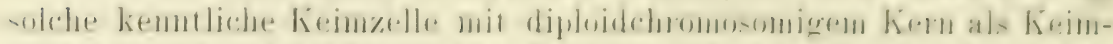

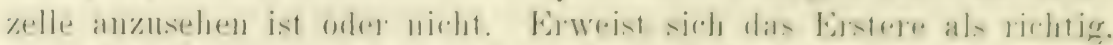

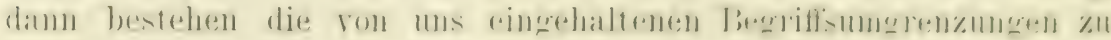
recht; trifft aber das letztere zu, so wird weiter zu entscheiden sein.

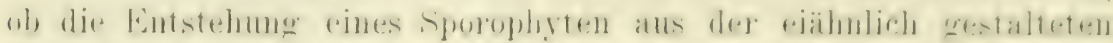

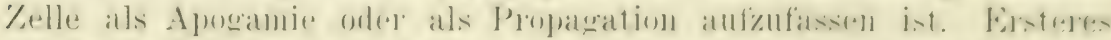

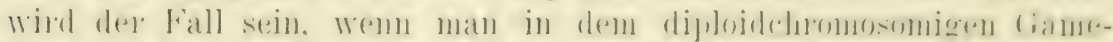

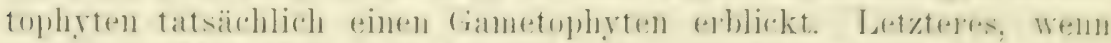

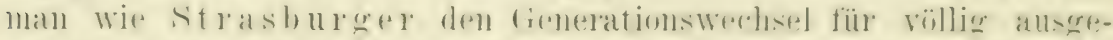

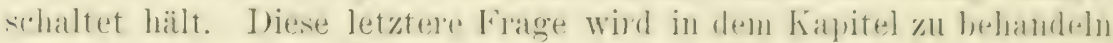

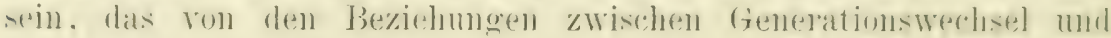
Apomixis handelt (Kapitel 7).

Wir untersuchen zuerst die Frage, welche Umstände dafür sfurechen. dali das Ei. anch wemn es einen kern mit der dipluiden ('hromosomemzahl besizt wie die Zellen des sporophyten, dor he eine-1 solchen nicht gleichwertig ist.

End zweitens die Frage. Welche Lnstinde dafïr sprechens, dafi anch rem bi mit diploidchromosomigem fiern heimzellcharakter znkommt. Der Kürze halber soll das Ei, dessen hern mit der diploiden Chromosomenzahl ansgeriistet ist. kïnftig einfach das diploide Ei in Gegensaty zum haploiden genannt werden. Es sei noch in volats. bemerkt. dab natürlich alles das, was wir in der Hauptsache für das diploide Fi ansführen. mutatis mutandis anch tïr das diploide siermat 0 z $00 \mathrm{n}$ gilt.

\section{Ist das diploide Ei einer somatischen Sporophytenzelle gleichwertig?}

Tras die Keinzellen wenigstens bei den höheren Pflanzen auf den ersten Blick ron allen anderen Zellen verschieden erscheinen lïbt, ist ihre typische Gestalt als Ei und spermatozoon, die nur ihnen zuhommt. Doch läßt sich daraus natürlich kein Schlub auf eine essentielle Verschiedenheit zwischen Keim- und Körperzellen ziehen, da ja die letzteren unter sich anch zahlreiche und sehr weitgehende Tersthiedenheiten in ihrer Gestaltung aufweisen. olne dadurch ihres gemeinsamen Charakters als Körperzellen entkleidet zu werden. Tenn daher die diploiden Eier und spermatozoen äuberlich durchalls die typische Ei- und Spermatozoen-Gestalt beibehalten, so wollen wir auf diese Tatsache, wemn sie auch rerdient, ausdrücklich betont zu merden, nicht allzuviel Gewicht legen, da die diploiden Keimzellen doch auch bei typischer Keimzellgestaltung Kürperzellcharakter haben kïmnten. Trenn es sich daher nur um die Frage handelt, ob die 
diploiden Keim- und Körperzellen einander gleichwertig sind oder nicht, so kömnen wir für ihre Beantwortung der Tatsache ihrer rerschiedenen Gestaltung keine entscheidenden Argumente entnehmen; wohl aber kömnen wir das, wie später zu erörtern sein wird. mit mehr Sicherheit für die Beantwortung der Frage, ob den diploiden Keimzellen echte Keimzellnatur zukommt.

Es sind, soviel ich sehe, vor allem zwei Tatsachen, die, abgesehen von theoretischen Überlegungen. zu der Annahme führen, dilf diploide heimzellen und somatische Körperzellen trotz der gleichen Chromosomenzahl. die ihre Kerne führen, doch wesentlich rerschieden, also einander nicht gleichwertig sind.

Die erste Tatsache ist der Cmstand, dab die auf parthenogenetischem Tege entstandenen Xachkommen diöcischer Gewäichse m ï nn nlichen Geschlechts sein können. Bereits Regel (1859, 1). 43) hat kurz darauf hingewiesen, dab, falls die Parthenogenesis einfach eine ungeschlechtliche Fortpflanzungsart sei, weibliche Pllanzen auf parthenogenetischem Tege auch nur weibliche Alsö̈mmlinge producieren kömnten. Denn wir wissen, daß - von sehr seltenen Ausnahmen abgesehen, die wir hier ruhig unbeachtet lassen kömen asexuell, aus regetativen Zellen propagativ erwachsene Nachkonmen einer Pflanze stets die Eigenschaften des Mrutterindividumns und vor allem auch - bei diöcischen Gewächsen - dessen Geschlecht beibehalten. So liefert denn anch die Caclebormne ilicifolia, leren Adrentivembryonen ja aus somatischen Sporophytenzellen hervorgehen, auschlieflich reibliche Nachkommen. Cnd auch Murbeck (1901, p. 36) erklärt „die merkwürdige Konstanz der Alchimillen” damit, ..dass die Embryobildung ein rein regetativer Torgang ist; der Same mit der daraus aufgewachsenen Pflanze ist, wie die Brutknospen und der Steckling ganz einfach ein selbständig gewordener 'Teil der' Mutteryflanze, und eben weil keine Befruchtung stattgefunden hat. ist der Abkömmling nur im Besitz solcher Eigenschaften, die das Mutterindividuum selbst kennzeichnen".

Wenn also das diploide Ei in der Tat einer beliebigen Kürperzelle gleichwertig wäre, dann diirfte aus ihm bei diöcischen Pflanzen mit somatischer Parthenogenesis stets nur weibliche Nachkommenschaft hervorgehen. Jun sind ron den somatisch parthenogenetischen Pflanzen diöcisch Antennaria, Thatictrum und Bryonia, ron welch letzterer allerdings die Parthenogenesis noch nicht mit absoluter Sicherheit feststeht.

Bei Antennaria alpina sind männliche Individuen nach Kerner (1876) und Juel (1900) zwar selten, kommen aber doch vor. Bei allen von $J$ uel untersuchten männlichen Blüten war entweder gar kein Pollen in den Antheren vorhanden, oder aber er war nicht normal entwickelt. Das scheint darauf hinzudeuten, dab sie partheno- 


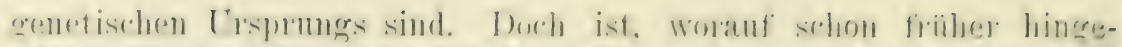

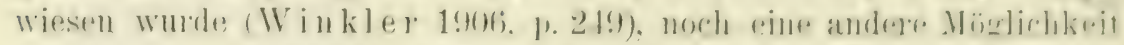
vorhanden: es könnte nämlich bei dutemuria alpina neben der

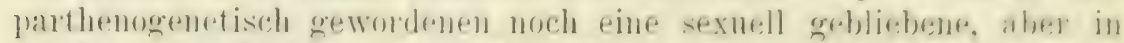

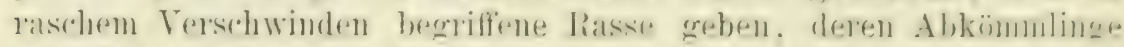

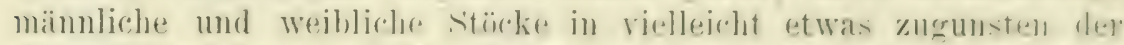

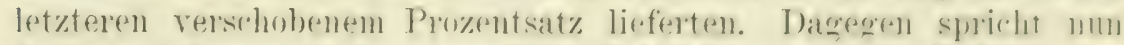

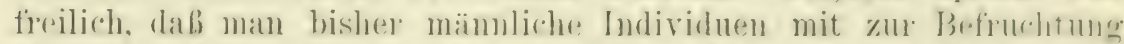

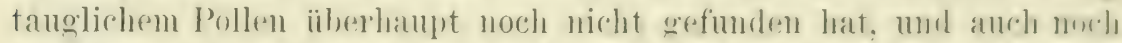
kein befruchtungsbediurtiger weiblicher stock bekannt geworden int. Trem daher die mämnlichen Exemplare nirht Knospenvarationen weiblicher stäcke dartellen. Was bei ihner verhiltnismäbig grobun Seltenheit immerhin nicht gan\% ausgeschlosen ist. bleiht r.s dis Wahrscheinlichste, auch sie als aus unbefuchteten Fiern entstanden anzusehen. Doch soll bei der Seltenheit der Fäle darauf zur Lutscheidung unserer Frage kein allangrobes fewicht gelegt werlen.

Als sichergestellt mub es bei Thaliotrum Fondleni gelten. dati dir parthenogenetisch erzengten Keime zum Teil minnliche Inflividuen ergeben. da Day $(1896,1)$. 2t1) ansdrücklich angibt: .. The seeds were planted and rielded abmuantly staminate and pistillate Flowers: Ob dasselbe für Thalictrum purpurescens gilt. ist nicht sicher. da Orerton (1902 und 190t) keine Angaben ïber das (Geschlecht dra Pflanzen macht. die er aus parthenogenetisch erzeugtem Samen diesel' Art erhielt. Daß hier mänuliche Bliiten häufig sind, unterliegt zwal keinem Zweifel; doch kamn man nicht behaupten. sie seien wenigstens zum Teil an parthenogenetisch entstandenen Pflanzen aufgetreten. da ja, wie frïher berichtet wurde. bei Thalictrum numurascens neben Parthenogenesis auch normale Amphimixis vorkommt. so daf man annehmen könnte, daß die männlichen Abkömmlinge immer nur aus den befruchteten Eiern hervorgingen. Kulturversuche kïnnen das leicht entscheiden. Einstweilen werden wir nach Analogie des Thrlictrmm Fendleri aber auch für Thatictrum purpurascens vermuten können. daß auch aus parthenogenetisch sich entwickelnden Eiern männliche Sï̈cke hervorgehen können.

Bei Bryonia endlich sind nach Bitter (1904) alle parthenogenetisch entstandenen Stöcke männlich. Doch reichen die Erfahrungen bei dieser Pflanze noch nicht sehr weit, überdies ist noch unbekannt, ob es sich hier um somatische oder um generative Parthenogenesis oder gar um Apogamie handelt.

Bei Tieren, die zur Parthenogenesis befähigt sind, liegen. wie vergleichsweise angeführt sei, die Dinge so, daß aus den unbefruchteten Eiern je nach der Species entweder nur Weibchen (Thelytohie) oder nur Mrännchen (Arrhenotokie) oder aber gemischte Brut iAmphoterotokie) hervorgehen. Man rgl. dazu die zusammenfassenden Dar- 
stellumgen von Taschenberg (1892), Phillips (1903) und Hewat (1906).

Zusammenfassend können wir also sagen, daß es, selbst nach Ansschaltung der zweifelhatten Fälle, für einige parthenogenetische Pflanzen als erwiesen gelten muß, daß aus der Eizelle ein männliches Individuum hervorgehen kann. Wäre nun die diploide Eizelle einer beliebigen Körperzelle gleichwertig, so könnte das nicht der Fall seiı, da dam das Tochterindividum dasselbe Geschlecht wie die Mutterpflanze haben mïßte. und wir kommen somit zu dem Schlusse, dab diploide Eizelle und somatische sporophytenzelle nicht gleichwertig sind.

Diese ganze Argumentation besteht anch damn noch zu recht. wemn wir die Erwägnngen von Correns (1907, p. 12 ff.) über die Beziehungen zwischen Parthenogenesis und Geschlechtsbestimmung: beriicksichtigen. Correns hat es in sehr scharfsimniger Beweisfïhrung wahrscheinlich gemacht, daß, zum mindesten bei Bryonic dioic, die weiblichen Keimzellen alle die 'T'endenz haben, wieder' weibliche Nachkommen zu liefern, die männlichen dagegen nu zu Hälfte die, zu Männchen zu werden, zur Hälfte die. Weibchen zu geben. Kü̈nstlich zu parthenogenetischer Entwicklung gebracht, müßten die Eier also ausschließlich Weibchen ergeben. Die Tatsache, daf num aber bei der habituellen Parthenogenesis ans den unbefruchteten Eiern anch Männchen hervorgehen kömnen, erklärt er sich (l. c., 1. 13) damit, dab erstens eimmal haploide und diploide Eier nicht streng vergleichbar seien, und daß zweitens und vor allem es sich bei der habitnellen Parthenogenesis um Anpassungserscheinungen handeln müsse. wobei anch die Geschlechtstendenz beeinflußt worden sein könne.

Unsere Argumentation wird durch diese Erwägungen insofern nicht beriilırt, als ja die Anpassungen, ihr Bestehen vorausgesetzt, allein die diploide Eizelle, nicht aber auch die Körperzellen betreffen, da bei propagativer Termehrung niemals ein Geschlechtswechsel auftritt. So bleibt also der Gegensatz zwischen den Sporophytenzellen und dem diploiden Ei bestehen.

Ian könnte sich übrigens auch, falls die Cor'rens'sche Annahme nicht für alle Pflanzen gelten und es Eizellen geben sollte, die wie die männlichen Keimzellen die Tendenz hätten, zur Hälfte männliche, zur Hälfte weibliche Nachkommenschaft zu liefern, umgekehrt das fïr parthenogenetische Organismen mit ausschließlich weiblicher Deszendenz wie Chara crinita dahin zurecht legen, daß bei ilnen in Anjassung an die sehr viel größere Wichtigkeit der weiblichen Individuen nur mehr Eier mit weiblicher Tendenz entstïnden.

Der zweite Punkt, der sich unseres Erachtens dafür anführen läßt, daß diploide Eizellen und vegetative Sporophytenzellen trotz der 


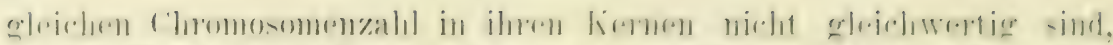

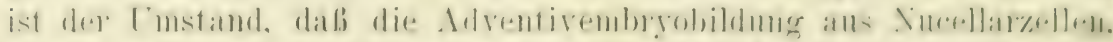

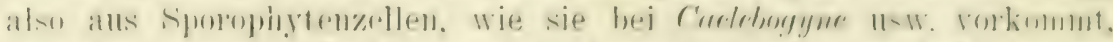

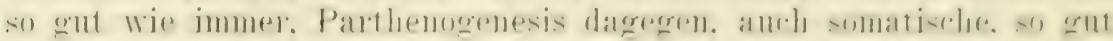

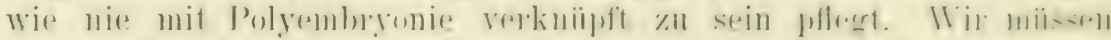

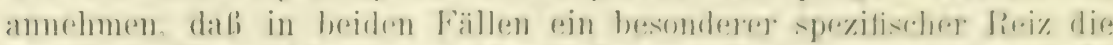

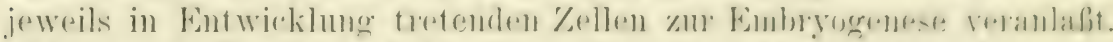

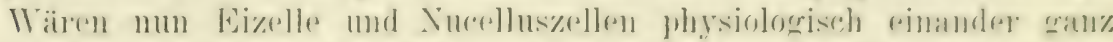

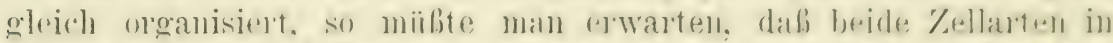

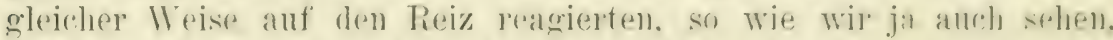

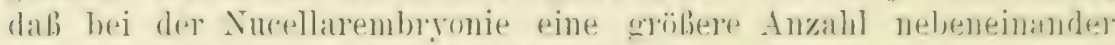

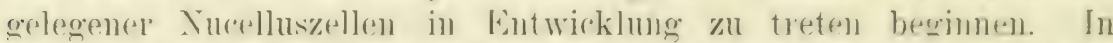
Wirklichkeit aber verläuft dir Sarhe eben so, dab entwerter nu die Eizelle allein reagiert. oder aber nur die Nucelluszellen. obwolld dorls beide in ummittelbarer Nachbarschaft gelegen sind. und obwohl im letzteren Falle. so \%. B. bei ('itmes und Funlia. die Fizello sugar be fruchtet worden ist. ihr Kiern also uiber dieselbe ('hromosomenzahl verfïgt wie die Kerne der Nucelluszellen. Tnd darans scheint mir hervorzugehen. dab die Eizelle eine \%elle sui generis auch dam bleibt. wenn sie diploid ist.

Wemn die beiden eben erörterten Tmstände der Ansicht. daf das diploide Ei und vegetative Sporophytenzellen gleirhwertig seien, nicht giunstig sind. so fragt es sich. ob diese nicht eine stiitze findet in dem Umstande. daß beide Zellarten die gleiche Chromosomenzall in ihren Kernen führen. Ist er es doch. der S trasburger reranlalit. das diploide Ei für eine vegetative Körperzelle zu halten.

Aber, wie bereits frïher ausgeführt wurde (W inklel 1906. 1. 237), darin liegt offenbar eine (Tberschätzung der Bedeutung. die die Chromosomenzahl für den phrsiologischen Charakter der Zelle hat. Finden wir doch. daß alle die zahllosen Zellen des Sporophrtenkïrpers trotz - im allgemeinen — gleicher (diploider) ('hromosomenzahl doch in ihren morphologischen Figenschaften und phrsiologischen Leistungen tausendfach roneinander verschieden sind: anch in ilner Entwicklungsfiihigkeit: es kann beispielsweise bei gewissen Pflanzen in Regenerationsrorgängen etwa eine Cambiumzelle eine neue Pflanze zu liefern imstande sein. eine Epidermiszelle aber nicht. obrohl die Kerne beider Zellen über die gleiche Chromosomemmenge zu rerfügen haben. Ebenso sind doch zweifellos die Zellen des Gametophyten, etwa die Rhizoiden, Assimilations- und Keimzellen eines AspleniumProthalliums, oder Ei. symergiden und Antipoden einer Phanerogame sehr wesentlich roneinander verschieden. wenn sie auch alle die gleiche (haploide) Chromosomenzahl in ihren Fermen fülıren. Ans alledem scheint sich mir der Schluh zu ergeben. dab über die spezifischen physiologischen und morphologischen Eigenschaften einer Zelle 
nicht die Zahl der Chromosomen entscheidet, die in ihrem Kerne vorhanden ist, und man kann daher auch lediglich daraus, daß das diploide Ei und die somatischen Sporophytenzellen dieselbe Chromosomenzahl besitzen, nicht auf Gleichwertigkeit der beiden Zellkategorien schließen.

So führen also alle unsere Erwägungen zu dem Schlusse, daß kein Grund vorliegt, die diploide Keimzelle für gleichwertig einer beliebigen vegetativen Körperzelle zu halten. Es erhebt sich num die Frage, ob es berechtigt ist, ihr Keimzellcharakter zuzuschreiben.

\section{Kommt der diploiden Eizelle Keimzellcharakter zu?}

Als selbstverständlich dürfte anzusehen sein, daß bei Organismen, bei denen die Keimzellen eine spezifische, von der der Körperzellen verschiedene Gestaltung haben, nur solchen Zellen die Keimzellnatur zugesprochen werden kann, die diese Form besitzen, also die charakteristische morphologische Ausbildung als Ei oder spermatozoon haben. Daher wir dem auch die Psendomixis von der Amphimixis zu unterscheiden haben. Diesen Anforderungen nun entsprechen die Eier und die Spermatozoen aller parthenogenetischen Pflanzen durchaus; sie haben durchaus typische Ei- oder Spermatozoenform. sind nur. den Regeln der Kernplasmarelation entsprechend, oft proportional größer. Speziell fïr die diploiden Farnspermatozoen ist iiberdies noch ausdruicklich festgestellt worden (Farmer und Digby 1907), daB nicht nur ihre Form, sondern auch ihr physiologisches Verhalten, ihre Schwimmfähigkeit und chemotaktische Empfindlichkeit durchaus normal sind, wie anch die diploiden Eier der apomiktischen Farne die chemotaktischen Reizstoffe ausscheiden. All das spricht sicherlich eher für, als gegen den Keimzellcharakter der fraglichen klemente.

So bleibt als einziger äußerlich wahnehmbarer Unterschied zwischen haploider und diploider Kieimzelle die verschiedene Chromosomenzahl. und wir würden in der Tat der diploiden Keimzelle den Keimzellcharakter absprechen müssen, wenn das eigentliche Wesen der Keimzelle darin bestïnde, daß ihrem Ker'n nur die haploide Chromosomenzahl zukommt. Das kann aber nicht der Fall sein, da sie den Besitz nur der haploiden Chromosomenzahl mit allen Zellen der normalen Gametophyten teilt, die deshalb, weil ihre Kerne die reducierte Chromosomenzahl haben, ebensowenig zu Keimzellen werden, wie eine Keimzelle deswegen ihren Keimzellcharakter zu verlieren brancht, weil sie diploid ist. Was also für das Wesen der Keimzelle charakteristisch ist, das kann nicht die reducierte ('hromosomenzahl sein, sondern das müssen außer der äußeren morphologischen Ausgestaltung seine spezifischen physiologischen Figenschaften sein. Man 


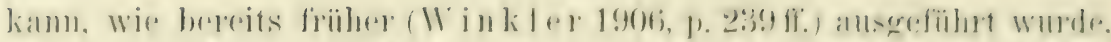

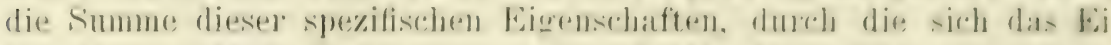

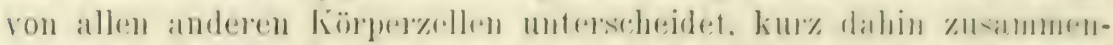

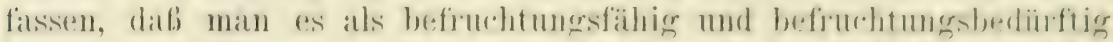

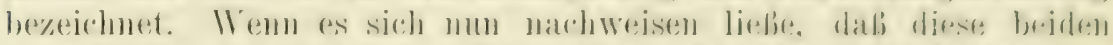

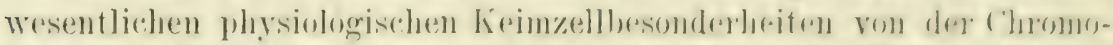
somenzahl abhingen derat, dab sie nur bei haphoiden Eiern anfraiten

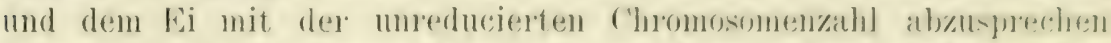
wiren, dam allerdings, aber anch erst dam wären wir berechtigr. diphoidchromosomigen \%ellen anch bei typisch keimzellenhafter äuberes Struktur den Keimzellcharakter abzuerkennen.

Nun haben aber oftenbar weder Befruchtungsbedurftigkeit noch Befinchtungsfähigkeit direkt irrend etwas mit de: ('hromosomenzahl zu tun. Ehe wir aber diese Behauptung kurz zu begründen rersuchen, wollen wir sehen, wie Strasburger seine gregenteilige Ansicht begründet.

Er fïhrt zur Lnterstiitzung seiner Annahme, dab diploide Eier weder befruchtungsbedürftig noch befruchtungsfähig seien, nur das Verhalten der parthenogenetischen Marsilien an, und meint (1907. 1. 166), diese gäben eine ,ziemlich bündige Antwort" auf die strittige Frage. . Womit kann nämlich", sagt er, .das apogame Ei einer Marsilia besser beweisen, dab es weder befruchtungsbedürtig noch befruchtungsfähig ist, als daß es den Spermatozoiden den Eintritt in das Archegonium unmöglich macht? Während ein die reducirte Chromosomenzahl führendes Ei die Tianalzellen zur Terruellung bringt, dadurch ein Öffnen des Archegoniumhalses bewirkt und dann chemo taktisch die Bewegungsrichtung der Spermatozoiden beeinflubt, fällt dieses alles bei dem diploiden Fi hinweg. Die Kanalzellen rerquellen nicht, der Archegoniumhals öffnet sich nicht, eine Ausscheidung ron Stoffen, welche die Spermatozoiden sonst anlocken, findet allem Anschein nach nicht statt. Die diploide Chromosomenzahl bedingt es also, daB im Ei das Befruchtungsbedürfnis sich nicht einstellt und damit auch der Reiz wegfällt, der die Tätigkeiten soust auslüst. welche die Befruchtung vorbereiten. Also kommt doch wohl eine grundsätzliche Bedeutung an dieser Stelle der Tatsache zu, dab nicht die einfaclie, sondern die doppelte Chromosomenzahl im Kern vertreten ist."

Aber gegen diese Argumentation läßt sich sehr viel einwenden.

Zunächst eimmal sind inzwischen durch Farmer und Digby (1907) Farne bekannt geworden, bei denen ebenfalls somatische Parthenogenesis wie bei Marsilia vorliegt, so Athyrium Filix-foemina var. clarissima Bolton, bei denen also das Ei auch die diploide Chromosomenzahl im Kerne besitzt, bei denen aber trotzdem die Verquellung der Kanalzellen, die Öffnung des Archegoniumhalses, die 
chemotaktische Anziehung der Spermatozoen durch vom Ei ansgeschiedene Stoffe und das Eindringen der männlichen Keimzellen in den Halskanal genau so wie bei normal amphimiktischen Formen vor sich geht. Das genügt zum Beweis, dab alle diese Erscheinungen mit der Chromosomenzahl des Eies nicht das Geringste zu tun haben, und wenn sie bei den parthenogenetischen Marsilien ausbleiben, so sagt das über die Befruchtungsbedürftigkeit und die Befruchtungsfähigkeit der Eier nichts aus.

Aber auch abgesehen von dieser ja erst später bekannt gewordenen Tatsache scheint mir die zitierte Argumentation Strasburger's durchaus nicht einwandfrei zu sein. Ebensogut könnte man nämlich etwa behaupten, kleistogame Blüten könnten nur durch den eigenen Pollen bestäubt werden, und dann argumentieren: wodurch kann die kleistogame Blüte besser beweisen, daß sie des fremden Pollens weder bedarf noch überhaupt durch ihn bestäubt werden kann, als dadurch, daß sie ihm den Eintritt in die Blïte ummöglich macht? Sie öffnet sich nicht, bleibt klein, kommt vielleicht überhaupt nicht über die Erde hervor, ihre Lockfarben bilden sich nicht aus, usw. Nun, hier wissen wir, daß die ganze Argumentation falsch ist, da wir leicht experimentell das Gegenteil beweisen können. Bei MIrisilia geht das, wenigstens vorlüufig, nicht; aber so wenig wie die ganze Beweiskette fiir die kleistogame Blüte bindend ist, so wenig ist sie das anch fïr Marsilia.

Jedenfalls sind solche Argumentationen wie die zitierte Strasburger'sche nicht imstande, den Beweiswert derjenigen Tatsachen zu erschïttern, die sich dafür anführen lassen, dab anch diploide Eier noch befruchtungsbedürftig und befruchtungsfähig sein können. dal. mit anderen Worten der Besitz der diploiden Chromosomenzahl an sich ihnen weder ohne weiteres die Entwicklungsfähigkeit verleiht, noch die Befruchtungsmöglichkeit nimmt. Wir können zum Beweise dessen auf früher Gesagtes (Winkler 1906, p. 239 ff.) verweisen, das hier nur kurz rekapituliert sei.

Was zunächst die Befruchtungsbedürftigkeit anbelangt, so spricht sie sich darin aus, daß das Ei nur dann seine Eutwicklung beginnen kann, wemn es vorher mit einer anderen Keimzelle verschmolzen ist, wobei eine Verdoppelung der Chromosomenzahl stattfindet, ohne übrigens das einzige Phänomen zu sein. Wenn es nun diese Verdoppelung der Chromosomenzahl wäre, die dem Ei die ihm bisher mangelnde Entwicklungsfähigkeit verliehe, dann könnte man allerdings schließen, daß einer der beiden wesentlichen Eicharaktere. die Befruchtungsbedürftigkeit, mit dem Besitze nur der haploiden Chromosomenzahl zusammenhinge, und daß dieser Charakter der Zelle fehle, die bei somatisch parthenogenetischen Organismen den Embryo liefert. So erklärt denn auch Overton (190t, p. 281) ausdrücklich 


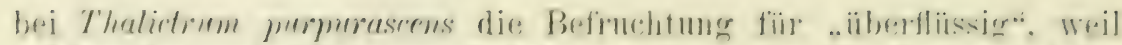
infolge der unterbliebenen liednktionsteilung in lig dies somatische Chromosomenzahl vorhanden sei, nimmt also an, dab der Pexity de. letzteren allein schon dem Ei die Entwicklungsfahiokeit garantik\%.

Demgegenüber ist aber darauf hinzuweisen. dati zwishen dem Besitze der einfachen oder dopnelten fluromosmenzahl einer Zelles und ihrer Fïhigk od oder Lnfähigkeit zur Entwicklung keinerlei direkte kansale Beziehungen bestohen oder zu bestrhen hraturen. Denn es befahigt weder der Besit\% der somatischen ('hromosmmenzahl an sich zur Entwicklung, noch ist andererseits das Vorhandemsen nur der haploiden Zahl notwendig mit Cnfähigkeit zur Entwirklung verkniupft. Ersteres erhellt aus der Tatsache. dah zahllose Zellen des Somas, trotzdem ihre Kerne mit der Vollzalıl ron Chromosmen ansgeriustet sind, doch durchaus entwicklungsunfähig sind (falls nicht besondere Reizanlässe dazukommen). Letzteres geht aus der Teilung:und Regenerationsfähigkeit der zellen in den Gametruhtroten ron Moosen, Farnen usw. herror, sowie aus der Möglichkeit der generattiven Apogamie und Parthenogenesis und der Merogonie. Fiir all das sind l. c. zahlreiche Beispiele beigebracht worden. Hier sei nur noch hinzugefügt. daß sich die dort (p. 242) ansgesprochene Vermutung. daf auch ans \%ellen mit reduciertem fieme surophyten hervorgehn könnten, deren Zellen durchaus die haploide Chromosomenzahl bei völlig normaler Gestaltung des ganzen Organismus beibehielten, inzwischen durch die Entdeckungen von Farmer und Dighy und von Y I manouchi (vgl. p. 68) bestätigt hat.

Aus alledem erhellt. dab die Chromosomenzahl an sich mit der Teilungs- uud Entwicklungsfähigkeit direkt nichts zu tun hat. rorausgesetzt natiirlich. dab mindestens die haploide Chromosomenzahl vorhanden ist. Man kann also nicht rom Besit\% der somatischen Chromosomenzahl ohne weiteres auf Torhandensein der Entwicklungsfähigkeit schließen. daher auch zwischen dem Ei mit diploider und dem mit laploider ('hromosomenzahl hinsichtlich ihres Befruchtung:bediurfnisses lediglich auf (trund der verschiedenen Chromosomenzahlen keinen $\pi$ esentlichen L'nterschied konstruieren. Wit anderen Worten. wenn das Ei der somatisch parthenogenetischen Organismen sich als entwicklungsfähig erweist. so kamn der Lmstand. dab sein Kern mit der diploiden Chromosomenzahl ausgestattet wurde. nicht das Moment sein. dem diese Entwicklungstähigkeit zu verdanken ist. sondern es muß durch irgendeinen anderen Faktor bewirkt werden. Damit aber befindet sich das diploide $\mathrm{Ei}$ in derselben Lage wie das haploide. nur das bei ihm die mangelnde Entwicklungsfähigkeit nicht durch die Befruchtung. sondern durch einen anderen Faktor hergestellt wird. Dab dieser Faktor aber nicht die Diploidchromosomigkeit sein kanm. ergeben unsere Erörterungen, und damit fällt einer der Hauptgriunde 
weg, wegen deren man das diploide Ei nur als eiähnliche, vegetative Zelle ansehen könnte.

Ähnlich verhält es sich mit der Befruchtung sähigkeit. Hier lautet die Frage: sind wir berechtigt. dem diploiden Ei auf Grund der Tatsache, dab es die unreducierte ('hromosomenzahl hat, die Befruchtungsähigkeit abzusprechen, und ist sexuelle Kernverschmelzung nur zwischen haploiden Kernen möglich? Das ist eine Frage, über die in jedem einzelnen Falle sicheren Entscheid natürlich nur das Experiment erbringen kamn. Vielleicht sind die diploiden Spermatozoen somatisch apogamer Farne und die diploiden Eier apospor entstandener Moose oder somatisch parthenogenetischer Farne ein dafür geeignetes Tersuchsmaterial: unsere Frage wäre beantwortet, wenn es sich etwa bei Bastardierungsrersuchen herausstellte, dab die Spermatozoen ron Athynium fitix-foemina var. clarissima Jones befruchtungsfähig wären.

Solange solche Versuche, die, falls sie negativ rerliefen, übrigens nur mit großer Torsicht zu verwenden wären, nicht rorliegen, sind wir auf theoretische Erwägungen und gelegentliche Beobachtungen angewiesen, wie solche früher gegeben wurden (Winkler 1906. p. $245 \mathrm{ff}$.). Aus ihnen geht herror, dab es nicht gerechtfertigt ist. dem diploiden Ei lediglich deswegen, weil es die somatische Chromosomenzahl besitzt, die Befruchtungsfähigkeit abzusprechen, es also dem haploiden Ei als wesensverschieden gegenüberzustellen.

Wenn nun so unsere bisherigen Überlegungen zu der Auffassumg: führen, dab die diploide Eizelle keineswegs einer beliebigen Kürper. zelle gleichwertig ist, und daß keine Grinde rorliegen, inr den Charakter einer Keimzelle abzuerkennen, so soll damit nun nicht etwa behauptet werden. daß haploide und diploide Keimzellen ihrerseits vollkommen identisch und gleichwertig wären. Das sind sie sicherlich nicht. reswegen wir ja auch generative und somatische Parthenogenesis voneinander zu unterscheiden haben. Es kam uns nul darauf an. zu zeigen. daß die Eizelle, anch wenn ihr Ker'n die diploide Chromosomenzahl besitzt, doch eine Zelle sui reneris bleibt. die sich nach Form, Entwicklungsgeschichte und physiologischem Charakter ron allen anderen Zellen wesentlich unterscheidet. Wenn daher aus ihx sich spontan ein Embryo entwickelt, so ist das ebenfalls ein Tolgang sui generis, der viel Gemeinsames mit der Eutwicklung der umbefruchteten haploiden Eizelle zum Embryo hat. sehr viel weniger Gemeinsames abel mit der Entstehung ron Keimen aus regetativen Zellen des Gametophyten oder gar des Sporophyten. also mit ler Apogamie und der regetativen Propagation. Es bleibt daher gerechtfertigt, die spontane Embryogenese aus dem diploiden Ei als soma- 


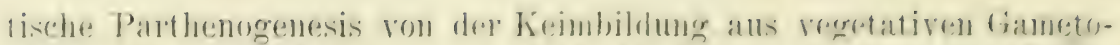

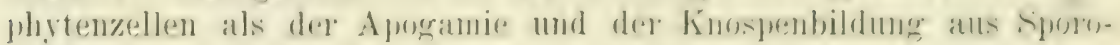
phytenzellen als der Propagation zu unterscheiden.

Siebentes Kapitel.

\section{Die Beziehungen zwischen Apomixis und Generationswechsel.}

Die Beziehngen zwischen den verschiedenen Arten der Apomixis und dem Generationswechsel erfordern eine spezielle Darlegung. da sie ziemlich komplizierter Natur sind, und eine Thereinstimmung unter den Forschern. die sich ïberhanpt darüber geäulert haben. nicht besteht.

Am einfachsten liegen die Dinge bei der vegetativen P'ropagation. Durch sie entstehen ja aus regetativen Gametophytenzellen immer wieder neue Gametophyten oder aus regetativen sporophytenzellen neue Sporophyten. Dabei wird zwar das ungleichnamige Stadium ausgeschaltet. aber nur faktisch, nicht anch theoretisch. da es mnter entsprechenden Bedingungen jederzeit wieder auftreten kam. Das gilt auch für Pflanzen, deren sporophyt sich jahrtausendelang immer nur auf propagativem Wege erhält. wie das z. B. bei der kultirierten Banane der Fall ist. Immer handelt es sich dabei um eine Existenzverlänger'ung der haploiden oder der diploiden Entwicklungsphase. durch die aber wenigstens theoretisch das eventuelle Eintreten der anderen nicht unmöglich gemacht, der Generationswechsel also nicht ansgeschaltet wird.

Anders ist es, wenigstens nach der Ansicht mancher Autoren. bei Parthenogenesis und Apogamie.

So meint Strasburger (1904, p. 160; vgl. auch 1905, p. 57 und die 8. Aufl. des Bonner Lehrbuchs, 1) 141), daß bei der somatischen Parthenogenesis der Generationswechsel einfach ausgeschaltet niirde; denn die mit diploidchromosomigen Kernen rersehenen Embryosïcke könnten ..nicht als Anfang einer nenen Generation, als Makrosporen, gelten, rielmehr sind sie Gewebszellen ihres Elters".

Eine weitere Beziehung zwischen Parthenogenesis und Generationswechsel findet er (Strasburger 1906, p. 2) darin, daß das Nichtvorhandensein des Generationswechsels bei manchen Organismen den Eintritt der Parthenggenesis erleichtere: "Das Fehlen einer diploiden Generation bei Chlorophyceen, Phaeosporeen erklärt es auch. 
warum Parthenogenesis bei ihnen so leicht sich einstellen kamn. Die Gameten, bezielnungsweise Eier, verfügen über die für die haploide, noch allein vorhandene Generation notwendige Chromosomenzahl. Es braucht somit aus ihrer Keimung nur die Reduktionsteilung ausgeschaltet zu werden, damit der Keimling über die ihm zukommende Chromosomenzahl rerfïge“. Und ebenso (1907. p. 167): „Bei jenen niederen pflanzlichen Organismen, welche zwar schon geschlechtlich differenziert sind. die aber aus dem Befruchtungsprodukt noch nicht eine besondere Generation ansgestaltet haben. die vielmeln die Keimung der Zygote gleich mit einem Reduktionsvorgang einleiten. ist demgemäß Parthenogenesis sehr leicht. Ein Ulothrix- oder Spirogyragamet enthält dieselbe Chromosomenzahl wie der Ulothrix- oder Spirogyrafaden; wenn also die Befruchtung unterbleibt, braucht nur die Reduktionsteilung ausgeschaltet zı werden, für die Bedürfnisse der einzigen, die Pflanze repräsentierenden haploiden (teneration ist unter allen Umständen gesorgt."

Die gleiche Ansicht hat übrigens schon vorher Davis (1905, p. 562) ausgesprochen: ..There are two types of parthenogenesis in plants: (1) that in the thallophytes where there is no sporophytic generation, and (2) that in higher forms when the life history is complicated by an alternation of generations. We know nothing of the cytological conditions in the first group including such types as Chara crinita, Cutlerio, some species of Spirogyra and Zygnema and numbers of the lower Chlorophyceae und Phaeophyceae whose motile gametes will germinate like zoospores should they fail to conjugate with one another. But since there is no reason to suppose that there are reduction phenomena at gametogenesis, the unfertilized gamete is fully prepared with respect to the number of chromosomes to continue the parent stock."

Die Fragen also, die wir in diesem Kapitel zu behandeln haben, lauten: 1. Wird durch die Parthenogenesis und Apogamie der.Generationswechsel ausgeschaltet? und 2. Ist bei den erwähnten Tallophyten der Eintritt der Parthenogenesis dadurch erleichtert, daß bei ihnen kein Generationswechsel vorhanden ist?

Um zunächst auf die zweite Frage einzugehen, so ist sie unseres Erachtens unbedingt zu verneinen. Denn was zunächst strasburger's Meinung anbelangt, die Chlorophyceen und Phaeosporeen seien hinsichtlich der Leichtigkeit, mit der bei ihnen Parthenogenesis auftreten könne, vor den höheren Gewächsen insofern bevorzugt, als .,bei ihrer Keimung nur die Reduktionsteilung ausgeschaltet zu werden braucht, damit der Keimling über die ihm zukommende Chromosomenzahl verfüge", so ist dazu zu bemerken, dab ja für die höheren Pflanzen das gleiche gilt: auch bei der Keimung ihrer Makrospore braucht ja nur die Reduktionsteilung ausgeschaltet zu werden, und 


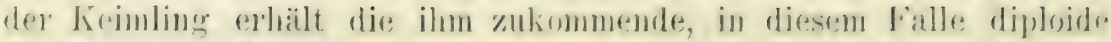
('lromosomenzalil.

'Zweitens aber und vor allem kïnnen wir der Ansicht nicht bei-

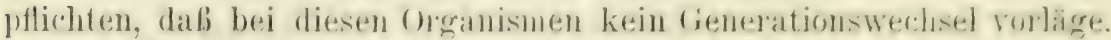
Inscres brarhtens mul.j man viehmehr anch im bitwicklungrgange

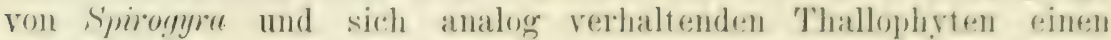
Generationswechsel arblicken, so dab heim Eintritt von forthengenesis anch hier die eine Generation, niamlieh des Sponophyt, die Cygote, mit der für die andere charaktoristischen Chromosonenzahl durchgemacht werden. also für die Einfïlnumg der Apomixis prinzipiell dieselbe schwierigkeit vorkiegen mul, wie bei den hïheren Pflanzen.

Die Ansicht. dab atuch Organismen wie Syirogyra einen regelrechten Generationswechsel haben, ist nnn ansführlicher zu begründen. Es erscheint das um so mehr geboten, als die Ansichten der verschiedenen Forscher über das Wesen und das Vorhandensein odel Fehlen des Generationswechsels bei dieser oder jener Organismengruppe merkwürdig verschieden und unbestimmt sind. So ist \%. B. Wettstein (1903, p. 6 ı. a. a. O.) der Ansicht, daß bei den Angiospermen kein Generationswechsel vorhanden ist, da die geschlechtliche Generation bei ihmen vollständig ausgefallen ist. während nach Engler (1904, p. 71) bei ihnen der Generationswechsel zwar ,in der Samenbildung verdeckt", aber doch noch da ist. Hinsichtlich der Archegoniaten herrscht natürlich Übereinstimmung; nicht aber für alle Abteilungen der Thallophyten. Daß Daris und Strasburger vielen Chlorophyceen und Phaeosporeen den Generationswechsel absprechen, wurde bereits erwïhnt. Auch Oltmanns (190う, p. 269) bemerkt: .. Bei zahlreichen Formen ist ein Generationswechsel in dem erwähnten Sinne [geschlechtliche und ungeschlechtliche Generation müssen miteinander abwechseln, wenn alle Gestalten zur Geltung kommen sollen, die in den Entwicklungsgang jener Pflanzen hineingehören」 einfach nicht vorhanden. Bei sämtlichen Fucaceen, zahlreichen Siphoneen, wie Dasycladus, Acctabularia, Codtum, Bryopsis, kennen wir nur Sexualpflanzen. Das befruchtete Ei eines Gametophyten liefert sofort wieder einen solchen und nichts anderes." Andere aber, wie Lotsy $(1905,1907)$ und Chamberla in neigen dazu, auch hier einen Generationswechsel anzunehmen.

Unseres Erachtens ist aber eine einheitliche Auffassung des Generationswechsels nur dann möglich, wenn man in ihm eine notwendige Folge der Einfülırung der Sexualität erblickt, und demgemäß annimmt, daß er überall da vorhanden sein muß. wo geschlechtliche Fortpflanzung da ist. Eine ausfïhrliche Begriundung dieser Ansicht kann hier natürlich nicht gegeben werden und soll an anderer Stelle unter eingehender Berücksichtigung der einschlägigen Literatur er- 
folgen; nur kurz sei angedeutet, in welchem Sinne wir die Entstehung und Verbreitung des Generationswechsels verstanden wissen möchten.

Daß die haploide Generation die phylogenetisch ältere ist, läßt sich nicht bezweifeln (vgl. bes. Lotsy 1905); als die erste Verschmelzung zweier haploider Zellen eintrat, war in dem Verschmelzungsprodukt die erste diploide Zelle gegeben. Sie war doppelt so grob resp. massig als die haploiden Zellen, da sie eben ans zwei solchen entstanden war, und besab auch die doppelte Kernmasse und die doppelte Chromosomenzahl: noch jetzt spiegelt sich in der Kernplasmarelation diese Entstehung der ersten diploiden Zelle wieder. Tenn sie sich num weiterentwickelte und dabei genau so gestaltete wie die haploide Generation, damn mußte sie wieder Gameten liefern, aus deren Verschmelzung tetraploide Zellen hervorgehen mußten. Diese nun waren offenbar nicht gut erhaltungsfähig, vielleicht weil sie wegen der notwendigen Kermplasmarelation zu groß wurden; möglich aber auch, daß urspriinglich mehrmals solche Steigerungen der Kernmasse und ('hromosomenzahl durch Verschmelzung diploider, tetraploider usw. Zellen stattfanden, um dann ein Ende zu finden, wenn die für die Species günstigste Zelloröße erreicht war. Dann war also eine weitere Bildung von Gameten nicht mehr möglich, da damit eine Steigerung der Chromosomenzahl über das zulässige oder wenigstens das optimale $\mathrm{Yah}$ hinaus verbunden gewesen wäre, es mußten wieder nur ungeschlechtliche Sporen gebildet werden, und so wurde die diploide Generation zum Sporophyten.

Die Sporen, die an ihm entstanden, mögen wohl zuerst diploid gewesen sein, einfach ungeschlechtlich gewordene Gameten, und so wäre die haploide Generation und mit ihr die Sexualität anf die Dauer verschwunden, wenn nicht bei der Sporenbildung das Bestreben, möglichst zahlreiche sporen zı erzeugen, verbunden mit dem möglichster Materialersparnis dazu geführt hätte, daß Sporen mit haploiden Kernen gebildet wurden, deren natürlich mit derselben Kernmasse die doppelte Anzahl gebildet werden konnte. So stabilisierte sich allmählich der Wechsel zwischen den beiden Generationen, wobei der diploiden die Aufgabe zufiel, durch Erzeugung möglichst zahlreicher Sporen für möglichst große Verbreitung der Art zu sorgen, der haploiden die, durch Erzengung von Gameten der Art die Vorteile der Amphimixis zugänglich zu erhalten, die im Anfang vielleicht nur darin bestanden, daß durch sie immer wieder die optimale Chromosomenzahl und damit die optimale Zellgröße erreicht wurde.

Die diploide Generation konnte ihre Aufgabe, möglichst viel Sporen zu liefern, natürlich um so besser erfüllen, je kräftiger entwickelt sie war, daher sie auch im Verlaufe der phylogenetischen Entwicklung auf Kosten der haploiden Generation bevorzugt wurde, zumal sie ja auch in dem Besitze der Chromosomenzahl war, die sich 


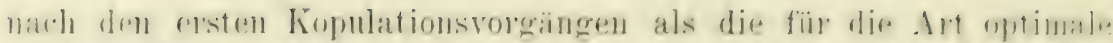

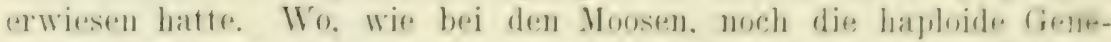
ration dominiert. dat tritt die diploide mit ihr in so imnige Verbin.

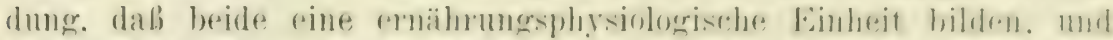

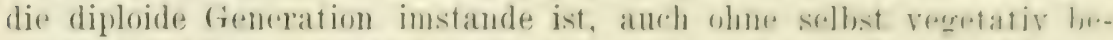
somders kräftig ansgebildet zo sein, eims seln grobe Anzalıl rou sporen zu liefertn. Sowie sie aher selbstandig wurde. mubtr s.. leistumgsfuhiger ansgebildet werden, und dieser mit den Farman definitiv einsetzende Prozeb führte dem anch zu einer immer weitergehenden Ausgestaltung der diploiden und einer inmer weiter fortschreitenden Rïckbildung der haploiden Generation. Ihas lotztrete int wohl folgendermalien zu verstehen: mit der Ausbildung müglichst zahlreicher Vermehruneszellen. Sporen. war die optimale Entwirklung der Art noch nicht garantiert; es mubten auch nowh jeden de-1 ans je einer spore hervorgehenden Pflänzchen die Torteile der Amphinnixizugänglich gemacht werden. Mit je weniger Materialanfwand dite geschehen komnte. um so besser für die Art. Cund su finden wir denn auch. daß schon bei den Farnen - die eben infolge der Finhaltung dieses Prinzipes der Ausgangspunkt für die Entwicklung der hïheren Pflanzen werden konnten - der Gametophyt klein hleibt: er ist nul der 'Träger' der' gametenbildenden Organe. Der ideale Fall. übel' te:11 hinaus eine Weiterentwicklung nicht mehr denkbar ist. ist natiirlin:l der, dali die Sporen selbst direkt zu Gameten werden. und er ist ja auch in der Tat bei den Tieren und manchen Pflanzen erreicht.

Nach dieser Anschaumo, die hier, wie gesagt. nur ganz flichtig skizziert und nicht ausführlich begründet merlen konnte, muli demnach überall, wo geschlechtliche Fortpflanzung rorkommt, auch ein Generationswechsel realisiert sein. wobei immer die haploide Generation die geschlechtliche, die diploide die ungeschlechtliche sein muß. End daß das auch wirklich der Fall ist, mul' man unseres Erachtens zugeben, ganz gleichgültig ob man die eben entwickelten Ansichten iiber Ursprung und Bedentung des Generationswechsels teilt oder verwirft.

Strasburger stïtzt sich bei der Annahme, dab bei chlorophyceen und Phaeosporeen keine diploide Generation rorhanden sei. in der Hauptsache auf die Untersuchungen ron Allen (1905) ül)el die Keimung der Zygote von Coleochaete, die mit einer Reduktionsteilung beginnt, so daß hier in der Tat die Zygote die einzige diploidchromosomige Zelle im ganzen Entwicklungscyklus ist. und meint. es sei auf Grund dieser Feststellung wohl zuliassig, anzunehmen. dab auch bei den Phaeosporeen und anderen Chlorophyceen die Keimung. mit einer Reduktionsteilung einsetze.

TVenn man nun wohl auch diese letztere Schlußfolgerung zugeben wird, so ist doch, was die sich daran anschließende Torstellung rom 
Fehlen eines Generationswechsels bei diesen Organismen anbelangt, daran zu erimnern, daß die befruchtete Hizelle iiberall, wo ein nicht zu bezweifelnder Generationswechsel vorhanden ist, die erste Zelle des Sporophyten ist. Und sie bleibt das doch auch dann, wenn sie die einzige Zelle des Sporophyten bleibt. Der Sporophyt ist in allen diesen Fällen durchaus nicht etwa gar nicht vorhanden, sondern nur anf eine einzige Zelle reduciert, eben die Zygote. Sie ist auch bei solchen Organismen wie Spirogyra ('Tröndle 1907) infolge der Verschmelzung der beiden Gametenkerne diploidchromosomig; und stellt daher so lange den Sporophyten dar, bis mit der Beendigung der Reduktionsteilung wieder die ersten haploidchromosomigen Zellen des Gametophyten vorhanden sind. Es gehört zum IVesen des Gametophyten, daß in ihm eine Reduktionsteilung unmöglich ist; eine solche kann nur im Sporophyten vor sich gehen, und wenn daher im Intwicklungsgange eines Organismus auch nur eine einzige Zelle da ist, immerhalb deren sich eine Reduktionsteilung abspielt, so ist diese als Sporophytenzelle anzusehen. Ich pflichte daher Wort für Wort Chamberlain bei, wenn er bei Besprechung der erwähnten Allenschen Arbeit (Botan. Gazette, Bd. 40. 1905, p. 388) sagt: "The statement that there is 110 generation which could be called a sporophyte, seems to the reviewer to be a serious mistake. Riccic has a sporophyte just as has Scquoin, the extent of its development being unessential as far as the logical presence of a sporophyte is concerned. The sporophyte generation in lower plants as well as in higher begins with the fertilized egg. Whether the egg then divides once, twice, or a million times, or not at all, neither strengthens nor weekens its title to the term sporophyte. It seems to us that there is an important difference between extreme reduction and complete elimination."

Es ist nur eine Konsequenz unserer Auffassungsweise, wenn wir nicht nur den erwähnten Chlorophyceen und Plıaeosporeen, sonder'n auch den höheren Pflanzen und Tieren einen typischen Generationswechsel zuschreiben. Auch den letzteren ist er ja gewöhnlich abgesprochen worden. Für uns aber ist er wie für Chamber lain (1905) auch hier vorhanden, um ist, wie bei Coleochacte und sich ähnlich verhaltenden Pflanzen der Sporophyt auf eine einzige Zelle reduciert war, so bei den 'Tieren die haploide Generation nur einzellig. Produkte der Reduktionsteilung sind bei den Tieren wie bei den Pflanzen die Sporen, und zwar Mikrosporen im männlichen und Makrosporen im weiblichen Geschlecht. Hier wie dort ergibt die Keimung der Makrosporen den weiblichen, die der Mikrosporen den männlichen Gametophyten, oder, wie wir hier wohl besser sagen, die weibliche resp. männliche haploide Generation. Während aber selbst bei den höchststehenden Pflanzen fast immel' die vegetativen 'Teile 


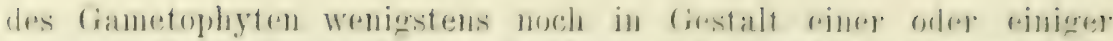

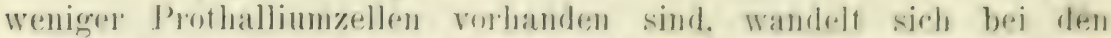

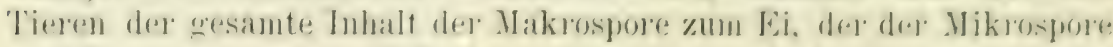

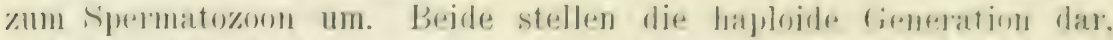

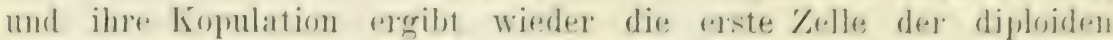
Generation, das befruchtete bi.

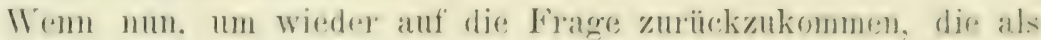

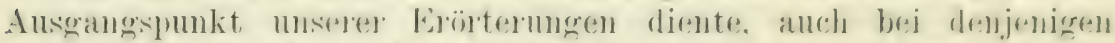

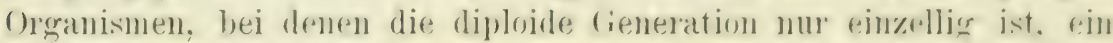
legelrechter Genelationswerhsel vollanden ist, damn kann matn natiulich nivlıt behaupten. dab. bei ihnen die Parthenogenesis infolge des Mangels eines Generationswechsels erleichtert sei. Anch brei Spromyre und den sich änlich verhaltenden Thallophyten muls beim Fintritt von Parthenogenesis die eine Generation. nämlich der sjonophyt, dis Zyorote, mit der für die andere Generation charakteristischen hajloiden ('hromosomenzahl durchgemacht werden, und es miissen daher. da das \%ygotenstadium ebenso notwendig in den kompletten Entwicklungsgang der spiroryyra hineingehört wie das sporogonstadim in das der Moose. prinzipieli hier für den Eintritt der Parthenogenesis dieselben schwierigkeiten vorliegen, wie bei den höheren Pflanzen. Jer einzige Unterschied ist der, das bei den letzteren der Gametophrt, bei den ersteren der Sporophyt die ungewohnte chromosomenzahl erhält. Ind dab der Tmstand, dal. bei I'lothrie, Spirogyra usw. die Ciamete die gleiche Chromosomenzahl besitzt wie der Thallus, noch nicht genünt, ihr eine besonders grobe Neigung zu parthenogenetischer Entwichlung zu verleihen, erhellt daraus, daß es ja doch im allgemeinen noch eines ganz besonderen Anstoßes, ganz besonderer äuberer Bedingrungen bedarf, un der an sich befruchtungsbedüftigen Gamete die Entwicklungstähigkeit zu geben.

Mit den voranstehenden Erwägungen ist zum Teil auch schon die zweite Frage beantwortet, mit der wir uns in diesem Kapitel zu beschäftigen haben, die nämlich, ob der an sich vorhandene Generationswechsel durch die Parthenogenesis oder Apogamie auscreschaltet wird. Wir müssen diese Frage entschieden verneinen. Weder durch Parthenogenesis noch durch Apogamie wird der Generationswechsel - dessen ursprïngliches Vorhandensein bei allen apomiktischen Organismen vorausgesetzt werden muß, da sie ron solchen mit geschlechtlicher Fortuflanzung und also auch mit Generationswechsel abstammen - beseitigt, sondern beide Generationen bleiben auch bei parthenogenetischen und apogamen Pflanzen und Tieren vorhanden. Nu besteht allerdings ein wichtiger Unterschied zwischen den sexuellen Organismen einerseits und den parthenogenetischen oder ajogamen andererseits insofern, als bei den ersteren der Gametoplyt stets die haploide, der Sporophyt die diploide Chromosomenzahl führen. während 
bei den letzteren beide Generationen gleicherweise entweder die eine oder die andere Chromosomenzahl haben.

Die Ansicht, daß durch Parthenogenesis und Apogamie der Generationswechsel aufgehoben werde, wäre demnach offenbar nur dann gerechtfertigt, wenn man in dem periodischen Wechsel der Chromosomenzahl das Wesen des Generationswechsels erblicken müßte und einen Gametophyten, der Kerne mit der diploiden Chromosomenzahl besitzt, nicht mehr für einen Gametophyten, sondern nur für einen gametophytenartig gestalteten Sporophyten ansehen dürfte. Es ist also ganz ähnlich wie bei dem diploiden Ei: wie dieses nach Strasburger wegen seiner diploiden Chromosomenzahl keinen Anspruch auf die Bezeichnung Ei melı hat, so sollen auch des Gametophyt kein Gametophyt und der Sporophyt kein Sporophyt mehr sein, wenn sie je die für den anderen charakteristische Chromosomenzahl aufweisen. Auch hier müssen wir darin wieder eine Überschätzung der Bedeutung sehen, die der Chromosomenzahl zukommt.

Selbstverständlich liegt es uns völlig fern, die große Bedeutung der vor allem von Strasburger (1894) betonten Tatsache zu leugnen, dab beim normalen Generationswechsel ein periodischer Wechsel der Chromosomenzahl vorkommt derart, daß der Gametophyt stets die haploide, der Sporophyt die diploide Zahl erhält. Nur sind moseres Erachtens diese Differenzen in der Chromosomenzahl weder die einzigen noch die wichtigsten Unterschiede der beiden Generationen. Wenn ein Sporophyt durchaus typisch gestaltet ist und Sporangien trägt, wie das nach Y aman ouchi (1907) bei Nephrodium molle der Fall zu sein scheint, so ist es gewib gezwungen. ihn deshalb, weil seine Kerne mit der haploiden Chromosomenzahl ausgestattet sind, für einen Gametophyten zu halten; und wenn ein Prothallium wie das der somatisch apogamen Farne bei völlig normaler äußerer Gestaltung Archegonien und Antheridien mit typischen Spermatozoen zur Ausbildung bringt, so ist es gewib natïrlicher, es auch beim Vorhandensein der diploiden Chromosomenzahl in seinen Kernen für einen Gametophyten als für einen Sporophyten zu halten.

Stras burger (1907, p. 139) bemerkt demn anch in seiner letzten Arbeit, der Fall von Marsitia Drummondii, die auch diploidchromosomige Kerne im Prothallium führt, lehre, „daß das zweimalige Vorhandensein eines jeden Chromosoms den Kern nicht an der Auslösung: der spezifischen Merkmale der haploiden Generation hindert." Freilich fährt er dann fort: "Anders in der diploiden Generation. wo das doppelte Vorhandensein der Chromosomen, zum mindesten für Pflanzen, so weit als die Erfahrungen reichen, Bedingung der Entwicklungsmöglichkeit ist. Da die halbe Chromosomenzahl, wie sie jede Geschlechtszelle führt, die Gesamtheit der Speziesmerkmale umfaßt, so handelt es sich in der auf die Doppelzahl eingerichteten 


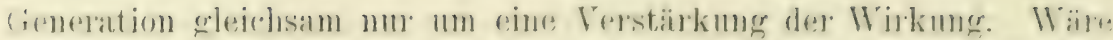
diese nicht notwendig. so lieben sich katum alle die ajugranen bin-

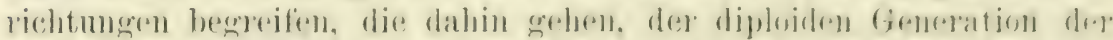

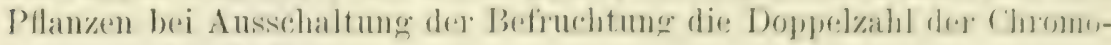
somen zi beschaffen."

Inzwischen sind mun aber doch melurere Falle konstatiert worden.

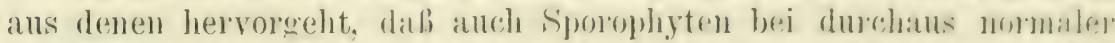
Ausbildung hajoiddhromosomige Kerne besitmen kinnen: $\Leftrightarrow$ bej

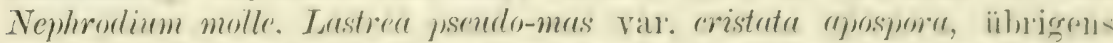
anch Sproogyer usw. In diesem tousammenlange sei anch noch einmal an die eigentimliche von Meves (10107) gefundene Tatsache elimnert, dab bei der Honigbiene das Mannchen haploidchomo:omign. das Weibchen diploidchromosomige Kerne hat. Strasburger wird also wohl selbst die Auffassung jetzt nicht mehr aufrecht erhalten. daß zur Entfaltung der Sporophytemmerkmale die diploide ('hromosomenzahl notwendig sei. (Daß) sie vorteilhaft sein kann, ist natïrlich zuzugeben).

Bei dieser Lage der Dinge neigen demn anch die meisten beteiligten Forscher dazu, die Beziehungen zwischen dem Generationswechsel und der periodischen Reduktion der Chromosomenzahl nicht mehr als so fest und unlösbar anzusehen, als man das frïher allgemein tat. So sagt I amanouchi $(1907$, p. 146): "It must he ardmitted that in the case of apogamy at least the number of chnomusomes is not the only factor which determines the character of the sporophyte and gametophyte." Auch Farmer und Digby (1907. p. 197) schlieben ihre theoretischen Erörterungen mit dem satze: .The general conclusion to be drawn from this discussion, on the relation between the periodic reduction in the number of the chromosomes and the alternation of generations, is that no necessary correlation exists between the two phenomena." sie ziehen diesen Schluß vor allem auf Grund dessen, daß ,it seems now certain that any cell the nucleus of which is provided with the requisite chromosomes. whether these are in single or duplicate number, is at least potentially endowed with the capacity of forming the starting-point of the entire life-history, in so far as the grosser morphological characters are concerned" (1. c., p. 196). Und endlich spricht auch Goebel (1907, p. 135) Ähnliches aus anläßlich seiner Regenerationsversuche mit den Keimblättern von Farnsporophyten, die Prothallien regenerierten. Er sagt: „Endlich zeigen die angefuihrten Tatsachen, daß zwischen den zwei „Generationen" der Farne kein scharfer Unterschied vorhanden ist. Man hat einen solchen nenerdings in der Chromosomenzahl finden wollen und gewiß ist die Tatsache sehr wichtig; daß das Prothallium gewöhnlich die $x$ - oder haploide, der Sporophyt die $2 x$ - oder diploide Generation darstellt. Indessen zeigen die neneren Beobachtungen von 
Strasburger und Farmer, daB es auch Prothallien mit nicht reduzierter ('hromosomenzahl geben kann, daß also die Formverschiedenheiten zwischen beiden Generationen jedenfalls mit der Chromosomenzahl nicht zusammenhängen."

Die Frage, worin denn num, wemn der periodische Wechsel der Chromosomenzahl nicht das Wesentliche am Generationswechsel ist. dieses eigentlich bestehe, können wir hier natiirlich nicht erörtern; es sei auf die frïher (Winkler 1906, p. 261 ff.; vgl. auch oben p. $118 \mathrm{ft}$.) gegebenen Andeutungen verwiesen.

Nach alledem muß also auch ein diploides Prothallium, wie es bei den somatisch apogamen und parthenogenetischen Farnen und Phanerogamen vorkommt, trotz des Besitzes diploidchromosomiger Kerne als Gametophyt angesehen werden. Und ebenso sind die haploiden Sporophyten der generativ apogamen und parthenogenetischen Gewächse Sporophyten, wenn ihre Kerne anch mit der für den Gametophyten charakteristischen Chromosomenzahl ausgerüstet sind. Wenn dem aber so ist, dann wird also auch durch Parthenogenesis und Apogamie der Generationswechsel nicht ansgeschaltet, er wird vielmehr trotz der konstant bleibenden Chromosomenzahl beibehalten. Nur wird er nicht unwesentlich modificiert. Demn es unterscheidet sich ja der ganze Entwicklungscyklus der parthenogenetischen oder apogamen Organismen von dem sexuell gebliebener gerade dadurch, dab die eine Phase des Generationswechsels mit der für die andere typischen Chromosomenzahl durchgemacht wird. Sporophyt wie Gametophyt besitzen also die diploide, für den Sporophyten charakteristische Chromosomenzahl, wenn somatische Parthenogenesis oder Alogamie vorliegt; beide sind dagegen haploidchromosomig; wenn es sich um generative Parthenogenesis oder Apogamie handelt. Das gilt anch für die 'Tiere. So wird bei der experimentellen Parthenogenesis der Seeigel die haploide, bei den zahlreichen Tieren, bei denen die Ausbildung des zweiten Richtungskörperchens unterbleibt, die diploide Chromosomenzahl beibehalten.

Als ausgeschlossen kann es übrigens nicht bezeichnet werden, daß auch bei Pflanzen, wie das für manche Tiere bekannt ist, eine nachträgliche Regulierung der Chromosomenzahl vorkommt, also eine Reducierung bei somatischer, eine regenerative Verdoppelung der Chromosomenzahl bei generativer Parthenogenesis oder Apogamie. Bisher sind aber solche Fälle noch nicht gefunden worden; doch gehört in gewissem Sinne die Pseudomixis hierher. 
Aclites Kapitel.

\section{Ursache und Auslösung von Parthenogenesis und Apogamie.}

Die wichtige Frage, wodurch in jedem einzeluen Falle Tarthenegenesis oder Apogamie reranlabt werden, ist noch weit davon entfernt, auch nur einigermaben exakt beantwortst werlen zu können. Ans den Erörtermoen des sechsten Kapitels geht jedenfalls so viel hervor. dali der Eintritt oder Xichteintritt parthenogenetischer order apogamer Entwicklung nichts direkt zu tum hat, mit der chromosomenzahl in den Kromen der Zellen, die als Als:rangspunkt der Entwicklung dienen.

Offenbar müssen wir bei einem Versuch, die möglichen intworten auf unsere Frage zu besprechen, die habituelle und die fakultative Parthenogenesis und Apogamie scharf auseinander halten. To die Apomixis habituell geworden ist. kimnte man versucht sein anzunelmen, dab es jedenfalls keines besonderen Anstolies ron anben bedürfe, um sie auszulösen. Die Entstehung eines Embryos in ler unbestäubten Blïte wäre dann lediglich aufzufassen als eine notwendige Phase im Entwicklungsgange der Pflanze, die im Terlauf der Blïtenentwicklung ebenso notwendig und spontan auf die rorangegangenen Stadien folgte wie etwa die Ansgliederung der CarpellPrimordien anf die der Staubfïden in einer Zwitterbliite. Tnd während soust eben gerade die Embryobildung im ganzen (normalen Lebenslauf der Pflanze der einzige Torgang ist. der nicht notrendig auf das Torangegangensein der vorhergehenden Stadien folgt. wïrde das Charakteristische der apomiktischen Embryobildung innerhalb des Fruchtknotens darin bestehen, dals sich die Pflanze auch für diesen Vorgang unabhängig ron dem Außenreize gemacht hat. Wenn man sich dieser Auffassumg anschließt, so fällt die Frage nach der Vatur des die Apomixis im Terlauf der Ontogenese auslüsenden Faktors weg. und es bleibt allein zu untersuchen. wodurch es der Pflanze im Terlauf der Phylogenese ermöglicht wurde. auf den an sich für die Embryobildung nötigen Außenreiz zu verzichten.

Freilich bleibt dabei die Möglichkeit offen, daß jeweils im kritischen Moment ein Innenreiz als auslösender Faktor in Betracht käme, und die Grenze zwischen Außenreiz und Innenreiz ist in unserem Falle nicht leicht zu ziehen. So wäre z. B. denkbar. daß die Änderungen physikalisch-chemischer Tatur, die in einer Blïte infolge des Ausbleibens der Bestäubung eintreten, die Eizelle zur Parthenogenesis veranlaßte. Daß infolge der Bestäubung imnerhalb der Blïte tiefgreifende Änderungen ror sich gehen, ganz unabhängig ron der Befruchtung der Eizelle, kamn keinem Zweifel unterliegen. Wissen wir 
doch, daß z. B. bei Orchideen das Eindringen des Pollenschlanches iiberhaupt erst die weitere Ausbildung der Samenknospen bis zum empfängnisfähigen Zustand bedingt, daß in vielen Fällen von Parthenokarpie die Teiterbildung des Fruchtknotens zur Frucht allein infolge der Bestäubung geschieht, und daß auch die Entstehung von Adventivembryonen lediglich eine Folge der Bestäubung sein kann wie z. B. bei Opuntia (Ganong, 1898). Wenn das Eindringen des Pollenschlanches in den Fruchtknoten an sich schon so weitgehende morphogene Wirkungen hat, so ist es klar, dab auch tieforeifende Änderungen physikalisch-chemischer Art in der Umgebung der Eizelle damit verknïpft sein müssen, Änderungen, die vielleicht bei der Entwicklungsanregung des befruchteten Eies mit beteiligt sind. Bleiben sie aus, so befindet sich also das Ei damit in anderer physikalisch-chemischer Umgebung, die ihren Charakter vielleicht beim Altern der unbestäubten Blüte noch mehr ändert. Normalerweise ist nun allerdings gerade diese Differenz nicht imstande, parthenogenetische Entwicklung der Eizelle auszulösen, wie das Verhalten unzähliger unbefruchteter Blüten beweist. Aber es wäre nicht undenkbar, daß einmal, etwa als Mutation, eine Bliite vorkäme, bei der gerade die physikalisch-chemischen Terhältnisse, wie sie in der unbestäubt bleibenden Blüte in der Umgebung des Eies herrschen. Parthenogenesis inducierten. Sie übertrug diese Eigenschaft auf ihre Nachkommen, und da bei denen also damit der Samenansatz gesichert war, so konnten sie allmählich die bestäubungsbedürftig gebliebenen Individuen verdrängen, zumal wenn bei diesen irgendwelche Erschwerung der Bestäubungs-Chancen dazu kamen.

Die Znlässigkeit einer solchen Auffassung kamn nicht bestritten werden, doch ist sie so hypothetisch, daß mit ihr nicht viel gewomen ist. Der ganze Gedankengang wurde in der Hauptsache auch nur angeführt, um zu zeigen, daß selbst bei der habituellen Apomixis, die durch ihr Dasein zu beweisen scheint, daß die Eizelle keines besonderen Anstoßes bedarf, um zum Embryo zu werden, doch sehr wohl ein versteckter Faktor vorliegen kann, der anf dem Wege eines Reizanstoßes der an sich nicht entwicklungstähigen Eizelle die Jintwicklungsfähigkeit verleiht.

Die Ansicht der meisten Parthenogenesisforscher geht denn auch dahin, daß auch bei habitueller Parthenogenesis und Apogamie nach den Ursachen zu forschen ist, die jeweils die Eizelle zur Entwicklung drängen.

Wie bereits in dem Kapitel über Parthenokarpie bemerkt wurde, könnte man da zunächst annehmen, es läge bei den parthenogenetischen oder apogamen Pflanzen autonome Parthenokarpie vor, die nun ihrerseits vermöge der engein korrelativen Wechselbeziehungen zwischen Samen- und Fruchtentwicklung die parthenogenetische Em- 


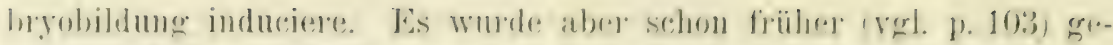
zeigt, dab diese Annahme nicht sehr wahrscheinlich ist.

Ton mehreren seiten ist ferner angenommen worden, dab als veranlassendes Doment fïr den bintritt der aponiktisclu Keinm\%engung Änderungen in den Ernähungsprerhalfnissen der Ovula in Betracht kämen. So gibt firnst (18x6) and. dafo beei Jisciphanir Ermstii. von der freilich noch nicht sicher bekamnt ist. welchen Iforlus der Apomixis sie besitzt, nach der Anthese die spindeln der weiblichen Ähren an der herabhängenden suitze infolge intensiven Zuflusses von Nährmaterial keulenförmig anschwellen. Lud da nun gerade an diesen angeschwollenen Inflorescenz-spitzen sich die apomiktisch entstehenden Frürhte ausbilden. so rermutet Ernst. dal.j die reichliche Xährstoffzufuhr die apomiktische inach Ernst's eigener Ansicht parthenogenetische) Embryoentstehung hervorrufe.

Auch Strasburger (1904, p. 145) vertritt ähnliche Anschanmgen. Er sagt: „Der Zufluß besonderer Nährstoffe nach den jungen Samenanlagen, wie er bei den apogamen Arten in der starken Inhaltsfüllung der Kellen und Anschwellung der Kernnukleolen sich kundgibt, löste wohl solche Torgänge [apogame Fortpflanzung] aus. Da die sexuelle Keimerzengung unterblieb, so fanden diese Xährstoffe keine Terwendung und veranlaßten schließlich eine regetative Weiterentwicklung des Archespors und damit auch die Bildung eines vegetativen Keimes."

Es ist dabei beachtenswert. daß es nach Strasburger's Ansicht von der spontanen Entwicklungsfähigkeit einer diploidchomosomigen Eizelle zum Aufkommen der Parthenogenesis schon genïgt. wenn das Archespor sich regetativ weiterentwickelt, also ohne Reduktionsteilung; "damit" ist für ihn auch die Bildung eines regetativen Keimes gegebell, so daß es dann für die Eizelle selbst keines weiteren Reizes bedarf, der sie dazu reranlabte, in Entwicklung zu treten. Wir werden auf diesen Punkt noch eingehender zu sprechen kommen. An dieser Stelle ist es aber für die Beurteilung des Wertes ron Ernährungseinflüssen als auslösender Faktoren für die Apomixis natürlich nebensächlich, ob sich die Wirkung der fraglichen Einfliisse auf eine Archesporzelle oder auf das Ei äußert.

Nun ist aber unseres Erachtens die Ansicht, daß der Zustrom besonderer Nährstoffe zu den Samenanlagen apomiktische Kieimerzeugung auslöse, aus verschiedenen Gründen ni cht haltbar.

Erstens erhebt sich sofort die Frage, warum demn iiberhaupt der reichliche Zufluß besonderer Nährstoffe nach den Samenanlagen noch stattfindet? Ist er doch auch bei normal sexuellen Pflanzen nicht unabhängig von der Entwicklung der Samenknospen, sondern vielmehr veranlaßt durch Wirkungen, die ron den eine befruchtete Eizelle enthaltenden Orulis ausgehen. Das erhellt ohne reiteres aus 
dem Verhalten der Fruchtknoten unbefruchtet gebliebener Blüten und noch deutlicher aus dem von vereinzelten Samenknospen, die innerhalb eines mehrere fertile Ovula enthaltenden Fruchtknotens absterben, weil sie nicht von einem Pollenschlauch erreicht wurden und also keinen Embryo entwickeln. Der reiche Zustrom von Nährstofien also, der in die ihmen unmittelbar benachbarten Samenknospen einfließt und diese mit ihrem Embryo reichlich ernährt, dringt nicht in sie hinein, obwohl er ihnen an sich ebenso leicht zugänglich ist als den anderen Ovulis. Das weist darauf hin, daß im allgemeineu der reichliche Zufluß von Nährmaterial zu jugendlichen Samenknospen nur dann stattfindet, wenn in ihnen wachsende Embryonen vorhanden sind, und es entspricht dieses Verhalten durchaus der allgemein bestätigten Erfahrung, daß Organbildung und Wachstum fast nie durch Stoffzufuhr veranlaßt werden, sondern daß umgekehrt sie die Zuwanderungen der Nährstoffe regulieren (vgl. Pfeffer 1897, p. $517 \mathrm{ff}$., 1). $599 \mathrm{ff}$.). So können z. B. auch Achselknospen nicht einfach durch starken Zufluß von Nährmaterial nach Belieben zum Austreiben gebracht werden; dafür sind andere Reizungen maßgebend (vgl. bes. II C Callum 1905). Wenn sie aber ihre Entwicklung begonnen haben, dann findet anch zu ihnen hin der Zustrom der nötigen Nährstoffe statt, offenbar unter dem Einfluß von Wirkungen komplicierter Art. die von den wachsenden Knospen selbst ausgehen. In Anbetracht dieser Terhältnisse erscheint es jedenfalls nicht ohne weiteres richtig. anzunehmen, daß bei den habituell parthenogenetischen Gewächsen ein reicher Zufluß von Nährstoffen zu den Samenknospen hin stattfinde, ehe die Embryoentwicklung begonnen hat. Dann kann aber selbstverständlich auch nicht nutritive Reizung als der die Embryogenese auslösende Faktor in Betracht kommen.

Nun gibt es allerdings Fälle, in denen trotz ausbleibender Bestäubung doch ein so reicher Zufluß von Nährmaterial zum Fruchtknoten stattfindet, daf dieser sich zu einer normal gestalteten Frucht ausbildet, nämlich die Fälle von autonomer Parthenokarpie. Diese kann ja unter Umständen sogar so weit gehen, daß auch die Samen sich äußerlich normal ausbilden, woraus also hervorgeht, daß auch in die Ovula hinein sich der Nährstoffzustrom ergossen hat.

Aber gerade dieses Verhalten läßt sich wieder als Argument gegen die Mitbeteiligung von Ernährungsfaktoren bei der Anslösung der Apomixis rerwenden. Denn es entwickeln sich ja eben gerade in diesen parthenokarpen Früchten trotz des reichlichen Vorhandenseins aller nötigen Nährsubstanzen keine Embryonen.

Überdies mub es natürlich auch in diesem Falle zweifelhaft bleiben, ob die parthenokarpe Fruchtbildung infolge des starken Zuflusses von Nährstoffen eintritt, oder ob auch in diesem Falle die umgekehrten Beziehungen herrschen. 


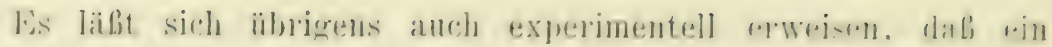

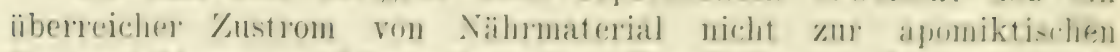

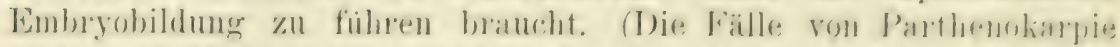
simd ja ebenfalls gewiscemaben Experimente der Vatur selbst. die das beweisenl. Sorgt man nämlich dafiir. etwa durch An-merehen aller anderen Blïten einer reichblütigen Inflorescen\%, dali zu eince

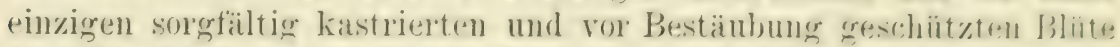

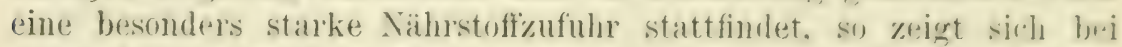
cytologischer Untersuchung in allen ron mir untersuchten Falle:l

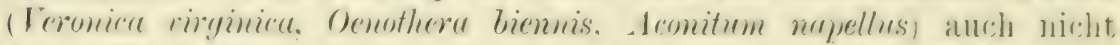
der erste Begimn einer parthenogenetischen Keim- oder Endospumentwicklung. Freilich lassen sich solche Tersuche nicht mit Sicherheit rerallgemeinem, doch erhöhen sie jedenfalls die Wahrscheinlichkeit nicht, dab nutritive Reizung parthenogenesiserregend wirken kömne. Lnd dem Finwand gegenüber, dab ein solches einmaliges Experiment nicht viel beweise, und dah, falls es nur .Jahrhunderte lang fortgesetzt werden könnte, der stets wiederholte Reiz auch liiwr schlieblich doch zum Eintritt der Apomixis führen wïrde, halse ich bereits an anderer Stelle (Winkler 1906, p. 256) an das Verhalten z. B. der kultivierten Banane erinnert, die seit Jahrtausenden angebaut wird und stets mit Nährstoffen vollgepfropfte Früclite erzengt. olne aber jemals anßer in seltenen Ausnahmefällen Samen hervorzubringen: Anch die kernlose Mispel kann hier angeführt werlen.

Endlich ist noch zu bedenken, daß, wie Orerton (1904) fand. bei Thalictrum purpurascens nebeneinander in demselben Bliitenkiiplichen parthenogenetische und befruchtungsbedürftige Blïten sich finden. Auch bei Hieracium excellens kommt Ähnliches vor (Rosenberg 1907, p. 156). In beiden Fällen dürften doch wohl die E1nährungsbedingungen, unter denen sich die beiderlei Blïtenarten gestalten, wesentlich gleich sein, und es wären jedenfalls wieder unwahrscheinliche Hilfshypothesen nötig, wollte man auch hier an der Anschauung festhalten, daß Ernährungsbedingungen die Parthenogenesis veranlaßten.

Aus alledem ergibt sich, daß der Tersuch, Ernährungsfaktoren als maßgebend für den Eintritt oder Nichteintritt parthenogenetischer oder apogamer Embryobildung anzusehen, nicht genïgend begründet ist. Es muß im Gegenteil als unwahrscheinlich bezeichnet werden, daß sie eine wesentliche Rolle dabei spielen.

Die Schwierigkeiten, die der Amnahme einer stofflichen Reizung entgegenstehen, bleiben aber auch dam bestehen, wenn man nicht die Quantität, sondern die Qualität der zuströmenden Substanzen als maßgebend ansieht, also annimmt, daß nicht überreicher Zustrom ron Nährmaterial in die Ovula das Ei zur Entwicklung anregt. sondern die Zuführung bestimmter entwicklungserregender Reizstofte, die etwa ein 
Analogon zu den organbildenden Substanzen von Sachs darstellten. Man könnte sich ja denken, daß etwa in den Blättern der parthenogenetischen Pflanzen gewisse spezifische Reizstoffe entstiunden, die, in die Samenknospen gelangt, das Ei zur Entwicklung reizten. Aber diese Annahme ist zunächst einmal rein hypothetisch und durch keine Tatsache unterstiitzt. Überdies würde sie das Bestehen der Apomixis ebensowenig erklüren, wie die Sachs'sche Annahme von blütenbildenden Substanzen die Blïtenbildung erklärt. Ferner würde sich sofort die Frage erheben. warum demn diese Stoffe eben nur bei den parthenogenetischen Gewächsen gebildet werden; das ganze Problem wäre also nur verschoben. Und endlich würden wieder Thalictrum purpurascens und Hierucium excellens dieser Hypothese ganz besondere Schwierigkeiten bereiten, da nicht einzusehen wäre, warum bei ihnen die entwicklungserregenden Substanzen nicht in alle Blïten einwanderten, oder in so reichlicher Menge gebildet wïrden, dab es für alle Blüten einer Inflorescenz ausreichte. -

Physikalische Zustandsänderungen in der Umgebung des Eies suchte Overton (1902, p. 372) als denjenigen Faktor hinzustelleı, de1 - zunächt bei dem von ihm näher untersuchten Thatictrum purpurascens - die parthenogenetische Entwicklung der Fizelle induciere. Coulter und Chamberlain (1904, p. 212) haben sich dieser Vermutumg Overton's angeschlossen und glauben, dab sie sich auch auf andere parthenogenetische Pflanzen ansdelmen lasse, ja sehen sogar alle Pflanzen, bei denen sich in der Nähe der Eizelle Ähnliches beobachten läßt wie bei Thalictrum purpurascens als parthenogenesisverdächtig an.

Overton's Vermutung gründet sich auf die Beobachtung, daß in der dichten Cytoplasmahïlle. die bei Thalictrum purpuruscens das unbefruchtete Ei umgibt, nachweislich kurz vor Beginn der parthenogenetischen Eiteilung physikalische Änderungen vor sich gehen, die wie er annimmt, irgendwie den osmotischen Druck innerhalb des Eies verändern. Da num Loeb in seinen allbekannten Arbeiten nachgewiesen hat, daß bei manchen marinen Tieren schon verhältnismäßig geringfügige Änderungen des osmotischen Druckes des umspülenden Mediums genügen, um parthenogenetische Entwicklung der unbefruchteten Eier hervorzurufen, so vermutet $\mathrm{Overton}$, daß auch bei Thatictrum purpurascens die ron ihm supponierten osmotischen Änderungen im Ei dessen Parthenogenesis zur Folge hätten. Noch weiter als er gehen Coulter und Chamberlain. die (190t, 1. 212) auf Grund der Overton'schen Beobachtung die Vermutung aussprechen, daß auch in anderen Fällen ,an envelop of cytoplasm may result in the segmentation of the egg.", und daß ,all cases in which there is a long delay before the egg segments may be suspected of occasional parthenogenesis". So sind ihnen z. B. einige Burmanniaceen partheno- 


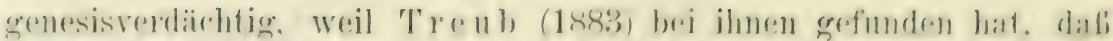

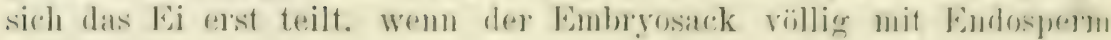
gefiillt ist.

Aber auch diese Ambamen rermögen nicht zu befiredierent. Zunärlist haben sie einen rein hypothetischen Chatakter, mod wor allem ist die Grundamahme einer Veränderung des osmotischen Inrucke innerhalb des Eies als Folge von Änderungen physikalisclur. Natur in seiner Umgebung eine blose Vermutung, die vorderhand durch keine Tatsache gestiitzt ist. Aber selbst wemn man wenigstens fïm Thalictrom purpurasems zugeben wollte, dab sie zol recht bestïnde, so wäre damit doch nicht viel gewonnen, da damn sofort wieder die: Frage entstünde, warmm denn die maligebenden physikalischen Änderungen des Makrosporenprotoplasmas nur in den parthenogenetischen Bliiten auftreten und nicht anch in den anderen. oder aber, wenn sie in allen Blïten eintreten, warum sir nicht auch in allen die parthenogenetische Embryobildung bedingen.

Und was die von Coulter und ('hamberlain geäulerte Termutung anbelangt, daß in allen Fällen , in which there is a long delay before the egg segments" Parthenogenesis rorliegen mögre, st ist ihr gegenüber daran zu erimnern, dab erstens auch bei mzweifelhaft parthenogenetischen Gewächsen oft die Eizelle ohne besonders merkbaren Terzug in Entwicklung tritt, und daf es zweitens genug Pflanzen gibt, deren Eier zweifellos der Befruchtung zu ihrer Weiterentwicklung bediufen, sich aber doch nicht sofort nach deren Vollzug teilen. So macht z. B. bei der sicher nicht parthenogenetischen The sinensis die Fizelle nach der Befruchtung geradezu eine Ruhezeit durch, die bis acht IIonate lang (von der Anthese an gerechnet) danert. und entwickelt sich erst weiter nach erfolgten Differenzierungen im Perikar') und den Samenhiillen. (Cavara 1898. p. 239.) Man wird hiernach also weder ans einem späten Entwicklungsbegimn des Eies anf das Torhandensein, noch aus einem frühen auf das Fehlen von Parthenogenesis mit Sicherheit schließen dürfen.

In Vorgängen chemisch-physikalischer Natur sieht anch Loeb) (1906, p. 353) die Ursache der Parthenogenesis. Nach seiner Ansicht besteht das Wesen der Befruchtung darin, daß im Ei ein bestimmter chemischer Torgang, etwa die Synthese von Chromatin aus gewissen Protoplasmabestandteilen hervorgerufen oder beschleunigt wird. Im unbefuchteten Ei kann dieser Prozeb deswegen nicht stattfinden, weil in ihm eine Hemmung besteht oder ein negativer Katalysator vorhanden ist, der durch das Spermatozoon beseitigt oder unschädlich gemacht wird. Bei der natürlichen Porthenogenesis nun „erfolgen die chemischen Vorgänge, welche zur Synthese von Chromatinsubstanz führen, spontan; sei es, dab das Ei schon den positiven Katalysator enthält oder selbst bildet, der sonst durch das Spermatozoon hinein- 
getragen wird; oder sei es, daß es den negativen Katalysator oder die Hemmung nicht enthält, welche in den ïbrigen Eiern durch das Spermatozoon oder die künstliche Parthenogenesis erst unschädlich gemacht oder beseitigt werden müssen".

Damit ist nun freilich nicht viel erklärt, selbst wenr man sich auf den Boden der Loeb'schen Befruchtungstheorie stellt. Denn die Frage ist doch eben gerade die, warum im parthenogenetischen Ei diejenigen chemischen Vorgänge, die zu seiner Entwicklung führen, und die normalerweise nu unter dem Einfluß des eingedrungenen männlichen Elementes begimnen, warum diese hier spontan erfolgen. Die Erörterung von Loeb ist also keine Erklïrung, sondern nur eine Umschreibung eben der zu erklïrenden Tatsache, dab sich das parthenogenetische Ei spontan entwickelt. -

Nahe liegt es natürlich anzunehmen, dab die Einführung der Apomixis irgendwie mit einer Schwächung oder dem gänzlichen Verluste der Sexualität zusammenhinge. Diese Termutung ist denu auch z. B. von Strasburger (1904, p. 158) und Kirchner (1904, p. 95) geäußert worden. Es ist ja auch selbstverständlich, daß indirekt solche Beziehungen zwischen Apomixis und Geschlechtsverlust bestehen, insofern als bei habituell apomiktischen Pflanzen eben infolge ihrer rein apomiktischen Fortpflanzungsweise die Befruchtung über: flüssig oder gar unmöglich geworden ist. Ob man num aber anch umgekehrt direkte Beziehungen zwischen den beiden Erscheinungen annehmen darf, derart, daß der Geschlechtsver'ust als primärer Vor. gang die Entstehung der Apomixis zur Folge gehabt habe, erscheint aus verschiedenen Gründen sehr zweifelhaft.

Die Annahme ist an sich so unbestimmt, daß zu ihrer näheren Präzisierung Hilfsannahmen nötig sind, um klar zu machen, wie und auf welchem Wege der Geschlechtsverlust die Apomixis bedinge. Denn daß duch den Geschlechtsverlust als solchen durchaus nicht inmer und notwendig Apomixis ausgelöst zu werden braucht, gibt Strasburger (190t, p. 159) selbst zu, indem er an das Verhalten der sterilen Bastarde erinnert. „Bei ihnen ist der Geschlechtsverhust jerlenfalls aber auch zu unvermittelt, um eine solche allmählich werdende Erscheinung veranlassen zu können." Hiernach wirkt also nicht der Geschlechtsverlust schlechthin, sondern nur allmählich eintretender Geschlechtsverlust. Übrigens genügt es, wem sich Apomixis einstellen soll, vielleicht schon, daß, die sexuelle Fortpflanzung zwar noch nicht erloschen ist, wohl aber bereits eine Schwächung erfuhr", ja, es kaun die Apomixis sogar schon "von einer Trennung der Geschlechter ansgehen. Diese hat bei den genannten beiden Pflanzen [Thatictrum purpurascens und Antennaria alpina] die Bestäubung erschwert, und dadurch ähnliche Bedingungen geschaffen, wie sie in anderen Fällen die Verbildung des Pollens mit sich bringt". Auch 


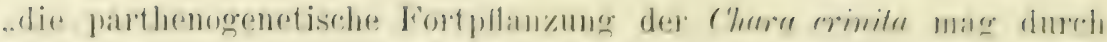
Diöcie ausgelöst worten sein". (Strasburger 1904, p. 1.58.)

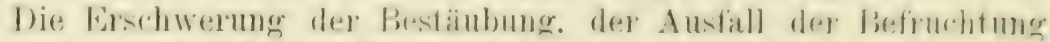

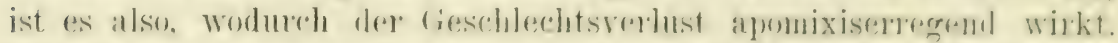

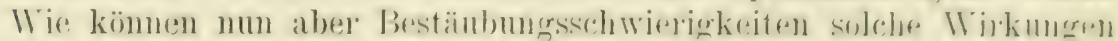
haben? Um diese frage zu beantworten. werden von sitrasburer und Kirchner biologische Momente herangezocen. Xiads strasburger (1904, p. 15) wird durh die erselowerte Bestaubung ..da: Forthestehen der betroffinen Art gefïhrdet. Apogame Fontpflanzunge stellt sich als Aushilfe in bestimmten Fälen ein". Whd ähnlicls möchte Kirchner (1904, p. 95) in der Parthenogenesis ..eine Einrichnug sehen. welche in einer andersartigen Theise. als es die viel weiter verbreitete spontane Sellstbestäubung tut, dazu dient, um die Ausbildung von keimfähigen Samen in soldhen Fällen sicher zn stellen. wo aus irgendeinem (irunde der Eintritt von Befruclitung ungewils oder schwierig geworden ist".

Aber abgesehen davon, daß man hier sofort fragen müfte, warum denn nicht anch bei den parthenogenetisch gewordenen Arten wie in so zahlreichen anderen Fällen zur Erhaltung der Art vlie Fähigkeit fast aller Pflanzen zu ausgiebiger ungeschlechtlicher Termelnrung benutzt wurde, warum also nicht Propagation anstatt Parthenogenesis zur Einführung kam, ist durchaus nicht einzusehen, inwiefern die T'atsache, daß für eine Art die Gefahr vorliegt. bei dauernd ausbleibender Bestäubung auszusterben, die Finführung parthenngenetischer oder apogamer Fortpflanzungsweise bewirken kann. Wenn in einem solchen Falle zur Frhaltung der Art die vegetative Fortpflanzung benutzt wird, so ist das ohne weiteres verständlich, da eben dam nur eine Befähigung in Anspruch genommen wird, die von vornherein vorhanden war und nun vielleicht im Laufe der .Jahrhunderte durch Selektion gesteigert wird.

Mit der Parthenogenesis oder der Apogamie aber miurde die Pflanze, um sich resp. ihre Art trotz der eingetretenen Bestäubungsschwierigkeiten zu erhalten. ad hoc ein ganz nenes ungewöhnliches Mittel einführen. Und diese Annahme verliert nichts von ihrer Ungeheuerlichkeit auch wenn man der Ansicht ist, daß Parthenogenesis und Apogamie ganz ,allmählich werdende Erscheinungen" sind. Tur also. wenn die Befühigung zur Parthenogenesis oder Apogamie schon vor Eintritt der erschwerten Bestänbung vorhanden war; wäre die Vorstellung haltbar, daß die Bestäubungsschwierigkeiten zu ihrer ausschließlichen Einfülrung mitgewirkt hätten. Damit bleibt aber gerade die Frage unbeantwortet, die wir beantwortet haben wollen, die nach der primären Ursache der beiden Apomixisarten.

Aus diesem Grunde können wir uns auch nicht mit der Hilfsannahme befreunden, die Kirchner (1904, p. 96) zur Unterstützung 
seiner Ansicht anführt. Er nimmt auf Grund der Beobachtungen Overton's an Thalictrum murmascens, ,nach denen diese Pflanze Eizellen von somatischem (harakter bildet, die sich wahrscheinlich allein parthenogenetisch entwickeln können und solche mit geschlechtlich differenziertem Kern, die sich wahrscheinlich ohne Befiruchtung nicht weiterbilden“, an, „dah ursprïnglich sehr allgemein in einer Anzahl von Samenanlagen, die gewissermaßen als Reserve für den Fall des Ausbleibens der Befruchtung dienten, bei der Entstehung des Embryosackes die Reduktionsteilung unterblieb und die Eizelle einen vegetativen Charakter behielt. Bei Arten mit gesicherter Befruchtung ist von dieser Einrichtung kein Gebrauch mehr gemacht und sie selbst unterdrückt worden, bei anderen, bei denen die Befruchtung, etwa infolge von Diklinie oder von übermäBig komplizierter Blïteneinrichtung unsicher wurde, ist die Möglichkeit der Parthenogenesis gewahrt geblieben und kann nun entweder, wie bei Thalictrom purpurascens, nur im Notfalle in die Erscheinung treten, oder endlich, wie bei den iibrigen besprochenen Arten, die geschlechtliche Fortpflanzung ganz ersetzen, wenn die Befruchtung unmöglich geworden ist".

Anch diese Annahme setzt eben das zu Erklärende schon voraus. sie steht zudem in unlösbarem Gegensatz zu den Vorstellungen, die wir über die Entstehung der Sexualität hegen müssen, und nach denen die Parthenogenesis zweifellos als abgeleitete Erscheinung gelten muß. Überdies wïrde sie sehr schwer anwendbar sein auf parthenogenetische Pflanzen wie Taraxacum officinale, die weder diklin noch mit übermäßig komplizierter Blüteneinrichtung ausgestattet sind, und bei denen auch ein so reicher Insektenbesuch stattfindet, daß sie geradezu als Beispiele für besonders gut an die Bestäubungsvermittlung angepaßte Blütenflanzen angeführt werden könnten.

Die weitere Annahme Strasburger's, das Ausbleiben der Bestäubung und Befruchtung wirke dadurch parthenogenesiserregend, dab die den Ovulis zuströmenden Nährstoffe keine Verwendung zur sexuellen Keimerzengung fänden, wurde schon früher (1. 128) als unhaltbar zurïckgewiesen. Und auch die von uns friiher (p. 126) angedentete Nöglichkeit, daß die physikalisch-chemischen Änderungen, die nach dem Ausbleiben der Bestäubung in der unbefruchteten Bliite vor sich gehen, als auslösendes Moment in Betracht kämen, bringt uns kaum weiter, da eben daun die Hilfshypothese nötig ist, daß durch Mutation eine Bliite erschien, deren Ei sich im Gegensatz zu dem aller anderen Bliiten eben so verhielt.

Überdies basieren alle diejenigen Hypothesen, die Bestäubungsschwierigkeiten und ausbleibende Befruchtung für die Einführung der Parthenogenesis oder Apogamie verantwortlich machen wollen, auf 


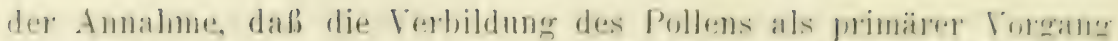
anzusehen sei. Das nehmen auch Overton (1904, p. 279) und

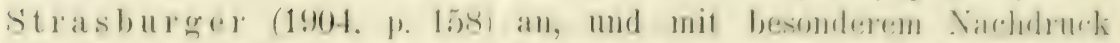

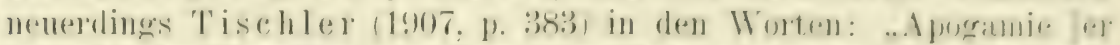
brancht den 'Terminus im Simmes rom sterasbuleger| hat sieh als

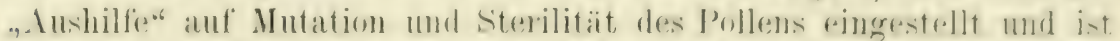

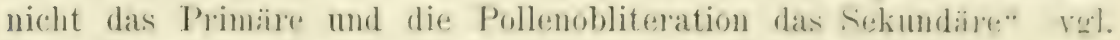
auch ' $\mathrm{T}$ 'ischler 1908, p. 138).

Aber das scheint mir nicht ohne weiteres einlenchtend oder selbstrerstïndlich zul sein. Der Grund, der die zitierten Auburn zu dirser Ansicht veranlabt laat, ist natiolich in erster Linie der Instand. dab bei vielen apogamen oder parthenogenetischen Pflanzen eben tatsächlich der Pollen verbildet ist. Wemn num aber wirklirh direkte kausale Beziehungen zwischen der Pollemobliteration und lem Sicheinstellen der Apogamie oder Parthenogenesis bestehen sull.n, damn mübte man doch annehmen, daß die beiden Ersohrinungen wenigstens insofern immer miteinander verbunden sein solltell. als Parthenogenesis stets mit Pollenverbildung verkniipft sein miilite. Das ist num aber durchaus nicht der Fall. Thalictrom jurpmosens hat durchaus normalen Pollen, Hieracium aurantiacum ebenfalls. wie aus einigen von Correns (1905, 1). 249) angetiilnten Bastardiertungversuchen Mendel's hervorgeht; auch bei Tarorurum verlatuft nach Juel (1905) die Pollenentwicklung ganz normal. und der Pollen ist wohl auch fähig, eine wirksame Befruchtung auszuführen. da innerhalb der Gattung Taraxacum nach $H$ a nde l- M a ze t t i 191007, Bastarde vorkommen. End da bei allen diesen Pflanzen rej(hlichel' Insektenbesuch stattfindet und auch Selbstbestäubung bei Hierurinm und Taraxum nicht ausgeschlossen wäre, so kamn in diesen Fällen jedenfalls nicht die fehlende Befruchtungsmöglichleit Lrsache für die Einführung der Parthenogenesis gewesen sein. Daduch wird aber gewib die Hypothese nicht wahrscheinlicher, daf. sie es in den anderen Fälien doch ist.

Freilich darf man nun auch nicht etwa ungekehrt behaunten, der Pollen habe sich seinerseits, weil iiberflïssig geworden, rerbillet, und wir werden Tischler darin recht geben. daß er sich dagegen wendet. Allerdings ist meines IVissens diese Annahme ron Niemandem vertreten worden; ich selbst habe vielmehr schon 1906, p. 259 ror ihr gewarnt, und es als von vornherein wahrscheinlich bezeichnet, daß ,derselbe Komplex von Ursachen, der die parthenogenetische Entwicklung der Eizelle resp. das Unterbleiben der Reduktionsteilung in der Makrospore veranlaßte, auch für das Rudimentärwerden der Mikrosporen maßgebend war". Demn es wären noch besondere Hiltshypothesen nötig, um zu erklären. warum sich die abnorme Entwichlung der Keimzellen nur auf die Wikrosporen oder die Makrosporen 
allein beschränkte. Wissen wir doch, daß bei Bastarden, bei denen ja sehr häufig die Entwicklung der Geschlechtszellen unnormal verläutt, nicht nur die Mikrosporen-, sondern auch die Makrosporenentwicklung davon betroffen wird. Zwar häufig in geringerem IIaße (Focke 1881, p. 478), aber doch immer merkbar und gelegentlich sogar stärker als die der Pollenzellen (Focke l. c., p. 480). Und neverdings hat Tischler selbst (1903; 1906) nachgewiesen, daß Embryosackobliterationen bei Bastardpflanzen durchius nichts Seltenes sind. Wemn also hier die UnregelmäBigkeiten bei der Bildung der Keimzellen nicht lediglich auf die Mikrosporenentwicklıng beschränkt blieben, so erhebt sich für die Verfechter der Ansicht, die Pollenverbildung als Primäres habe Apogamie oder Parthenogenesis als Aushilfe zur Folge gehabt, die Frage, warum denn nicht auch hier die Makrosporenentwicklung in Mitleidenschaft gezogen wurde.

T'ischler (1907, p. 383) meint, für die Ansicht, daß sich die Apogamie als Aushilfe auf die Sterilität des Pollens eingestellt habe, spräche anch „die Unsicherheit in der "Wahl des Weges" bei den Farnen (Farmer und Miss Digby) und Hieracien (Rosenberg), wo neben Apogamie auch Aposporie, vielleicht sogar Parthenogenese ausgelöst wird".

Eine nähere Begründung, inwiefern die angebliche Unsicherheit in der Wahl des Weges solche Schlïsse zulasse, gibt er indessen auch in seiner ausführlichen Arbeit (Tischler 1908, p. 138) nicht. Jedenfalls scheint mir der Hinweis auf die Farne deswegen wenig glïcklich zu sein, als gerade bei ihnen läufig die Spermatozoenbildung durchaus normal, die Archegonienentwicklung aber abnorm verläuft, gerade bei apogamen Formen. In diesein Zusammenhange anfïhren könnte man sie doch aber nur, wenn anch bei ihnen die Entwicklung der männlichen Keimzellen mehr gestört wäre, als die der weiblichen, so dah man auch hier in der Apogamie eine Aushilfe auf die fehlende Befruchtungsmöglichkeit sehen kömnte. Warum aber gerade die "Unsicherheit in der Wahl des Weges" für die Richtigkeit der Ansicht sprechen soll, daß die Pollenverbildung als Primäres die Apogamie zur Folge gehabt habe, ist mir nicht recht verständlich. Selbst wenn man einmal zugeben wollte, daß bei den Farnen die abnorme Ausbildung der Spermatozoen das Primäre war, so kann doch gerade daraus, daß "zur Aushilfe" sich entweder Apogamie oder Parthenogenesis oder Aposporie einstellten, der Schluß gezogen werden, daß zwischen keiner dieser drei Erscheinungen und der spermatozoenverbildung eine notwendige kausale Beziehung bestehen kann.

Aus alledem scheint mir hervorzugehen, daß für die Annahme, eine durch irgendwelche unbekannten Faktoren veranlaßte Sterilität der männlichen Keimzellen sei dasjenige Moment, das im Verlauf der 


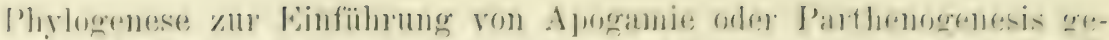
fiihrt labe, bisher keinerlei positiven Anhaltspunkte vonlierent.

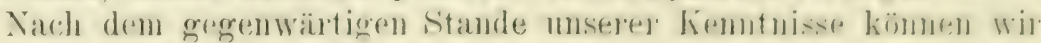

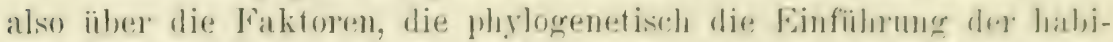
tuellen Parthenogenesis oder Apogamie hewirkt, haben. ebensowenigr otwas Nicheres anssagen als über die Natur der Reizvoneränge dir jeweils im Verlauf der Ontogenese sie anslïsen. Die granz: Frage wird dadurch noch komplizierter, dab es ja eigentlich zwei Vortringe sind. die bei somatischer Parthenogenesis zoll erkliren sind; das Unterbleiben der Reduktionsteilung und die spontane Entwirklungr des Eies. Für die Strasburegershe Ansicht fällt diest Komplikation allerdings weg, da nach ihr die Entwicklung des Fies ja darin ihre Erklärung findet, dab es diploidchromosomig ist. Ind da der Besitz der diploiden Chromosomenzahl für das Fi die notwendige Folge des Unterbleibens der Reduktionsteilung ist. so ist also nur zu erklären, warmm und auf frund welcher lieize diese nicht stattfindet. Nach unserer Ansicht dagegen ist das Ei lediglich auf Grund der unreducierten Chromosomenzahl noch nicht entwicklungstühig, es bedarf daher einer besonderen Erklärung, warum es das wirl. Ioch ist selbstverständlich auch nach dieser Ansicht es sehr gut denkbar, dali anch über die Entwicklungsfähigkeit des Eies schon zu der Zeit entschieden wird. in der das Unterbleiben der Reduktionsteilung bestimmt wird. Irgendwelche Anhaltspunkte zur Entscheidung dieser Frage fehlen uns vorderhand völlig. Es wäre dabei sehr gut denkbar, daß das Ei unbeschadet seiner spontanen Entwicklungsfïhigkeit befruchtungsfähig bliebe, wie das ja z. B. bei dem Ei der Honigbiene vielleicht tatsächlich der Fall ist.

Vielleicht lieben sich für die Beantwortung aller dieser Fragen Anhaltspunkte finden, wenn man etwa versuchte, bei Pflanzen. die wie Thatictrum purpurascens und manche Hieracien parthenogenetische und bestäubungsbedürftige Bliiten nebeneinander besitzen, die Bedingungen festzustellen, unter denen sie entweder ausschlieblich parthenogenetisch oder ausschlieblich amphimiktisch sind. Solche Tersuche liegen bisher nicht vor. Versuche, nach ähnlichen Methoden wie bei Tieren experimentell anch bei höheren Pflanzen Parthenogenesis zu erzielen, sind zwar verschiedentlich unternommen worden. z. B. von Overton (1902), haben aber bisher immer negative Ergebnisse gehabt. Aber auch wenn sie positive Ergebnisse gezeitigt hätten, ist es sehr fraglich, ob diese viel Wert für die Beantwortung der Frage nach der Ursache der habituellen Parthenogenesis gehabt hätten. Denn oftenbar können die Ursachen sehr mannigfache und von Fall zu Fall verschiedene sein. Aus diesem Grunde sind auch die Kenntnisse, die wir von der Ursache der fakultativen Parthenogenesis haben. nicht unmittelbar zur Erklärung der habituellen verwendbar. 
Unter fak ultativer Parthenogenesis wollen wir diejenige Form der Parthenogenesis verstehen, die nur damn zustande kommt, wenn ein ganz bestimmter nachweisbarer Außenreiz sie auslöst. Bleibt der Außenreiz aus, so geht das unbefruchtete Ei der hierhergehörigen Pflanzen zugrunde, olme sich zum Embryo zu entwickelı.

Zu erwähnen wäre hier an erster Stelle Ficus hirta (vgl. p. 43) bei der ja freilich die Parthenogenesis noch nicht mit völliger Sicherheit nachgewiesen. aber ihr Bestehen doch durch die Untersuchungen ron 'Treub (1902) sehr wahrscheinlich gemacht worden ist. So viel ist jedenfalls sicher, daß die Ausbildung embryonenhaltiger Samen nur in solchen Rezeptakeln erfolgt, in die die Blastophaga eingedrungen ist. Es liegt nahe, daraus zu schließen, dab hier durch den Einstich des Inquilinen der Reiz gegeben sei, der die parthenogenetische Entwicklung der Eizelle auslöse. Treub neigt auch zu dieser Amnahme, die durch die allbekannte morphogene Trirkung des Stiches und der Eiablage der gallbildenden Insekten gestuitzt wird. Aber zwingend ist sie nicht, da Eisen (1896) durch besondere Bestäubungsversuche dargetan hat, daß wenigstens bei der Smrrnafeige die Reife der Rezeptakeh nicht rom Stiche des bestäubenden Insektes, sondern von der Bestäubung als solcher abhängt. da kïnstliche Übertragung des Pollens mittels eines Gänsekieles denselben Effekt auf die Ausbildung der Frucht ansuibte wie die Kaprifikation. Auch stellte er durch Bastardierungsversuche fest. daß bei Ficus carica eine durch die Bestäubung oder den Insektenstich ausgelöste Parthenogenesis nicht vorliegt. Nun sind zwar selbstverständlich diese Ergebnisse nicht ohne weiteres auf Ficus hirta iibertragbar. immerhin weisen sie darauf hin, daß der Schlub auf eine parthenogenesiserregende Wirkung des Blastophagastiches nicht zwingend ist. sondern daß ebensogut die ja nicht zu bezweifelnde Apomixis durch die Bestäubung als solche ausgelöst sein kann, zumal T'reub ausdrïcklich konstatiert hat, daß eine solche stattfindet, und daß die Pollenkörner auch keimen und in das Gewebe der weiblichen Blüte eindringen. wenn es auch nicht zur Befruchtung selbst kommt.

Die Möglichkeit einer solchen Auslösung der Parthenogenesis durch die Bestäubung ist nicht von der Hand zu weisen. Wissen wir doch, daß die propagative Adrentivembryobildung außer bei C'aclebogyne iticifolia auch bei Opuntia und Euphorbia dulcis durch die Bestäubung ausgelöst wird derart, dab sie eben unterbleibt, wemn die Blüte nicht bestiubt wird. Das wurde von Strasburger (1878, 1. 662) durch Kastrierversuche bei Nothoscordum fragrans zuerst nachgewiesen; es triftt auch für Funtia orata, Allium odonum und andere polyembryonate Pflanzen zu. Nun wird allerdings in der Mehrzahl der hier anzuführenden Fälle die Eizelle befruchtet, und es muß daher vorerst unentschieden bleiben, ob die Entwicklungsanregung für die 


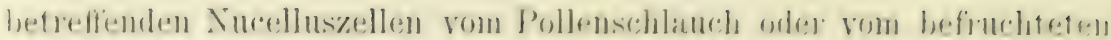

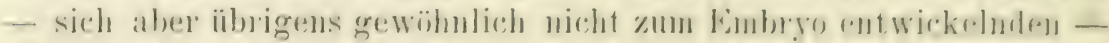

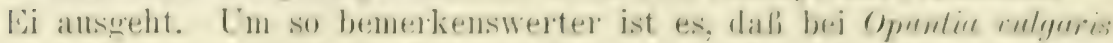

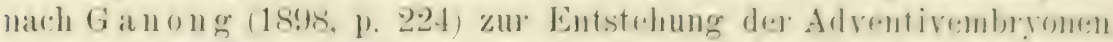
die Befruchtumg der Eizelle nicht nötigr ist, wohl aber die Bestiulunge. ber Pollenschlaureh tritt aurh nach den Beobathtungen lianonge stets in den bimbryosack ein, doch geht ans seinen Ingaben nicht hervor: ob nicht anch schon das Eindringen des Pollenschlauches in las Narbengewebe genïgt. Jedenfalls aber reigt das Verhalten der Opuntin relgoris, dafo durch die Bestïubung als solche ein lieiz gexgehen sein kamn, der die Entstehmo von Adventivembryonen zur Folge haben kann, und das magr wohl der Ansicht als Stïtze dienen. dali anch unter Lmständen Jarthenggenesis durch die Jestäubng ausgelöst werden kann. Für Ficnes hirta wäre das durch die frühel (vgl. 1. 44) angedeuteten Experimente wohl zu entscheirlen.

Die Amlahme, dab durch die Bestäubung, ohne dab eine eigentliche Befruchtung stattfïnde, eine parthenogenetische Entwicklung der Eizelle angeregt wïrde, ist, worauf schon bei der besprechung der noch unsicheren Fälle von Parthenogenesis wiederholt hingewiesen wurde, vor allem zur Erklärung des eigentuimlichen Terhaltens der faux hybrides herangezogen worden. Und in der 'Tat, wenn verschiedene Rassen von T'itis cinifero mit Pollen von Ampelopsis hederueren bestäubt in der Generation F1 durchaus reine litis cinifera-Xachkommen der mütterlichen Rasse ergeben, oder wenn Znygurtulum IIackayi nach der Bestäubung mit dem Pollen der verschiedensten Arten ron sechs anderen Orchideengattungen inmer wieder r'eine Zygopetalum Mackayi-Brut liefert, so ist eine der für dieses auffällige Verhalten möglichen Erklärungsarten sicherlich in der Annahme gegeben, dab infolge der Bestäubung, etwa unter dem Einflusse eines in dem Pollenschlauche enthaltenen II uchsenzyms, Parthenogenesis im Vitis- oder Zygopetalum-Ei ansgelöst wird. Und wenigstens für Ziygopetalum Mackayi ist ja durch den früher (p. 40) zitierten Versuch von Mc William erwiesen, daß eine zweite Erklärungsmöglichkeit, wonach es sich um echte Bastarde handeln würde, bei denen sämtliche miitterlichen Charaktere dominierten, ausgeschlossen ist, da die dann zu erwartende Spaltung in der Generation F2 ausblieb.

Nun bleibt freilich neben den erwähnten Erklärungsmöglichkeiten noch eine dritte ïbrig, die durch die interessanten und wichtigen Versuche ron Godlewski (1906) über Kireuzungen zwischen Echiniden und Crinoiden nahe gelegt wird. Dieser Forscher fand bekanntlich, daf die Eier mehrerer Echinidenarten, mit dem Sperma des ('rinoiden Antedon rosucea befruchtet, sich zu Bastardlarven mit ausschließlich mütterlichen Charakteren entwickelten, eine Beobachtung, die, wie man sieht, ein völliges Analogon etwa zu dem Terhalten 
von Zygopetalum Mackayi darstellt. Nun konnte aber Godlewski bei seinen Objekten ausdrücklich feststellen, daß eine regelrechte Verschmelzung des Antedon-Spermakerns mit dem Echiniden-Eikern vor sich geht, und daß sich auch das Chromatin des männlichen Kernes an der Bildung der Furchungskerne beteilig't. Hier kam man also nicht gut von einer Auslösung parthenogenetischer Entwicklung durch die Einwirkung des Spermatozoons sprechen, sondern muß den Vorgang offenbar auffassen als eine normale Befruchtung: bei der aber die männlichen Erbträger nicht imstande sind, in dem fremden Cytoplasmamedium ihre Eigenschaften zur Geltung zu bringen.

Eine ganz entsprechende Erklärung läßt sich natürlich anch für die pflanzlichen faux hybrides aufstellen. Entschieden werden kamn es selbstverständlich nur durch die zytologische Untersuchung. Für die Annahme, dab die faux hybrides in der Tat einen Analogiefall zu den Godlewski'schen Echinid-Crinoid-Bastarden darstellen. scheint mir der Umstand zu sprechen, daß bei Fragaria faux hybrides bekannt sind, die nach Millardet (1894) und Solms (1907) rein dem Vater und nicht der Mutter gleichen. Bei ihnen kann natürlich keine Parthenogenesis der Eizelle vorliegen, sondern es muß unbedingt angenommen werden, daß geformte Elemente aus dem Pollenschlauch in das Ei eindringen; wahrscheinlich geht die Befruchtung regehecht vor sich, nur sind es hier die weiblichen Erbträger, die ihre Eigenschaften nicht zur Geltung bringen können. Immerhin ist damit natürlich nicht ausgeschlossen, dab in denjenigen Fällen, wo die Nachkommenschaft der Mutter gleicht, die Entwicklung der Eizelle auf einer durch die Bestäubung ausgelösten Parthenogenesis beruht. Diese Möglichkeit bleibt also bis auf weiteres offen. (Tol. auch Tischler 1908, p. 109 Anm. 1.)

So haben wir, wie die Dinge jetzt liegen, wenigstens bis zu einem gewissen Grade einen Einblick in die die Parthenogenesis bedingenden Faktoren nur für die verhältnismäßig seltenen Fälle von experimenteller Parthenogenesis. Doch muß von vornherein bemerkt werden, dah uns eine Einsicht in die Mechanik des Vorganges in allen Fällen noch vollkommen fehlt, und daß es auch nicht zulässig ist. zu schlieben, daß auch bei der habituellen Parthenogenesis dieselben oder ähnliche Faktoren für die Auslïsung der Eientwicklung in Betracht kämen.

Vor allen Dingen haben wir es hier mit den wichtigen Versuchen von Klebs (1896) über die experimentelle Parthenogenesis bei Algen zu tun, für deren richtige Würdigung zu beachten ist, daß sie schon längst abgeschlossen vorlagen, als $\mathrm{L}_{0} \mathrm{eb}$ und Andere ihre bekannten Versuche über experimentelle Parthenogenesis bei Tieren anstellten. Es ist sehr wohl möglich, daß eine ausgedehnte und kritische Weiter- 
fiilmung dor Klebsichen Versuche woch manche fiir das Probum der Ib-fruchtung und Parthenogenesis fundamental wichtiere Tatsaches anfdecken wird. und es wire daher sehr erwinscht. Wenn sie unter genatuer Berëirksichtigung der Gesichtspunkte, die inzwirchen dies zoolugische Parthenogenesis-Forschung eqreben haben, wieder anforenommen würden. Dabei ware wohl zunächst die intensive Dureharbeitumer eines Falles wichtiger als die Ausdehnumer auf mïrlichst. viele Formen.

Von den Faktoren, die unter limständen bei Algen partluenugenesiserregend wirken kömen, ist zunächst die 'Jemperatur zu nennen. Klebs fand (1896, p. $209 \mathrm{fr}$.$) , dafs die Kopulation der$ Sichwärmer von Protosiphon ziemlich mabhängig von der 'Temperatu' vor sich geht, falls diese sich zwischen etwa 0 und 23) Grarl be regt. Lïßt man aber auf die Schwärmer in ihrem letzten Bildungsstadium rine konstante 'Temperatur von 25-27 Grad einwirken, so verlieren sie ihre Kopulationsfähigkeit, gehen nun aber nicht zugrunde, sondern werden zu Parthenosporen, aus denen sich neue Pflänzchen entwickeln hïnnen. Trichtig dabei ist. daß diese Wirkung der Temperatur nur dann deutlich zur Geltung kommt. wenn man Zellen zu dem Tersuche verwendet, die gerade mit den letzten Stadien der Gametenbildung beschäftigt sind: „der bloße Aufenthalt der Zellen bei einer Temperatur von $29-40^{\circ}$ übt auf die später bei niederer Temperatur entstehenden Schwärmer keine Nachwirkung aus".

In diesem Zusammenhange ist bemerkenswert. dal, nach $\mathrm{K} l e \mathrm{~b}$ s (1896, p. 114, p. 127 fí.) bei Taucheria höhere 'Temperatur die Oogonienanlagen veranlaßt, zu vegetativen Fäden auszusprossen, ein Vurgang, der natürlich nicht als Parthenogenesis zu deuten, sondern einfach als ein Wiedervegetativwerden aufzufassen ist.

Die Angaben von Nathansohn (1900), dab auch bei manchen Marsilia-Arten Temperaturerhöhung die unbefruchteten Eier zu yarthenogenetischer Entwicklung veranlassen künne, hat sich, wie bereits früher erwähnt wurde, bei der Tachuntersuchung durch Strasburger (1907) nicht bestätigt. Doch konnte auch Strabburger einen gewissen entricklungsfördernden Einfluf der Tempeperaturerhöhung feststellen, wie aus der folgenden Angabe (1907, p. 137) herrorgeht: „Bevor das unbefruchtete Ei der Marsilia Dirmmomdii, trotz seiner Doppelzahl ron Chromosomen, sich entschliebt. in die apogamische Entwicklung einzutreten, ist. allem Anschein nach, ein gewisser Wriderstand zu überwinden. Zum mindesten boten Makrosporen, die zu einer Zeit fixiert worden waren, die den Beginn der Keimentwicklung erwarten lieb, stets zahlreiche noch ruhende Eier dem Beobachter dar. Es hatte eben an jener Anregung zur Keimentwicklung gefehlt, die sonst ron der Befruchtung ausgeht. Diese Anregung kann aber durch Steigerung der Temperatur des um- 
gebenden Wassers innerhalb bestimmter Grenzen geschaffen werden, und die Zahl der sich apogamisch weiter entwickelnden Fier erhöhen."

Hier bleibt es freilich vorerst noch zweifelhaft, ob eine spezifische Wirkung der Temperatur auf die diploide Eizelle der Mursitiu vorliegt, oder ob nicht vielmehr die angewandte höhere Temperatur einfach dem Tenperatur-Optimum entsprach. Es ist ohne weiteres klar, daß sich, wenn der ganze Entwicklungsproceß sich unter optimalen Temperaturbedingungen vollzieht, mehr Eier entwickeln rerden, als wemn das nicht der Fall ist. und das würde auch für die befruchteten Eier sexuell gebliebener Arten gelten.

II ie in allen diesen Fällen die Temperaturerhöhung wirkt, ist noch völlig unaufgeklärt.

Der zweite und wichtigere Faktor, durch den es Klebs gelang; bei manchen Algen experimentell Parthenogenesis zu inducieren, sind Änderungen in der physikalisch-chemischen Konstitution des II ediums. Wir kömen die zahlreichen Tersuche. die Klebs mit verschiedenen Formen und verschiedenen MLedien in dieser Richtung angestellt hat, hier natürlich nicht im einzelnen anführen, sondern nur einige Fälle als Beispiele herausgreifen (man vgl. auch die Angaben in unserem Kapitel 2).

So verlieren die Gameten von Protosiphon die Kopulationsfähigkeit, wenn sie in nährsalzreichen Medien gehalten werden oder in hochprozentigen Rohrzuckerlösungen, kömnen aber unter Umständen durch Übergang aus Nährlösung in Wasser wieder geschlechtlich gemacht werden. Auch die früher geschilderte experimentelle Parthenogenesis von Spirogyza wurde vor allem hervorgerufen durch Nährsalzoder Rohrzuckerlösungen von bestimmter Konzentration. Lnd Ähnliches gilt auch für Chlamydomonas media.

Anch hier wieder ist noch unbekannt, wie die Anderungen im Medium wirken; doch diurfte er sich durch kritische Versuche Wenigstens mit einiger Sicherheit entscheiden lassen, ob in erster Linie chemische, oder ob physikalische Reize maggebend sind. Beides wäre denkbar. Klebs (1896, p. 218) meint (für Protosiphon), ,daß der Eintritt der Salze in den Plasmakörper des Schwärmer's ihm die Kopulationsfähigkeit raubt, der Austritt sie ihm wieder verleiht. Die Salze werden in erster Linie durch ihre chemische Eigenschaft, in zweiter durch ihre wasserentziehende Kraft hemmen". Die Ergebnisse der zoologischen Parthenogenesis-Forschung lassen nun allerdings vermuten, dab auch bei der pflanzlichen experimentellen Parthenogenesis der osmotische Reiz weit wichtiger ist als der chemische. Doch das läßt sich nur durch Versuche entscheiden. Die Frage bleibt freilich auch dann noch unbeantwortet, - ebenso wie das ja. 
anch bei der tierisehen experimentellen Parthenogenes de for Fall in

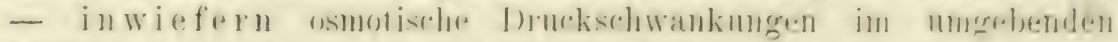
Medium entwicklungserregend wirken können.

Neuntes Kapitel.

\section{Biologische Bedeutung der Parthenogenesis und Apogamie.}

Die biologische Bedeutung der Parthenogenesis und Aporamir. wird man natürlich ror allem darin finden müssen. daf beide $\perp_{\text {lor- }}$ mixis-Arten es den mit ihnen ansgestatteten Pflanzen armöglichen. sich hinsichtlich reichlicher Samenproduktion unabhängig ron dwnjenigen äuberen Faktoren zu machen, auf die bestäubungsbediuftige Pflanzen angewiesen sind. Selbst in Jahren also, in denen zur Blïtezeit Insehtenmangel oder naßkalte Witterung oder ähnliche die Bestäubung erschwerende Tmstände herrschen, wird die apomiktische Samenuroduktion so reichlich als sonst stattfinden müssen oder iwenigstens theoretischi kömnen. Für diöcische Pflanzen kommt als weiterer Torteil in biologischer Hinsicht dazu. daf weibliche Stïcke, falls sit parthenogenetisch oder apogam sind, auch an Lokalitäten fruchten künnen. wo mämnliche Individuen röllig fehlen oder wenigstens sehr selten sind.

Zweifellos liegt hierin ein gewisser Torteil fül die parthenngenetischen und apogamen Gewiichse gegeniiber den befruchtungsbedürftigen, ein Torteil, den sie übrigens mit den propagativ-apomiktischen Pflanzen teilen. die sich durch Ausläufer, Adventivembryobildung usw. vermehren. Freilich haben sie sich die Sicherung der Samenproduktion zu erkaufen durch den Verzicht auf die Torteile. die mit der Amphimixis rerknüpft sind. Das dieser Terzicht aber jedenfalls für einen erheblichen Zeitraum den Fortbestand der Art nicht gefährdet. das zeigt die große rerbreitung in so ungeheurer Indiriduenzahl z. B. des parthenogenetischen Taraxacum officinale. Andererseits ergibt ein Tergleich der Terbreitung und des Individuenreichtums z. B. der parthenogenetischen und der sexuell gebliebenen Hieracien. daß der mit der Befähigung zu apomiktischer Samenbildung gegebene Torteil nicht so groß ist, den ihn geniebenden Pflanzen unbedingt die röllige Terdrängung verwandter befruchtungsbediurftiger Arten zu ermöglichen, wenu man auch geneigt sein wird, die auberordentliche Terbreitung des Taraxacum officinale zum groben Teile mit auf Rechnung der unbedingten Sicherheit zu schreiben. mit der 
es vermöge seiner Parthenogenesis alljährlich seine zahlreichen flugkräftigen Frïchte zur Reife bringt.

Pflanzen wie der Löwenzahn geben uns auch Anhaltspunkte für die Beantwortung der Frage. worin der eventuelle Torteil der Parthenogenesis und Apogamie vor der dritten Art der Apomixis, der Propagation, bestehen kann: darin nämlich, daß die Pflanze nicht auf die Ausnutzung der Verbreitungseinrichtungen zu verzichten braucht, die gerade die Samen resp. die Früchte zu den Hauptrerbreitungsorganen stempeln. Wenn so anch nicht geleugnet werden kann. dal. mit der Einführung der Parthenogenesis oder Apogamie für die betroffenen Pflanzen ein gewisser Torteil verbunden war, so darf man diesen doch auch nicht überschätzen. Eine solche Ü̉berschätzung liegt aber unseres Erachtens vor, wenn man die Einfiihrung der apomiktischen Samenproduktion überhaupt in Zusammenhang mit den damit rerbundenen biologischen Torteilen bringt, wie das Kirchner. Strasburger u. a. tun.

Grundroranssetzung dieser Ansicht, die also in Parthenogenesis und Apogamie nur ein Rettungsmittel erblickt, das die Art zur Terliütung der Aussterbegefahr ergreift, ist natürlich, dab durch irgendwelche Torgänge die Bestäubung erschwert oder ganz ummöglich gemacht ist. Diese Torgänge können ron mancherlei Art sein.

Bei diöcischen Pflanzen könnte z. B. ein Seltenerwerden des männlichen Geschlechtes oder eine dauernde örtliche Tremnung beider Geschlechter das Bestäubungshindernis abgeben. Strasburger (1904. p. 158) macht denn anch diese Annahme, wenn er sagt, die Tremung der Geschlechter habe bei Thatictrum purpuruscens und Antemaria alpina ..die Bestäubung erschwert, und dadurch ähnliche Bedingungen geschaffen, wie sie in anderen Fällen die Terbildung des Pollens mit sich bringt. Bei Antennaria alpina sind die männlichen Indiriduen so selten geworden, daß dieses dem Fehlen ron befruchtungsfähigem Pollen völlig gleichkommt. Bei Thalictrum purpurascens konnte J. B. Overton (1902, p. 363 und 1904, p. 274) öfter's eine ürtliche Trennung der männlichen und weiblichen Individuen feststellen .... Die parthenogenetische Fortpflanzung der Chara crinita mag auch durch Diöcie ausgelöst worden sein". Dabei ist selbstverständlich nicht Diöcie an sich gemeint, sondernn Diöcie in Terbindung mit erschwerter Bestäubung, wie sie eben mit örtlicher Trennung der Geschlechter oder Verschwinden des männlichen Geschlechtes gegeben ist.

Wir haben schon im vorigen Kapitel (p. 133) darauf hingerriesen, daß die Annahme, Befruchtungserschwerung habe parthenogenesisauslösend gewirkt, eine Reihe von Hilfsannahmen im Gefolge hat, die das Problem nicht vereinfachen. An dieser Stelle sei nun betont, daß auch vom biologischen Standpunkte aus durchaus kein Grund vor- 
liegt. anzunehmen. das seltenerwerden des männlichen Geschlechtes als primaner Torgang habe den Fintritt der aponikticchen Samenbildung als rettenden Auswer zur Folge gehabt. Jemu es ist sehr

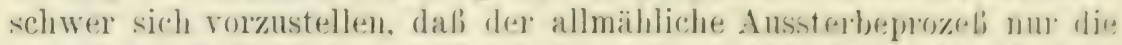
mämnlichen Individuen ergriffen laben soll, zumal ja beide Gieschlechloter in ihren vegetativen Teilen völlig gleich organisiert zu sein pflecren. Tiel näher liegt da doch die Annahme, dab das seltenerwerden und schliebliche völlige Terschwinden männlicher l'fianzen einfach daranf beruht, daß eben die parthenogenetisch erzengten samen immer bei den betreffenden Gewächsen nur weibliche Individuen ergeben. wilhrend die männlichen stïcke rein auf propagative Termehrung angewienen sind. Iange grentg fortgesetzt, mub das natürlich zum ïberwircen und endlich zum gänzlichen Aussterben des männlichen Geschlechtes führen. So ist dies die Folge und nicht die Crsache der Parthenngenesis, und der Grund für deren erstes Auftreten bleibt nach wire vor zu erklären. Für die örtliche feschlechtertrennung bei Thalictrom mupurcescens gilt, wie ja nach dem Torausgehenden nicht näher ausgeführt zu werden braucht, das gleiche.

Die Befruchtungserschwerung könnte aber auch daran liegen, und das würde nicht nur für diöcische, sondern auch für monöcische Pflanzen gelten. daß die Bestäubungsvermittler aus irgendeinem Grunde ausblieben oder verschwanden. Diese Annahme ist an sich nicht sehr wahrscheinlich: aber selbst wemn sie für die eine orler andere parthenogenetische Phanerogame zutreffen sollte. so vertrüge sie doch keine Verallgemeinerung, da manche parthenogenetischen (iewächse. wie Taraxacum officinale und die Hieracien, gerade zu den von Insekten am reichlichsten besuchten gehören.

Endlich aber könnte die Befruchtungserschwerung auf der Terbildung des Pollens beruhen. Es wurde indessen schon friiher gezeigt, daß auch diese Annahme unïberwindlichen Schwierigkeiten begegnet (vgl. p. 136).

Es muß somit die Amnahme an sich, daß ïberhaupt bei den parthenogenetisch gewordenen Pflanzen Bestäubungsschwierigkeiten eintraten. als durchaus unbewiesen und nicht einmal sehr wahrscheinlich bezeichnet werden. Aber selbst wenn wir sie als richtig gelten lassen wollten, so wäre damit doch noch lange nicht die weitere Annahme gerechtfertigt. daß nun diese Befruchtungsschwierigkeiten die Parthenogenesis induciert hätten. Abgesehen ron den Grïndell. die wir bereits dagegen angeführt haben, wäre hier noch all das anzuführen, was Göbel (1904. p. $780 \mathrm{ff}$.) gegen die entsprechende Hypothese ins Feld führt, die Bildung kleistogamer Bliiten hinge mit dem Yangel an Bestäubungsvermittlern zusammen. Es sei auf die Argumentation Göbel's verwiesen. 
Zehntes Kapitel.

\section{Die Beziehungen zwischen Parthenogenesis und Polymorphismus.}

Vor allem Strasburger hat mehrfach (1904, p. 144; 1907, p. 171; vgl. auch Tischler 1908, p. $136 \mathrm{ff}$.) die auffallende und zweifellos nicht bedeutungslose Tatsache betont, daß Parthenogenesis gerade bei sehr polvmorphen Gattungen so verhältnismäßig häufig auftritt. Gehören doch von den wenigen Gattungen, innerhalb deren Parthenogenesis mit Sicherheit nachgewiesen ist, die Mehrzahl zu besonders vielgestaltigen. So Alchimilla, Hieracium, Taraxacum, Marsilia, Athyrium, Nephrodium; auch Chara crinita ist von unseren Charen die formenreichste, und auch Wilistroemia indica ist (nach brieflicher Mitteilung des Herrn Professors Gilg) „sehr variabel“. Man wird Strasburger und Tischler recht geben müssen, wenn sie meinen, daß dieses Zusammentreffen kaum zufällig sein könne. Es entsteht also die Frage, wie es zu verstehen ist.

Strasburger legt sich (l. c.) die Beziehungen zwischen Polymorphismus und Parthenogenesis oder Apogamie so zurecht, daß er annimmt, der Polymorphismus habe eine schlieblich bis zur Sterilität gehende Geschlechtsschwächung verursacht, und diese habe dann „mittelbar die Ausbildung der apogamen Fortpflanzung gefördert". Die Sterilität soll dabei nach seiner Annahme nicht unmittelbar durch die Mutation, sondern erst durch die Mutantenkreuzungen reranlaBt werden, eine Ansicht, die 'T ischler (1908, p. 139) "unnütz scheint, wenn wir sehen, wie z. B. bei manchen Pflanzen, so den pelorischen Linarien sofort mit der Mutation auch die Unfruchtbarkeit sich eingestellt hat". Dabei ist sich übrigens Stra s burger (1907, p. 171) bewußt, daß seine Vorstellung keine Verallgemeinerung zuläßt, wie „die Untersuchung der polymorphen Gattungen Rubus und Rosa lehrte, welche trotz ihrer Tielgestaltigkeit in ihren geschlechtlichen Leistungen keine Störungen erlitten und Apogamie nicht aufwiesen“". Der Satz, daß apomiktische Organismen häufig polymorph sind, verträgt also keine Umkehrung in dem Sinne, daß polymorphe Organismen nun auch apogam oder parthenogenetisch sein mïBten. Ein Gegenbeweis gegen den vermuteten Zusammenhang zwischen Apogamie und Irutation kann aber nach Tischler (1908, p. 139) hierin nicht erblickt werden, da, wie er festgestellt habe, bei der mutationsverdächtigen Potentilla Tabernaemontana eine beginnende Pollensterilität, bei der konstanten Potentilla rubens nur guter Pollen vorhanden sei; bei beiden Arten ist übrigens die Befiuchtung „noch" normal, „weil die restierenden guten Pollenkörnel selbst bei ersterer Art vollauf genügen." 
Weme num anch die leegiehungen zwischen den beiden ApemixisArten und den Polymorphismus nicht gelengret werdent sollen. so mub doch datauf hingewiesen werden, dab die Amalnue moln oder weniger direkter kansaler Beziehungen zwischen den beiden Tirschejnumgen mit erheblichen Schwierigkeiten zn kimpfen hat.

/ounächst sind unseres firachtens die Finwände nicht zul leicht zu nehmen, die sich darans ergeben, dab eben in anderen Fällen sehr ausgesprochener Vielgestaltigkeit sich keine Schwächung der Sexualität und weder Parthenogenesis noch Apogamie als Ersatz eingestellt haben. Zudem aber bleiben die vorher (vgl. 1. 134 fi.) erörterten Schwierigkeiten im vollen Umfange bestehen, die der Ammahnes kausaler Beziehungen zwischen dem Ausfall der Befruchtung und dem Eintritt der Parthenogenesis entgegenstehen. Ehe aber nicht positive Anhaltspunkte für das Bestehen solcher Beziehungen vorliegen, steht natürlich die noch weitergehende Hypothese. wonach Polymorphismus Geschlechtsschwächung und diese Apomixis verursachen sollen, in der Luft.

Unter diesen Umständen liegt es vielleicht näher, die Bezielıungen zwischen Mutation und dem Eintritt ron Parthenogenesis oder Apogamie einfach darin zu finden, daf bei stark mutierenden Gattungen oder Arten eher als bei durchaus konstanten eimmal eine Irutante auftreten konnte, die eben gerade durch die Tendenz zu parthenogenetischer Fortpflanzung charakterisiert ist, oder die so organisiert war, dab bei ihr durch die in ihrem Entstehungsbezirk obwaltenden Außenbedingungen Parthenogenesis induciert wurde. Und da das ausgleichende Moment der Amphimixis bei den apomiktischen Pflanzen ja wegfällt, so können sich eben auch alle durch Mrutation entstandenen apomiktischen Einzeltypen konstant erhalten. So erklïrt sich ja anch M urbeck (1901, p. 36) „die merkwiirdige Konstanz der Alchimillen".

Darin liegt die Annahme, daß parthenogenetisch oder apogam gewordene Pflanzen nicht mehr mutieren oder variieren könnten. T'atsächlich findet anch bei den parthenogenetischen Alchimillen ..eine solche Mutation nicht mehr statt, es zeichnen sich vielmehr die rorhandenen Arten durch große Beständigkeit ihrer auch noch so unbedeutenden Merkmale aus" (Strasburger 1905, p. 155, wo auch Beispiele dafür angeführt sind). Doch fügt Strasburger mit Recht hinzu, daß die Mutation durchaus nicht notwendig mit dem Eintritt des Geschlechtsverlustes ihr Ende nehmen müsse, nur könnte sie sich weiterhin nur auf vegetativem W'ege, durch Vermittlung ron Ausläufern und der apogam erzeugten Samen, äußern.

Hier könnten vergleichende Kulturversuche von Pflanzen, die aus parthenogenetisch entstandenem, und von solchen, die aus sexuell erzeugtem Samen erzogen wurden, und deren Tariabilität und even- 
tuelle Intation vergleichend beobachtet werden, wichtige und interessante Ergebnisse haben. Vielleicht wären Thatictrum purpurascens oder manche Hieracien oder einige der apogamen oder parthenogenetischen Farne ein für solche Versuche geeignetes Material.

Dabei wäre im Sinne unserer Auffassung der Parthenogenesis zu beachten, daß apomiktisch entstandene Samen und Ausläufer in ihrer Bedeutung für die Übertragung der spezifischen und individuellen Merkmale nicht gleichwertig sind, wie Strasburger das will. Wir haben schon friiher (vgl. p. 107) kurz darauf hingewiesen, als wir die Tatsache besprachen, daß aus parthenogenetisch entstandenem Samen diöcischer Pflanzen auch männliche Individuen hervorgehen können. Bei rein propagativer Vermehrung wäre das so gut wie ausgeschlossen.

Da also nach unserer Ansicht auch die diploide Eizelle wie die haploide eine Zelle sui generis ist, die keineswegs einer beliebigen Körperzelle gleichwertig ist, so müssen auch die aus ilır sich bildenden neuen Individuen noch mutations- und variationsfähig sein, auch abgesehen von der Möglichkeit der Mutation auf rein vegetativem Wege. Und daß dem so ist oder wenigstens so sein kann, wird dadurch wahrscheinlich, dab ja, wie wenigstens für einige somatisch parthenogenetische Pflanzen nachgewiesen ist (vgl. p. 77, 81, 86), bei der Entwicklung der diploiden Eizelle in ihrem Kerne gerade einige derjenigen Vorgänge noch beibehalten worden sind, die nach einer weit verbreiteten Auffassung maßgebend sind für die Eigenschaften der künftigen Generation. Diese Vorgänge sind die Prophasen der Reduktionsteilung, vor allem die Synapsis und die Diakinese, und sie finden eben ansschließlich bei den Teilungen der Gonotokontenkerne statt, bei keiner der zahllosen sonst im Verlaufe der Ontogenese vor' sich gehenden Karyokinesen finden sie sich wieder. Man nimmt nun (vgl. z. B. de Vries 1903 b; Strasburger 1905, p. 37 ff.) an, daß während dieser Vorgänge zwischen den bis dahin getrennt voneinander durch alle Körperzellen hindurchgegangenen durch die Befruchtung zusammengebrachten väterlichen und mütterlichen Chromosomen ein Austansch von Erbeinheiten stattfindet, wodurch erreicht wird, daß in den Sporenkernen eine große Mannigfaltigkeit der Kombination hinsichtlich des Ursprungs der Pangene oder wie man die Erbeinheiten sonst nennen will, herrschen kann. "Somit ist die Vereinigung der Geschlechtskerne in den Eiern nicht das letzte Wort der Befruchtung:" (Strasburger 1905, p. 38), sondern erst die Verschmelzung der entsprechenden väterlichen und mütterlichen Chromosomen, und die geht eben während der vorbereitenden Stadien der Reduktionsteilung vor sich. Diese sind daher nach der eben skizzierten Anschaumg diejenigen Stadien, in denen in erster Linie entschieden wird, welche Eigenschaften von den bei beiden Eltern vorhandenen 
den Keimzellen für die fiestaltung des künftigen Goursation mitgegeben werden.

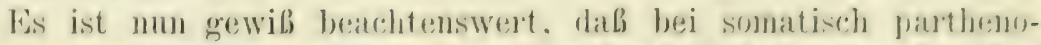
gemetischen Gewiichsen grelade diese stalien beibehallen werlen ibei Treracum offirmale geht der Embryosackmutterkern ja somar morle in die Diakinese ein; rgl. p. 86 ). Das bleibt beachtenswert, anch wemln man die eben entwickelte Ansicht über die Berlentung der fraclichen stadien der Reduktionsteilung nicht in allem teilt. Warun der Lirn der Makrosporenmutterzelle bes Tararacum und Alchimilla - und es ist sehr wahrscheinlich, daß sich das auch für andere somatisch parthenogenetische Pflanzen verallgemeinern läßt - die Prophasen der lieduktionsteilung noch durchmacht, die er doch nicht vollendet. ist nicht recht verstaindlich, gewinnt aber hohe Bedentung, wenn man in Sinne der amgeführten Anschaumg annimmt, daß so auch bei ajomiktischen Organismen noch eine Neukombination von Erbeinheiten ermöglicht wird.

Denn es ist klar, dab, wenn die Amphimixis einmal ungezählte Generationen hierdurch ungestört vor sich gegangen ist, daf. heimplasma von einem bestimmten Momente an eine Mannigfaltigkeit in der Zusammensetzung aus Erbeinheiten verschiedener individueller Herkunft aufweisen muß, die nicht melu zu ïbertreffen ist, da chen dann jede Einheit einen individuell spezifischen Stammbaum besitzt. Ton diesem Momente an aber wird, selbst wenn fürderhin die Amphimixis ausbleibt, doch noch die Möglichkeit vorhanden sein, eine mgehener große Anzahl der verschiedensten Erbeinheits-Kombinationen zu schaffen, wofern nur bei der Entstehung der nenen Generation diejenigen Vorgänge nicht ausgeschaltet werden, durch die die Teukombination erfolgt. Und gerade das triftt ja bei denjenigen somatisch parthenogenetischen Pflanzen zu, bei denen der Makrosporemmutterkeru noch einen Anlauf zur heterotypischen Teilung nimmt. Vielleicht wird es so verständlich, warum er das überhaupt noch tut.

Selbstverständlich ist dies ein rein hypothetischer Erklärungsversuch, der mit der Richtigkeit der angeführten Ansicht über die Bedeutung von Synapsis und Diakinese für die Neukombinierung der Erbeinheiten steht und fällt.

Wie man sich aber auch zu ihm stellen möge, die Tatsache bleibt bestehen, daß sich in den Kernen der diploiden Eizellen oder in denen ihrer Mutterzellen Vorgänge abspielen, die in allen anderen Kernen nicht vor sich gehen, und die sehr wahrscheinlich für die Vererbung von Bedeutung sind. Auch daraus erhellt wieder, daß die diploide Eizelle nicht ohne weiteres gewöhnlichen Körperzellen vergleichbar ist, auch nicht hinsichtlich der Nutations- und Tariationsfähigkeit der aus ihnen hervorgehenden Abkömmlinge.

T ü bingen, Botanisches Institut, 6. März 1908. 


\section{Nachtrag.}

Zu p. 17: E. Strasburger [Einiges über Characeen und Amitose. Wiesner-Festschrift, Wien 1908, p. 24-47] fand bei Chara crinita dieselbe Chromosomenzahl 18 wie bei der sexuell gebliebenen $C h$. fragilis; er hält die oogonientragende Generation für die haploide, sieht also die Parthenogenesis der $C h$. crinita als generative in unserem Sinne an. Auch er nimmt an, daß normal die Reduktionsteilung beim ersten Teilungsschritt der Characeenzygote sich vollzieht. Wenn er freilich (l. c., p. 39) meint, daß daher die Parthenogenesis bei Chara crinita ,auf nicht allzu große Schwierigkeiten stoßen wird", denn „es braucht nur die Reduktionsteilung bei der Keimung der Azygote ausgeschaltet zu werden, für die auszubildende haploide Generation wäre ja die erforderliche Zahl von Chromosomen da“. - so ist demgegenüiber an unsere Erörterungen auf p. 117 zu erinnern und überdies zu fragen, warum denn, wenn der Eintritt der Parthenogenesis bei Chara wirklich so verhältnismäßig leicht war, er doch nur bei der einen Art crinita erfolgt ist.

Zu p. 30: An Humaria gramulata scheint sich [nach E. T. Welsford, Fertilisation in Ascobolus furfuraceus Pers. (New Phytologist, Bd. 6, 1907, 1. 156-161; ref. im Botan. Centralbl., Bd. 107, 1908, p. 322)] Ascobolus furfuraceus insofern unmittelbar anzuschließen, als bei ihm ebenfalls keine Antheridien mehr entstehen und im Ascogon parthenomiktische Kernverschmelzungen stattfinden.

Zu p. 35: Die Parthenokarpie von Cycas revoluta L. wurde von A. Usteri [Parthenocarpia do Cycas revoluta L. (Rev. da Soc. scien. de Sao Paulo, 1906, p. 177-179; ref. in Just's Jahresber., Bd. 34, 2. Abt., p. 75)] cytologisch untersucht mit dem Ergebnis, daß das unbefruchtete Ei sich dabei einige Male teilen kann, ohne daß es aber zur Entwicklung eines Embryos käme. Es lägen also Anfänge zu einer - wohl zweifellos generativen - Parthenogenesis vor.

Zu p. $111 \mathrm{ff}$ : In einer sehr wichtigen Arbeit berichten J. u. W. Docters vall Leeuwen-Reijnvaan [Über eine zweifache Reduktion bei der Bildung der Geschlechtszellen und darauf folgende Befruchtung mittels zwei Spermatozoiden und über die Individualität der Chromosomen bei einigen Polytrichumarten. (Rec. d. Trav. botan. Néerlandais, Bd. 4, 1907, p. 1-44)], daß bei Polytrichum der Sporophyt 12, der Gametophyt 6 und die reifen Keimzelleu 3 Chromosomen haben. Sowohl bei der Keimzell-, wie bei der Sporenbildung tritt also je eine Reduktion der Chromosomenzahl auf die Hälfte ein. Vor 


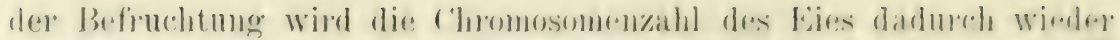
anf 6 erhöht, dals sein kern mit dem der Banchkanalgelle verselmilgt.

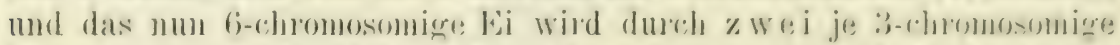
spermatozoen befouchtet, wodureh die ('hromosomemzahl 12 des Spontegons wieder hergestellt wird.

Da wir hier oweifellos drei als die haploide Thromosmmen\%ahl betrachicen, den Gametophyten also als diploide und den sporophyten als tetraploide Generation ansehen müssen, so beweist dies: merkwürdige Entdeckung, falls sie sich bestätigt, direkt die Befruchtungsfähigkeit der diploiden Eizelle. Cherdies ist sie ein Hinweis daranf. daß in der Tat mehrfache Verdoppelungen der chomosomen bestehen, wie wir sie ähnlich p. 119 supponiert haben.

\section{Literaturverzeichnis.}

Arbeiten, die ich nicht im Original einsehen konnte, sind mit einem Stern gekennzeichnet.

1) Allen, Ch. E. (1905), Die Keimung der Zygote bei Coleochaete. Ber. d. deutschen botan. Gesellsch., Bd. 23, 1905, p. 285-292.

2) Andersson, G., och Hesselman, $H$. (1900), Bidrag til kïmnedomom sjut:bergens och Beeren Eilands kärlväxtflora. Bih. till Srensk Vet.-Akad. Handl., Bd. 26 Afd. 3 Nr. I. 1900.

3) Arcangeli, G. (1876), Sulla Pilularia e la Salvinia. Nuoro giorn. botan. ital.. Bd. 8. 1876.

4) Bainier, G. (1883), Sur les zygospores des Mucorinées. Ann. d. sciences natur., 6. sér., Botan., T. 15, 1883, p. 342-356.

5) Bary, A. de (1878), C̈her apogame Fame und die Erscheimung der Apogamie im Allgemeinen. Botan. Zeitung, Bd. 36, 1878, p. 449 .

6) - (1884), Vergleichende Morphologie und Biologie der Pilze, Iycetozoen und Bakterien. Leipzig 1884.

7) Baur, E. (1901), Die Anlage und Entwickelung einiger Flechtenapothecien. Flora, Bd. 88, 1901, p. 319-332.

8) - (1904), Untersuchungen über die Entwickelungsgeschichte der Flechtenapothecien. I. Botan. Zeitung, Bd. 62, 1904, 1. Abt., p. 21-44.

*9) Beck von Managetta, G. (1901), Neue Beobachtungen iuber Parthenogenesis im Pflanzenreiche. Lotos, N. F., Bd. 21, 1901, p. 151-153.

10) Berthold, G. (1881), Die geschlechtliche Fortpflanzung der eigentlichen Phaeosporeen. Mitteil, d. zool. Station zu Neapel, Bd. 2, 1881, p. 401-412.

11) Bitter, G. (1904), Parthenogenesis und Variabilität der Bryonia dioica. Abliandl. d. Naturwiss. Vereins Bremen, Bd. 18, 1904, p. 99-107.

12) Blackman, V. H. (1904), On the fertilizatiou, alternation of generations and general cytology of the Uredineae. Ann. of Botany, Bd. 18, 1904, p. 323 -374 . 
13) Blackman, V. H., and Fraser, H. I. C. (1905), On the Sexuality and Development of the Ascocarp of Humaria granulata Quél. Proc. of the Royal Soc. London, Ser. B. Bd. 77, 1905/6, p. 35̃ł-368.

14) Bonavia, E. (1890), Fertilization without pollen. Gard. Chronicle, 3. ser., Bd. 8, 1890, p. 295.

15) Boveri, Th. (1889/, Ein geschlechtlich erzengter Organismus ohne miitterliche Eigenschaften. Sitzungsber. d. Gesellsch. f. Morphol. u. Physiol. zu München, Bd. 5, 1889, p. 73.

16) Braun, A. (1857), Über Parthenogenesis bei Pflanzen. Abhandl. d. kgl. Akad. d. Wissensch. zu Berlin, Phys. Kl., 1856, p. 311-376.

17) - (1860), Über Polyembryonie und Keimung von Caelebogyne. Ebenda, 1859, p. $109-263$.

18) Brizi, U. (1892). Appunti di teratologia briologica. Amnuario del Ist. botan. di Roma. Bd. 5, 1892, p. 53-57.

19) Buysman, M. (1892), Morus nigra. Gartenflora, Bd. 41, 1892, p. 529.

20) Campbell, D. H. (1905), Studies on Araceae. III. Ann. of Botany, Bd. 14, 1905 , p. $329-345$.

21) Candolle, A. de (1905), La parthénogenèse chez les plantes d'après les travaux récents. Arch. d. Sciences phys. et natur., 4. pér., T. 19, 1905, p. $259-272$.

22) Carrière, E. A. (1881), Fructification du Pandanus furcatus. Rev. horticole, T. 53,1881, p. $174-176$.

23) Cavara, F. (1898), Ricerche sullo sviluppo del frutto della Thea chinensis Sims. Boll. della Soc. botan. ital. 1898, p. 238-241.

24) Chamberlain, Ch. J. (1897), Contribution to the life history of Salix. Botal. Gazette, Bd. 23, 1897, p. 147-179.

25) - (1905), Alternation of generations in animals from a botanical standpoint. Ebenda, Bd. 39, 1905, p. 137-144.

26) Chauveaud, G. (1892), Sur la fécondation dans les cas de polyembryonie. Reproduction chez le Dompte-venin. Paris 1892.

27) Chodat, R., et Bernard, C. (1900), Sur le sac embryonnaire de l'Helosis guyanensis. Journ. de Botanique, T. 14, 1900, p. 72.

28) Cienkowski, L. (1876), Über die Morphologie der Ulotricheen. Bull, de l'Acar. des sciences de St. Pétersbourg, Bd. 21, 1876. p. 529.

29) Claußen, P. (1906), Über neuere Arbeiten zur Entwicklungsgeschichte der Ascomyceten. Ber. d. deutsch. botan. Gesellsch., Bd. 24, 1906, p. (11)-(38).

30) - (1907), Zur Kenntnis der Kernverhältnisse von Pyronema confluens, V. II. Ebenda, Bd. 25, 1907, p. 586-590.

*31) Cook, A. J. (1895), Parthenogenesis among plants. Tiural Californian, Bd. 18, 1895, p. $237-238$.

3:) Correns, C. (1899), Untersuchungen iiber die Vermehrung der Laubmoose durch Brutorgane und Stecklinge. Jena 1899.

33) - (1905), Gregor Mendel's Briefe an Carl Naegeli. Abhandl. d. math.-phys. Klasse d. kgl. sächs. Gesellsch. d. Wissensch., Bd. 29, 1905, p. 189-265.

34) - (1907), Die Bestimmung und Vererbung des Geschlechtes nach nenen Versuchen mit höheren Pflanzen. Berlin 1907.

35) Coulter, J. M. (1902), Parthenogenesis in seed plants. Science, N. S., Bd. 15, 1902 , p. $462-463$.

36) - and Chamberlain, C. J. (1904), Morphology of Angiosperms. London 1904.

37) Cunningham, D. D. (1888), On the phenomena of fertilization in Ficus Roxburghii Wall. Ann. of the Roy. Botan. Garden Calcutta, Bd. 1. 1888. Appendix, p. 15-47. 


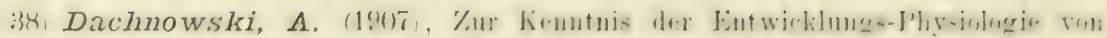
Marchantia polymorpha. Jahrb. f. wissensch. Botanik, Bil. 44, 1907, p. 254 -286 .

39) Dangeard, P. A. (1906), La fécondation nucléaire che\% les Mucorinées. Comptes rendus de l'Ac, d. sciences Paris, 'T'. 142, 1906, p. 645-6546.

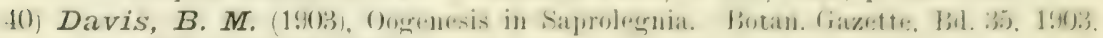
p. $233-249,320-349$.

41) - (1905), Studies in the plant cell. VII. Americ. Naturalist, Bd. 39, 1905, р. $555-599$.

42) Day, D. F. (1896), Parthenogenesis in Thalictun Fendieri. Botan. Gutette. Bd. 22, 1896, 1. 241.

43) Debski, Br. (1897), lieobachtmenen iber Kernteilungen bei ('hara fratgiliJahrb. f. wissensch. Botanik, Bd. 30, 1897, p. 227-248.

4.4) - (1898), Weitere Beobachtungen an ('hara fragilis Desr. Eletuda, Br. 32. 1898, p. 635-670.

45) Delage, Y. (1899), Etules sur la mérogonie. Arch. de zoulngie expérim. et gén., 3. sér., T. 7, 1899, p. 383.

46) Digby, L. (1905), On the Cytology of Apogany and Apospory. II. Preliminary Note on Apospory. Proceed. of the Roy. Soc. London, Ser. B, Bd. 76, 1905 , p. 463-467.

47) Dingler, H. (1906), Fakultative parthenogenetische Fortuflanzung bei Rosa rubiginosa? Mitt. d. naturw. Vereins zu Aschaffenburg, Bd. 5, 1906, p. 39.

48) - (1907), Versnch einer Erklärung gewisser Erscheinungen in der Aushildung nnd Verbreitung der wilden Rosen. Ebenda, Bd. 6, 1907, p. 1-38.

49) Dodel, A. (1876), Ulothrix zonata, ihre geschlechtliche und ungeschlechtiche Fortpflanzung. Jahrb. f. wissensch. Botanik, Bd. 10, 1876, p. 417-550.

j0) Druery, Ch. T. (1901), A résumé of fern phenomena discorered in the nineteenth century. Gard. Chronicle, 3. ser., Bd. 29, 1901, p. 199-200.

51) Eichler, A. W. (1878), Blüthendiagramme. Bd. 2. Leipzig 1878.

52) Eisen, G. (1896), Biological studies on Figs, Caprifigs and raprification. Proceed. of the Californ. Acad. of Sciences, Sec. ser., Bd. 5, 1896, p. 897-1003.

53) Engler, A., (1904), Syllabus der Pflanzenfamilien. 4. Aufl. Berlin 1904.

54) Ernst, A. (1886), A new case of parthenogenesis in the regetable kinglom. Nature, Bd. 34, 1886, p. 549-552.

55) Ewert, R. (1906), Blïtenbiologie und Tragbarlieit unserer Obstbïume. Landw. Jahrb., Bd. 35, 1906, p. 259-287.

56) - (1907), Die Parthenokarpie oder Jungfernfriichtigkeit der Obstbäume und ihre Bedentung für den Obstbau. Berlin 1907.

57) Fairchild, D. G. (1897), Über Kerntheilung und Befruchtung bei Basidiobolus ranarum Eidam. Jahrb. f. wissensch. Botanik, Bd. 30, 1897, p. 28 ó-296.

58) Farmer, J. B., and Digby, L. (1907), Studies in Apospory and Apogamy in Ferns. Ann. of Botany, Bd. 21, 1907, p. 161-199.

59) Farmer, J. B., Moore, T. E. S., and Digby, L. (1903), On the Cytology of Apogamy and Apospory. I. Preliminary Note on Apogamy. Proceed. of the Roy. Soc. London, Bd. 71, 1903, p. 453-457.

60) Farlow, W. G. (1874), An Asexual Growth from the Prothallus of Pteris cretica. Quart. Journal of microsc. Science, Bd. 14, 1874, p. 266-271.

61) Fick, R. (1907), Vererbungsfragen, Reduktions- und Chromosomenhypothesen. Bastard-Regeln. Erg. d. Anat. u. Entwickelungsgesch., Bd. 16, 1907, p. $1-140$.

62) Fischer, A. (1880), Zur Embryosackentwickelung einiger Angiospermell. Jen. Zeitschr. f. Naturwiss., Bd. 14, 1880, p. 90-132. 
63) Fischer, A. (1892), Phycomycetes. Leipzig 1892.

*61) Fischer, L. (1879), Die Erscheinung der pflanzlichen Parthenogenesis. Mitt. d. naturf. Gesellsch. Bern a. d. Jahr 1879, Bern 1880, Sitzb., p. 4.

65) Focke, W. O. (1881), Die Pflanzen-Mischlinge. Berlin 1881.

66) - (1890), Versuche und Beobachtungen über Kreuzung und Frnchtansatz bei Blüthenpflanzen. Abh. d. naturf. Ver. Bremen, Bd. 11, 1890, p.412-422.

67) Francé, R. (1894), Die Polytomeen, eine morphologisch-entwickelungsgeschichtliche Studie. Jahrb. f. wissensch. Botanik, Bd. 26, 1894, p. 295-378.

68) Fraser, H. C. J. (1907), On the Sexuality and Development of the Ascocary in Lachnea Stercorea Pers. Ann. of Botany, Bd. 21, 1907, p. 349-360.

69) - (1908), Contributions to the Cytology of Humaria rutilans Fries. Ebenda, Bd. 22,1908, p. $35-55$.

70) Fünfstück, M. (1884), Beiträge zur Entwickelungsgeschichte der Lichenen. Jahrb. d. kgl. botan. Gartens u. botan. Mnseums zu Berlin, Bd. 3, 1884, p. $15-174$.

71) Furlani, J. (1905), Zur Embryologie von Colchicum antumnale. Österr. botan. Zeitschr., Bd. 54, 1905, p. 318.

72) Ganong, W. F. (1898), On polyembryony and its morphology in Opuntia vulgaris. Botan. Gazette, Bd. 25, 1898, p. 221.

73) Gard, M. (1903), Etudes anatomiques sur les Vignes et leurs Hybrides artificiels. Act. Soc. Linn. Bordeaux, Sér. 6, T. 8, 1903, p. 185-319.

7t) Gasparrini, G. (1816), Notes sur l'origine de l'embryon dans les graines des plantes phanérogames. Ann. d. sciences natur., 3. sér., Botan., T. 5, 1846, p. 305-312.

75) Gates, R. R. (1907), Hybridization and germ cells of Oenothera mutants. Botan. Gazette, Bd. 44, 1907, p. 1-21.

76) Gärtner, J. (1788), De fructibus et seminibus plantarum. Bd. 1. Stuttgard 1788.

77) Gärtner, C. F. (1844), Versuche und Beobachtungen über die Befruchtungsorgane der vollkommneren Gewächse. Stuttgart 1844.

78) - (1849), Versuche und Beobachtungen ïber die Bastarderzeugung im Pflanzenreich. Stuttgart 1849.

79) Giard, A. (1899), Parthénogèse de la macrogamète et de la microgamète des organismes pluricellulaires. Cinquantenaire de la Soc. de Biol. Vol. jubil. 1899, p. 654 .

80) - (1901), Pour l'histoire de la mérogonie. Comptes rendus de la Soc. de Biol., T. 53,1901, p. $875-877$.

81) - (1903), Les faux hybrides de Millardet et leur interprétation. Ebenda, T. 55, 1903, p. $779-782$.

82) Godlewski, E., jun. (1906), Untersuchungen ïber die Bastardierung der Echiniden- und Crinoiden-Familie. Arch. f. Entwickelungsmech. d. Organismen. Bd. 20, 1906, p. 574-643.

83) Göbe1, K. (1879), Über Sproßbildung auf Isoetesblättern. Botan. Zeitung, Bd. 37, 1879, p. 1-6.

84) - (1904), Die kleistogamen Bliiten und die Anpassungstheorien. Biol. Centralblatt, Bd. 24, 1904, p. 673.

85) - (1907), Experimentell-morphologische Mitteilungen. Sitz.-Ber. d. bay. Akad. d. Wiss. zu München, math.-phys. Kl., Bd. 37, 1907, p. 119-138.

86) Götz, G. (1899), Über die Entwicklıng der Eikuospe bei den Characeen. Botan. Zeitung, Bd. 57, 1899, 1. Abt., p. 1-13.

*87) Greene, E. L. (1898), Parthenogenesis in common plants. The plant world. Bd. 1, 1898, p. 102-103. 
88) Guérin, $P .(1904)$, Les comaissances actuelles sur la fécondation chez les phanérogames. Paris 190.t.

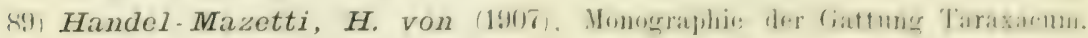
Leiprig u. Wien 1307.

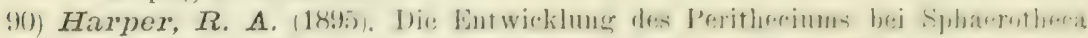
Castagnei. Ber, d. dentschen botan. Gesellsch., 13d. 13, 1895, p. 475.

$91)$ - $(1900)$, Sexual reproduetion in Pyronema coniluens and the morphology of the ascocarp. Anm. of Botany, Bd. 14, 1900, p. 321-400.

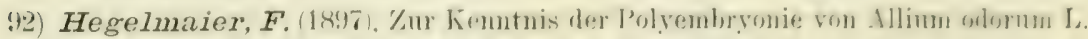
Botan. Zeitung, Bll. 55, 1897, 1. Abt., p. 133-140.

93) - (1901), Cher einen menen fall von habitueller Polyembryonie. Ber. d. deat rh. botan. Gesellsch., 13d. 19, 1901, p. 488-499.

94) - (1903), Zur Kenntnis der Polyembryonie von Euphorbia dulcis Jaçu. Ebenda, Bd. 21, 1903, p. 6-19.

$95)$ - (1906), Alchimillen ldes schwäbischen Jura. Jahresh. d. Vereins f. vaterl. Naturk. in Württemberg, Bd. 62, 1906, p. 1-12.

96) Hertwig, O. и. R. (1887). Experimentelle Studien an thierischen Ei. Jen. Zeitschr. f. Naturwiss., Bd. 20, 1887, p. 120 u. 477.

97) Hewat, C. G. (1906), (ytological aspects of parthenogenesis in insects. Men. of Manchester Lit. a. Phil. Soc., Bd.50. 1906.

98) Hezer, $F$. (1883). Untersuchungen iber das Verhältnis der Geschlechter bei einhäusigen und zweihäusigen Pflanzen. Diss. Halle 1883.

99) Hurst, C. C. (1899), Experiments on Hybridisation and Cross-Breeding. Crard. Chronicle, 3. ser., Bd. 26, 1899, p. 55.

100) - (1903), Recent Experiments in the Hybridisation of Orchids. Ehenda. Brl. 34. 1903, p. 226.

101) Jaensch, O. (1905), Beitrag zur Embryologie von Arlisia crispa A. DC: Iris.s. Breslan 1905.

102) Jeffrey, E. C. (1896), The gametophyte of Botrychium rirginianum. Transact. of the Canad. Inst. 1896-1897. S.-A. $32 \mathrm{pp.}$

103) Juel, O. (1898), Parthenogenesis bei Antennaria alpina (L.) R. Br. T. M. Botan. Centralbl., Bd. 74, 1898, p. 369-372.

104) - (1900), Vergleichende Untersuchungen iiher typische und parthenogenetische Fortpflanzung bei der Gattung Antennaria. Kgl. svenska Vetensk.-Akad. Handl., Bd. 33, No. 5, 1900, p. 1-39.

105) - (1902), Über Zellinhalt, Befruchtung und sporenbildung bei Diporlascus. Flora, Bd. 91, 1902, p. 47-55.

106) - (1903), Zur Entwickelungsgeschichte des Samens ron Cynomorium. Botan. Centralbl., Beihefte, Bd. 13, 1903, p. 191-202.

107) - (1904), Die Tetradenteilung in der Samenanlage von Taraxacum. V. I. Arkiv f. Botanik, Bd. 2, No. 4. 1904.

108) - (1905), Die Tetradenteilungen bei Taraxacum und anderen Cichoriaceen. Kgl. svenska Vet,-Akad. Handlingar, Bd. 39, 1905, No. 4.

109) Karsten, G. (1900), Die Auxosporenbildung bei den Gattungen Cocconëis, Surirella und Cymatopleura. Flora, Bd. 87, 1900, p. 253-283.

110) Kerner, A. (1876), Parthenogenesis bei einer angiospermen Pflanze. Sitz.Ber. d. math.-nat. Classe d. Akad. d. Wissensch. zu Wien, Abt. I, Bd. 74, 1876, p. 469.

111) - (1896), Pflanzenleben. 2. Aufl. 2 Bde. Leizig 1896.

112) King, G. (1887), On the fertilization of Ficus hispida: a problem in regetable physiology. Scientif. Nemoirs by medic. officers of the army of India. 1887. 
113) Kirchner, O. (1904a), Taxus baccata. In Kirchner, Loew und Schröter, Lebensgeschichte der Blütenpflanzen Mitteleuropas, Bd.1, Lief. 1. Stuttgart 1904.

114) - (1904b), Parthenogenesis bei Blïtenpflanzen. Ber. d. dentschen botan. Gesellsch., Bd. 22, 1904, p. (83)-(97).

115) - (1905), Parthenogenesis bei Blïtenpflanzen. Jithresh. d. Vereins f. raterl. Naturk. in Wiirttemberg, Bd. 61, 1905, p. LIII-LIV.

116) Klebs, G. (1896), Die Bedingungen der Fortpflanzung bei einigen Algen und Pilzen. Jena 1896.

117) - (1899), Zur Physiologie der Fortpflanzung einiger Pilze. II. Saprolegnia mixta de Bary. Jahrb. f. wissensch. Botanik, Bd. 33, 1899, p. 513-593.

118) (Klotzsch) (185̃), Die sogenannte Parthenogenesis von Caelebogyne ilicifolia. Bonplandia, 1857, p. 209.

119) Kostanecki, K. (1904), Cytologische Studien an künstlich parthenogenetisch sich entwickelnden Eiern von Mactra. Arch. f. mikrosk. Anat. 11. Entwicklungsgesch., Bd. 64. 1904.

*120) Kuckuck, M. (1907), Es gibt keine Parthenogenesis. Allgemein verstïndliche wissenschaftliche Beweisführung. Herausgegeben von F. Dickel. Leipzig 1907.

121) Lang, W. H. (1901), On Apospory in Anthoceros laevis. Ann. of Botany, Bd. 15, 1901, p. 503-510.

*122) Leavitt, R. G., and Spalding, L. J. (1905), Parthenogenesis in Antennaria. Rhodora, Bd. 7. 1905.

123) Lidforss, B. (1905), Studier öfver artbildningen inom slïktet Rubus. Ark. f. Botanik, Bd. 4, 1905, No. 6.

124) - (1907), Studier öfver artbildningen inom släktet Rubus. II. Ebenda, Bd. 6, 1907, No. 16.

125) Limpricht, G. (1890), Die Laubmoose Deutschlands, Österreichs und der Schweiz. Bd. 1. 1890.

126) Loeb, J. (1906), Vorlesungen ïber die Dynamik der Lebenserscheinungen. Leipzig 1906.

127) Löw, E. (1894), Blïtenbiologische Floristik. Stuttgart 1894.

128) Lombard-Dumas (1904), Variations sexuelles de l'Ancuba japonica. Bull. de la Soc. Botan. de France, Bd. 51, 1904, p. 210-213.

129) Longo, B. (1905), Acrogamia aporogama nel Fico domestico (Ficus carica L.). Nota prel. Ann. di Botanica, Bd. 3, 1905, p. 14-17.

130) Lotsy, J. P. (1899), Balanophora globosa Jungh., eine wenigstens örtlich verwittwete Pflanze. Ann. du Jardin botan. de Buitenzorg, 'T. 16, 1899, p. $174-186$.

131) - (1901), Rhopalocnemis phalloides Jungh., a morphological-systematical study. Ebenda, Bd. 17, 1901, p. 73-101.

.132) - (1903), Parthenogenesis bei Gnetum Ula Brogn. Flora, Bd. 92, 1903, p. $397-404$.

133) - (1905), Die x-Generation und die 2x-Geueration. Biol. Centralbl., Bd. 25, 1905, p. $97-117$.

134) - (1907). Vortrïge ïber botanische Stammesgeschichte. Bd. 1. Algen und Pilze. Jena 1907.

135) Massart, J. (1902), Sur la pollination sans fécondation. Bull. du jard. botan. de l'état à Bruxelles. Bd. 1, 1902, Fasc. 3.

136) McCallum, W. B. (1905), Regeneration in plants. Botan. Gazette, Bd. 40, 1905, p. 97-120, 241-263.

137) Marchal, El. et Em. (1907), Aposporie et sexualité chez les mousses. Bull. de la classe d. sciences de l'Acad. roy. de Belg. 1907, p. 765-789. 
138) Mechan, Th. (189!), (intributions to the lifw-hi-tory of pauts. No. XIII 7. Parthenogenesis. Proceed. of the Acad, of natur. Sciences of Philadelphia. 1899, p. 97-99.

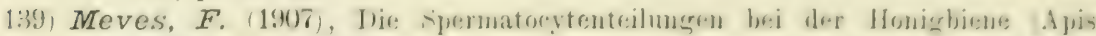
mellifiea L.), nebst Bemerkungen über (hromatinreduktion. Arch. f. mikrosk. Anat. u. Entwicklungsgesch., Bd. 70, 1907, p. 414-491.

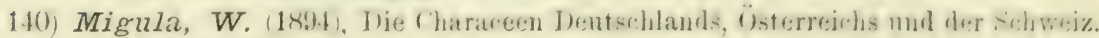
Leipzig 1897.

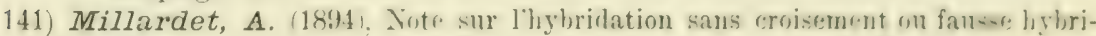
dation. Mém. de la Soc. d. Sciences phys. et natur. de Bordeaux, 4. sér. T. 4,1894, p. $347-372$.

142) - (1901), Note sur la fauste hybridation che\% les Aupridies. Revue de Viticulture, T. 16,1901, p. 677-680.

143) Möller, A. (1887), Über die Cultur flechtenbildender Asermyceten shue Algen. Unters. a. d. botan. Inst. d. k. Akad. zu Münster i. W. 1887, p. 52.

144) - (1888, Über die sogrenannten Spermatien der Ascomyceten. Botan. Zeitung, Bd. $46,1888, p .421-425$.

145) Mori, A. (1880), Cixca la partenogrenesi della Datisca cannabina. Nuowo giorn. botan. ital., Bd. 12, 1880, p. 371.

146) Müller-Thurgau, H. (1903), Die Folgen der Bestäubung bei Obst- und Rebbliithen. VIII. Bericht d. Züricher botan. Gesellsch. 1901-1903, p. $45-63$.

147) Murbeck, Sv. (1897), Om regetativ embryobildning hos flertalet Alchemillar och den fürkläring üfrer formbeständigheten inom slägtet, som densamma innebär. Botan. Notiser. 1897.

148) - (1901). Parthenogenetische Embryobildung in der Gattung Alchemilla. Lunds Univ, Arsskrift, Bd. 36. Afd. 2. No. 7. 1901.

149) - (1902), Über Anomalien im Baue des Nucellus und des Embrynsackes bei parthenogenetischen Arten der Gattung Alchemilla. Ebenda, Bd. 38. Afd. 2. No. 2. 1902.

150) - (1904), Parthenogenese bei den Gattumgen Taraxacum und Hieracium. Botan. Notiser. 1904.

151) Nathansohn, A. (1900), Über Parthenogenesis bei Marsilia und ihre Abhängigkeit von der Temperatur. Ber. d. deutschen botan. Gesellsch., Bd. 18, 1900 , p. $99-109$.

*152) Nathorst, A. G. (1900), Parthenogenesis hos fanerogama räxter. Stockholm 1900. $13 \mathrm{pp}$.

15̌3) Nelson, E. (1902), Totes on certain species of Antennaria. Botan. Gazette, Bd. 43, 1902, p. 114-124.

154) Němec, B. (1902. 1903), Ü̉her ungeschlechtliche Kernverschmelzungen. I. II. III. Sitzungsber. d. kgl. böhm. Gesellsch. d. Wissensch,, 1902, No. LIX. 1903, No. XXVII und No. XLII.

155) Noll, F. (1902), ய̈ber Fruchtbildung ohne rorausgegangene Bestäubung (Parthenocarpie) bei der Gurke. Sitzungsber. d. Niederrhein. Gesellsch. f. Natur- u. Heilk. zn Bonn. 1902. S.-A.

156) Odell (1901), Parthenogenesis in Datisca camnabina. Gard. Chronicle, 3. ser., Bd. 36, 1904, p. 134 .

157) Olive, E. W. (1906), Cytological studies on the Entomophthoreae. I. The morphology and development of Empusa. Botan. Gazette, Bd. 41, 1906, p. $192-208$.

158) Oltmanns, F. (1899), Über die Sexualität der Ectocarpeen. Flora, Bd. 86, 1899, p. 86-99. 
159) Oltmanns, F. (1904), Morphologie und Biologie der Algen. 1. Bd. Spezieller Teil. Jena 1904.

160) - (1905), Morphologie und Biologie der Algen. 2. Bd. Allgemeiner Teil. Jena 1905.

161) Ostenfeld, C. H. (1904a), Zur Kenntnis der Apogamie in der Gattung Hieracium. Ber. d. deutschen botan. Gesellsch., Bd. 22, 190t, p. 376-381.

162) - $(1904 \mathrm{~b})$. Weitere Beiträge zur Kenntnis der Fruchtentwicklung bei der Gattung Hieracium. Ebenda, p. 537-541.

*163) - (1906), Castration and Hybridisation Experiments with some species of Hieracia. Botan. Tiddskr., Bd. 27, 1906, p. 225-248.

164) Overton, J. B. (1902), Parthenogenesis in Thalictrum purpurascens. Botan Gazette, Bd. 33, 1902, p. 363-375.

165) - (1904), ¿̈ber Parthenogenesis bei Thalictrum purpurascens. Ber. d. deutschen botan. Gesellsch., Bd. 22, 1904, p. 274-283.

166) - (1906), The morphology of the ascocarp and spore-formation in the manyspored asci of Thecotheus Pelletieri. Botan. Gazette, Bd. 42, 1906, p. 450 $-492$.

167) Péchoutre, F. (1902), C'ontribution à l'étude du développement de l'ovule et de la graine des Rosacées. Ann. d. sciences natur., 10. sér., Botan., T. 16, 1902 , p. $1-158$.

168) Petrunkewitsch, A. (1901), Die Richtungsliörper und ihr Schicksal im befruchteten und unbefruchteten Bienenei. Zool. Jahrb., Abt. f. Anat. 'u. Ontog., Bd. 14. 1901.

169) Pfeffer, W. (1897), Pflanzenphysiologie. Bd.1. Leipzig 1897.

170) Phillips, E. F. (1903), A review of parthenogenesis. Proceed. of the americ. philos. Soe. Philadelphia, Bd. 42, 1903, p. 275-345.

171) Pirotta, R. e Longo, B. (1901), Osservazioni e ricerche sul Cynomorium coccineum. Rendic. Acad. dei Lincei. Nuova serie., Bd. 9, 1900, p. 150-152.

*172) Poulsen, A. (1906), sciaphila nana Bl. Ein Beitrag zur Fruchtknotenbildung bei den Triuridaceen. Wissensch. Mitteil. d. naturgesch. Vereins in Kopenhagen. 1906.

173) Pringsheim, N. (1874), Weitere Nachträge zur Morphologie und Systematik der Saprolegnieen. Jahrb. f. wissensch. Botanik, Bd. 9, 1873-1874, p. $191-234$.

174) - (1878), Über Sprossung der Moosfrïchte und den Generationswechsel der Thallophyten. Ebenda, Bd. 11, 1878, p. 1-46.

175) Raciborski, M. (1896), Über den EinfluB äußerer Bedingungen auf die Wachsthumsweise des Basidiobolus ranarum. Flora, Bd. 82, 1896, p. 107-132.

176) Ramlow, G. (1906), Zur Entwicklungsgeschichte von Thelebolus stercorens Tode. Botan. Zeitung, Bd. 64, 1906, 1. Abt., p. 85-99.

177) Raunkiaer, C. (1903), Kimdannelse uden Befrugtuing hos Maelkebotte. Botan. Tidsskr., Bd. 25, 1903, p. 109-140.

178) - og Ostenfeld, C. H. (1903), Kastreringsförsäg med Hieracium og andre Cichorieae. Ebenda, p. 409-413.

179) Regel, E. (1859), Die Parthenogenesis im Pflanzenreiche. Mém. de l'Acad. impér. des Sciences de St.-Pétersbourg. VII. sér., Bd. 1, 1859, Heft 2, p. $1-48$.

*180) Riddle, L. W. (1906a), Contributions to the cytology of the Entomophthoraceae. P. N. Rhodora, Bd. 8, 1906, p. 67-68.

*181) - (1906b), On the cytology of the Entomophthoraceae. Proceed. of the americ. Acad. of Arts and Science, Bd.42, 1906, p. 177-197.

182) Ritzerow, H. (1907), Über Bau und Befruchtung kleistogamer Bliiten. Flora, Bd. 98, 1907, p. 163-212. 


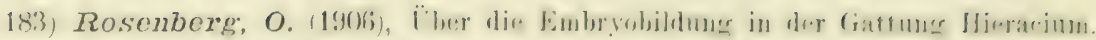
Ber. d. deutschen botan. Gesellsch., Bil. 24, 1906; r). 157-161.

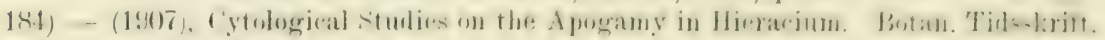
Bd. 28,1907, p. 14:- 170 .

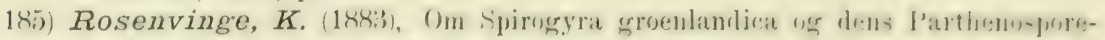
dannelse. Ofversigt af k. Vetensk.-Acad. Förhandl. 1883. No. 8, p. 37-43.

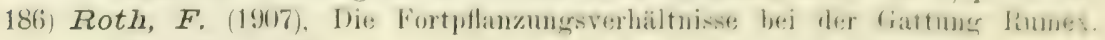
Diss. Bonn 1907.

187) Ruhland, W. (1900), Fortpflanzungsverhailtnisse und Eutwickelung-gatuer du Musci. In Engler-Prantl's Pflanzenfamilien. 'Teil I, 3. Abt.

188) Sadebeck, R. (189s), Pteridophyta. In Englex-Prantl s Pflanzenfamilien. 'T'eil I, 4. Abt., 1898-1902.

189) Schmidt, $H$, (1907), Ciber die Entwicklumg der Bliiten und Jilitentiinde: von Euphorbia L und Diplocyathium n. g. Botan. Centralbl., Beihefte, Bd. 22, I. Abt, 1907, p. 21-69.

190) Schnegg, H. (1902), Beitrüge zur Kenntnis der fattung (innnera. Flora. Bd. 90, 1902, p. 161-208.

191) Schröder, Chr. (1901), Blïtenbiologische [ntersuchungen an der Erluse (Pisum sativum L.) und der Bohne (Phaseolus vulgaris L.). Allg. Zeitschr. f. Entomologie, Bd. 6, 1901, p. 1-3.

192) Shaw, W. R. (1897), Parthenogenesis in Marsilia. Botan. (iazette. Bul. 24. 1897, p. 114.

193) Shibata, K. (1902), Experimentelle Studien über die Entwicklung des Endrsperms bei Monotropa. V. MI. Biol. Centralbl., Bd. 22, 1902, p. 705-714.

194) Siebold, Th, von (1856), Die wahre Parthenogenesis bei den Fichmetterlingen und Bienen. 1855 .

195) Smith, J. (1841), Notice of a Plant which produces Seeds withont any apparent Action of Pollen. Transact. of the Linn. Soc. London, Bd. 18, 18 1 , p. $509-511$.

196) Solacolu, Th. (1905), Sur les fruits parthénocarpiques. C'omptes rendus de l'Acad. d. sciences, Bd. 141, 1905, p. 897-898.

197) Solms-Laubach, H. Graf zu (1882), Die Herkunft, Domestication und Terbreitung des gewöhnlichen Feigenbaums (Ficus Carica L.). Abh. d. kgl. Gesellsch. d. Wissensch. zu Göttingen, Bd. 28, 1882.

198) - (1907), Üher unsere Erdbeeren und ihre Geschichte. Botan. Zeitung, Bd. 65. 1. Abt., 1902, p. 45-76.

199) Stahl, E. (1876), Über künstlich hervorgerufene Protonemabildung an dem Sporangium der Laubmoose. Botan. Zeitung, Bd. 34, 1876, p. 689-695.

200) Strasburger, E. (1877), Über Befruchtung und Zelltheilung. Leipzig 187.

201) - (1878), Über Polyembryonie. Jen. Zeitschr. f. Naturwiss., Bd. 12, 1878, p. $647-670$.

202) - (1894), Über periodische Reduktion der Chromosomenzahl im Entwicklungsgang der Organismen. Biol. Centralbl., Bd. 14, 1894, p. 817.

203) - (1904), Die Apogamie der Eualchimillen und allgemeine Gesichtspunte. die sich aus ihr ergeben. Jahrb. fo wissensch. Botanik, Bd. 41, 1905, p. 88-164.

204) - (1905), Die stofflichen Grundlagen der Vererbung im organischen Reich. Jena 1905.

205) - (1906), Zur Frage eines Generationswechsels bei Phaeophyceen. Botan. Zeitung, Bd. 64, 2. Abt., 1906, p. 1-7.

206) - (1907), Apogamie bei Marsilia. Flora, Bd. 97, 1907, p. 123-191.

207) Taschenberg, O. (1892), Historische Entwickelung der Lehre von der Parthenogenesis. Abhandl. d. naturf. Gesellsch. Halle, Bd.17. 1892. 
208) Tieghem. Ph. van (1896). Sur l'organisation florale des Balanophoraces. Bull. de la Soc. Botan. de France, Bd. 43, 1896, 1). 295-309.

209) Tischler, G. (190:3), Über Embryosach-Obliterationen bei Bastardpflanzen. Butan. Centralbl., Beihefte, Bd. 15, 1903, p. $408-420$.

210) - (1906), Über die Entwicklung des Pollens und der Tapetenzellen bei RibesHybriden. Jahrb. f. wissensch. Botanik, Bd. 42, 1906, p. 545-578.

211) - (1907), Weitere Untersnchungen über Sterilitätsursachen bei Bastardpflanzen. V. II. Ber. d. deutschen botan. Gesellsch., Bd. 25, 1907, p. 376-383.

212) - (1905), Zellstudien an sterilen Bastardpflanzen. Arch. f. Zellforschung; Bd. 1, 1908, p. 33-151.

213) Tretjakow, S. (1895), Die Beteiligung der Antipoden in Fïllen der Polyembryonie bei Allium odorum L. Ber. d. deutschen botan. Gesellsch, Bd. 13, 1895, p. $13-17$.

214) Treub, M. (1883), Notes sur l'embryon, le sac embryommaire et l'ornle. III et IV. Ann. du jardin botan. de Buitenzorg, T. 3, 1883, p. 120-128.

215) - (1898), L'organe femelle et l'apogamie du Balanophora elongata. Ebenda, Bd. 15, 1898, 1). 1-22.

216) - (1902), L'organe femelle et l'embryogénèse dans le Ficus hirta Vahl. Ebenda, 2. sér., 'T. 3, 1902, p. 124-157.

217) - (1905), L'apogamie de l'Elatostema acuminatum Brongn. Ebenda, 2. sér., T. 5,1905, p. $141-152$.

218) Tröndle, A. (1907), Über die Kopulation und Keimung von Spirogyra. Botan. Zeitung, Bd. 65, 1907, 1. Abt., p. 187-216.

219) Trow, A. H. (1904), On Fertilization in Saprolegnieae. Ann. of Botany, Bd. 18, 1904, p. 541-570.

220) Usteri, A. (1907), Studien über Carica Papaya L. Ber. d. deutschen botan. Gesellsch., Bd. 25, 1907, p. 485-495.

2.21) Vries, H. de (1901), Die Mutationstheorie. Bd. 1. Leipzig 1901.

2.2) - (1903a). Die Mutationstheorie. Bd. 2. Leipzig 1903.

2.23) - (1903 b), Befruchtung und Bastardierung. Leipzig 1903

2.24) Vuillemin, P. (1900), Développement des azygospores d'Entomophthora. Comptes rendus de l'Acad. d. sciences, Paris, T. 130, 1900, p. 522-524.

225) - (1907), Les bases actuelles de la systématique en mycologie. Progr. rei botan., Bd. 2, 1907, p. 1-170.

206) Warburg, O. (1900). Pandanaceate. Engler's I'tanzenreich, IT, 9. Leipzig 1900.

227) Went, F. A. F. C. (1899), Les modes de reproduction du Codium tomentosum. Nederl. kruidk. Arch., 1889, 5. Deel.

228) - and Blaauw, A. H. (1905), A case of apogamy with Dasylirion acrotrichum Zucc. Rec. d. trav. botan. Néerlandais, 1905, Nr. 3. 12 pl).

229) Wettstein, $\boldsymbol{R}$. von (1903), Handbuch der systematischen Botanik. I. Bd. Leipzig u. Wien 1903.

230) - (1907), Handbuch der systematischen Botanik. II. Bd, 2. Teil, 1. Hülfte. Leipzig u. Wien 1907.

231) Williams, J. H. (1904), Studies in the Dietyotaceae. I. The eytology of the Tetrasporangium and the germinating Tetraspore. Ann. of Botany, Bd. 18, 1904, p. 141-160.

2:30) Winklex, Hans (19)1), Über Herogonie un Befruchtum. Tahrb. f. wissensch. Botanik, Bd. 36, 1901, p. 753-775.

233) - (1904), Über Parthenogenesis bei Wikstroemia indica (L.) C. A. Mey. Ber. d. dentschen botan. Gesellsch., Bd. 22, 1904, p. 573-580.

234) - (1906), Botanische Untersuchungen aus Buitenzorg. II. 7. Über Parthenogenesis bei Wikstroemia indica (L.) C. A. Mey. Ann. du jardin botan. de Buitenzorg, 2. sér, T. 5, 1906, p. 208-276. 
235i) Woronin, $H .(1997)$, Apregamie und Aposporie bei ainigen Farnen. Flora. Bil. 98, 1907, p. 101-16i2.

2366) Wydlex, H. (1878), Zur Morphologie, hauptsiichlich der dichotomen Blithenstimile. Jahrl. f. wissensch. Botanik, Bil. 11, 1878, 1. 312-379.

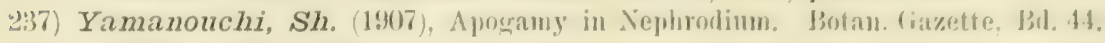
$1907,1), 142-146$.

2:38) Zahn, H. (1904). J3enerkungen ibber (:. It. Ostenfeld's Artikel: Zur Kemutuis der Apoganie in der Gattung Hieracinm. Allg. Jotan. 'Keitschr. Bil. 10, 1904, 1. 170-172.

u3:9) Zinger, $N$. (1898), Beitrige zur Kenntnis der weiblichen Jilithen nul JnHorescenzen bei Cammabineen. F'Jora, Jil. 85, 1898, 1). 189-253. 


\section{Namen- und Sachverzeichnis.}

Absidia capillata 20.

- seputata 20 .

Achlya debaryana 21 .

- polyandra 21.

- racemosa 21.

Aconitum napelius 130 .

Adventivembryonie $5,43,110,139$.

Alchimilla š Eualchimilla 80 if.

- sericata 12, 64.

Algen 13, 141.

Allium odorum 139.

Amblogyne persicarioides 45.

Amblystegium serpens 33 .

- subtile 33 .

Ampelopsis hederacea 2 2.

Amphimixis, Definition 6 .

Amphoridium Mougotii 32.

Anacardiaceae $\check{1}$.

Antedon rosacea 140.

Antennaria alpina $77 \mathrm{ff.} .107$.

- canadensis 78 .

- dioica 78, 79. 80.

- fallax 78

- neodioica 78.

- Parlinii 78.

- plantaginifolia 78 .

Anthoceros laevis 31,62 .

Antipodenembryonen 56, 69.

Aphanochaete repens 16 .

Aphanomyces scaber 21.

Apogamie 9, 11, $58 \mathrm{ff}, 105 \mathrm{ff}$.

- -, generative $67 \mathrm{ff}$.

-. somatische $60 \mathrm{ff}$.
Apomixis, Definition 8, 10

Aposporie $61,89,94$.

- bei Laubmoosen 33, 72.

Araceae 37

Ardisia crispa 56 .

Asclepiadaceae 56.

Ascobolus furfuraceus 151.

Ascolichenes 24, 29.

Ascomycetes, Fortpflanzungsverhältnisse $24 \mathrm{ff}$.

—, Kernverschmelzung im Asens 7 Aum., 25.

Aspicarpa hirtella 48 .

Athyrium Filix-foemina var. clarissima Bolton 72, 112

- - var. clarissima Jones 63, 105.

- - var. uncoglomeratum 74 .

Aucuba japonica 5 jo.

Anlacomium turgidum 32.

Auslösumg der Parthenogenesis $126 \mathrm{ff}$.

Azygosporen 19 if.

Bakterieu 10.

Balanophora elongata 64,66 .

- globosa 65.

- indica 64.

Banane 130.

Barbula convoluta 33̉.

- muralis 33.

- recurvifolia 32.

Bartramia pomiformis 33 .

Basidiobolus ranarum 24.

Basidiomycetes 31 . 
Befruchtmugshediirftierkeit 112, 113.

Befrnehtungstihigkeit 112, $115,138,152$.

biene 95, 124.

Billbergia pallescens 37.

Bingelkrant 50.

Biologische Bedeutumg der A pomixis $144 \mathrm{ff}$.

Blastophaga 43, 139).

Botrychium virginianum 33 .

Brachythecium rutabulum :33.

Bromeliaceae 37.

Bryonia dioica 57, 108, 109.

Bryopsis 16.

Bryum 32, 33.

Bufo calamita 47.

Burmanniaceae 131.

(achehougne ilicifulia 3. 5, 11, 107. 13:5.

Calanthe vestita 40 .

Calicium 30.

Cannabis sativa 41 .

Carica papaya 53 .

Ceratodon purpurens 33.

Ceratozamia 35.

Chara crinita 4, 17 f., 72, 109, 134, 147, 151 .

- foetida 18.

- fragilis 18, 151.

Chenopodiaceae 45.

Chlamydomonadaceae 13.

Chlamydomonas media 13, 143.

Chlorophyceae $13,116$.

Chromosomenzahl 110, 111, 114, 123.

Chroolepidacene 16.

Citus 41, 110.

Claviceps 29.

Closterinm Lumula 98.

Codium tomentosum 16 .

Colchicum autumuale 38.

Coleochaete 120, 121.

Collema 30.

Coniferae 35.

Conjugatae 96.

Cordyceps 29.

Corethron 13.

Cornaceae 55

Cosmarium Botrytis 98.

Costus 93 .

Cucumis sativus $57,10^{\circ}$.

Cucurbitaceae . 5 .

Cutleria multifida 16 .

Cyanophyceae 10.

Cycadeen 35., 151 .
Cyeas revoluta 151.

('ylindroentasa Jo.

(ynomorimm 6í).

Cystosira barbata 100.

Dangearl'sche Fision 7 Amm., 25.

Dasylirion acrotrichum 37.

Datisea cannabiua 5i3.

Desmidiaceae 98.

Diatomeen 13.

Dicranoweissia cirrata 33.

Dictyota 62, 99.

Diöcie und P'arthenogenesis 1(17, 1333, I4t 1 .

Disciphania Erustii 45, 128.

Draparnaldia 15.

Eotocitrul: 16 .

Fibe 36.

Elatostema acuminatum 44 .

Encephalartos 35.

Entomophthora gloeospora 20, 27.

Ernährungsverhältnisse als Ursache der Apomixis $128 \mathrm{ff}$.

Enapogamie 10, 11.

Euphorbia cyparissias 11.

- dulcis 12.50, 139

Euphorbiaceae 49.

Eupristis 43.

Farne 3t, 137.

Faux hybrides 39, 47, こૅ, 141.

Feige 42.

Ficus carica $42,139$.

- hirta 43, 139

- hispida 43.

- Roxburghii 45.

Flechten 29.

Fragaria $46,141$.

Fruchtungsvermügen 102.

Fucaceae 101, 118.

Fuchsia arborescens $う 4$.

Fucus resiculosus 101.

Fumaria hygrometrica 33.

Funkia orata 139.

Generationswechsel 99, $116 \mathrm{ff}$.

Geschlecht der parthenog. PHanzen $107 \mathrm{ffi}$., 146.

Geschlechtsverlust $133 \mathrm{ff}$.

Giffordia secunda 17.

Gnetum gnemon 36. 
Gnetum ula 36.

Gonatonema 97.

Gunnera 54.

Gurke 57, 102.

Gymnospermen 35.

Habranthus 39.

Haliseris 99.

Halorrhagidacene $5 t$.

Hanf 41.

Helosis guyanensis 65 .

Hieracinm 86-92.

- aurantiacum 86, 91, 92, 136.

- excellens 88, 90, 92, 130.

Hippeastrum 39.

Hopfen 42.

Humaria gramulata 29, 30.

- rutilans 28.

Humulus lupulus 42.

Hymenocallis 39 .

Hуриuт 32, 33.

Isoëtes 35.

Keimzelle, Wesen der $105 \mathrm{ff}$.

Lachnea stercorea 27.

Laelia anceps 40 .

Lastrea pseudomas var. cristata apospora $68,95$.

— - var. polydactyla 7, 59.

Laubmoose 32, 72 .

Lebermoose 31.

Lemna 93.

Lilium 38, 93.

Linum usitatissimum 11.

Löwenzahn 71.

Lycaste Skinneri 40.

\section{Mactra 9.}

Makrospore 94.

Malpighiaceae 48 .

Marchantia polymorpha 31 .

Marsilia Drummondii 74 ff., 112, 123, 142.

- vestita 76,77 .

Uenispermaceae 45.

Mercurialis imma 49 .

- perennis 50.

Merogonie 100.

1lesotaeniaceae 96.

IIispel, kernlose 102.

Mnium hornum 33.
Mnium insigne 32.

Monotropa hypopitys 55.

- uniflora 55.

Moose $31 \mathrm{ff}, 68$.

Moracene 41.

Morus niger 41 .

Nucor 19, 20.

Mutation 148.

Myrsinaceae 56 .

Narcissus 93.

Neckera Besseri 32.

Nectria 29.

Nephrodium molle 61, 68, 95, 123.

Nephroma 29.

Nothoscordum fragrans 139.

Nucellarembryonie 5, 43, 110, 139.

Nymphaea 45.

Obione sibirica 45 .

Obturator 49.

Odontoglossum 40.

Oenothera biemnis 130 .

- Lamarckiana 54.

- latia 54.

Oncidium tigrinum 40.

Oomycetes 20.

Opegrapha 30.

Opuntia 127, 140.

Orchideen 39, 127.

Paludella squarrosa 32.

Pandanaceae 36.

Papilionaceae 48.

Parthenapogamie 10.

Parthenogenesis 11, $70 \mathrm{ff}$., $104 \mathrm{ff}$.

-, generative $94 \mathrm{ff}$.

-. somatische $71 \mathrm{ft}$.

Parthenokarpie $101 \mathrm{ff} ., 127,151$.

Parthenomixis 28, 60, 151.

Pelobates fuscus 47.

Peltidea 29.

Peltigera 29.

Peziza stercorea 27.

Pfropfhybride 7.

Phaeophyceae 16, 116.

Phycomycetes 19.

Physikalische Faktoren als Ursache der Parthenogenesis $131 \mathrm{ff}$., 143.

Pilularia 35, 75.

Pirolaceae 5 5. 
Pistavia narbenengis is.

P'ismum sativmm 18.

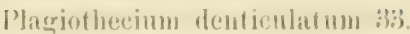

PJeospora 2\%.

Pohlia nutans :3:3.

Pollenverbilalume 1366, 1.17.

P'olygonaceate 45.

l'olymorphismus $147 \mathrm{ff}$.

Polystigma rubrum 27.

Polytoma 13.

Polytrichum 151.

Potentilla 147.

Propagation 10, 12, 116, 1:34.

['rophasen der Reduktionsteilung 77, 81. 86,149 .

Protosiphon botryoides $14,142,143$.

Psendapogamie 7.

Pseudogamie 38.

Pseudomixis $6,27,59$

P'teris cretica 34.

Pterogonium gracile 32.

Pyronema confluens 8 Amm.. 26.

Rana fusca 47.

Rhabdonema arcuatum 13.

Rhizopus nigricans 20.

Rhopalocnemis phalloides 6i\%.

Ricinus communis 49 .

Rosa $46,147$.

Rubus 47, 48, 147.

Rumex 45 .

Salix glancophylla 93.

Saprolegnieae 20.

Schleiden'sche Lehre 3.

Sciaphila nana 37.

Scolopendrium vulgare rar. crispum Drummondae 74.

Sium 93

Spermatienkeimung 30 .

Sphaerotheca Castagnei 26 .

Spinellus 20.

Spirogyra 96, 97, 143.

Sporodinia grandis 19 .

Symedra aftinis 13 .

Synergidenembryonen 56, 64, 70 .
'Taraxacum 8i) officinale $85,865,135,1345,141$

'T'axis baceata 36 .

'Teichespora 2!9.

'Teiclosiporella 29.

'Temperatur, parthenogenesiserregenl 142.

'T'etrallenteilıug :3:3.

Thalictroum disicem 8อั. Fendleri 8:. 108

- purpurascens 12,82,87,92, 108, 114, 130 .

Thea sinensis 131.

Thecothens P'elletieri 8 Anm.

Thelebolus stercorens 2 ?.

'T'huidium abietium 32.

'Tierischer Generationswechsel 121.

'T'riuridaceae 37.

Ulothrix zonata $15,117$.

Uredinene 7

Ursache der Parthenogenesis 104, 126 fi. Urticaceae 44.

Uswea 29.

Vanda caerulea 40.

Vaucheria 142.

Verdoppelung, regenerative, der Chromosomenzahl 60,67,95.

Verlust der Sexualität $133 \mathrm{ft}$.

Veronica virginica 130.

Vincetoxicum 56 .

Violaceae 52.

Vitaceae $\mathbf{5 1 .}$

Vitis rotundifolia วิ2.

- vinifera $52,103,140$.

- rupestris 52.

Volvox 14.

Tikstroemia indica $49,91,147$.

Xylaria 29.

Zephyranthes 39.

Zyguema 97.

Zygomjcetes 19.

Zygopetalum Machayi 40, 140.

Zygorhymehus 20 Anm. 1. 
Biologische mud morphologische Untersuchungen riber Wasser- und Sumpfoewaichse. Von Prof. Dr. Ilugo Glicek iu Lebensgeschichte der enropiischen Alismacen. Jlit 25 T'extfiguren und 7 lithograph. Doppeltafeln. Preis: 20 Mark. - Z weit e r T'eil: Lntersuchungen iiber die mitteleuropaischen Utricularia-Arten; iber die Turionenbildung der Utricularia-Arten; iber die Turionenbildung bei Wasserplinzen, sowie iiber Ceratophyllum. Jit 28 'Textfiguren und 6 lithographierten Doppeltafeln. Preis : 18 Mark.

Vorlesungen iiber Pflanzenphysiologie. Von Dr. Ludwig Jost, wirtschaftlichen Akademie Bonn-Poppelsdorf. Zweite A uflage. Preis: brosch. 14 Mark, geb. 16 Mark.

Pathologische Pflanzenamatomie. In ihren Grundzügen dargestellt. Von Dr. Ernst Kiister. Dozent 1903. Preis : 8 Mark.

Vorlesungen iiber Deszendenztheorien mit besonderer Bericksichtigung der botanischen Seite der Frage, gehalten an der Reichsunirersität zu Leiden. Von Dr. J. P. Lotsy. Erster Teil. Mit 2 Tafeln u. 124 Textfiguren. Preis 8 Mark. geb. 9 Mark. - Z $\mathrm{Z}$ eiter Teil. Mit 13 Tafeln uml 101 Textfiguren. 1908. Preis: 12 Mark, geb. 13 Mark.

\section{Vorträige iiber botanische Stammesgeschichte. Gehalten}

Reichsunirersität zn Leiden. Ein Lehrbuch der PHanzensrstematik. Von Dr. J. P. Lotsy. Erster Baud. Algen und Pilze. Mit 430 Abbildungen im Text. 1907. Preis : 20 Mark.

Inhalt: 1. Einleitung. 2. Volvocales. 3. Siphonales. 4.-Archimycetes und Siphononycetes. 5. MLultizelluläre monoenergide Isokonten. 6. Stephanokonten. 7. Heterokonten. 8. Desmidiaceae. 9. Die Phaeophytenreihe. 10. Die Peridinales. 11. Die Diatomeen. 12. Phaeophyceae. 13. Rhodophyceae. 14. Die Schizophyten (Bakterien). 15. Schizophyceen. 16. Die Myxobakterien. 17. Myxomyceten. 18. Die Ascomyceten. 19. Erysiphales. 20. Pletascieae. 21. Pyrenomyceten und Laboulbeniales. 22. Lichenen. 23. Discomyceten. 24. Helvellineae. 25. Eutuberaceae. 26. Exoascineae. 27. Die Saccharomyceten. 28. Basidiomycetes, Hemibasidii. 29. Die Uredineae. 30. Basidiomyceten. 1. и. 2. Teil. Charophyten. Namenregister. Sachregister.

Progressus rei botanicae. Fortschritte der Botanik. Progrès de la gegeben von der Association Internationale des Botanistes of Botany. HeransJ. P. Lotsy in Leiden.

Die "Progressus" erscheinen in zwanglosen Hefteln, die in einem Zwischenraum von 4 Monaten zur Ausgabe kommen sollen. Die Hefte werden zu Bänden von etwa 40 Druckbogen vereinigt, so daß jührlich ein Band erscheinen wird.

Die Mitglieder der Association erhalten die Progressus zu dem Vorzugspreis von 13 Mark. Bestellungen zu diesem Vorzugspreise sind seitens der Herren Mitglieder direkt an die Verlagsbuchhandlung oder an den Generalsekretär der Association, Herrn Dr. J. P. Lotsy in Leiden, zu richten. Bestellungen, welche durch den Buchhandel anfgegeben werden (auch solrhe seitens der Mitglieder der Association) kömen mur zu dem Preise für Nichtınitglięler, welcher 18 Mark fǜ einen Band beträgt, Erledigung finden.

Inhalt des ersten Bandes: Erstes Heft. R. v. Wettstein u. J. P. Lotsy, Vorwort. Eduard Strasburger, Die Ontogenie der Zelle seit 1875. Dr. II. Scott, The Present Position of Palacozoic Botany. E. A. Newell A rber, Bibliocraphy of Literature on Palaeczoic fossil Plants. Ch. Flahault, Les progrès de la Geographie botanique depuis 1884. Zweites Heft. L. Lanrent, Les Progrès de la paléobotanique angiospermique dans la dernière décade. W. Bateson, The proeress of Genetics since the rediscovery of Mendel's papers. Friedrich Czapek, Die Eruithrungsphysiologie der Pflanzen seit 1896. Drittes Heft. R. P. van Calcar, Die Fortschritte der Immmitits- und Spezifizititslehre seit 1870 mit besonderer Beritcksichtigung der T'nberkelbazillen und der sä̈refesten Stäbchen. - Zweiter Band. Erstes Heft. Preis des Bandes: 18 Mark. Inbalt: I'a u I V u illemin, Les bases actuelles de la systématique en mycologie. R. Keiller, Les Progrís de la Paléobotanique de l'ère des gymnospermes. 
Botanische Praktika. II. Teil. Pralitikum dere hota-

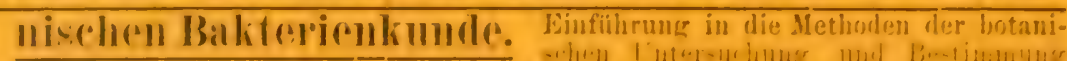

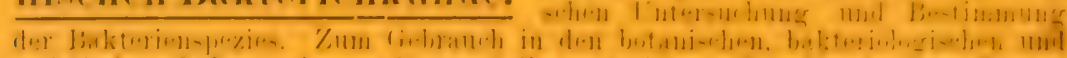

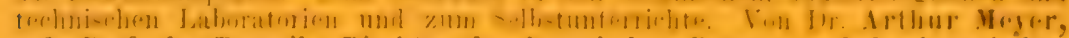
ord. Prof. der Botanik, Direktor des botanischen Giartens mul des botanischeu

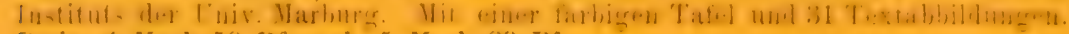
I'reis: 4 Mark 50 I'f., greb. i) Mark 20 I’f.

Botanische Mitteilungen aus den Tropen. Herangeg. von Ise. Jeresor I) T'reis: 109 Mask. $\quad \| \cdot 11 \mathrm{~J}$ : Die Wechselbeziehungen zwischen Pflanzen und Ameisen: im tropischen Amerika. Von A. F. W. Schimper. 1888. Mit 3 Tafeln. I'reis: 4 Mark 50 Pf. - Il eft II: Die epiphytische Vegetation Amerikas. Von A. F. IV. Schimper. Mit 6 Tafeln. 1888. Preis: 7 Mark 50 Pf. - Iteft I I I: Die

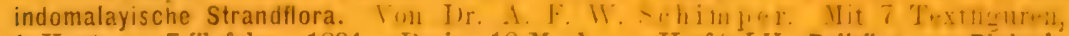
1 Karte u. 7 Tafelu. 1891. I'reis: 10 Mark. - Heft I V : Beiträge zur Bỉologie und Anatomie der Lianen. im Besonderen der in Brasilien einheimischen Arten. Vin Dr. H. Sehenck, Priratdozent an der Unirersität Bonn. I. 'Teil: Beiträge

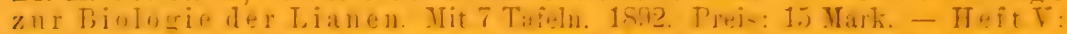
Beiträge zur Biologie und Anatomie der Lianen, im Besonderen der in Brasilien einheimischen Arten. Von Dr. H. Schenck. II. Teil: Beiträge zur Anatomie

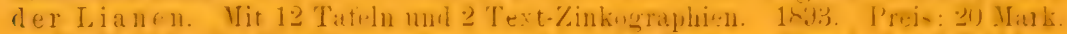

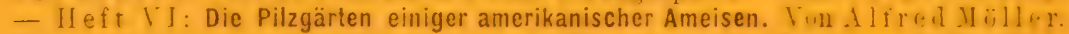
Mlit 7 Tafeln und 4 Holzschnitten. 1893. Preis: 7 Jark. - Heft VII:

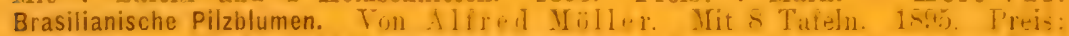
11 Mark. - Heft VIII: Protobasidomyceten. Inter-nchungen an- lirasilien. Von Alfred Möller. Mit 6 Tafeln. 1895, Preis: 10 Mark. - Heft IX: Phycomyceten und Ascomyceten. Tintersuchumgen ants Dirasilien. Tin Alired Möller. Mit 11 Tafeln und 2 Textabbilhumgen. 19fo1. Preis: 24 Mark.

\title{
Praktikm fiir morphologische und systematische \\ Botanik. Hilfsbuch bei praktischen Uebungen und Anleitung zu selb- Botanik. ständigen Studien in der Jiorphologie und Systematik der Pflanzenwelt. Von Prof. Dr. Karl Schumann, weil. Kustos am Kel. Botani- schen II useum u. Privatrozent an der I'nwessiät zu Berlin. Mit 154 Figruren im Text. Preis: 13 Mark, geb. 14 Jark.
}

Pharmaceutische Zcitung, 1004, Nr. 75

\begin{abstract}
Uas Juch hat siche:lich rugen praktischen Wert. Wir wisen ja alle, wie wen:

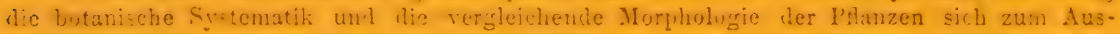
wendiglemen eignet. Das muB man sehen und von jeder einzelnen Familie einige herror-

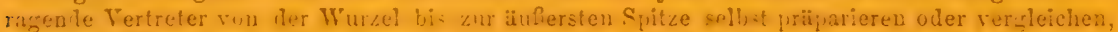

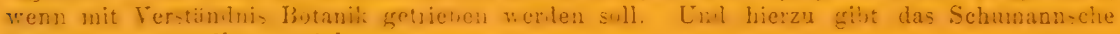
I'raktikum vorzüglichc Anleitung.
\end{abstract}

\section{Lehrouch der Botanik fïr Ifochschulen. You Dr. Etuard}

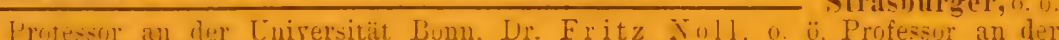
Unirersität Iralle a. S., Dr. Heinrich Schenck, Professor an der Technischen Hochschule Darmstadt, Dr. George Karsten, a. o. Professor an ler Luirercitä Fonn. Fente umgearbeitele Inflage. Mit $x 2$ zum Teil farbigen $A b$ -

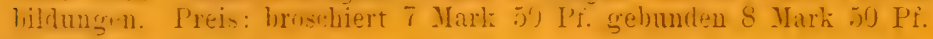

Das botanische Praktikum. Arleitung zum Sellststudium der mikro. shonischen Botanik für Anfinger und Geübtere, zugleich ein Handbuch der mikivskopischen Technik. Ton Prof. 1)r. Eduard Strasburger. Vierte umgearlieitete A uflage. Jit 230 Holzschnitteri. 1902. Preis: 20 Jark, geb. 22 Jark 5 if Pf.

Apotheker-Zeitung, Nr. 98, v. 6. Dez. 19?2:

Was ich schon bei Anzeige des klcinen ['raktikums hervorhob. sei hier noch einmal gesagt: Wer Neigung in sich spitrt, das Stulium let Butanik mit dem Mikroskop zu verticfen, und wer sich damit eine unerschö;fliche (quelle reinen nnd cllen Yaturgenuesez verschaffen will, der vertraue Eich Strasburger: Liichern a n. 




Winkler, Hans/Parthenogenesis und Apogam

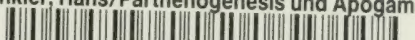

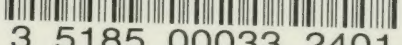

5185000332401 
